SAND92-7340

Distribution

Unlimited Release

Printed April 1993

Category UC-721

\title{
Seal Design Alternatives Study
}

\author{
L.L. Van Sambeek \\ $\mathrm{RE} / \mathrm{SPEC}$ Inc. \\ Rapid City, SD 57709-0725 \\ D. D. Luo, M.S. Lin, W. Ostrowski, D. Oyenuga \\ Parsons Brinckerhoff Quade \& Douglas, Inc. \\ San Francisco, CA 94107-1317
}

\begin{abstract}
This report presents the results from a study of various sealing alternatives for the WIPP sealing system. Overall, the sealing system has the purpose of reducing to the extent possible the potential for fluids (either gas or liquid) from entering or leaving the repository. The sealing system is divided into three subsystems: drift and panel seals within the repository horizon, shaft seals in each of the four shafts, and borehole seals.

Alternatives to the baseline configuration for the WIPP seal system design included evaluating different geometries and schedules for seal component installations and the use of different materials for seal components. Order-of-magnitude costs for the various alternatives were prepared as part of the study. Firm recommendations are not presented, but the advantages and disadvantages of the alternatives are discussed. Technical information deficiencies are identified and studies are outlined which can provide required information.
\end{abstract}

* The content of this report was effective as of January 1993. This report was prepared by RE/SPEC Inc. under Contract 69-5174 with Sandia National Laboratories. 


\section{ACKNOWLEDGMENT}

The authors gratefully acknowledge the Sandia National Laboratories' technical reviewers. The review comments by Dr. Frank D. Hansen, Dr. Joe R. Tillerson, and Dr. Rudy Matalucci provided insight and guidance for the final version. 


\section{FOREWORD}

This report was prepared by a joint effort between Parsons Brinckerhoff Quade \& Douglas, Inc. and RE/SPEC Inc. for Sandia National Laboratories under Contract 69-5174 and meets the requirements for quality assurance as described in NQA-1. 


\section{CONTENTS}

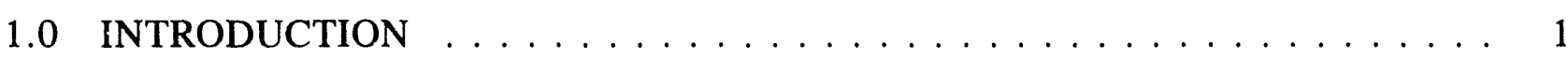

1.1 Seal Requirements ....................... 3

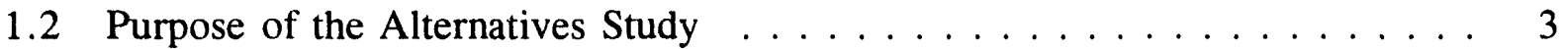

1.3 Report Organization . . . . . . . . . . . . . . . . . . 4

2.0 ROCK MECHANICS $\ldots \ldots \ldots \ldots \ldots \ldots \ldots \ldots \ldots$

2.1 Crushed Salt Consolidation $\ldots \ldots \ldots \ldots \ldots \ldots$

2.1.1 Shaft Closure $\ldots \ldots \ldots \ldots \ldots$

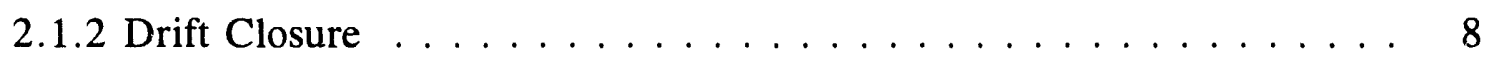

2.1.3 Closure Between Rigid Structures . . . . . . . . . . . . . . . . 10

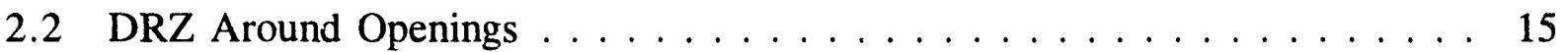

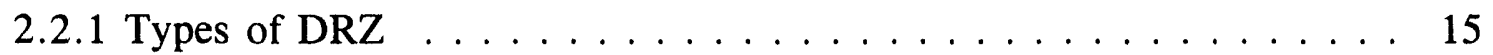

2.2 .2 Opening-Shape Effects $\ldots \ldots \ldots \ldots \ldots$

2.2.3 Stratigraphical Influences $\ldots \ldots \ldots \ldots$

2.3 Loading on Rigid Structures Emplaced in Salt f . . . . . . . . . . 31

2.3.1 Schedule Effects on Loading Magnitude . . . . . . . . . . . . . 31

2.3.2 Geometrical Effects on Loading Distribution $\ldots \ldots \ldots \ldots . \ldots 32$

3.0 DRIFT AND PANEL SEALS $\ldots \ldots \ldots \ldots \ldots \ldots \ldots \ldots$

3.1 Purpose of the Drift and Panel Seals $\ldots \ldots \ldots \ldots \ldots \ldots$

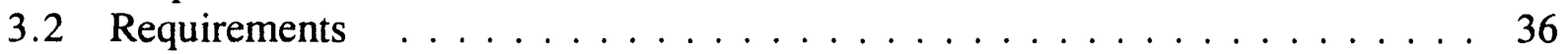

3.2 .1 Reference Seal System . . . . . . . . . . . . . . 36

3.2.2 Considerations for Design Alternatives $\ldots \ldots \ldots \ldots \ldots$

3.3 Assumptions . . . . . . . . . . . . . . . . . . . . . . 39

3.4 Evaluation Criteria $\ldots \ldots \ldots \ldots \ldots \ldots \ldots \ldots \ldots \ldots$

3.5 Seal Design Types . . . . . . . . . . . . . . . . . . . 41

3.5.1 Type 1 - NRxx Seal . . . . . . . . . . . . . . . . . . . . 43

3.5.2 Type 2 - LGxx Seal . . . . . . . . . . . . . . . . . . . 49

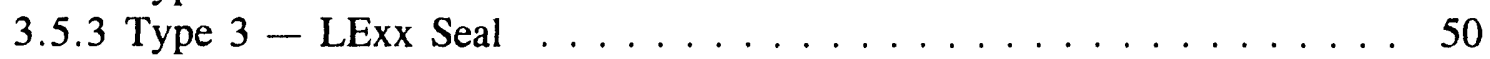

3.5.4 Type $4-$ NR/LE14 Seal $\ldots \ldots \ldots \ldots \ldots \ldots$

3.6 Evaluation and Selection of Design Types $\ldots \ldots \ldots \ldots \ldots$ 


\section{CONTENTS (Continued)}

3.6.1 Evaluation of Design Types $\ldots \ldots \ldots \ldots \ldots \ldots \ldots \ldots$

3.6.2 Seal Type Selection and Combination $\ldots \ldots \ldots \ldots \ldots \ldots$

3.7 Conclusion $\ldots \ldots \ldots \ldots \ldots \ldots \ldots \ldots \ldots \ldots \ldots \ldots \ldots \ldots \ldots$

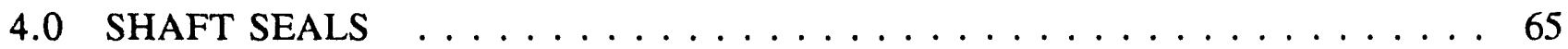

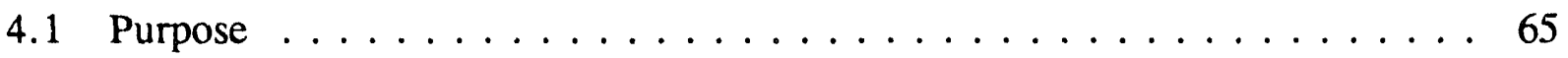

4.2 Requirements for the Shaft Seals $\ldots \ldots \ldots \ldots \ldots \ldots \ldots \ldots$

4.2.1 Lower Shaft Seals . . . . . . . . . . . . . . . . . 67

4.2.2 Upper-Shaft Seals . . . . . . . . . . . . . . . . . . 69

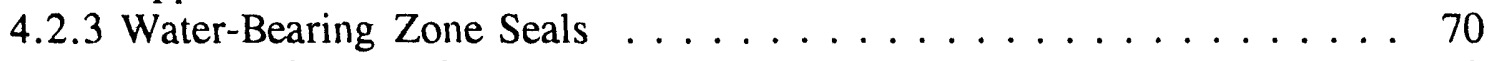

4.2.4 Near-Surface Shaft Seals . . . . . . . . . . . . . . . 70

4.3 Reference Design/Materials $\ldots \ldots \ldots \ldots \ldots \ldots \ldots \ldots \ldots \ldots$

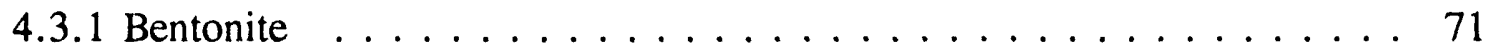

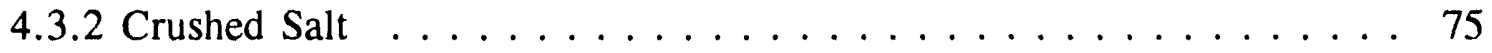

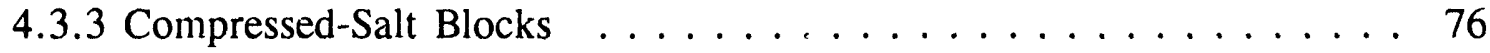

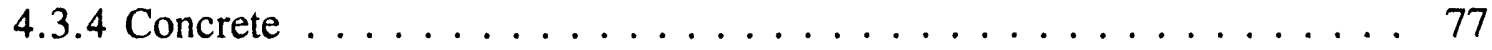

4.3.5 Alternative Seal Materials . . . . . . . . . . . . . . . 79

4.4 Description of Seal Design Alternatives $\ldots \ldots \ldots \ldots \ldots \ldots \ldots$

4.4.1 Lower-Shaft Sealing Subsystem $\ldots \ldots \ldots \ldots \ldots \ldots \ldots$

4.4.2 Upper-Shaft Sealing Subsystem . . . . . . . . . . . . . . 89

4.4.3 Water-Bearing Zone Sealing Subsystem . . . . . . . . . . 93

4.4.4 Near-Surface Shaft Sealing Subsystem . . . . . . . . . . . . . 94

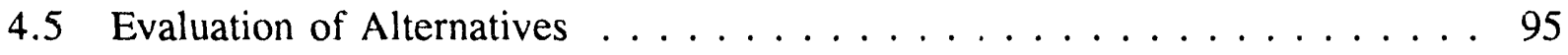

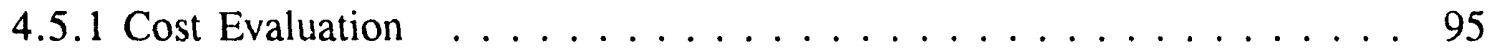

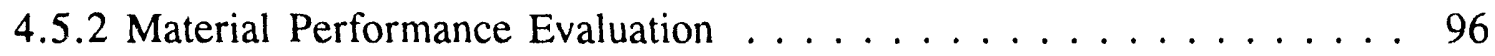

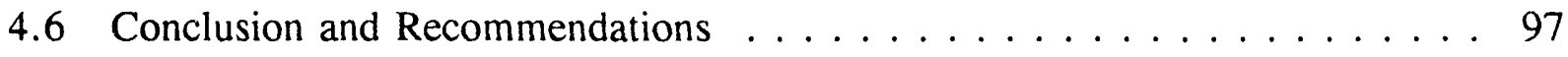

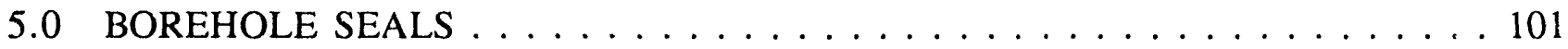

5.1 Purpose . . . . . . . . . . . . . . . . . . 101

5.2 Requirements for the Borehole Seals . . . . . . . . . . . . . 103

5.3 Boreholes Requiring Sealing . . . . . . . . . . . . . . 105 


\section{CONTENTS (Continued)}

5.4 Borehole Sealing Strategy $\ldots \ldots \ldots \ldots$. . . . . . . . . . 106

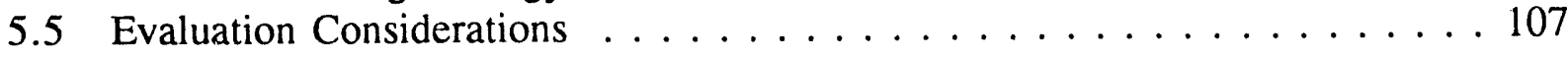

5.5.1 Seal Effectiveness . . . . . . . . . . . . . . . 107

5.5.2 Emplacement Techniques . . . . . . . . . . . . . . 108

5.6 Description of Alternatives $\ldots \ldots \ldots \ldots \ldots \ldots \ldots \ldots \ldots \ldots \ldots$

5.6.1 Definition . . . . . . . . . . . . . . . . . . . . . 109

5.6.2 Emplacement Considerations and Constructibility $\ldots \ldots \ldots \ldots 110$

5.7 Evaluation of Alternatives $\ldots \ldots \ldots \ldots \ldots \ldots \ldots \ldots \ldots \ldots$

5.7.1 Seal Effectiveness . . . . . . . . . . . . . . . . . . . 119

5.7.2 Emplacement Techniques . . . . . . . . . . . . 121

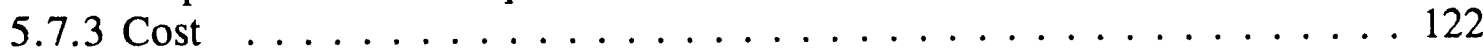

5.8 Discussions and Conclusions $\ldots \ldots \ldots \ldots \ldots \ldots \ldots \ldots \ldots \ldots$

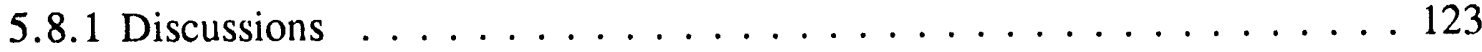

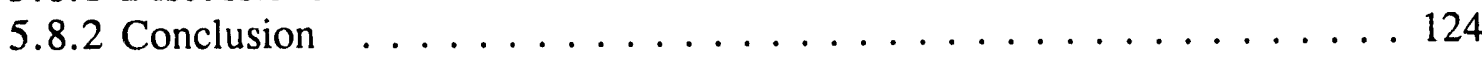

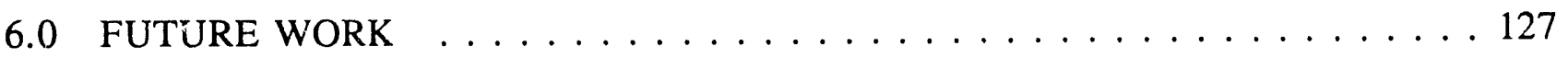

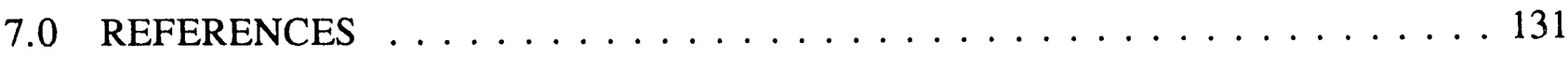

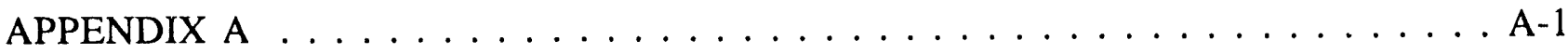

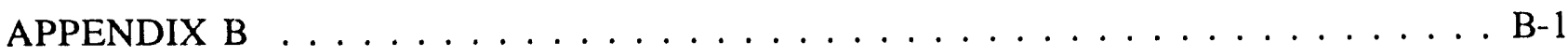

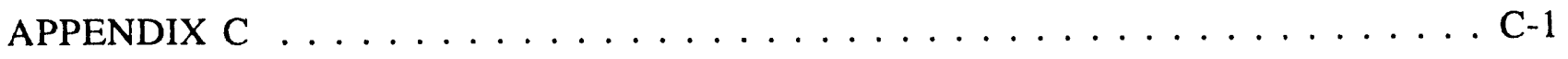

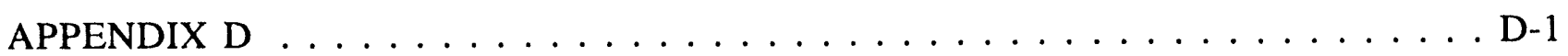


Figures

Figure

2-1 Volumetric strain for six depths from the surface in 50-year-old shaft . . . . . . 9

2-2 Volumetric closure for two rectangular-shaped drifts . . . . . . . . . . . . . 11

2-3 Geometries for a $1 \mathrm{~W}$ rigid sleeve and $2 \mathrm{~W}, 3 \mathrm{~W}$, and $4 \mathrm{~W}$ salt-filled region lengths 13

2-4 Excavation and emplacement sequence for rigid sleeve and salt fill . . . . . . . . 14

2-5 Volumetric strain at the center of the region between the rigid sleeves . . . . . . 16

2-6 DRZ in salt around a 14- × 12-foot excavation immediately after excavation . . . 21

$2-7 \quad$ DRZ in salt around a $14-\times 12$-foot excavation after 1 year $\ldots \ldots \ldots \ldots 22$

2-8 DRZ in salt around a $14-\times 12$-foot excavation after 40 years $\ldots \ldots \ldots \ldots \ldots \ldots$

2-9 DRZ in salt around a $25-\times 12$-foot excavation immediately after excavation $\ldots \ldots 25$

2-10 DRZ in salt around a $25-\times 12$-foot excavation after 1 year $\ldots \ldots \ldots \ldots$

2-11 DRZ in salt around a $25-\times 12$-foot excavation after 40 years $\ldots \ldots \ldots . \ldots 27$

2-12 Vertical uplift of MB139 below a $14-\times 12$-foot excavation $\ldots \ldots \ldots \ldots \ldots \ldots$

2-13 Vertical uplift of MB139 below a $25-\times 12$-foot excavation $\ldots \ldots \ldots \ldots \ldots$

2-14 Liner loading as affected by delayed liner installation $\ldots \ldots \ldots \ldots$

3-1 Reference drift and panel seals, plan, elevation, and section $\ldots \ldots \ldots . \ldots 37$

3-2 Drift and panel seals location plan $\ldots \ldots \ldots \ldots \ldots \ldots \ldots \ldots \ldots \ldots$

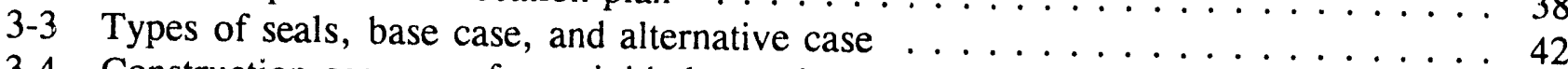

3-4 Construction sequence for a rigid sleeve ring segment . . . . . . . . . . . . 44

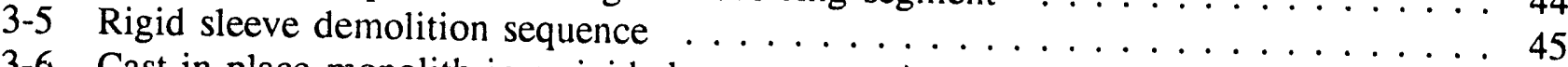

3-6 Cast-in-place monolith in a rigid sleeve or grouting sleeve $\ldots \ldots \ldots \ldots \ldots \ldots$

3-7 Construction scheme for long-term salt seal $\ldots \ldots \ldots \ldots \ldots \ldots$

3-8 DRZ excavation concept for salt seal $\ldots \ldots \ldots \ldots \ldots \ldots \ldots$

4-1 Schematic location of shaft sealing subsystems $\ldots \ldots \ldots \ldots$

5-1 Approximate locations of boreholes in relation to the WIPP underground . . . . 104

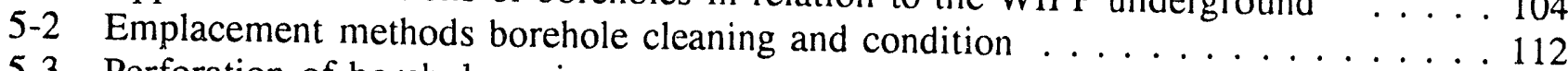

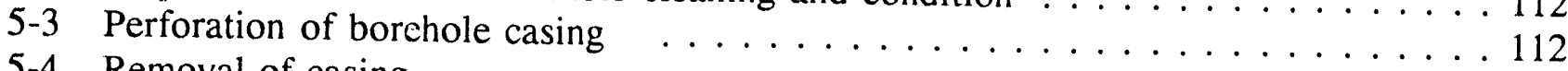

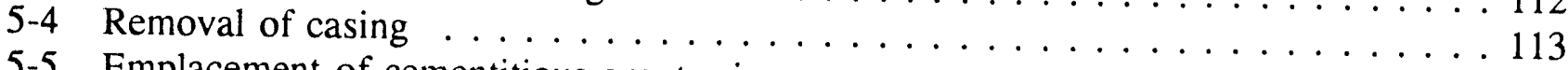

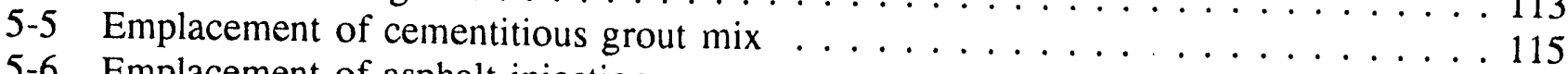

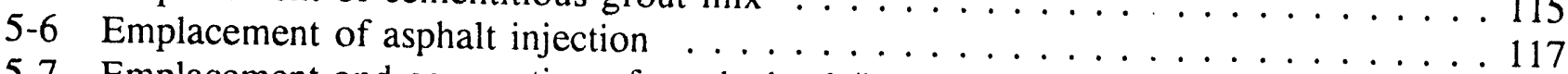

5-7 Emplacement and compaction of crushed salt/bentonite-salt $\operatorname{mix} \ldots \ldots \ldots \ldots \ldots$ 


\section{Tables}

Table

Page

1-1 Sealing Subsystem Functions $\ldots \ldots \ldots \ldots \ldots$

3-1 Order-of-Magnitude Unit Cost Estimates for Base Case and Alternative Case Seal

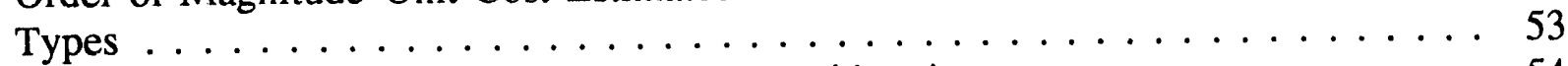

3-2 Drift and Panel Seals Now Versus Later Considerations . . . . . . . . . . . . 54

3-3 Drift and Panel Seal Combination .................... 61

3-4 Summary of Rough Order-of-Magnitude Cost Evaluation . . . . . . . . . . 62

4-1 Brine Pressures at Various Depths in Shafts . . . . . . . . . . . . . 74

4-2 Dow Chemical Seal Ring Installation Locations and Hydraulic Pressure Resisted . 79

4-3 Properties of Dowell Chemical Seal Ring Formulations . . . . . . . . . . . . . 83

4-4 Brine and Rock Pressures Against Seals in the Upper-Shaft Seal System . . . . . 92

$5-1$ Borehole Sealing Subsystem . . . . . . . . . . . . . . . . . . . 102

5-2 Order-of-Magnitude Cost Estimate $(\times \$ 1.0 \mathrm{M})$ Summary of Total Capital Cost for

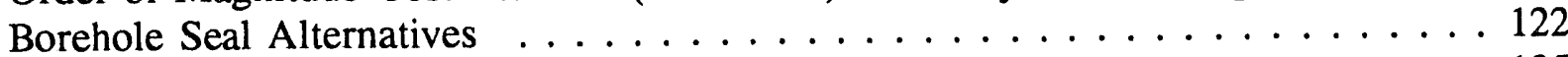

5-3 Summary of Comparisons of Alternatives ................. 125

A-1 Order-of-Magnitude Cost Estimate, Type 1 "NOW RIGID" Rigid Sleeve Seals

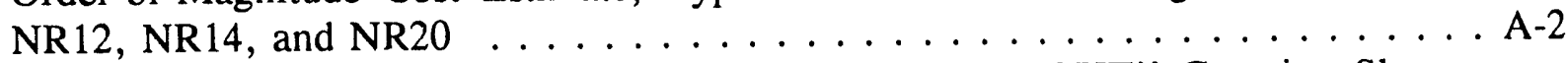

A-2 Order-of-Magnitude Cost Estimate, Type 2 "LATER GROUT"' Grouting Sleeve Seals LG12, LG14, LG18, LG20, and LG25 . . . . . . . . . . . . . A-3

A-3 Order-of-Magnitude Cost Estimate, Type 3 'LATER EXCAVATE' Overexcavation Seals LE12, LE14, LE18, LE20, and LE25 . . . . . . . . . . . . . A-5

A-4 Order-of-Magnitude Cost Estimate, Type 4 Rigid Sleeve/Overexcavation Seals

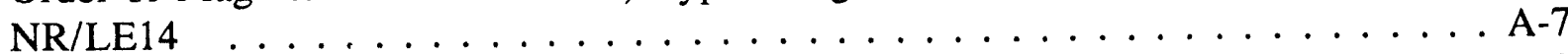

A-5 Rough Order-of-Magnitude Cost Evaluation of Combination $1 \ldots \ldots$. . . . . . A-8

A-6 Rough Order-of-Magnitude Cost Evaluation of Combination 1A . . . . . . . A A-9

A-7 Rough Order-of-Magnitude Cost Evaluation of Combination 2 . . . . . . . . . A-10

A-8 Rough Order-of-Magnitude Cost Evaluation of Combination 2A . . . . . . A-11

A-9 Rough Order-of-Magnitude Cos Evaluation of Combination $3 \ldots \ldots$. . . . A-12

A-10 Rough Order-of-Magnitude Cost Evaluation of Combination 3A . . . . . . . A-13

A-11 Rough Order-of-Magnitude Cost Evaluation of Combination $4 \ldots \ldots$. . . . . A-14

B-1 Bentonite Layer Seal and Emplaced Salt Seal Order-of-Magnitude Capital Cost Estimate for Four WIPP Shafts . . . . . . . . . . . . . . . . B-2

B-2 Bentonite Ring Seal and Emplaced Salt Seal Order-of-Magnitude Capital Cost Estimate for Four WIPP Shafts ...................... . . . . .

B-3 Chemical Seal Ring and Emplaced Salt Seal Order-of-Magnitude Capital Cost Estimate for Four WIPP Shafts . . . . . . . . . . . . . . B-4 
B-4 Asphalı Column and Emplaced Salt Seal Order-of-Magnitude Capital Cost Estimate for Four WIPP Shafts . . . . . . . . . . . . . . . . . . B-5

C-1 WIPP Conceptual Seal Design Alternative Study, Borehole Sealing Unit Costs . . C-2

C-2 WIPP Conceptual Seal Design Alternative Study, Borehole Sealing Alternative, Cost

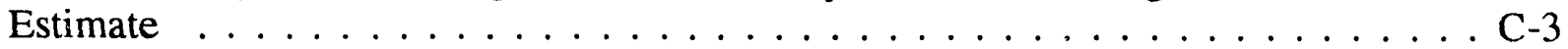

\section{Sketcines}

$\underline{\text { Sketch }}$

Page

SK-1 Drift and Panel Seals Type 1 - NR 12 Seal, B-3B-B Rigid Sleeve . . . . . . . . D-2

SK-2 Drift and Panel Seals Type 1 - NR 14 Seal, B-3B-B Rigid Sleeve . . . . . . . . D-3

SK-3 Drift and Panel Seals Type 1 - NR 20 Seal, B-3B-B Rigid Sleeve . . . . . . . . D-4

SK-4 Drift and Panel Seals Type 2 - LG 12,14,18,20,25 Seals, $\mathrm{B}_{1}-3 \mathrm{~B}_{2}-\mathrm{B}_{1}$ Grouting

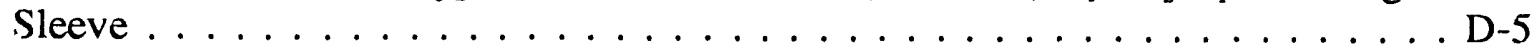

SK-5 Drift and Panel Seals Type 3 - LE 12,14,18,20,25 Seal, Later Excavate DRZ . D-6

SK-6 Drift and Panel Seals Type 4 - NR/LE Seals, $B_{1}-3 B_{2}-B_{1}$, ALT. $1+3 \ldots \ldots$. . .

SK-7 Shaft Seals, Location of Seals . . . . . . . . . . . . . . . . . . . D-8

SK-8 Shaft Seals, Long-Term Consolidated Salt, Short-Term Bentonite Layer Seal . . D-9

SK-9 Shaft Seals, Long-Term Consolidated Salt, Short-Term Bentonite Ring Seal . D-10

SK-10 Shaft Seal, Long-Term Consolidated Salt, Short-Term Chemical Seal . . . . . D-11

SK-11 Shaft Seal, Long-Term Consolidated Salt, Short-Term Asphalt Column . . . . D-12

SK-12 Borehole Sealing Location and Classification Plans . . . . . . . . . . D-13

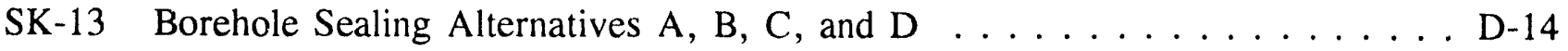




\subsection{INTRODUCTION}

The Waste Isolation Pilot Plant (WIPP) near Carlsbad, New Mexico, is planned as the first mined geologic repository for transuranic (TRU) wastes generated by defense programs of the United States Department of Energy (DOE). Sealing systems in the panels, drifts, shafts, and boreholes are important components of the WIPP facility that will be designed to limit the release of waste materials to the accessible environment.

This document presents the results from a study of various sealing alternatives for WIPP seal design. The seal system will be designed to reduce to the extent possible the potential for radionuclide release to the accessible environment and to reduce the flow of groundwater into the repository. Materials used in the seals will be selected to be compatible with the surrounding rock. Emplacement procedures will be selected to minimize construction time and cost, and to provide for safety while producing an effective seal. The sealing system includes multiple redundant barriers to provide greater confidence for sealing of the repository.

The sealing system has been organized into four subsystems that include panel, drift, shaft, and borehole seals. The shaft sealing subsystem has been further divided into lower, upper, water-bearing, and near-surface.

The functions of these seals cover different times consisting of two phases: (1) the operational phase (lasting approximately 35 years) and (2) the postclosure phase (lasting 10,000 years). The operational phase consists of the waste emplacement period (30 years) and the underground decommissioning period (5 years). The postclosure phase consists of the short-term period (100 years) and the long-term period (beyond 100 years).

A summary of the seal functions is given by Bailey et al. (1992a) and is shown in Table 1-1. The redundant features listed in Table 1-1 were considered to be mandatory functions, i.e., the redundant features must be provided by the sealing subsystem. For example, the panel seals must include a long-term barrier to release of waste materials in addition to its principal function of limiting release of waste materials in the operational period. 
Table 1-1. Sealing Subsystem Functions (from Bailey et al., 1992a)

\begin{tabular}{|c|c|c|c|}
\hline \multicolumn{2}{|c|}{ Sealing Subsystem } & Principal Function & $\underline{\text { Redundant Feature }}$ \\
\hline \multirow{2}{*}{\multicolumn{2}{|c|}{ Panels }} & $\begin{array}{l}\text { Limit release of waste materials during } \\
\text { the operational phase. }\end{array}$ & $\begin{array}{l}\text { Limit release of waste materials during } \\
\text { the short-term period. }\end{array}$ \\
\hline & & & $\begin{array}{l}\text { Limit release of waste materials during } \\
\text { the long-term period. }\end{array}$ \\
\hline \multirow{2}{*}{\multicolumn{2}{|c|}{ Drifts }} & $\begin{array}{l}\text { Limit release of waste materials during } \\
\text { the operational phase. }\end{array}$ & $\begin{array}{l}\text { Limit release of waste materials during } \\
\text { the short-term period. }\end{array}$ \\
\hline & & & $\begin{array}{l}\text { Limit release of waste materials during } \\
\text { the long-term period. }\end{array}$ \\
\hline \multirow{5}{*}{ Shafts } & $\begin{array}{l}\text { Lower } \\
\text { (Salado) }\end{array}$ & $\begin{array}{l}\text { Limit release of waste materials during } \\
\text { the short-term period. }\end{array}$ & $\begin{array}{l}\text { Limit groundwater flow during the } \\
\text { short-term period. }\end{array}$ \\
\hline & & $\begin{array}{l}\text { Limit release of waste materials to the } \\
\text { accessible environment during the long- } \\
\text { term period. }\end{array}$ & \\
\hline & $\begin{array}{l}\text { Upper } \\
\text { (Rustler/ } \\
\text { Salado) }\end{array}$ & $\begin{array}{l}\text { Limit groundwater flow during the short- } \\
\text { term period. }\end{array}$ & None \\
\hline & $\begin{array}{l}\text { Water- } \\
\text { Bearing }\end{array}$ & Separate aquifers. & None \\
\hline & $\begin{array}{l}\text { Near- } \\
\text { Surface }\end{array}$ & Cap and provide marker. & None \\
\hline \multirow{5}{*}{\multicolumn{2}{|c|}{ Boreholes }} & $\begin{array}{l}\text { Limit release of waste materials during } \\
\text { the short-term period. }\end{array}$ & None identified at this time. \\
\hline & & $\begin{array}{l}\text { Limit release of waste materials to the } \\
\text { accessible environment during the long- } \\
\text { term period. }\end{array}$ & \\
\hline & & $\begin{array}{l}\text { Limit groundwater flow during the short- } \\
\text { term period. }\end{array}$ & \\
\hline & & Separate aquifers. & \\
\hline & & Cap and provide marker. & \\
\hline Note: & \multicolumn{2}{|c|}{$\begin{array}{l}\text { Operational Phase - Release is in gaseous medium } \\
\text { Short-Term - Release is in gaseous medium } \\
\text { Long-Term - Release is in gaseous or liquid medium. }\end{array}$} & \\
\hline
\end{tabular}




\subsection{Seal Requirements}

The functional requirements for the WIPP sealing system are:

- Provide engineered barriers that will prevent WIPP excavations from becoming preferred pathways for the release of waste materials in quantities that compromise compliance with applicable regulations.

- Limit groundwater flow into the repository underground during the short-term to allow consolidation of the salt to take place.

- Form multiple barriers to gas/liquid flow at strategic locations.

Specific seal performance criteria for the various subsystems will be described in sections of the report appropriate to that sealing subsystem.

\subsection{Purpose of the Alternatives Study}

The Initial Reference Seal System Design (IRSSD) (Nowak et al., 1990) provides one type of seal for each of the sealing subsystems. This study explores other types of seals which involve different sizes, shapes, materials, seal installation schedules, elimination or addition of components, and remediation and maintenance requirements. Sealing subsystems are evaluated qualitatively as to whether or not the sealing subsystem can meet the performance criteria. The evaluation often is that engineering judgment deems one alternative to have greater subjective probability of failure compared to another alternative, despite the fact that both alternatives have a reasonable expectation for success. Cost differences are developed for each alternative. Factors influencing the cost are size, shape, materials, seal installation schedule, and remediation and maintenance requirements, and for boreholes, the number of holes considered for sealing.

The alternatives study as performed did not include detailed cost comparisons or technical evaluations. In that regard, neither specific recommendations nor comprehensive performance conclusions are made. Rather, alternatives are compared mostly in terms of their advantages and disadvantages. 


\subsection{Report Organization}

This report is organized as follows. Section 2.0 describes several rock mechanics issues relevant to the design of seals or schedule for seal installation. Issues discussed include: (1) consolidation of crushed salt as a seal component, (2) the development and extent of a disturbed rock zone around openings, and (3) the loading imposed on load-bearing seal components. The results from rock mechanics studies are applicable to panel and drift seals, shaft seals, and borehole seals.

Sections 3.0, 4.0, and 5.0 present the alternatives studies for panel and drift seals, shaft seals, and borehole seals, respectively. In each of these sections, the reference seal design and seal materials are presented followed by discussions of alternative seal components, materials, and schedules for installation, as appropriate. The alternatives for seal subsystems in each section are then evaluated in terms of its favorable features and shortcomings and order-of-magnitude costs. Future work required to validate or reconcile issiles and assumptions is identified where necessary.

Section 6.0 lists studies or future work that provide missing information or validate concepts for the seal system. Section 7.0 provides a list of references for the report. 


\subsection{ROCK MECHANICS}

Rock menhanics analyses were used to provide basic information on threc concerns relevant to the design of the sealing system:

1. The time required for consolidation of crushed salt or quarried-salt blocks into a nearly impermeable seal material.

2. The development and extent of a disturbed rock zone (DRZ) around openings, where such a DRZ may be in the salt or the interbeds and is time-dependent in its characteristics.

3. The loading on rigid structures resulting from salt creep surrounding the structure.

Information about each of these concerns is presented in separate sections in this chapter. Whenever possible, the discussion of rock mechanics analysis uses normalized results such that the same results can be applied to seal design in either panel and drift seals, shaft seals, and borehole seals.

For most of the analyses, the thermomechanical finite-element program SPECTROM-32 (Callahan et al., 1989) was used io model the mechanical behavior of the host rock surrounding the opening and the concrete structure(s), if any. Four-noded, quadrilateral elements were used in all of the finite element meshes. Material properties listed in the preliminary Design Data Base Document (Bailey et al., 1992b) were used unless otherwise noted. For salt, the Munson-Dawson creep law and parameter values determined from laboratory tests and field data verification analyses [e.g., Munson et al. (1992)] were used in these analyses. For concrete, an elastic model was used. The following initial conditions and assumptions were used:

1. For axisymmetric analyses, the WIPP stratigraphy can be ignored and an all-salt medium assumed.

2. For plane strain analyses, the stratigraphy, with the exception of the location of Clay Seams F and G, was modeled as shown in the preliminary Design Data Base Document (Bailey et al., 1992b) for the WIPP sealing system. The location of Clay Seams $F$ and $G$ are modeled as shown in the WIPP alcove gas barrier (AGB) final design report (Lin and Van Sambeek, 1992b). 
3. The modeled excavations are sufficiently remote from other excavations that a single-room in an infinite medium is representative.

4. The initial stress-state prior to excavation is lithostatic and equal to $-14.76 \mathrm{MPa}$ at the WIPP horizon (655-m depth). The stress varies $0.0226 \mathrm{MPa} / \mathrm{m}$ above and below the WIPP horizon from gravitational loading.

5. The mechanical behavior of the rock mass surrounding the excavation was predicted using the material models and properties for halite, argillaceous halite, anhydrite, polyhalite, and clay as given in the preliminary Design Data Base Document (Bailey et al., 1992b) for the WIPP sealing system.

6. The modeled region remains isothermal at $27^{\circ} \mathrm{C}$.

7. The excavation and emplacement operations can be performed instantaneously without impacting the utility of the results.

Similar assumptions and modeling approaches were used to model experiments and in situ measurements at WIPP: South Drift, Room G, and Room D (Munson and DeVries, 1991; 1990), heated rooms (Munson et al., 1990; 1991), heated pillar (Munson et al., 1988), and shaft closure measurements (Munson et al., 1992).

\subsection{Crushed Salt Consolidation}

According to the WIPP IRSSD (Nowak et al., 1990), reconsolidated crushed salt is the principal long-term barrier to fluid flow. The crushed-salt emplacement density and the time required to achieve reconsolidation to the desired density are two interrelated design considerations. Modeling the consolidation of crushed salt within the WIPP seal system is an intensive computational effort. The consolidation process is driven by the creep closure of the opening, such that whenever the opening experiences a volume reduction because of closure, the same volume reduction (by way of consolidation) is also experienced by the crushed salt.

The development of internal stress in the consolidating crushed salt is a complex, timedependent function of the current consolidation rate and the density. The stiffness of the crushed salt in terms of its bulk and shear moduli can be related to the density (Sjaardema and Krieg, 1987). Because crushed salt will consolidate by creep (e.g., Holcomb and Shields, 1987), the lowest possible stresses exist when the volumetric strain rate from creep 
consolidation equals the imposed volumetric strain rate closure. When the two strain rates are equal, none of the imposed volumetric strain is available for elastic volumetric strain, which induces a stress increment. Therefore, so long as the closure rates for a salt-filled opening are low, the stresses in the crushed salt will also be low urtil the density no longer allows the crushed salt to creep consolidate at a fast enough rate. The density at which this transition seems to occur is about 95 percent of the intact salt density (Holcomb and Hannum, 1982; Holcomb and Shields, 1987).

One way to determine whether or not a region of crushed salt in the sealing system can possibly achieve consolidation to a predetermined density within a desired time frame is to inspect the expected closure history for the same region without crushed salt. A region without crushed salt will always exhibit a faster closure rate than the same region with crushed salt. Thus, if the region does not meet a time-to-consolidation objective without crushed salt, it will never meet the same objective with crushed salt.

The volumetric strain, $\varepsilon_{\mathrm{v}}$, required to consolidate crushed salt from a starting density of $\rho_{o}$ to $\rho$ is

$$
\varepsilon_{\mathrm{v}}=\frac{\rho_{o}}{\rho}-1
$$

where $\varepsilon_{\mathrm{v}}$ is negative for volume reduction. For example, to consolidate from a starting density of $1,700 \mathrm{~kg} / \mathrm{m}^{3}$ to $2,000 \mathrm{~kg} / \mathrm{m}^{3}$ requires a volumetric strain of -15 percent. This volumetric strain corresponds to the volumetric room closure required to cause the consolidation. The density terms in Equation 2-1 can be either density or fractional density.

Numerical modeling analyses were made to determine the volumetric closure rates and times required to achieve given amounts of closure for several geometric situations of interest for drift and shaft seals.

\subsubsection{Shaft Closure}

Munson et al. (1992) describe an analysis that was performed to calculate the long-term closure rates for shafts and boreholes. The results from their calculation were obtained from the authors and used in this study. It is emphasized that the closure rates presented 
by Munson and coworkers are for an empty opening in salt; that is, there is no lining or crushed salt in the opening to impede closure.

The closure rate in various intervals of shafts and boreholes is highly dependent on the depth of the interval. The lithostatic stress increases with depth and the closure rate is a strong function of the stress state. The closure rate also depends on the time that has elapsed between the excavation of the shaft or the drilling of the borehole and the time at which the closure rate is desired. Munson et al. (1992) shows the influence of a 20-year elapsed period on the resulting time to achieve a given volumetric strain (areal closure) as a function of depth.

The procedure and modeling results of Munson et al. (1992) were used to determine the influence of a 50-year elapsed time between shaft excavation and shaft sealing. The results are shown in Figure 2-1 for several depths in the shaft. In Figure 2-1, the closure was converted to volumetric strain to facilitate determining the degree of consolidation resulting from the closure.

At a depth of $2,000 \mathrm{ft}$, the volumetric strain increases from zero at 50 years after excavation (time equal to zero in the figure) to 14 percent at 100 years after closure. If crushed salt had been placed in the 50-year-old shaft, the crushed salt would have had to consolidate 14 percent in order to accommodate the closure. This volumetric strain relates directly to the change in density or fractional density as used in Equation 2-1. A caveat to this example is that if crushed salt had actually been present in the shaft, the closure rate will slow when the crushed salt began to develop internal stress, which in turn will slow the creep of the surrounding salt. The information shown in Figure 2-1 must not be used without recognizing this simplification.

\subsubsection{Drift Closure}

The design of the drift seals requires estimates of the consolidation rate of crushed salt in the permanent seal region. An approximation of the consolidation rate for drifts was obtained by converting open drift closure rates (no crushed salt or rigid structures) to a volumetric closure rate quantity, which provides an upper-bound estimate of the consolidation rate for crushed salt in the drift. It is emphasized that this procedure produces a result that is only an order-of-magnitude result because the back pressure from the crushed salt (or quarried-salt blocks) and the restraint from rigid structures will cause 


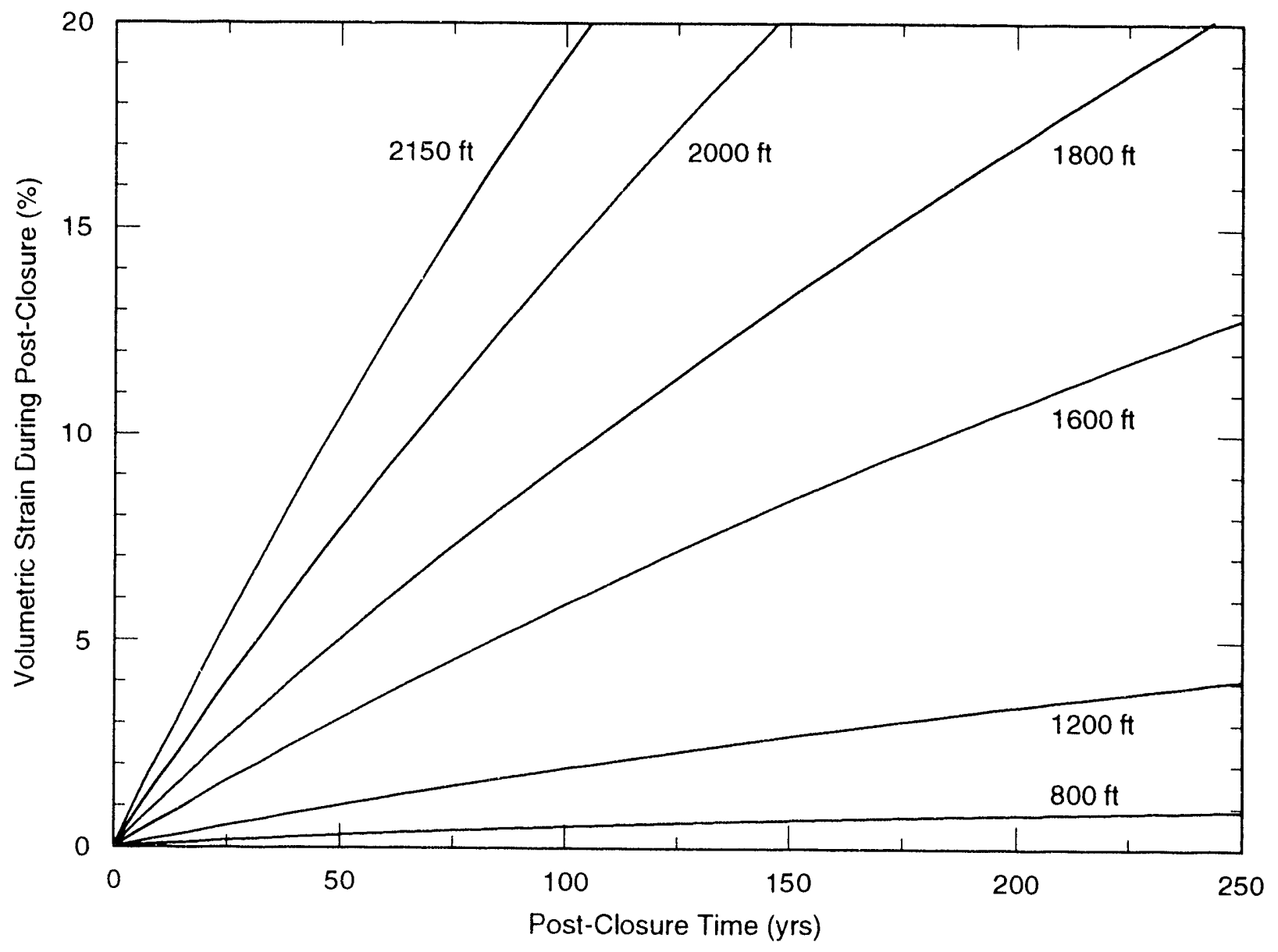

TAI. 6121.72 .0

Figure 2-1. Volumetric strain for six depths from the surface in 50-year-old shaft. 
slower drift closure rates, and it is the drift closure rate that controls the consolidation rate of the emplaced salt. The results shown in Figure 2-1 for a depth of 2,150 ft are also applicable to drift and panel seals within the WIPP horizon.

Figure 2-2 presents a plot of volumetric closure for a 50-year time period after excavation for two different drift geometries $(14 \times 12$ - and $25 \times 12$-ft drifts). During the first 40 years of the 50-year period, the drift is open and unsupported. After 40 years, a rigid sleeve was installed in the drift and closure is effectively arrested. Of interest here is the closure during the first 40 years. The difference in closure rates for the two drift geometries is not large despite the relatively large difference in size and shape. In particular, the volumetric closure rate after about 20 years is relatively constant. This constant rate is used to estimate the consolidation time for a crushed-salt filled portion of a drift.

The time required (years), $\mathfrak{t}_{\mathrm{c}}$, for consolidation of crushed salt (or quarried-salt-block mortar) in the permanent seal region of drift/panel seals is estimated (order-of-magnitude only) by

$$
t_{c}=\frac{C}{0.0033},
$$

where $C$ is the required volumetric consolidation strain and the denominator $(0.0033)$ is the average slope of the two curves shown in Figure 2-2. For example, if a 15 percent volumetric strain (closure) is required to consolidate a crushed-salt fill, at least 45 years is required. An uncertainty exists because some back stress will develop in the crushed salt, which slows the closure and extends the consolidation time required.

\subsubsection{Closure Between Rigid Structures}

The reference seal systems include rigid structures to provide confinement of other seal materials such as crushed salt and bentonite. The rigid structure will prevent the natural creep closure of opening at the location of the structure and reduce the creep closure for some unknown distance beyond either end of the structure. Because crushed salt must be forced to consolidate by the creep closure in order to be an effective sealing material, calculations were made to determine the degree of creep closure reduction for different 


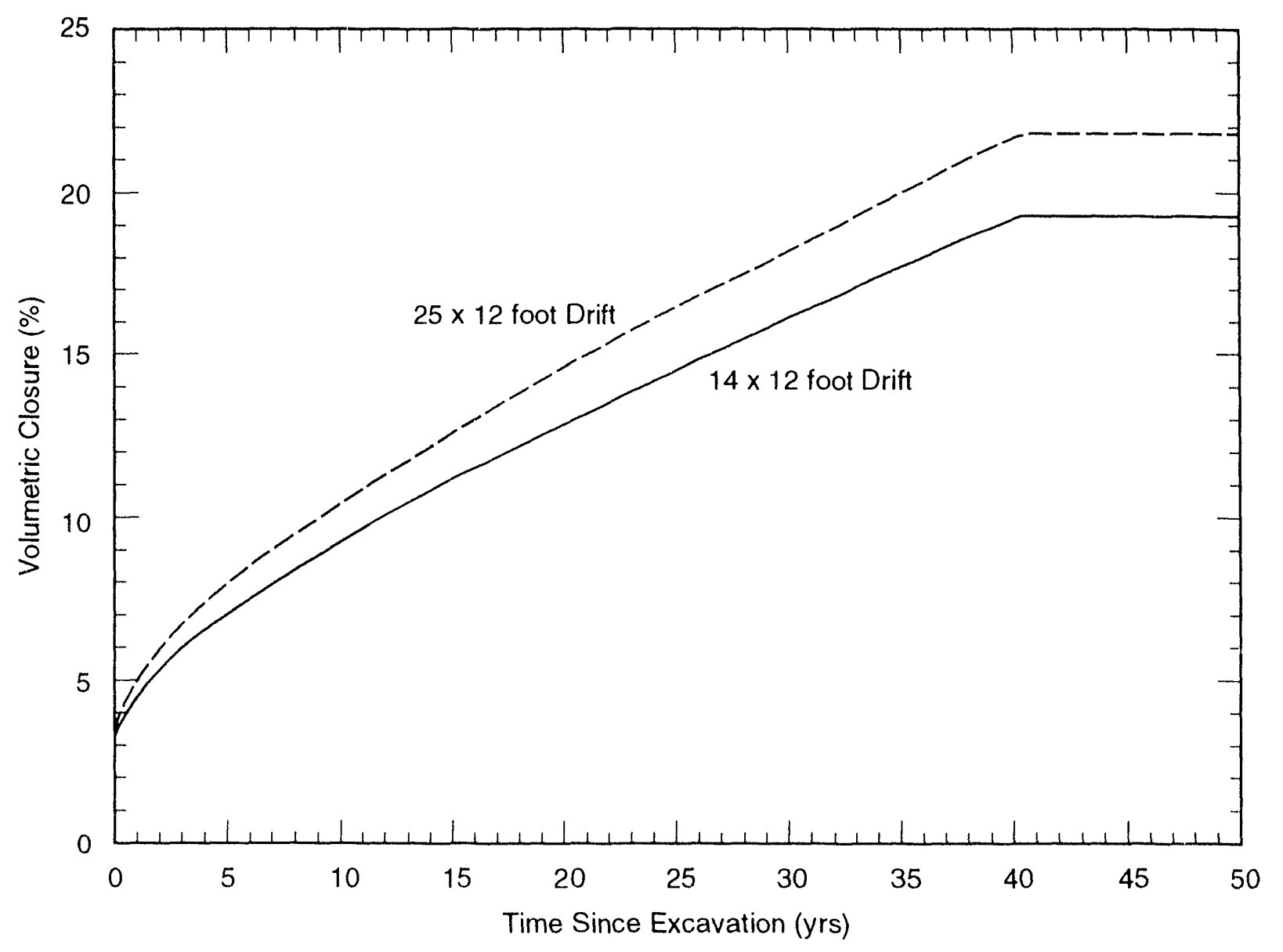

TAI.6121.73.0

Figure 2-2. Volumetric closure for two rectangular-shaped drifts. 
spacings between rigid structures.

Rigid structures in an opening will retard the closure of the opening both in the immediate area of the structure and for some distance on either side of the structure. The geometric situations modeled to study the influence of rigid structures on the closure between the structures are shown in Figure 2-3. The following steps (which are also shown in Figure 2-4) were included in the analysis:

1. Excavate a circular opening of sufficient length to simulate a very long opening in a homogeneous material. (The diameter of the opening (W) is not important to the results as no stratigraphy is included in the models).

2. Analyze the creep of the salt surrounding the unsupported opening to 10 years.

3. Install a rigid sleeve over an appropriate length of the opening; for example, five times the diameter of the opening $(5 \mathrm{~W})$ in the case of the eventual $3 \mathrm{~W}$ salt-filled region.

4. Analyze the creep of the salt surrounding the supported and unsupported areas of the opening for an additional 5 years.

5. Remove the sleeve in the central portion of the supported opening to produce the region to be filled with salt (for example, $3 \mathrm{~W}$-long in the case of the $3 \mathrm{~W}$ backfilled region). Convert the two $1 \mathrm{~W}$-long sections of rigid sleeve to monolithic structures, one at each end of the salt-fill region. Record the liner loading on the monolithic structures after the removal of the central portion of the rigid sleeve.

6. Analyze the creep of the salt for the new geometry to about 100 years. Record the closure of the central portion (salt-filled region - although no salt fill is actually emplaced). Also record the liner loading on the monolithic structures.

The numerical modeling results for the different geometrical situations show that the volumetric strain from room closure is relatively uniform between the two monolithic structures. The closure is restrained by the rigid sleeve to a distance of about 1 opening radius into the central portion from each rigid sleeve. This is in agreement with earlier calculations made by Argüello (1988).

In terms of cumulative room closure (volumetric strain) for the three cases, the greater the span between rigid sleeves, the greater the volumetric strain, although the difference is 

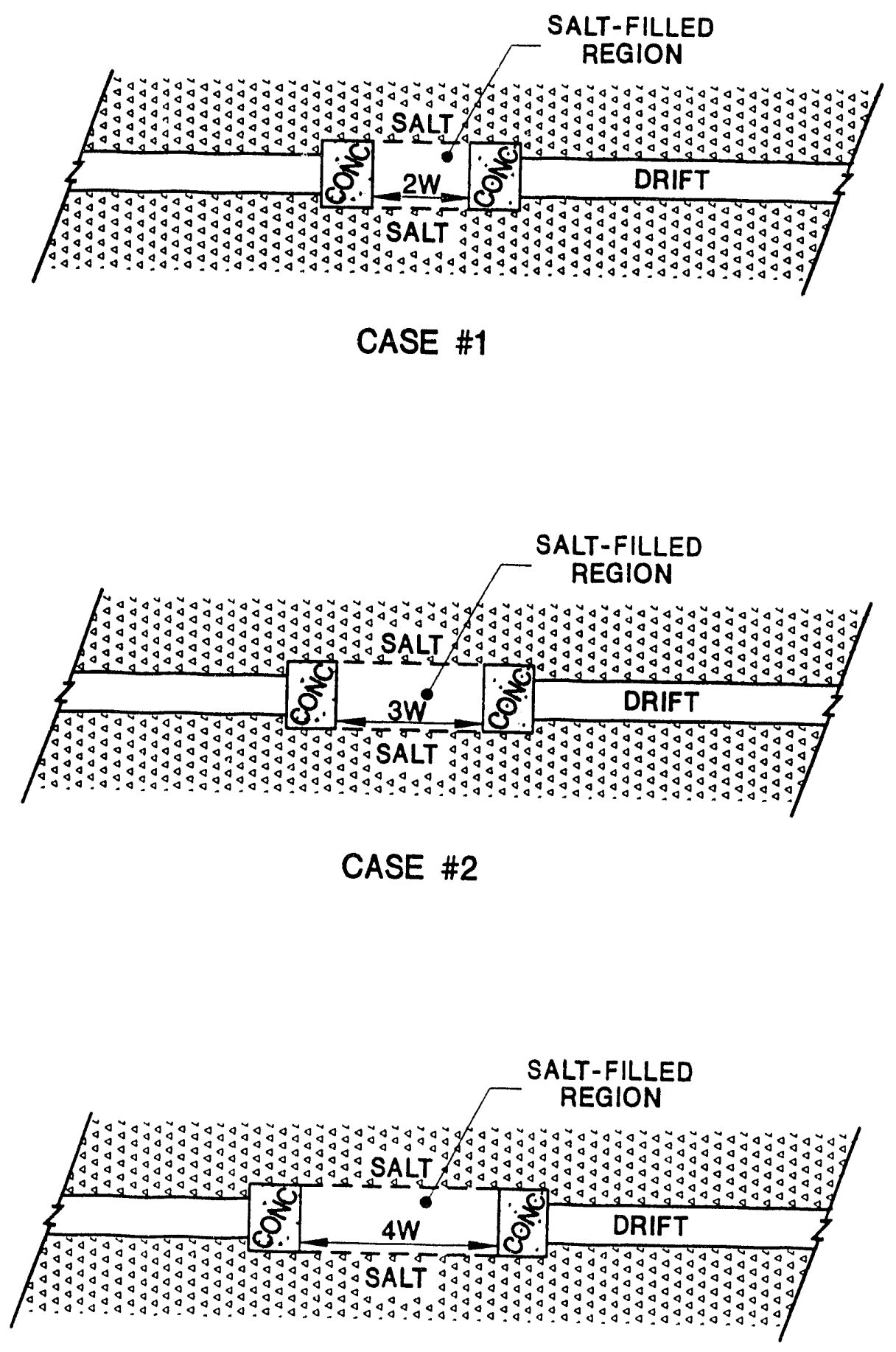

CASE \#3

RS1-02-213-033

Figure 2-3. Geometries for a $1 \mathrm{~W}$ rigid sleeve and $2 \mathrm{~W}, 3 \mathrm{~W}$, and $4 \mathrm{~W}$ salt-filled region lengths. 


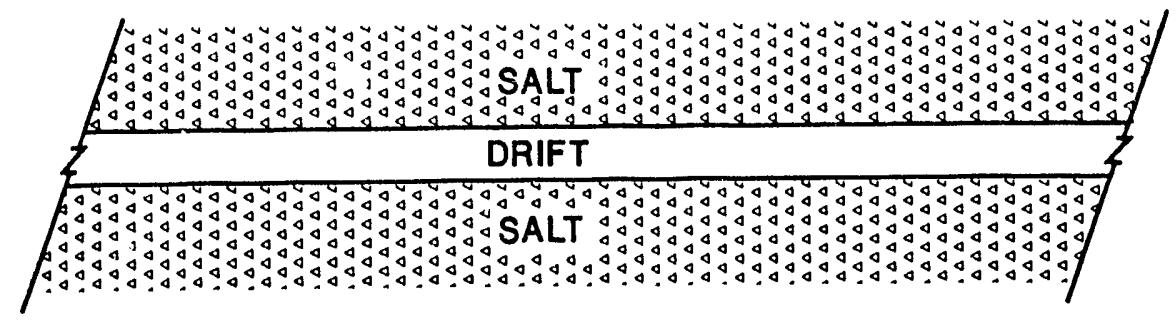

(a) $0<t \leq 10$ years

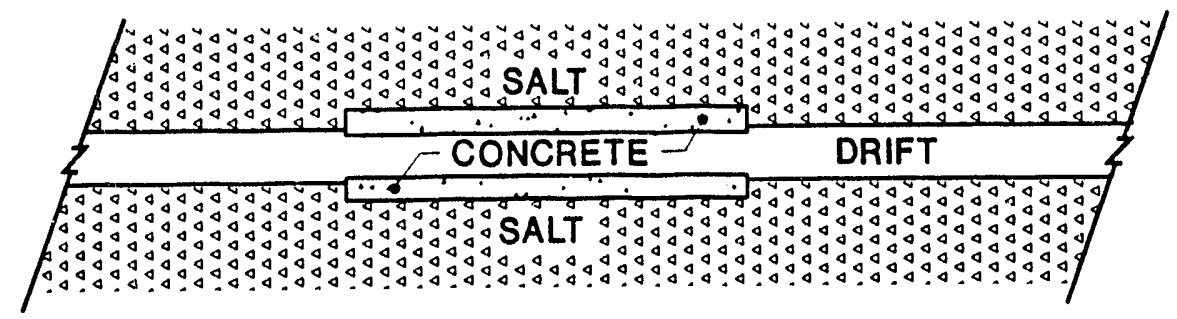

(b) $10<t \leq 15$ years

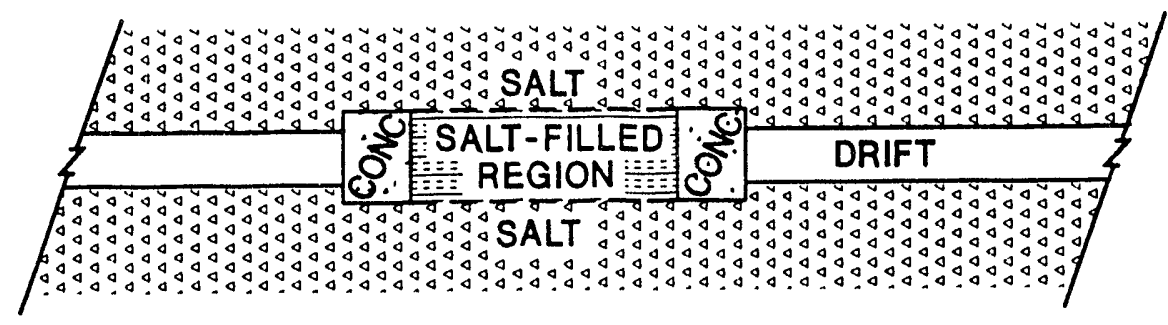

(c) $15<t \leq 100$ years

RS1-213-02-032

Figure 2-4. Excavation and emplacement sequence for rigid sleeve and salt fill. 
not large. The volumetric strains at the midlength of the salt-filled regions are shown in Figure 2-5 for the $2 \mathrm{~W}-, 3 \mathrm{~W}$-, and $4 \mathrm{~W}$-long central portions.

\subsection{DRZ Around Openings}

\subsubsection{Types of DRZ}

It is commonly recognized that a disturbed rock zone (DRZ) develops around any underground excavation. At the WIPP, a DRZ is defined by J.C. Stormont in the 1991 memorandum titled "An Approach to Address DRZ Development and Healing in Rock" as that region near an excavation that experiences a change in its hydrologic or mechanical properties. Boreholes in the roof, floor, and ribs at WIPP have revealed fracturing within the first meter beyond the excavation surface. Some of the fracturing, particularly that in interbeds (anhydrites, clays, polyhalites, and argillaceous halite), increases in frequency and aperture through time. In general, t 'e DRZ consists of an "initial" DRZ that develops upon excavation of the opening and a "secondary" DRZ that develops in the salt and interbeds because of the creep deformation of the salt and the stress redistribution as a consequence of creep. A DRZ is generally assumed to have the following characteristics (e.g., Stormont, 1990; Stormont et al., 1987; and Stormont et al., 1991):

- Increased volume resulting from micro- or macro-fracturing,

- Decreased load-bearing capacity, and

- Increased fluid (gas or liquid) permeability.

\subsubsection{DRZ IN SALT}

Studies of the development of a DRZ in salt lead to the conclusion that the DRZ is intimately tied to the stresses that occur in the zone. In particular, certain combinations of applied stresses cause dilation in laboratory tests on salt cores. The stress states can be represented by stress measures describing the bulk pressure (mean stress or first invariant of the total stress tensor) and shear stress (second invariant of the deviatoric stress tensor). The two stress measures signal both the development of the DRZ in rock salt and the healing of damage (e.g. fractures) within salt.

Two efforts at characterizing the DRZ in WIPP salt use the assumption that the extent of the DRZ (at any time) can be determined through an examination of the two 


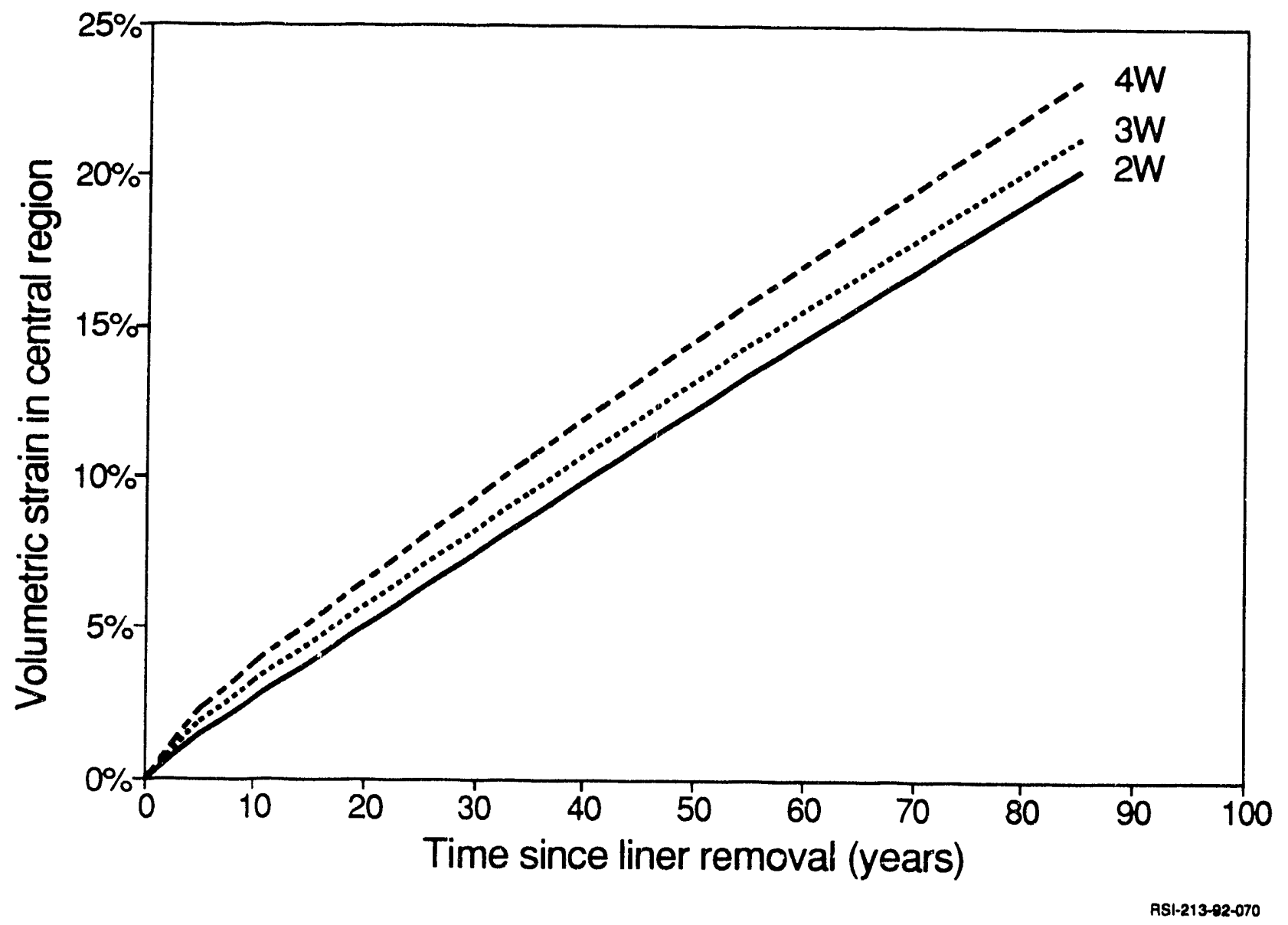

Figure 2-5. Volumetric strain at the center of the region between the rigid sleeves. 
instantaneous values of the aforementioned stress invariants (Ratigan et al., 1991 and Stormont 1991 memorandum, as cited above). Another effort is pursuing the development of a rate-based constitutive model with mechanistically based, stress-invariant dependence that requires integration of the rate equations to determine DRZ extent (Fossum et al., [1992]). Each effort recognizes that the DRZ is a zone of damaged rock that has experienced an increase in volume, which is commonly referred to as dilation, and is attributable, at least in part, to microfacturing.

Ratigan et al. (1991) proposes that the states of stress that do and do not cause dilation in laboratoly creep tests are separated by the relationship

$$
\sqrt{\mathrm{J}_{2}}=0.27 \mathrm{I}_{1} \text {, }
$$

where $J_{2}$ is the second invariant of the deviatoric stress tensor and $I_{1}$ is the first invariant of the total stress tensor $\left(I_{1}=3 \sigma_{m}\right)$. This equation can be used to determine the potential for a DRZ whenever the stress state is known or can be calculated.

\subsubsection{DRZ IN INTERBEDS}

The anhydrite of Marker Bed 139 (MB139) is the closesi major interbed to the panel and drift seal locations. The anhydrite is brittle, unlike the WIPP salt. When an excavation is made a short distance above MB139, the rock stress at the boundary of the opening is reduceu to zero, creating an upward thrust on the bed. The bed deforms upward toward the excavation because of both elastic and creep deformation of the salt. The deformation of MB139 is most severe directly under the excavation, but deformation of MB139 extends under the adjacent pillars as well. The deformation will produce a DRZ within MB139, which is characterized by micro- and possibly macro-fractures. When fractures develop in MB139, the permeability of the interbed will increase significantly, and such fracturing is not expected to heal naturally, except by long-term mineralization. Grouting should reduce the permeability; however, the effectiveness of grouting is diminished if the salt continues to creep toward the excavation, resulting in further deformation and potential continued fracturing of MB139.

Clay seams also exist near the WIPP excavations. Characterization of DRZs around the clay seam interbeds has not been performed. It is possible that the zone of damage outside 
the seam itself is small because the "clay" is weak and will yield before allowing shearing stresses to build to the point where the surrounding rock (salt) is damaged.

\subsubsection{Opening-Shape Effects}

\subsubsection{CIRCULAR OPENINGS}

A necessary element of the conceptual design of a shaft seal within the Salado Formation is determining the thickness of the DRZ around the shaft after standing unlined for 30 to 50 years. A first approximation of the thickness of the DRZ will be made in this subsection using analytical solutions for the stress distributions in the salt around the shaft and a salt damage criterion based on stress invariants.

The calculation could also be made using numerical modeling methods, but modeling the problem is a more intensive effort and is beyond the scope of a first approximation. The analytical solution for the stress distributions are available, for example, in Van Sambeek (1986). The analytical solution applies only if the following conditions are met or assumed:

1. No creep strain occurs in the direction parallel to the axis of the shaft, and

2. The creep behavior of the salt can be described by a Norton-type creep law, a condition that applies a long time after excavation (i.e., after any transient creep phase has ended).

A condition of stationary stress, as defined by Van Sambeek (1986), is assumed to exist around the shaft at the time of sealing; that is, some 30 to 50 years after shaft excavation. Moreover, a condition of zero vertical creep displacement is assumed in order to meet the "axially restrained" condition. An axially restrained condition is not truly appropriate because subsidence is known to occur, but the vertical strain is believed to approach zero at moderate distances above the repository horizon.

According to Van Sambeek (1986), the stationary stress distributions around a circular opening in an infinitely extending material whose creep behavior can be modeled by a Norton-type creep law are 


$$
\begin{aligned}
& \sigma_{r r}=P_{o}\left[(a / r)^{2 / n}-1\right] \\
& \sigma_{\theta \theta}=P_{o}\left[(1-2 / n)(a / r)^{2 / n}-1\right] \\
& \sigma_{z z}=\left(\sigma_{r r}+\sigma_{\theta \theta}\right) / 2,
\end{aligned}
$$

where "a" is the excavated radius of the shaft, " $r$ " is an arbitrary radius, $P_{o}$ is the lithostatic stress magnitude for the depth of interest, and " $n$ " is the effective stress exponent in the Norton creep law. The Norton creep law can be assumed to represent an individual steadystate mechanism of the Munson-Dawson creep law.

Combining the equation for the deviatoric stress states that cause dilation in laboratory creep tests (Equation 2-3) and the stationary stress condition (Equation 2-4) around a shaft:

$$
\sqrt{J_{2}}=\frac{1}{2}\left(\sigma_{\theta \theta}-\sigma_{r r}\right)=\frac{3 \alpha}{2}\left(\sigma_{\theta \theta}+\sigma_{r r}\right)=\alpha I_{1}
$$

from the stress invariants

$$
\begin{aligned}
\sqrt{3 J_{2}} & =\frac{\sqrt{3}}{2}\left|\left(\sigma_{\theta \theta}-\sigma_{r r}\right)\right| \\
I_{1} & =\frac{3}{2}\left(\sigma_{\theta \theta}+\sigma_{r r}\right) .
\end{aligned}
$$

Rearranging and substituting Equation 2-4,

$$
\begin{gathered}
(3 \alpha-1) \sigma_{\theta \theta}+(3 \alpha+1) \sigma_{r r}=0 \\
(3 \alpha-1) P_{o}\left[(1-2 / n)\left(a / r_{d}\right)^{2 / n}-1\right]+(3 \alpha+1) P_{o}\left[\left(a / r_{d}\right)^{2 / n}-1\right]=0,
\end{gathered}
$$

where $r_{d}$ is the radius to the edge of the DRZ where the equality in Equation 2-3 is met exactly. Solving for this radius as a proportion of the shaft radius gives

$$
\frac{r_{d}}{a}=\left[\frac{(1-2 / n)(3 \alpha-1)+(3 \alpha+1)}{6 \alpha}\right]^{n / 2} \text {. }
$$

Typically, the Norton-type creep law exponent is in the range $3 \leq n \leq 6$, and $\alpha=0.27$ according to Ratigan et al. (1991). For the extreme values for $n$, the radius to the DRZ 
edge is relatively insensitive $\left(1.119 \leq \frac{r_{d}}{a} \leq 1.122\right)$, and $r_{d}=1.12 a$ is a good approximation.

The thickness of the DRZ surrounding a shaft in salt is, therefore, expected to be about 12 percent of the excavated shaft radius. The DRZ thickness is relatively insensitive to the creep law stress exponent (n) within the range of expected values for $n$ and is, at least theoretically, independent of the initial stresses as determined by the depth below the ground surface.

\subsubsection{RECTANGULAR OPENINGS}

Two numerical modeling analyses were performed to predict the extent of the DRZ around drift and panel excavations at the WIPP that are left open for 40 years after excavation. The DRZ is assessed both in the salt surrounding the excavations and in MB139 directly below the excavations. In order to bracket the DRZ for all drift and panel excavations, both the smallest $(14 \times 12 \mathrm{ft})$ and the largest $(25 \times 12 \mathrm{ft})$ excavation sizes were evaluated.

\subsection{DRZ in the Salt}

A quantity termed the "damage factor" is used to illustrate the extent of the DRZ. The damage factor is the ratio of the predicted deviatoric stress and the deviatoric stress state at the same mean stress that would produce dilation in salt based on laboratory core testing (Ratigan et al., 1991). A damage factor value of 1.0 is the limit stress state for dilation to occur. Dilation (and hence, permeability) is expected to increase with increasing damage factor values. On the other hand, dilation is not expected for damage factors less than 1.0. It must be recognized that damage factors are time-dependent so long as the stress state is changing. Therefore, regions that initially dilate can reheal if the more favorable stress state occurs later. Healing is expected when the damage factor becomes less than 1.0 (i.e., as the damage factor decreases, the expectancy for healing increases). Qualitatively, it is also expected that the lower the damage factor value, the faster that healing may occur.

Contours of the damage factor are shown immediately after excavation (Figure 2-6), after 1 year (Figure 2-7), and after 40 years (Figure 2-8) for a 14- $\times 12$-ft rectangular 


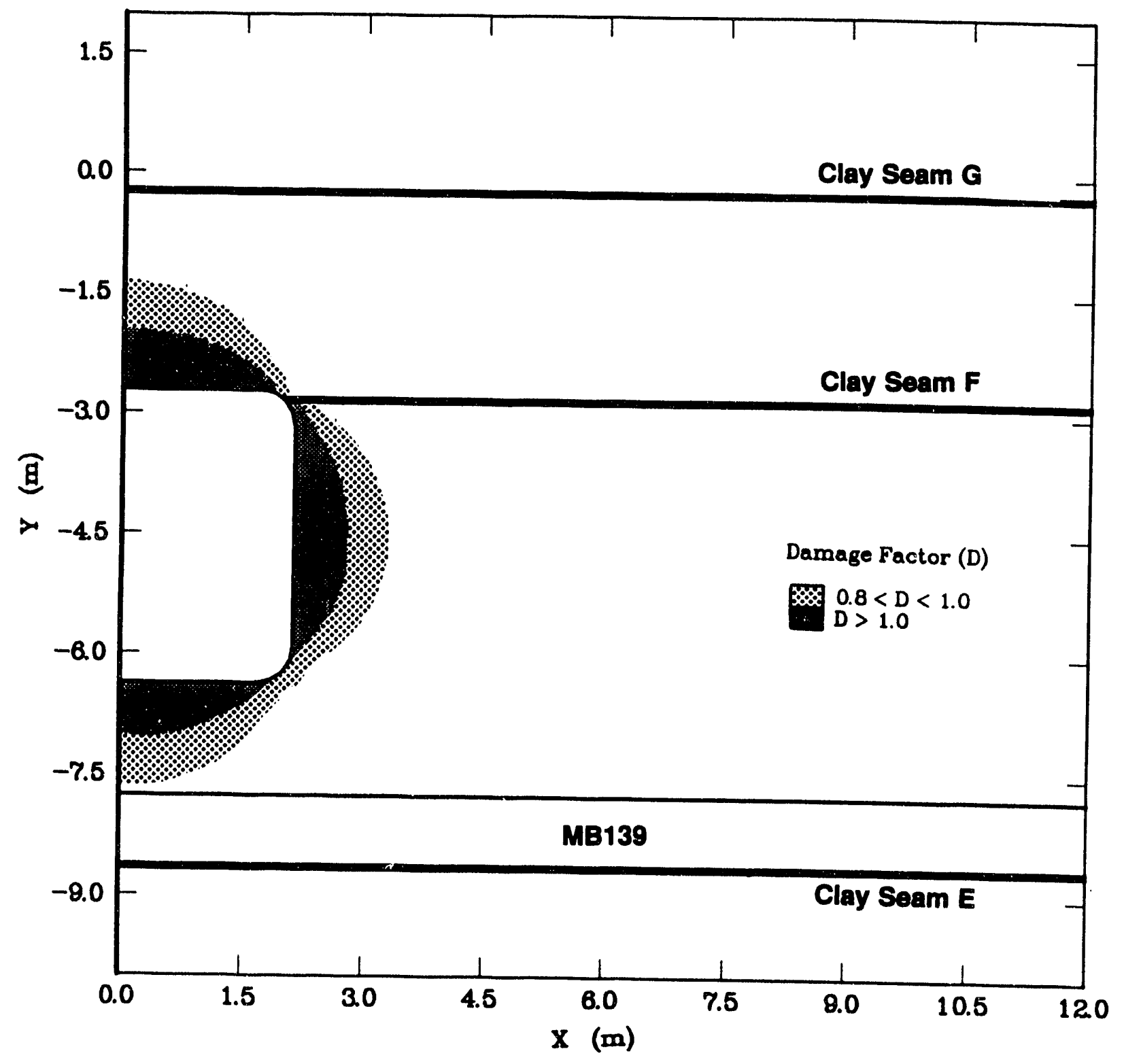

RS1-02-213-004

Figure 2-6. DRZ in salt around a $14-\times 12$-foot excavation immediately after excavation. 


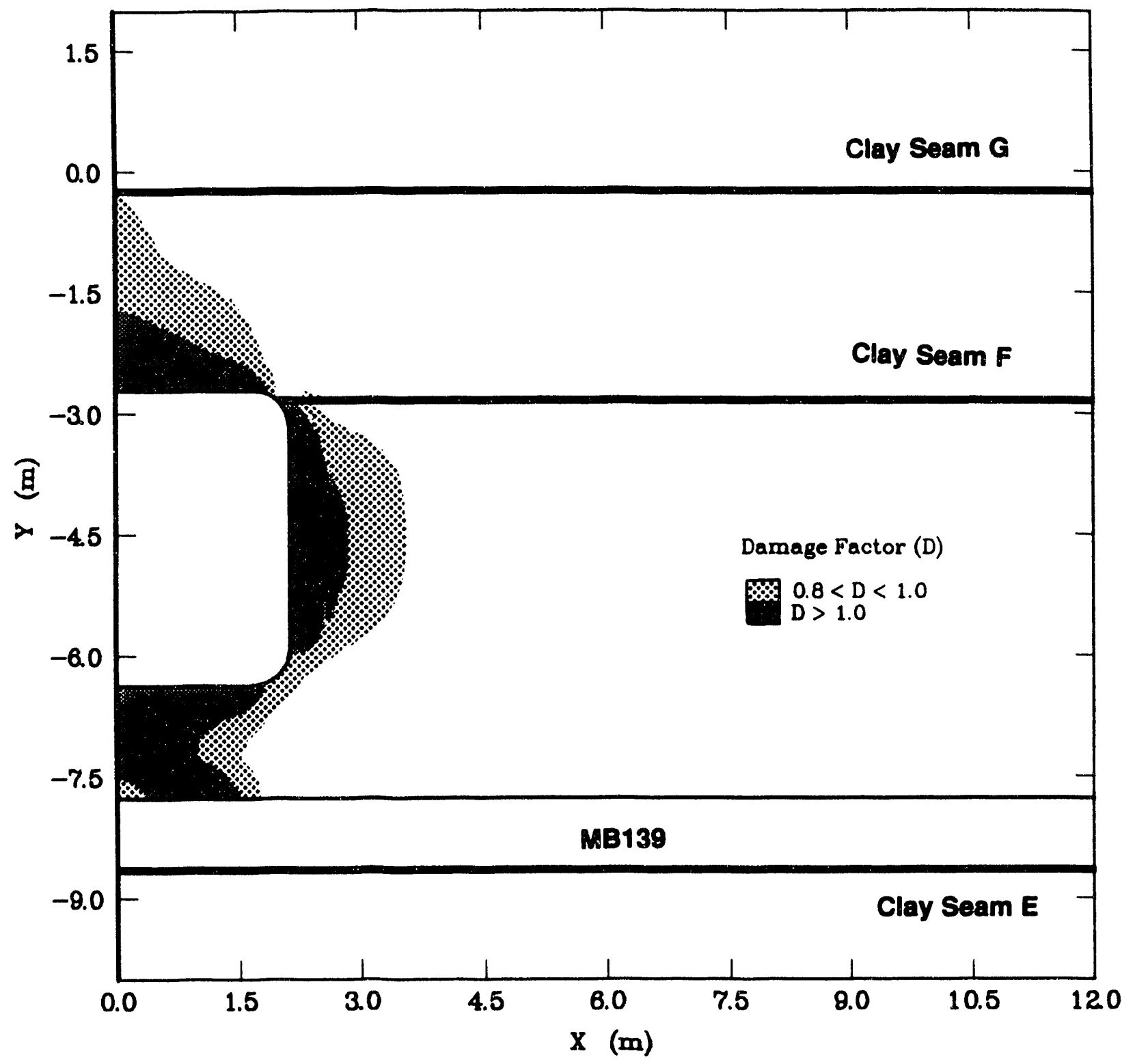

AS1-02-213-035

Figure 2-7. DRZ in salt around a $14-\times 12$-foot excavation after 1 year. 


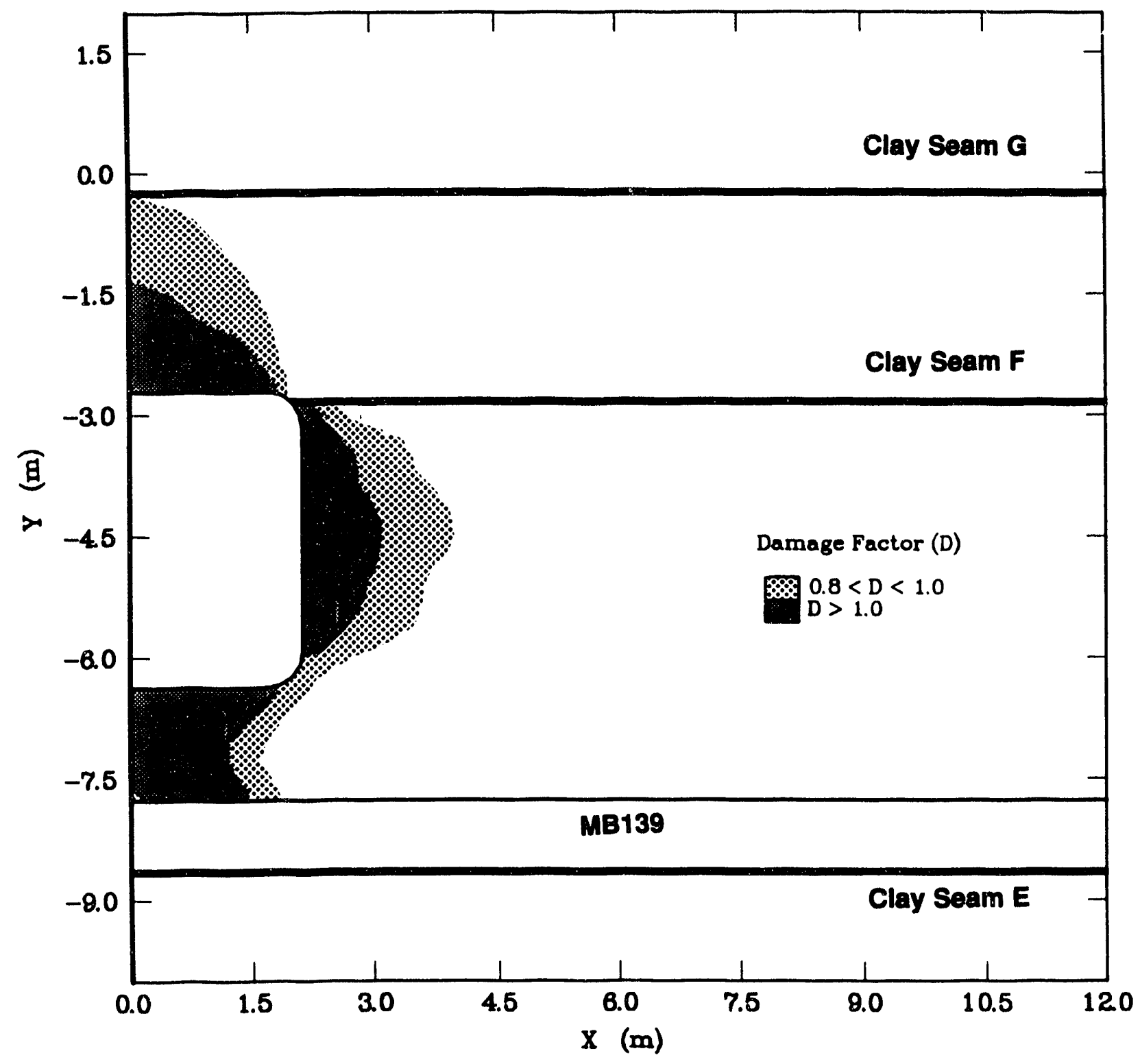

RS1-213-92-040

Figure 2-8. DRZ in salt around a $14-\times 12$-foot excavation after 40 years. 
excavation. Immediately after excavation, a significant amount of salt surrounding the excavation experiences stresses which will cause damage. Within 1 year after excavation, the damaged zone is almost completely developed. Only very small increases in the cross-sectional area of the DRZ in the WIPP salt are predicted between 1 and 40 years. The fully developed DRZ for the 14- $\times 12-\mathrm{ft}$ excavation extends from the floor of the excavation to MB139. The DRZ extends a maximum of about $1 \mathrm{~m}$ horizontally into the pillar and about $1.5 \mathrm{~m}$ above the excavation.

Figures 2-9 through 2-11 show contours of the damage factor for a $25 \times 12-\mathrm{ft}$ rectangular excavation. Similar to the 14- $\times 12$-ft excavation, most of the DRZ is developed during the first year after excavation. However, growth of the DRZ above the excavation over the 40 years is somewhat larger than that seen for the $14-\times 12$-ft excavation. The fully developed DRZ for the 25- $\times 12$-ft excavation extends from the floor of the excavation to MB139. The DRZ extends to a maximum of about $1 \mathrm{~m}$ horizontally into the pillar and about $2.75 \mathrm{~m}$ above the excavation.

\subsection{DRZ in Marker Bed 139}

Figures 2-12 and 2-13 show the calculated vertical deflection (uplift) of the top of MB139 at various times for the $14-\times 12-$ and the $25-\times 12$-ft excavations, respectively. The maximum uplift occurs at the center of the excavation. The maximum for the $14-\times 12-\mathrm{ft}$ excavation uplift is about one-half of that for the $25-\times 12-\mathrm{ft}$ excavation. The uplift of MB139 is most rapid immediately after excavation and slows with time as evidenced by the deflection curves.

The potential for yielding (based on the Drucker-Prager yield criterion) in MB139 for the two excavation geometries was examined for both geometries. Although the confidence in the analysis results is not high because material properties of this anhydrite are not well defined, a qualitative comparison of the influence of excavation geometry can be made. Yielding was not indicated in the finite element analysis until 10 years after excavation for the 14- $\times 12$-ft opening and the severity of damage continued to increase for the duration of the simulation. By 40 years, most of the marker bed within $10 \mathrm{~m}$ of the excavation centerline showed a high potential for yielding. For the $25-\times 12-\mathrm{ft}$ excavation, yielding in the marker bed was possible within the first year after excavation. Similar to the smaller excavation, the potential for yielding in the marker bed continued to increase throughout the duration of the simulation. 


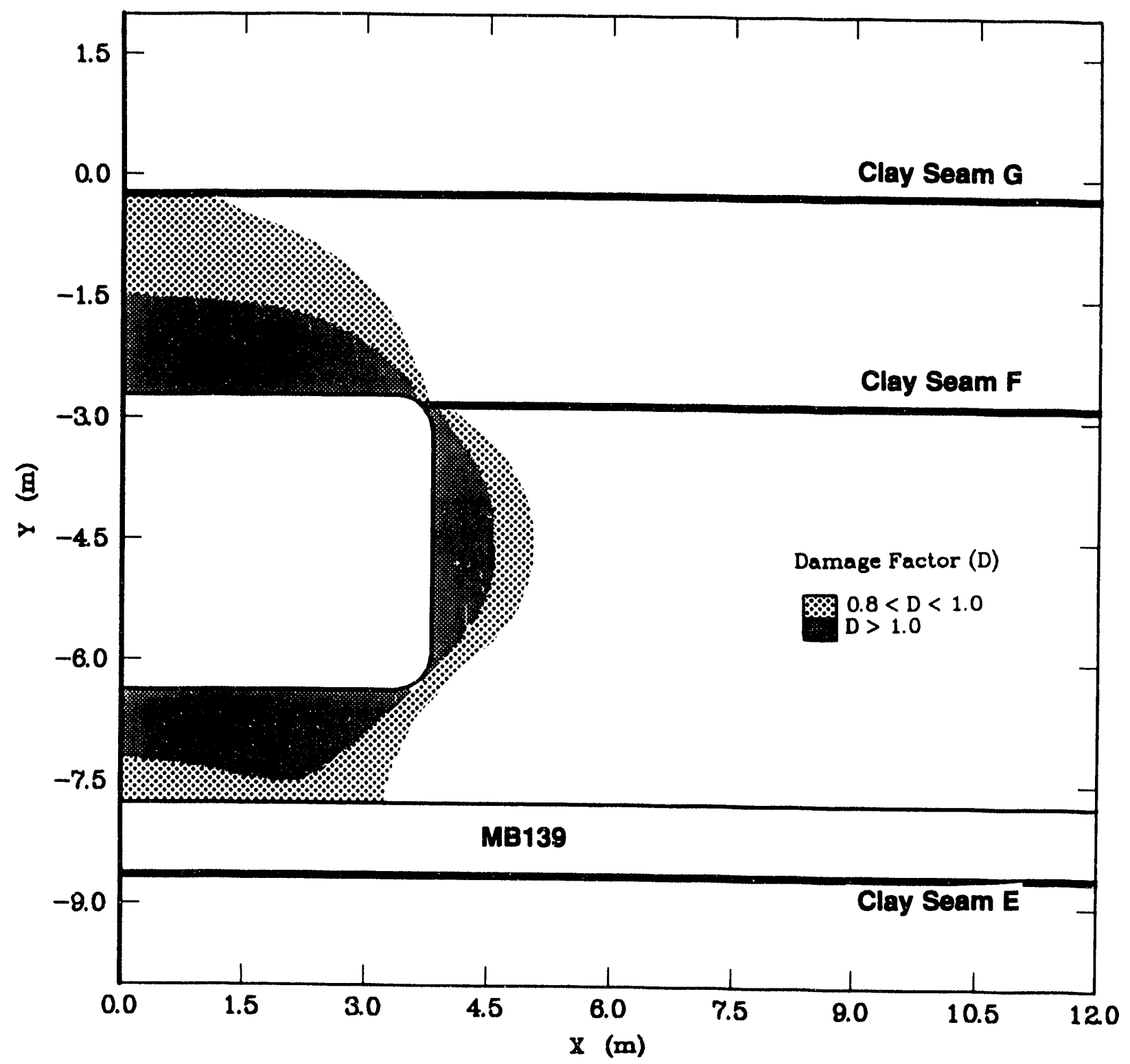

RS1-213-92-041

Figure 2-9. DRZ in salt around a $25-\times 12$-foot excavation immediately after excavation. 


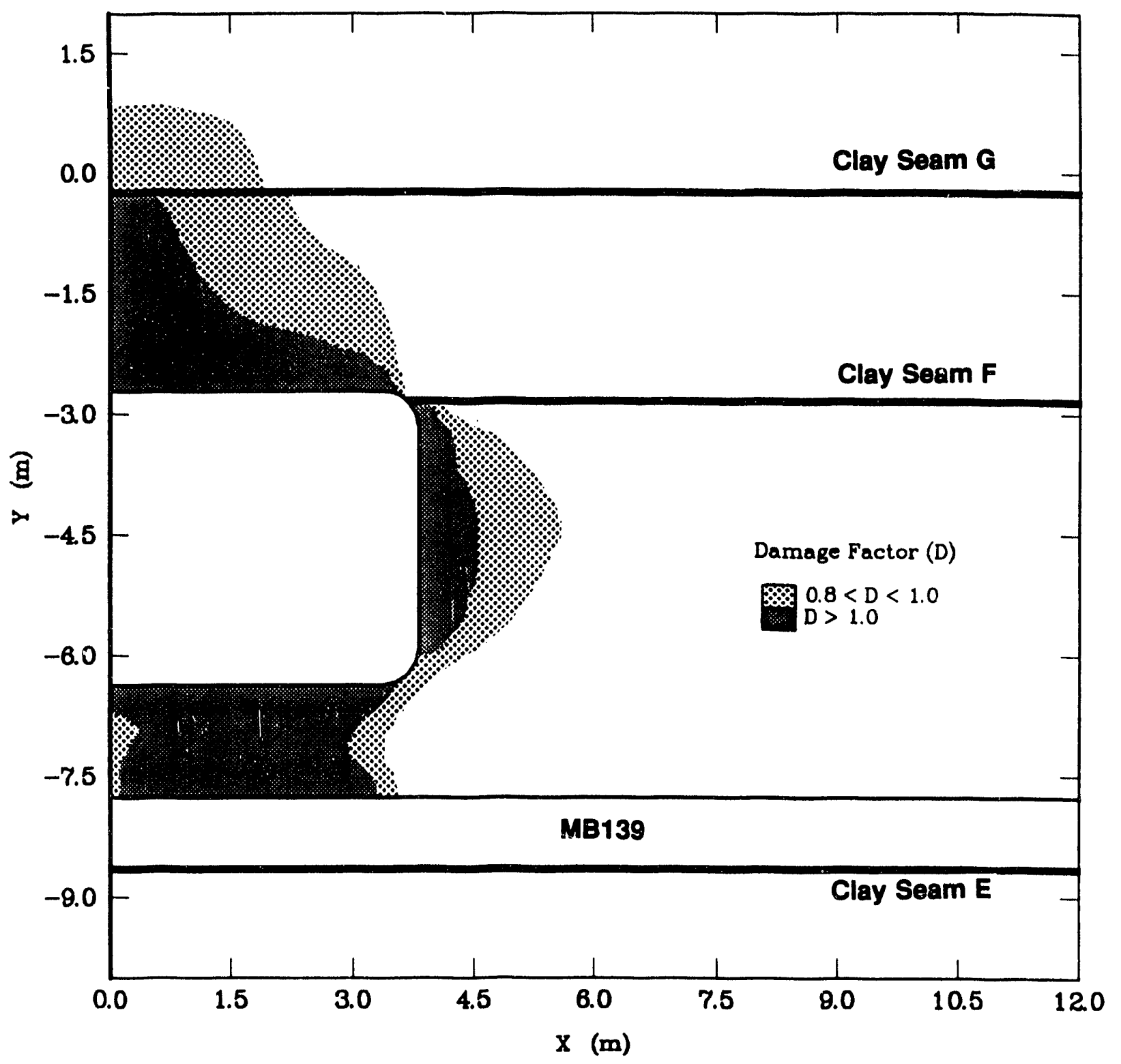

RS1-213-02-042

Figure 2-10. DRZ in salt around a $25-\times 12$-foot excavation after 1 year. 


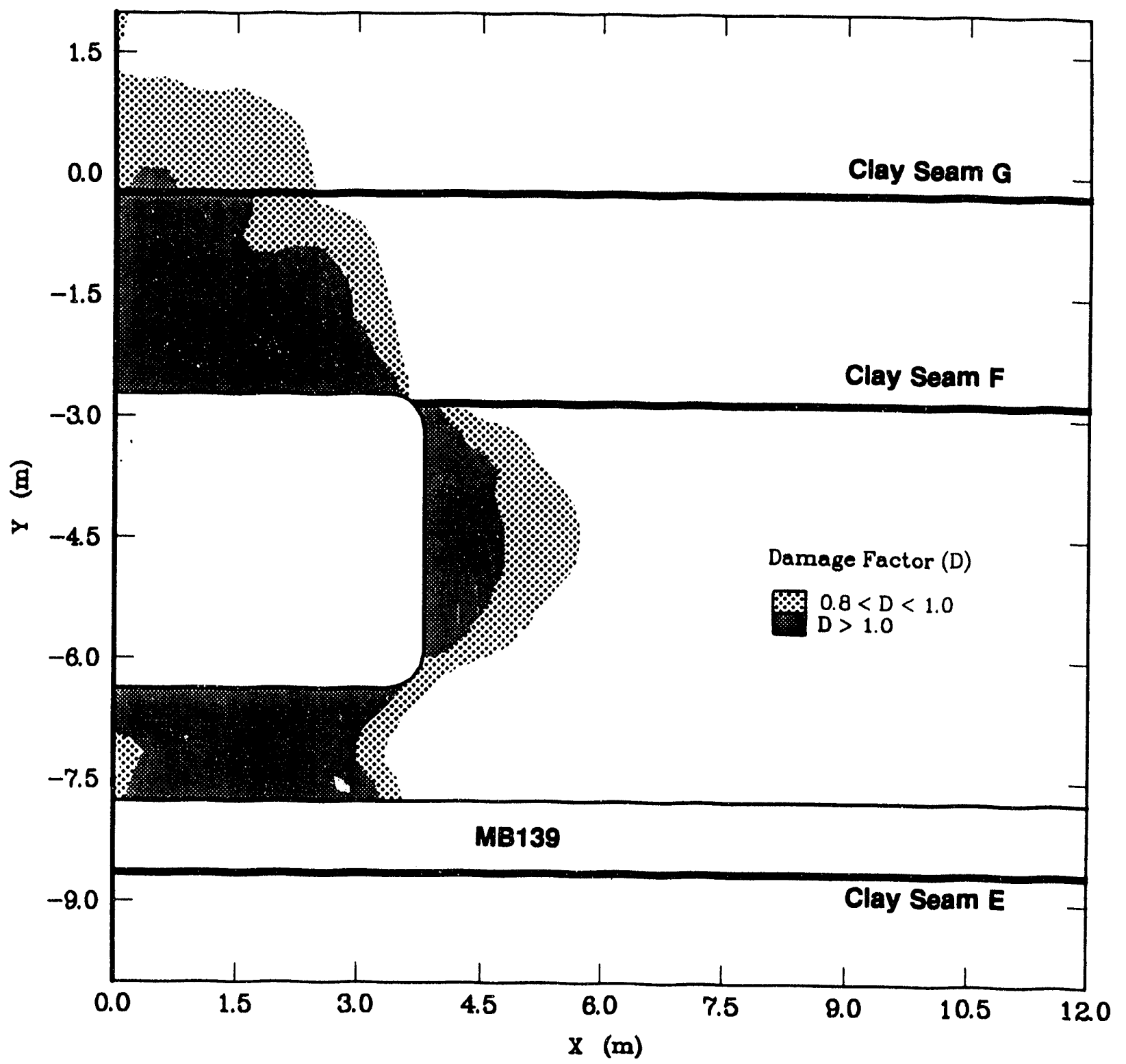

RSI-213-92-047

Figure 2-11. DRZ in salt around a $25-\times 12$-foot excavation after 40 years. 


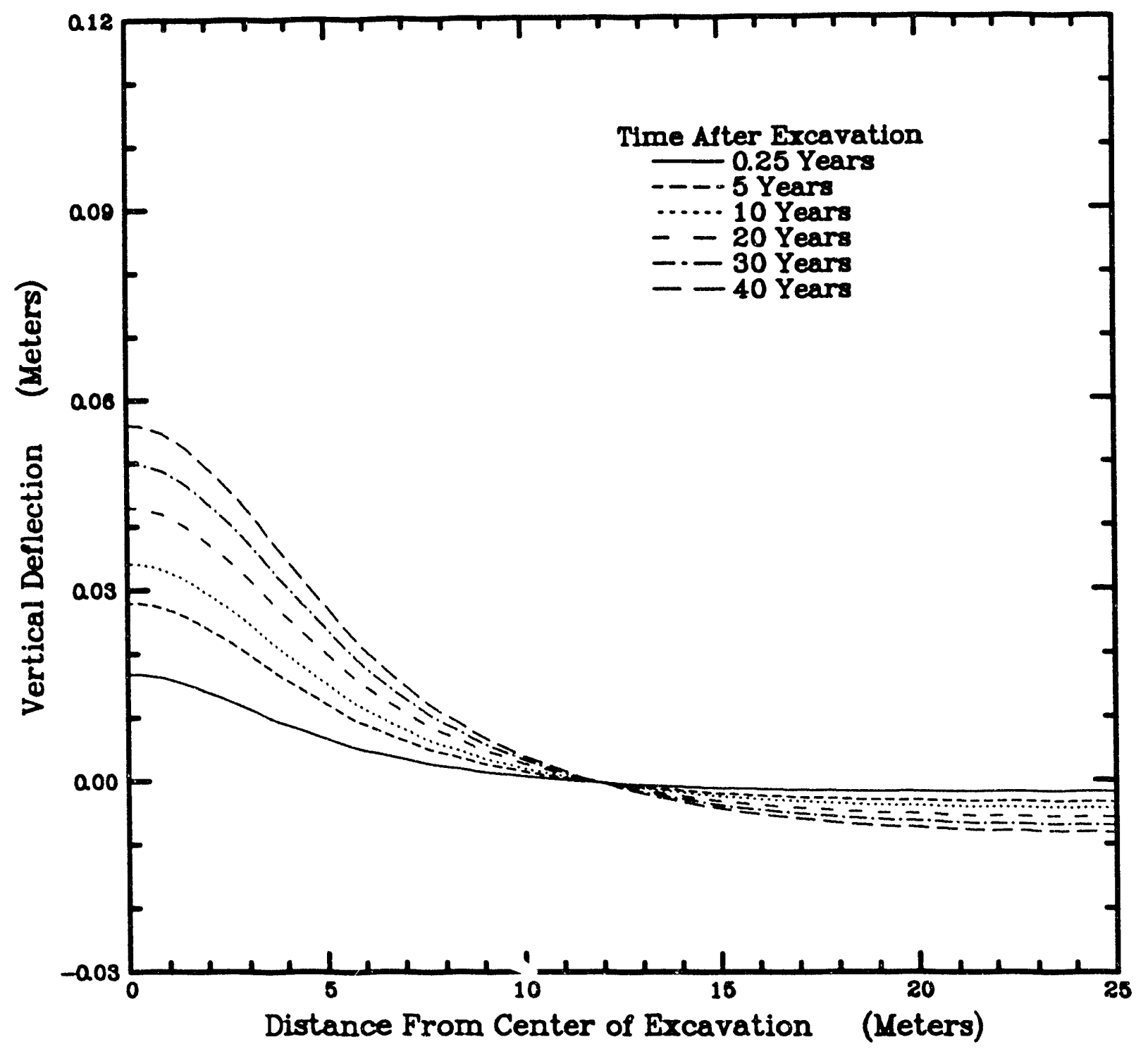

AS1-213-02-048

Figure 2-12. Vertical uplift of MB139 below a 14- x 12-foot excavation. 


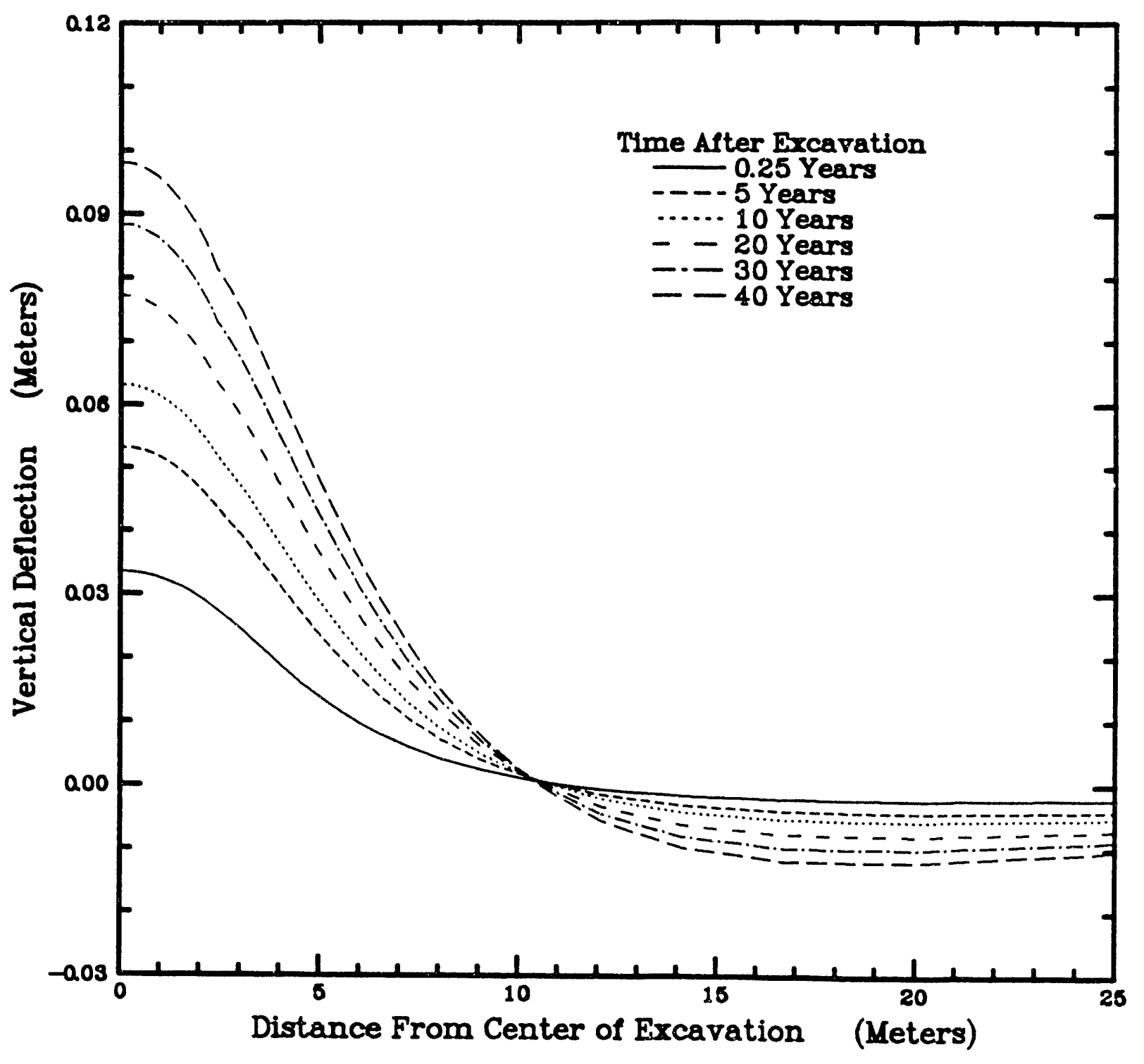

RS1-213-02-049

Figure 2-13. Vertical uplift of MB139 below a 25- x 12-foot excavation. 
In summary, numerical modeling suggests that around rectangular openings the DRZ in salt develops to almost its full extent in the first year after excavation. The calculated expansion of the DRZ during the time period from 10 years to 20 or 35 years after excavation is negligible [e.g., compare Figure 2-7 to Figure 2-8]. The DRZ in the interbeds (particularly MB139) does continue to expand, but at a diminishing rate. For instance, the uplift of MB139 shortly after excavation is about one-third the long-term uplift (40 years). Two-thirds of the uplift occurs in the first 10 years. The zone of yielding within the MB139 expands throughout the 40 years in direct response to the imposed uplift. The size of the zone for which yielding of the rock is suggested by a Drucker-Prager failure criterion is not well defined because of uncertainty in material properties presently available for use in calculations.

Another consideration is the uplift and deflection of MB139 below the salt seal portion of drift seals during the consolidation period (see Section 2.1.2). Based on the volumetric closures shown in Figure 2-2 and the MB139 uplifts shown in Figures 2-12 and 2-13, about 2.5 and $3.5 \mathrm{~mm}$ uplift occurs at the centerline of $14-\times 12$ - and $25-\times 12$-ft drifts for each 1 percent closure. Thus, for 15 percent closure, about 40 - to $55-\mathrm{mm}$ uplift could occur during the crushed-salt consolidation. Uplifts of this magnitude are of the same order as what occurs during the first 10 years after excavation.

Installing a rigid sleeve in the existing $25-\times 12$-ft drifts will soon prevent accumulation of additional deformation in the salt and marker bed, but the most significant damage would already have occurred before the rigid sleeve is installed. One benefit of installing a rigid sleeve (regardless of when it is installed) is preserving the integrity of the salt rock in the roof. If the roof rock will fall at some time during the operational phase, perhaps it is better to have a sleeve in place to hold the roof rock there, rather than having to fill a void later.

\subsubsection{Stratigraphical Influences}

It is possible that particular stratigraphic units might influence the DRZ in other stratigraphical units beyond that considered above. For example, a clay seam is modeled at the bottom of MB139, and it possibly influences the extent of the DRZ in salt below MB139 and the calculated factors-of-safety within MB139. A question remains concerning 
whether or not a similar weak seam or sliding interface should also be modeled above MB13? to debond the anhydrite from the salt.

It is also emphasized that the mechanical and strength properties for MB139 may not be represintative of the anhydrite. Laboratory testing on representative samples of MB139 material are being performed. Prelinınary, unpublished results indicate that the material being tusted is less stiff (lowe- Young's modulus) and weaker (lower unconfined compressive strength) than indicated by the properties listed in the preliminary Data Base Document (Bailey et al., 1992b).

\subsection{Loading on Rigid Structures Emplaced in Salt}

Rigid structures are included in the seal system to provide confinement of seal materials such $i$ crushed salt, bentonite, or asphalt, or to prevent the natural creep closure of an opening as a means of avoiding damage in the salt and interbeds. Whenever a rigid structure is placed in contact with salt, loading will develop on the structure because the structure restrains the salt creep. If the rigid structure was infinite in length, the loading magnitude would eventuall, equal the lithostatic stress in the salt and the salt would no longer c.eep. The rigid structures in the sealing system are finite in length, however, and the liner loading will eventually exceed the lithostatic stress because of stress concentration and end-effect loading. A series of analyses was performed to determine the timedependent characteristics and magnitudes for loading baseci un different schedules and geometries for the rigid structures.

The need for a confinement structure at both ends of the crushed-salt-filled region of the drift and panel seals has not been demonstrated. If redundant operational seals are not required, one of the rigid structures can possibly be omitted and a longer region of crushed salt can be used to provide any required confinement. The confinement structure issue will require additional study relative to operational seal requirements.

\subsubsection{Schedule Effects on Loading Magnitude}

The loading that develops on rigid structures emplaced in salt results from restraining the creep closure of the opening. The long-term load on the structure must be the same regardless of when the structure was installed relative to the time of excavating the opening. 
However, the short-term loading, i.e., during a few years after installation, may be a function of the length of time the opening was allowed to creep unrestrained. It is intuitively expected that the sooner a rigid structure is installed after excavation, the faster the loading will develop. If the design life is within the "window" for the faster loading, then a larger design loading must be accounted for. This aspect was studied in the following manner.

The axisymmetric geometry for the calculations described in Section 2.1.3 was reanalyzed with a different time sequence for excavation and liner installation. Two analyses were performed; in one case the liner was installed 5 years after excavation and in the other it was installed 35 years after excavation. The liner loadings as a function of time after installation are shown in Figure 2-14. The development of loading is moderately influenced for a 5-year design life (the design load would need to be increased from about $9 \mathrm{M} . \mathrm{Pa}$ to $13 \mathrm{MPa}$.) However, for a 50-year design life, the design loads are about the same.

\subsubsection{Geometrical Effects on Loading Distribution}

A calculation involving three different geometries was described in Section 2.1.3. The liner loadings from that calculation are discussed here. The liner loading for the three different geometries is essentially the same. The only difference noted is that the liner loading increases somewhat faster initially for the longer unsupported spans, but by 50 years, the liner loadings are the same for all three cases. The eventual average load on the liner is about $17 \mathrm{MPa}(2,500 \mathrm{psi}$; in the center and about $25 \mathrm{MPa}(3,600 \mathrm{psi})$ at the edges; these values are, however, specific to a liner whose length equals its diameter.

\subsubsection{EFFECT OF OPENING SHAPE}

Lin and Van Sambeek (1992a) present numerical modeling results concerning the variation in liner loading around circular and horseshoe-shaped liners. The variation is small and subsequently there is no need to incorporate special design considerations.

\subsubsection{EFFECT OF INTERBEDS}

Lin and Van Sambeek (1992b) present numerical modeling results that show the influence of interbeds (i.e., the clay seams and MB139 are most significant) on liner loading. 


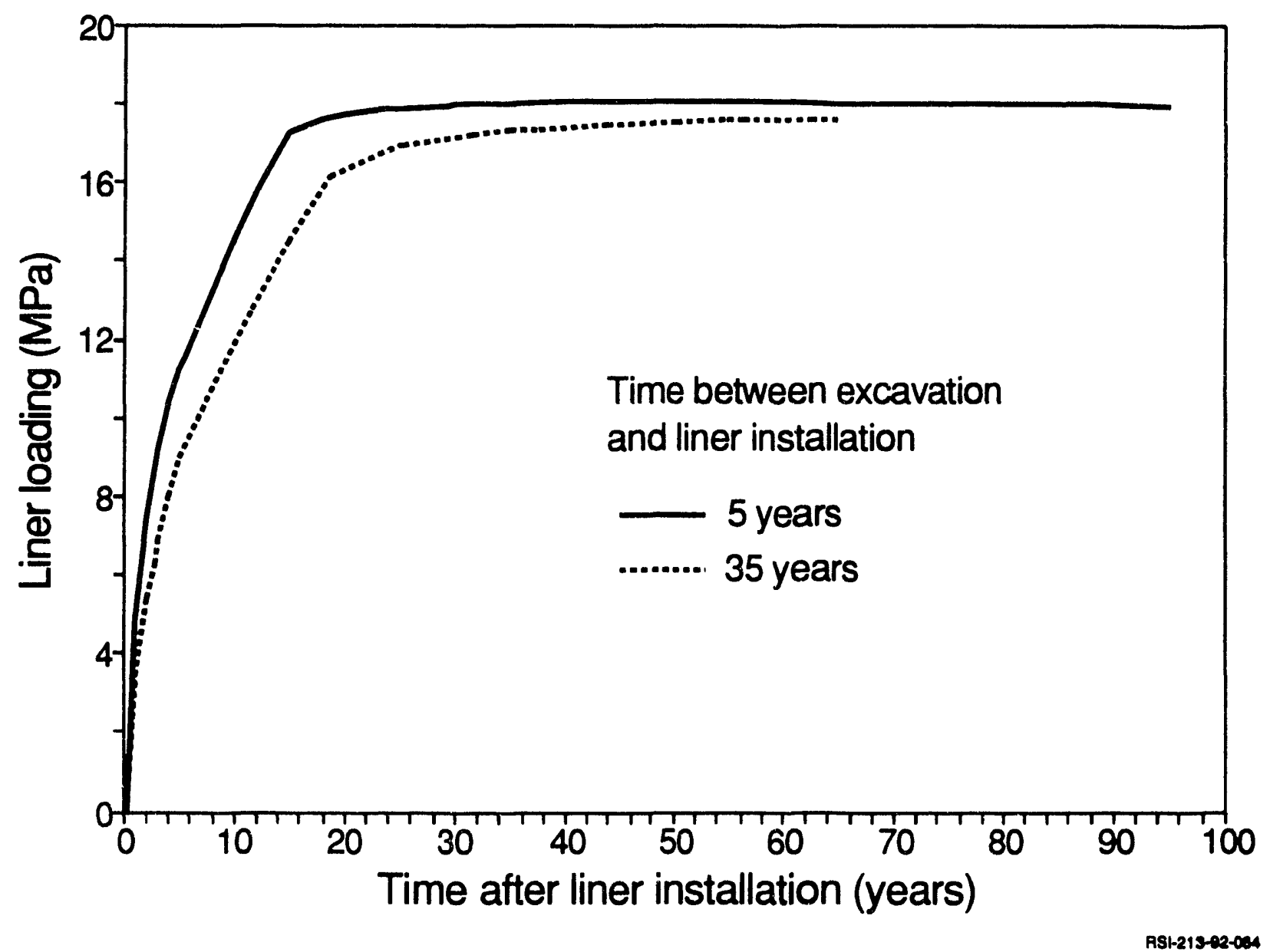

Figure 2-14. Liner loading as affected by delayed liner installation. 
The clay seams cause some variation in liner loading above and below the contact with the liner, but the effect is small. The influence of MB139 on the liner loading distribution depends on the thickness of salt between the liner and MB139. For a thickness of $4 \mathrm{ft}$ or more, MB139 does not affect the distribution enough to warrant special design consideration. 


\subsection{DRIFT AND PANEL SEALS}

The alternatives study for drift and panel seals has two objectives:

- To evaluate design alternatives to the initial reference seal system design (IRSSD) (Nowak et al., 1990), and

- To define future study required for the preliminary design of the drift and panel seals.

The study was performed in the following steps. First, the requirements for the drift and panel seals, as defined in the Design Requirements Document (DRD) and IRSSD, were studied to determine both the function- and performance-related issues that could be addressed by different design alternatives. These preliminary requirements are discussed in Sections 3.1 and 3.2. The reference seal design is also briefly described in terms of the components involved and the number and location of the drift and panel seals (Section 3.2.1):

Second, considerations for alternatives to the reference design were developed, such as size of excavations, the DRZ at seal locations, schedule, cost, and modifications of the sealing requirements. Together with these considerations, assumptions were formulated (Section 3.3) that address schedule uncertainties, operational needs, and construction costs, regardless of the specific alternative. Evaluation criteria are presented in Section 3.4. The rock mechanics aspects of the design for various alternatives were based on the information presented in Section 2.

Third, a series of types of design were developed based on considerations for when various seal construction was to occur (i.e., now versus later) and the size of excavations. These design types were further developed into different arrangements of seals and different options within the same design type to explore cost variations. The descriptions of the seal designs, arrangements, and options are presented in Section 3.5.

Finally, the alternatives are discussed in terms of effectiveness, constructibility, and cost. The evaluations are discussed in Section 3.6. Conclusions about the arrangements and options are discussed in Section 3.7. Recommendations for future work and technology development were also identified and are discussed in Section 6.0. 


\subsection{Purpose of the Drift and Panel Seals}

The principal function of the panel seals is to limit the release of hazardous material from filled disposal rooms during the operational phase to meet EPA requirements. The reference seal-design (Nowak et al., 1990) uses components which consist of a permanent salt seal placed between two concrete monoliths seals. The monoliths are operational seals which limit release of waste by providing resistance to gas flow and confine the crushed salt of the long-term seal. Confidence for sealing during the operational phase is bolstered because access will exist for remedial maintenance, ventilation, and monitoring.

In addition to the reference design, other design options should also be considered for decision making. Such options may entail the timing of seal emplacement; viz, whether action needs to be taken immediately prior to the development of an emplacement panel, or construction of the seal should start subsequent to waste emplacement in the panel. Design options may also include various shapes and sizes and construction materials. Further, before a decision can be made, cost estimates for various options are needed.

This study provides the information on the impact of shapes, sizes, construction materials, timing and cost, and discusses the pros and cons, including performance evaluation, of the various design options.

\subsection{Requirements}

\subsubsection{Reference Seal System}

The reference seal system is defined in the Design Requirement Document (Bailey et al., 1992a), which is based largely on the design (see Figure 3-1) described in the IRSSD (Nowak et al., 1990). The reference seals consist of monoliths and grouting for the shortterm seals and emplaced WIPP-salt as the long-term seal. The short-term component of the drift and panel seals will function as barriers to the migration of the hazardous material from the waste disposal area during the operational phase. Additionally, the short-term seal is considered necessary for confinement of the emplaced WIPP-salt until the long-term salt seal becomes adequately consolidated by creep closure of the host rock salt. The long-term seal is required to consolidate to 95 percent fractional density to achieve a state of permeability to fluids comparable to the permeability of undisturbed host rock salt (Holcomb and Hannum, 1982; Holcomb and Shields, 1987). Figure 3-2 depicts the drift and 

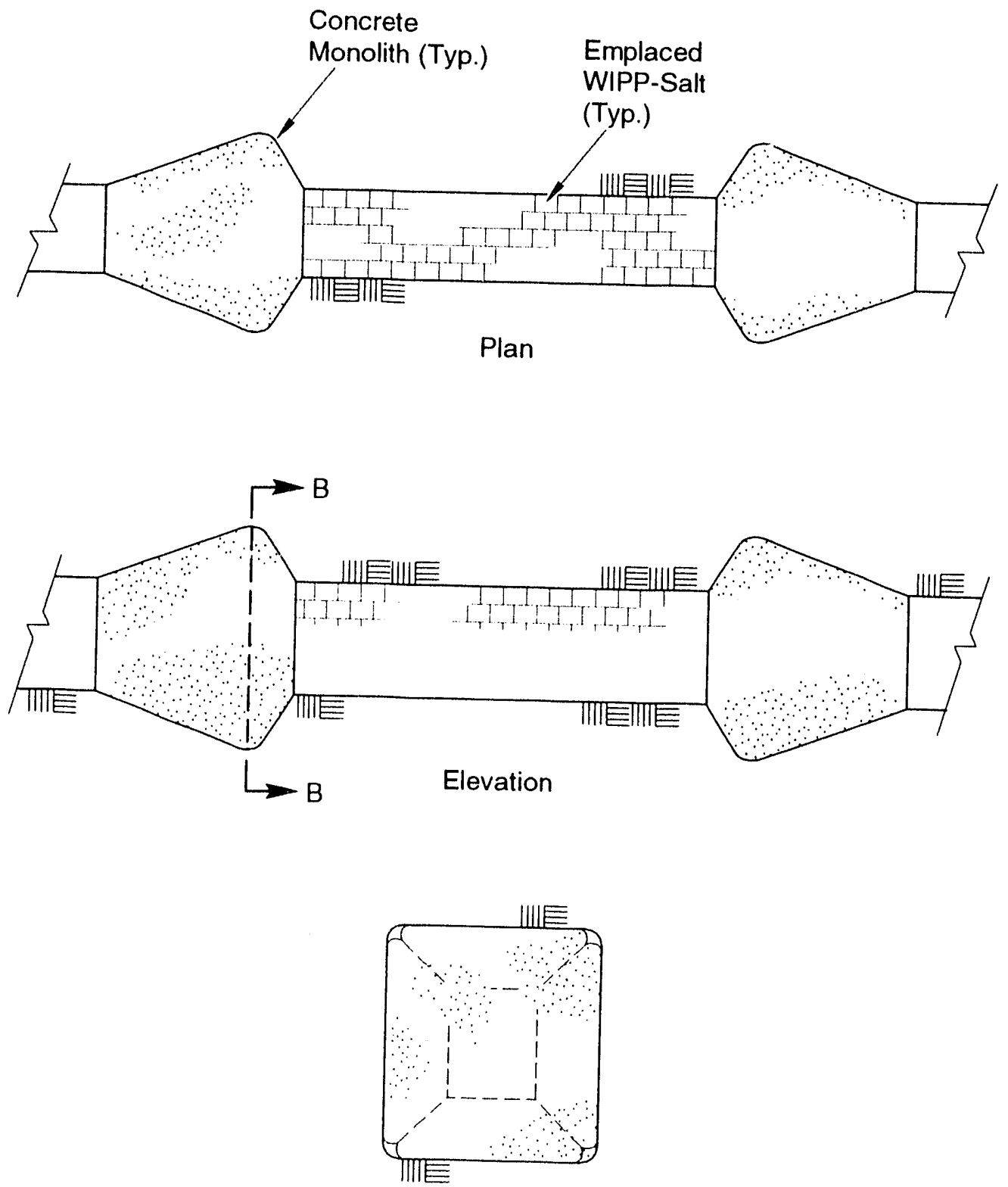

Section B - B

TRI-6121-79-0

Figure 3-1. Reference drift and panel seals, plan, elevation, and section. 


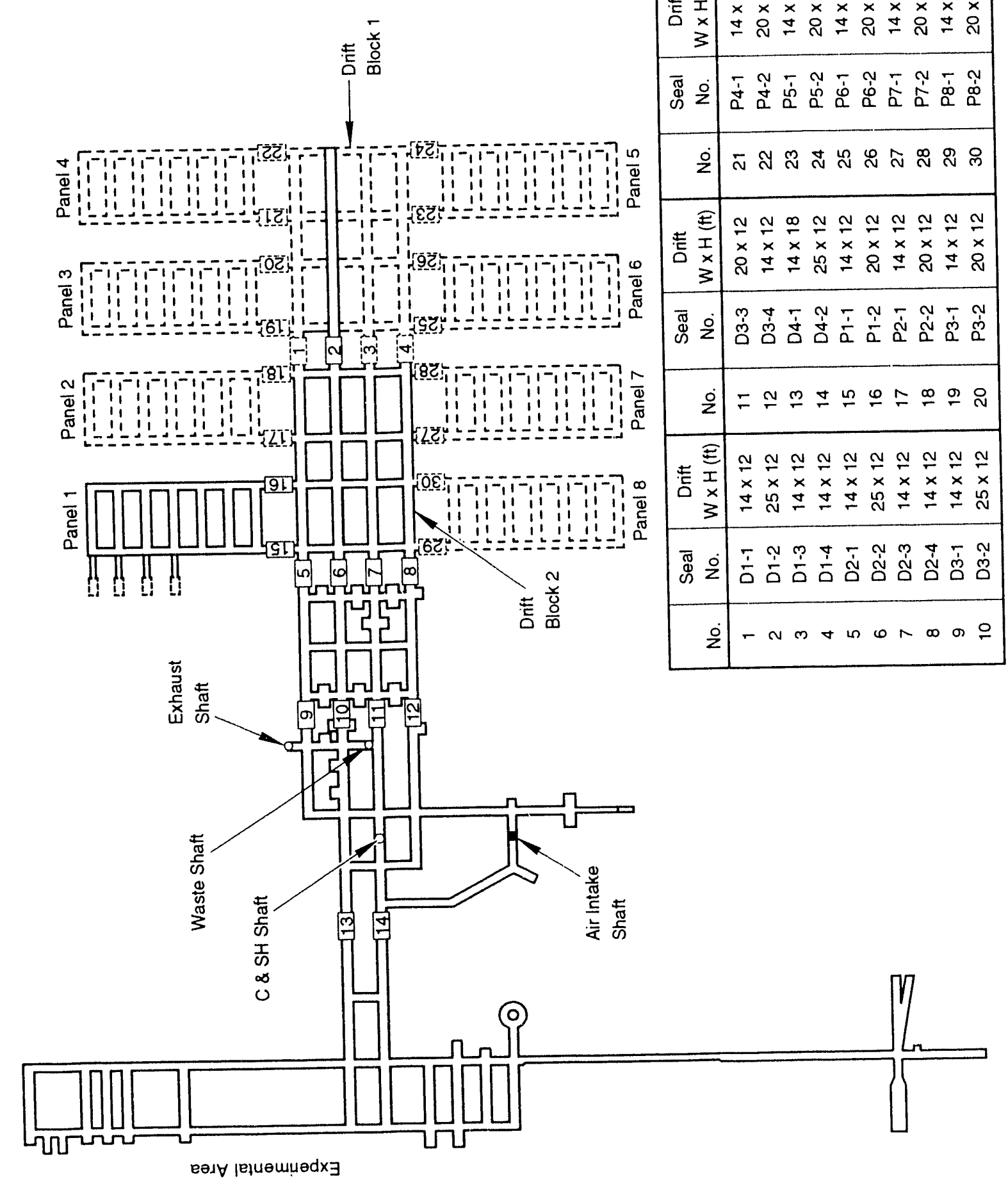

\begin{tabular}{|c|c|}
\hline 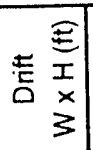 & 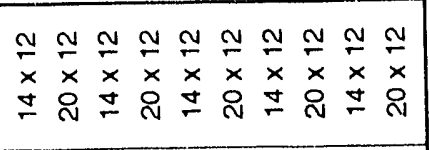 \\
\hline 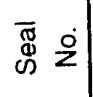 & 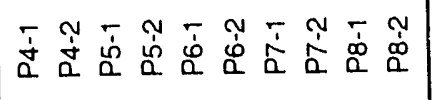 \\
\hline$\dot{0}$ & 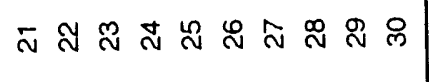 \\
\hline 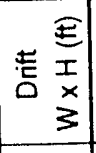 & 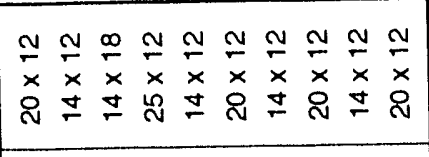 \\
\hline $\begin{array}{ll}\bar{\sigma} & 0 \\
\infty & 2 \\
\infty & 2\end{array}$ & 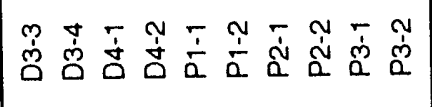 \\
\hline$\dot{0}$ & 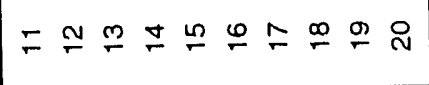 \\
\hline 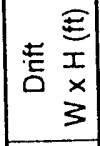 & 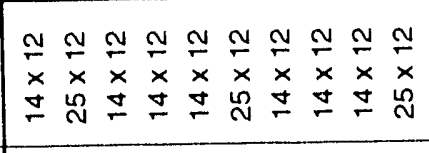 \\
\hline ळ & 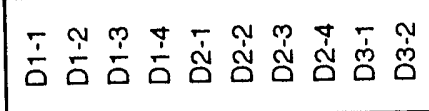 \\
\hline$\stackrel{\dot{z}}{z}$ & $-\sim m \forall \omega \infty \sim \infty \theta$ \\
\hline
\end{tabular}


panel seal location plan in the IRSSD. There are 30 seals; 14 seals are located in the haulage and ventilation drifts and 16 seals are located at the entrance drifts of the eight panels. Thirteen seal sites (Seal Nos. 2 and 5 through 16) have already been excavated. These sites were excavated for site characterization activities and have been open for periods ranging from 5 to 10 years. An average age of excavations for all existing drifts is assumed to be 10 years.

\subsubsection{Considerations for Design Alternatives}

Basic data, such as the excavation widths and heights, and the underground layout, are provided in the IRSSD, the Design Requirements Document, and the Data Base Document. Considerations for alternatives are as follows:

1. Adequacy of the sizes of the planned openings,

2. Prevention of DRZ growth by early installation of a rigid sleeve,

3. Postponing all sealing activities until as late as possible,

4. Construction cost, and

5. Justification of the need for a long-term seal and a redundant short-term seal.

The study includes discussions on the design, analysis, seal performance, constructibility, and future works needed for the preliminary design.

\subsection{Assumptions}

To reduce the number of possible alternatives and because of a lack of data and precedence in seal construction techniques, certain assumptions were made. These assumptions include:

1. The existing drifts are assumed to be 10 years old (as-built condition),

2. New panels are to be excavated, emplaced, and sealed over a period of 5 years (based on engineering judgment), 
3. For rigid sleeve installation, a salt thickness of $4 \mathrm{ft}$ is provided between the bottom of the rigid sleeve and the top of MB139 (Lin and Van Sambeek, 1992a). The salt floor in the area of the rigid sleeve will be ramped up and down at a 10 percent maximum slope as required to provide this thickness. The salt bed under the rigid sleeve is to provide a cushion for uniform distribution of the liner loading and to mitigate the upward thrust of MB139 during construction of the rigid sleeve,

4. Airlocks are not required for personnel radiation safety at any drift and panel seal locations,

5. The minimum clear opening for access to a repository panel is $14 \times 12 \mathrm{ft}$ with no operational inconvenience, or $12 \times 12 \mathrm{ft}$ with some operational inconveniences,

6. Some form of grouting will be effective for plugging the disturbed rock around the operational/short-term seals. However, the confidence for preventing leakage by grouting is less than that for preventing flow by not allowing a disturbed zone (DRZ in salt or damage in the marker bed) to develop,

7. Cost for the salt seal emplacement can be based on unit costs of nonshrink cement-based grout $(\$ 1,800 /$ cy) as an approximation for cost evaluation. The unit cost of the mechanically compacted salt is assumed to be one-half of the cost of the salt block scheme,

8. The length of the seal is assumed to be five times the width of the excavation. The seal pattern is B-3B-B for monolith-salt-monolith, respectively, where B is the width of excavation and is equal to the width of the drift, $W$, plus the depths of excavation at the ribs for seal installation. This pattern is derived from an engineering rule of thumb that the length of a rigid, solid seal shall be as long as its width. The $3 \mathrm{~B}$ length for the salt seal is based on one $\mathrm{B}$ minimum permanent seal plus one $B$ allowance at each side of the salt seal to minimize the end effects of the monolith on the consolidation of the salt seal,

9. The volume of seal construction warrants custom-designed construction equipment, as required, for excavation and erection of the seals, and

10. High-strength concrete, fiber-reinforced concrete, and nonshrink, cement-based grout will be developed as required to supplement the concrete mixes provided in the Data Base Document. 


\subsection{Evaluation Criteria}

Various options of seal design will be evaluated for the advantages and disadvantages without weighting or ranking. Seal design alternatives are evaluated primarily by engineering judgment and such factors as:

- Seal effectiveness,

- Constructibility, and

- Rough order-of-magnitude construction cost.

\subsection{Seal Design Types}

Due to the constraints of the as-built conditions at WIPP, the waste panel layout, and requirements for the waste emplacement operations, several design types must be considered for the drift and panel seals. Four design types are established based on NOW vs. LATER concepts and engineering requirements for the DRZ and MB139. Each design type consists of two variations: a Base Case and an Alternative Case. Figure 3-3 shows two cases for each design type. The Base Case seal has two identical concrete monoliths designed to provide redundant operational seals. The Alternative Case seal has only one operational seal and the near-end (drift side) monolith of the Base Case seal is replaced by a plain concrete monolith for the purpose of confining the emplaced salt of the long-term seal. In both cases, confidence for sealing during the operational phase can be bolstered by remedial maintenance, ventilation, and monitoring measures at the access drift adjacent to the nearend monolith.

For convenience, a shorthand notation for the four design types is used in the text:

- $\mathrm{NR}=$ "NOW RIGID"

- $\mathrm{LG}=$ "LATER GROUT"

- $\mathrm{LE}=$ = LATER EXCAVATE"

- NR/LE = "NOW RIGID/LATER EXCAVATE" 

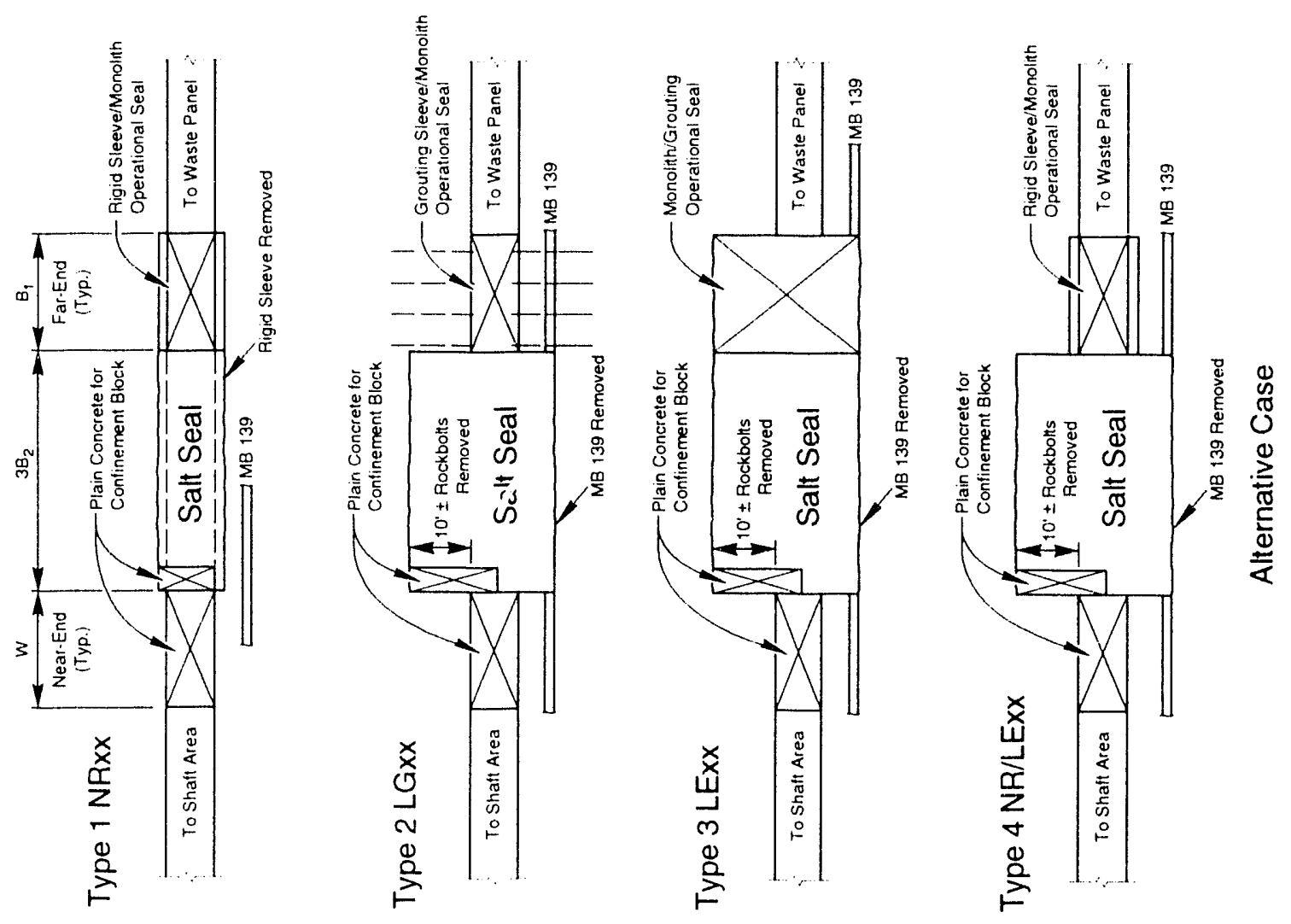

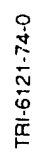
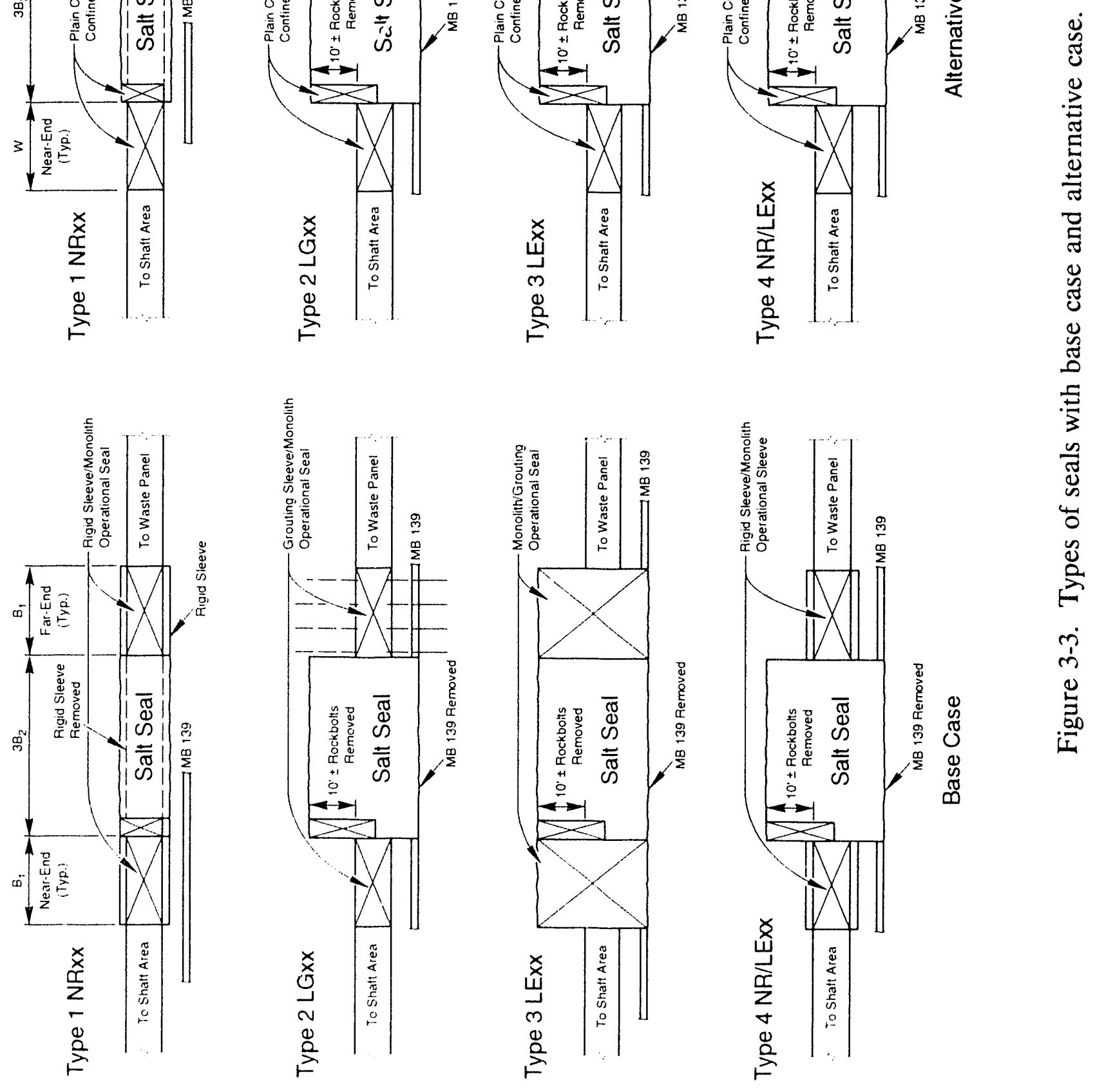
The "NOW RIGID" concept is centered around the assumption that a rigid sleeve is installed at the future seal location immediately after excavation. Based on the results of rock mechanics analyses in Section 2, a rigid sleeve installed as soon as possible after excavation prevents some deformation of MB139 and arrests development of the DRZ. In the absence of a timely placed rigid sleeve, the deformation in MB139 and the development of the DRZ will likely compromise the seal system or at least require remedial activities to achieve an adequate seal. The "LATER" concepts assume nothing is done to the excavation until time for seal emplacement (i.e., a rigid sleeve is not immediately installed). Therefore, remedial grouting and/or excavation of MB139 and the DRZ is considered necessary for these types of seals. Excavation of MB139 may be required for the salt seal region of NR seals also, as will be discussed below.

Each of the seal types will require technology to be developed for emplacing the salt (whether crushed or as blocks) in the salt seal portion of the drift and panel seals.

\subsubsection{Type 1 - NRxx Seal}

The Type 1 - NR Seal is a "NOW RIGID" seal which uses a 5B pattern rigid sleeve (Figure 3-3; for details, see Sketches SK-1, SK-2, and SK-3) to check and control the development of the DRZ around the opening and deformation of MB139. The rigid sleeve is installed in the seal area prior to further development of the drifts and panels. The dimension B is established by the width of excavation in the seal. The term " $x \mathrm{x}$ " in NRxx denotes the width of the passageway through the rigid sleeve; three sizes, $12 \mathrm{ft}, 14 \mathrm{ft}$, and $20 \mathrm{ft}$, are considered. After waste emplacement, the middle section of the sleeve (length $=3 \mathrm{~B}$ ) will be removed, the end sections ( $1 \mathrm{~B}$ each) will be filled with concrete, and the middle $(3 \mathrm{~B})$ section will be filled with emplaced salt for development of a long-term seal.

The rigid sleeve is a steel shell and concrete composite structure similar to that described in the WIPP alcove gas barrier (AGB) final design report (Lin and Van Sambeek, 1992b). The lining is made of ring segments which consist of four precast elements. Figure 3-4 depicts the basic construction sequence for a rigid sleeve ring segment. A more detailed construction procedure is presented in the AGB final design report (Lin and Van Sambeek, 1992b). One edge of the roof element is modified to include a rigid sleeve removal key block. Additionally, the connection details between two adjacent ring elements will provide a bond breaker so the rigid sleeve can be removed with nominal prying force as shown in Figure 3-5. 

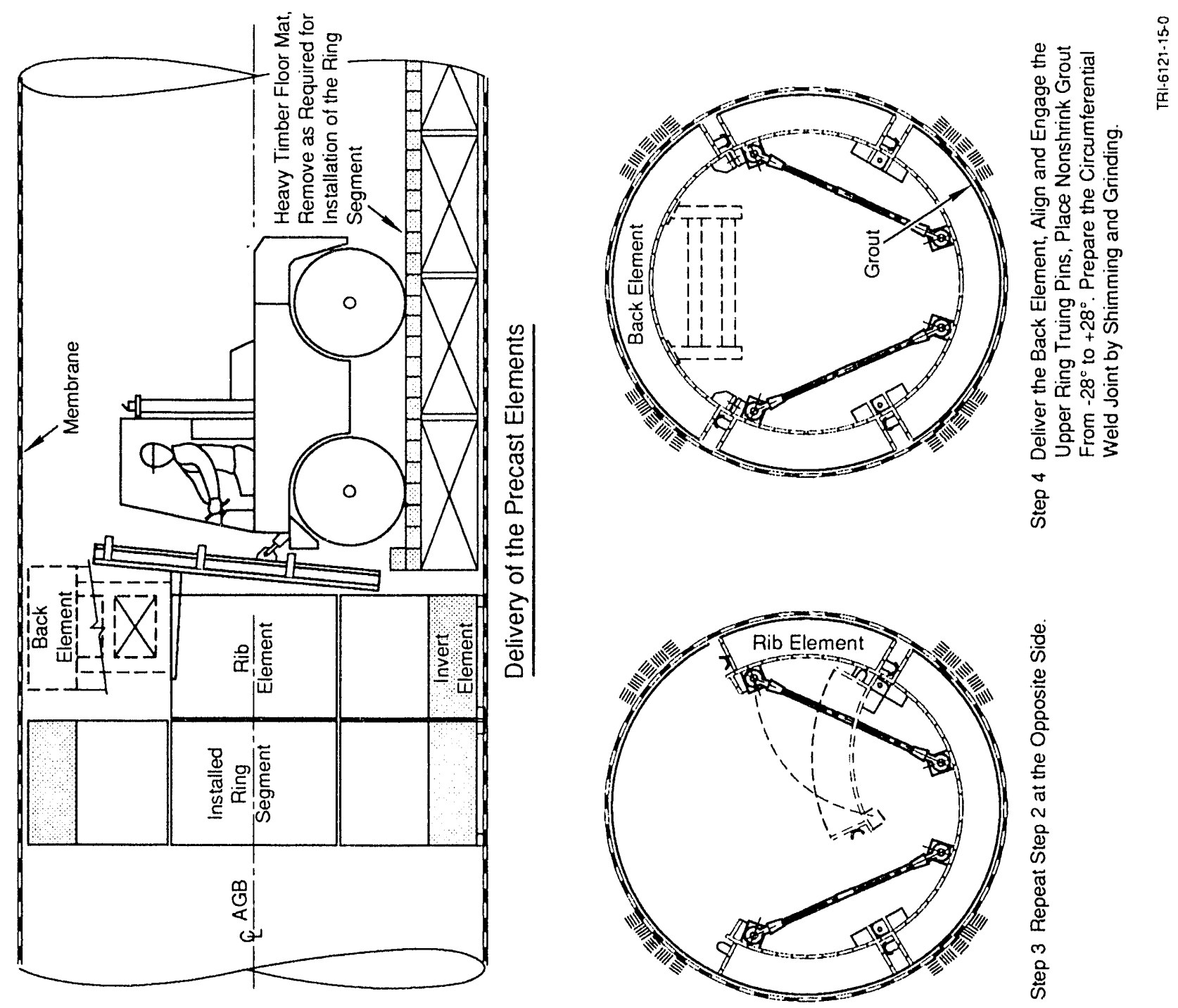

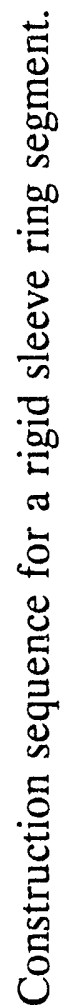
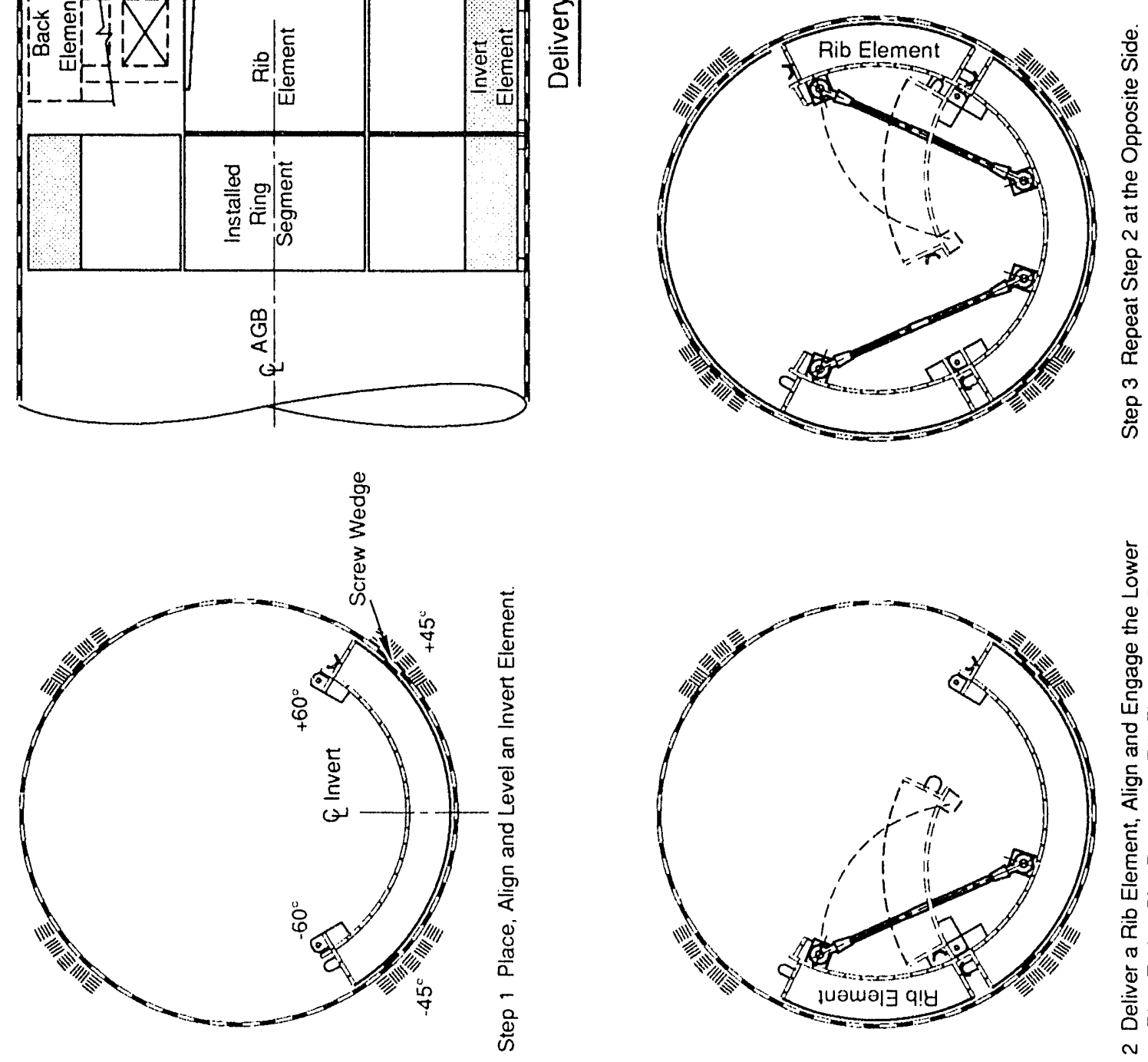

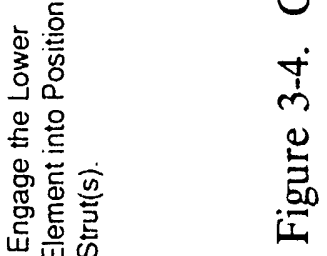


(2)
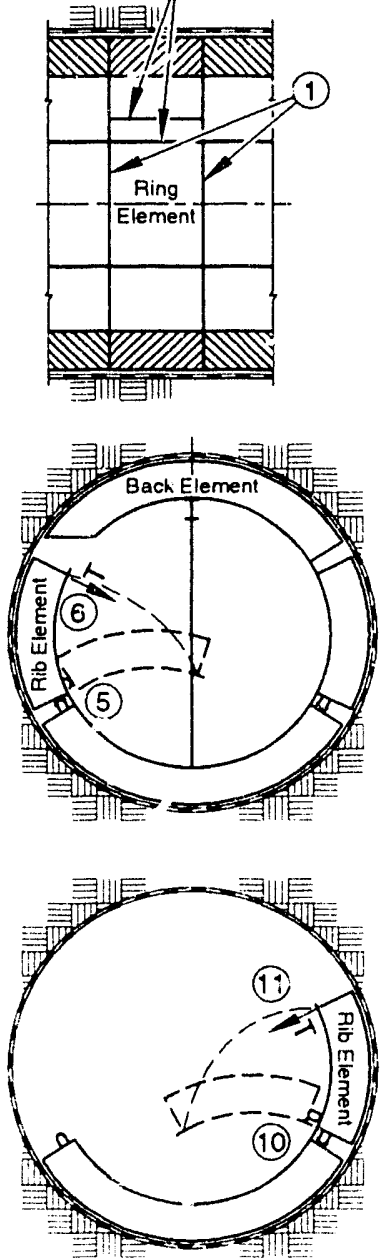
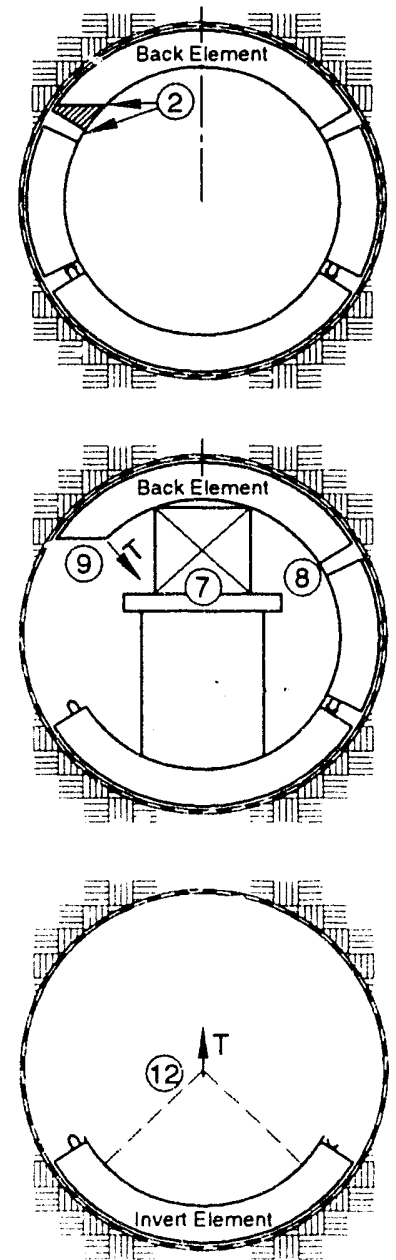

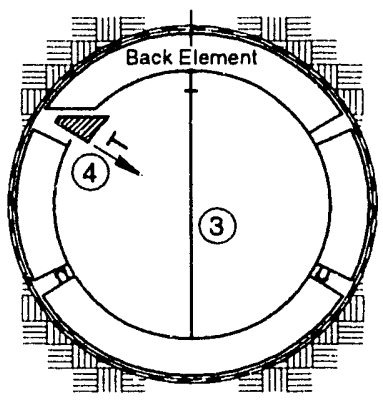

1 Bum-off the circumferential seal welds

2 Bum-off the longitudinal shell plate around the key block

3 Erect the back element support bent

4 Remove the key block

5 Bum-off the longitudinal seal weld

6 Pry loose and remove the rib element

7 Erect the back element support platform

8 Bum-off the longitudinal seal weid

9 Pry loose and remove the back element and the platform

10 Burn-off the longitudinal seal weld

11 Pry loose and remove the rib element

12 Pry loose and remove the invert element

Note: The pull force T may be applied by a double action hydraulic cylinders attached by a pair of eye brackets welded to the shell plate

Figure 3-5. Rigid sleeve demolition sequence. 
The rigid sleeves are sized according to a working stress design for an average liner loading of 2,150 psi, which approximates the lithostatic stress magnitude. A rock mechanics study (see Section 2.3) indicated that the average liner loading approaches the lithostatic stress in 5 years and exceeds that value in later years. The maximum loading at the ends of the rigid sleeve is about 3,500 psi. The NR12 sleeve is 21 -in thick with a $13 / 4$-in steel shell. The NR14 sleeve has the same thickness, but with a $21 / 4$-in steel shell. The NR20 sleeve is 33 -in thick with a $31 / 4$-in steel shell. The structure is expected to have a ductile mode of failure so ample warning will be given prior to any failure. Refined design calculations will be necessary for selectior of material strength and monolith configuration at the design stage.

The monoliths are built within the 1B segment at each end of the rigid sleeve. Figure 3-6 illustrates a concept for construction of the cast-in-place (CIP) monolith at the drift side of the seal. Two 3/8-in steel plate bulkheads serve dual functions as a gas barrier and as the formwork for a prepacked concrete monolith. These steel plates are protected from corrosion by a 2 -ft thick concrete covering. The solid core masonry wall is a construction form for placement of the cast-in-place concrete. Prepacked concrete block is used to minimize any concrete shrinkage problems.

The 3B (central) portion of the rigid sleeve is removed prior to construction of the salt seal. The construction scheme for the salt seal is similar to the one shown in Figure 3-7 except there is no further excavation required beyond the rigid sleeve. The lower portion of the salt seal is placed in layers and mechanically compacted to at least 80 percent fractional density. The upper portion of the salt seal, approximately $10 \mathrm{ft}$ high, uses quarried-salt blocks and salt mortar and is built like a masonry block structure. The concrete grout placed in the construction access protects the steel bulkhead in the outer monolith from corrosion.

The DRZ in the salt around the monolith is expected to be healed so the monoliths can act immediately as operational seals. The two monoliths will function as redundant operational seals. The outer rigid sleeve may serve as the core structure for remedial grouting of the DRZ if required. A rock mechanics calculation in Section 2 suggests that the emplaced salt with 80 percent minimum fractional density may consolidate enough in about 45 years to meet the requirement of the long-term seal. A more conservative statement is that the emplaced salt is expected to consolidate adequately within the 100-year time frame. 


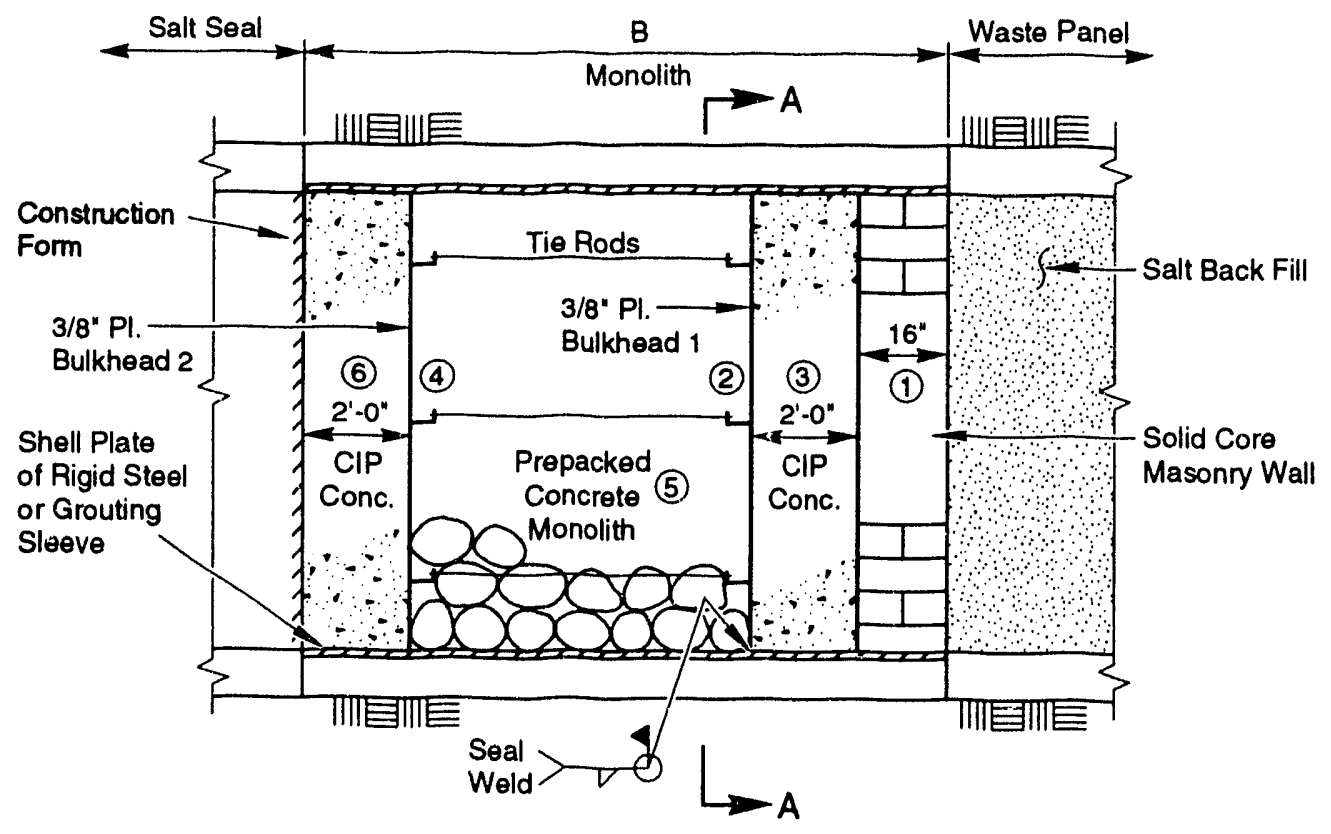

Construction Sequence

1 Erect Masonry Wall as the Far Side Form

2 Install Bulkhead 1

3 Place Cast-In-Place (CIP) Concrete

4 Install Bulkhead 2, Ties and Prepacked Precast Blocks

5 Grout Monolith with Cement-Based Non-Shrink Grout

6 Form and Place CIP Concrete

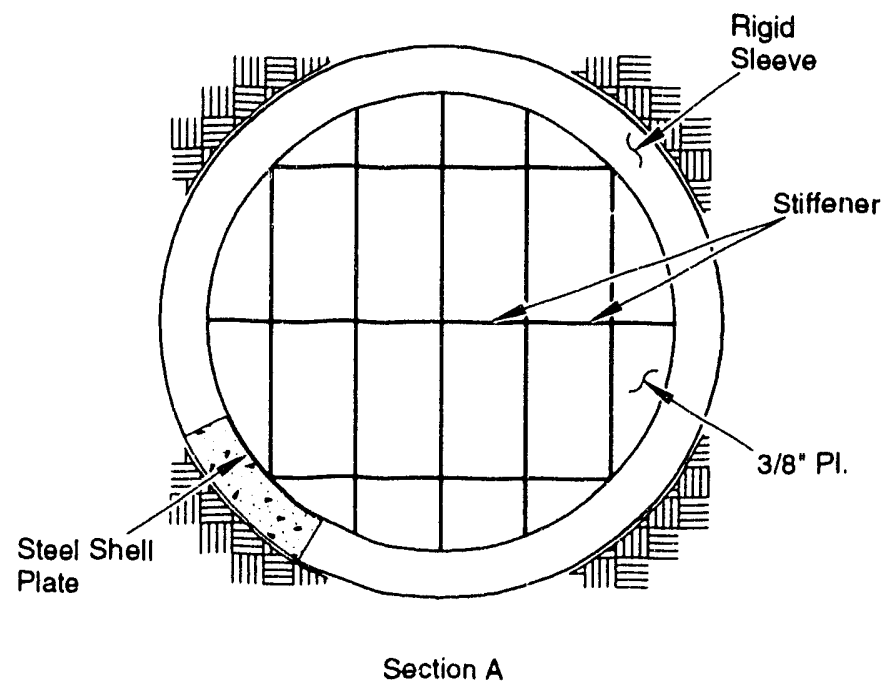

TAI.6121.76.0

Figure 3-6. Cast-in-place monolith in a rigid sleeve or grouting sleeve. 


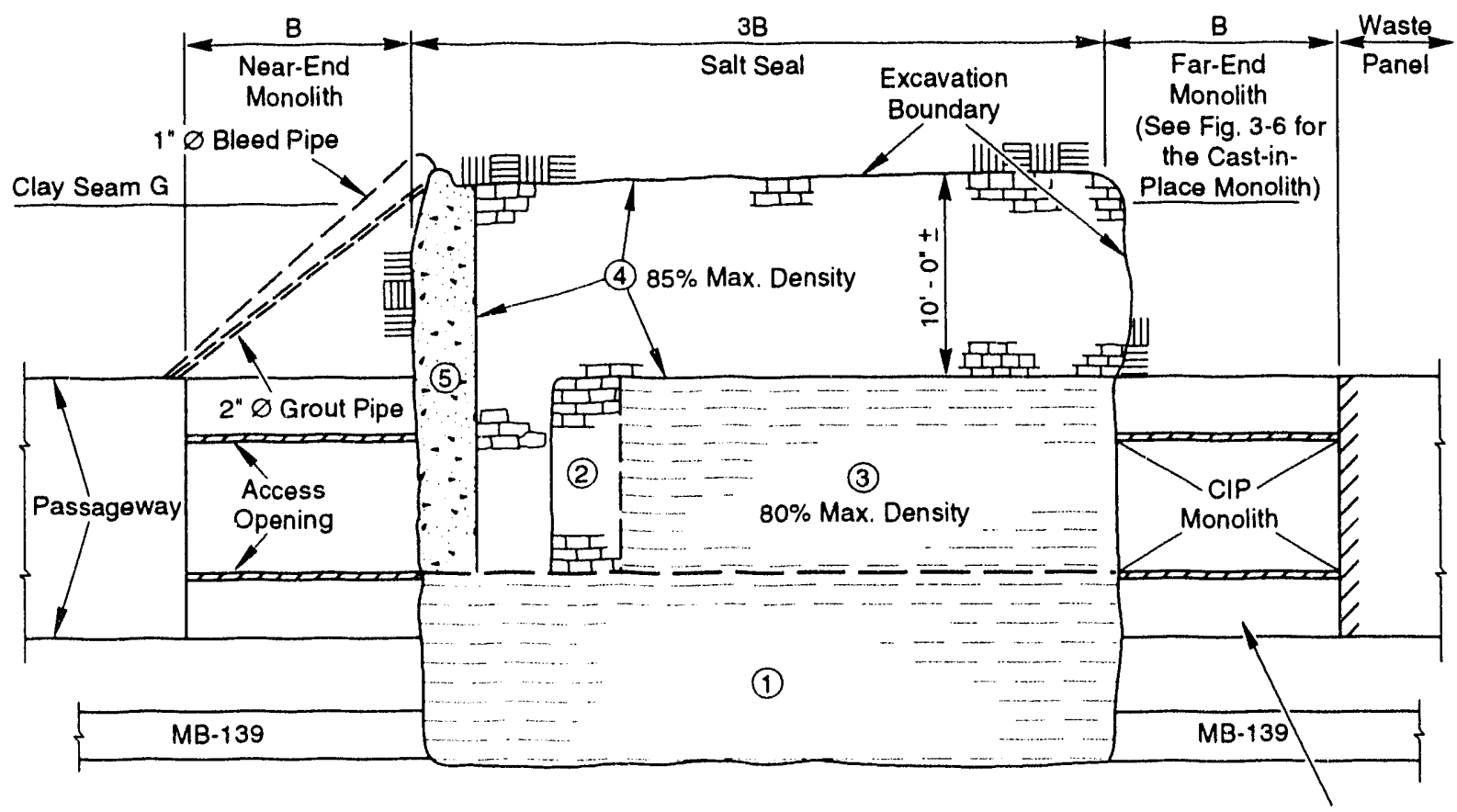

Rigid Sleeve or Grouting Sleeve

Construction Sequence

1 Place salt in optimum thickness layer and water content and mechanically compacted to $80 \%$ Maximum Density to the access opening level.

2 Install quarried-salt block dike and 3 place mechanically compacted salt in layers to about $10 \mathrm{ft}$. below the roof of the opening.

4 Place quarried-salt block and mortar salt seal.

5 Grout the construction access with nonshrink cement-based grout.

Figure 3-7. Construction scheme for long-term salt seal. 
An unresolved concern is the deflection of MB139 beneath the salt seal region during the consolidation period. As much as 20 percent room closure must occur before an 80 percent emplaced-density crushed salt is completely consolidated (5 to 10 percent room closure could be required for quarried-salt blocks). Therefore, significant deflection and fracturing of MB139 could occur in the salt seal region, despite continued restraint against deflection in the monolith regions. This may necessitate removal of the marker bed before salt emplacement or development of a special method for sequential rigid sleeve removal with concurrent high-density salt emplacement (salt blocks) to reduce the amount of closure and subsequent deflection of the marker bed.

\subsubsection{Type 2 - LGxx Seal}

The Type 2 - LG Seal is a "LATER GROUT" seal in which nothing is done to the excavated opening until time for seal construction after waste emplacement. The seal uses a $B_{1}-3 B_{2}-B_{1}$ pattern, where $B_{1}$ is the width of the existing excavation at the monolith location and $B_{2}$ is the width of the excavation in the central portion where the salt seal is to be constructed. The term "xx" in LGxx denotes the width of the initial passageway. Five sizes $(12 \mathrm{ft}, 14 \mathrm{ft}, 18 \mathrm{ft}, 20 \mathrm{ft}$, and $25 \mathrm{ft}$ ) are considered for this type of seal.

After waste emplacement, the seal construction will begin with the erection of the grouting sleeves at the monolith locations. The two grouting sleeves, each made of a $\mathrm{B}_{1} \mathrm{ft}$ long, $10 \mathrm{ft}$ inside diameter steel shell, and cast-in-place concrete, are located $3 \mathrm{~B}_{2}$ distance apart (Figure 3-3; for details, see Sketch SK-4). The sleeve provides the resistance against the pressure loading from the DRZ grouting. Grouting fans will be drilled through the shell plate through which the DRZ will be grouted. When the DRZ grouting is completed, the far-end monolith may be constructed according to the sequence shown in Figure 3-6.

The next step is to excavate the DRZ and MB139 which might have been fractured in the middle $3 \mathrm{~B}_{2}$ section. From the rock mechanics study in Section 2.2, it can be seen that the DRZ extends about $3 \mathrm{ft}$ horizontally into the ribs, about 5 to $10 \mathrm{ft}$ above the roof, and to the bottom of MB139. During the 5-year period when the panel is being developed and emplaced, additional rock bolts may be needed at the roof of the drift for operational safety, or there could be significant damage at clay seam $G$ which is located about $9 \mathrm{ft}$ above the roof of the drift, as shown for example in Figure 2-7. It is assumed that during the salt seal 
construction, the DRZ below clay seam $G$ will be removed both for safety and for a conservative design.

A DRZ excavation concept for the salt seal is shown in Figure 3-8. The excavation will be done by a custom-made shearer, starting from the roof down to the bottom of MB139. The equipment will be designed to fit the 10 -ft-diameter access through the outer grouting sleeve. A roof support shield is required for personnel safety during excavation of the roof. A placement scheme for the salt seal is shown in Figure 3-7.

\subsubsection{Type 3 - LExx Seal}

The Type 3 - LE Seal is a "LATER EXCAVATE" seal in which nothing is done to the seal area until time for seal construction after waste emplacement. This seal also uses a B-3B-B pattern, with B being the width of excavation at the monolith locations. The term " $x x$ " in LExx denotes the width of the initial passageway.

Five sizes $(12 \mathrm{ft}, 14 \mathrm{ft}, 18 \mathrm{ft}, 20 \mathrm{ft}$, and $25 \mathrm{ft}$ ) are considered for this type of seal. The seal consists of two cast-in-place concrete monoliths at the ends and a salt seal in the center (Figure 3-3; for details, see Sketch SK-5). Prior to the seal construction, the DRZ around the seal area and MB139 will be excavated.

Based on analysis, the DRZ extends into the stratigraphy as shown in Section 2.2, the overexcavation extends about $10 \mathrm{ft}$ above the roof, about $3 \mathrm{ft}$ into the ribs, and to the bottom of MB139. The construction starts with DRZ removal similar to that shown in Figure 3-8, but for the total length of 5B. The far-end (waste side) monolith is placed with steel plate bulkheads and cast-in-place concrete. An interface grouting system or longitudinal membrane system is provided around the monolith for an operational seal. Placement of the salt seal is similar to that of the Type 2 seal. The near-end (drift side) monolith is built similar to the far-end (waste side) monolith.

\subsubsection{Type 4 - NR/LE14 Seal}

This NR/LE ("NOW RIGID/LATER EXCAVATE") seal combines the features of the Type 1 rigid sleeves and the Type 3 overexcavation for the central salt seal at a later time. It uses the $B_{1}-3 B_{2}-B_{1}$ pattern described for Type 2 seals. Fourteen denotes the size of the 


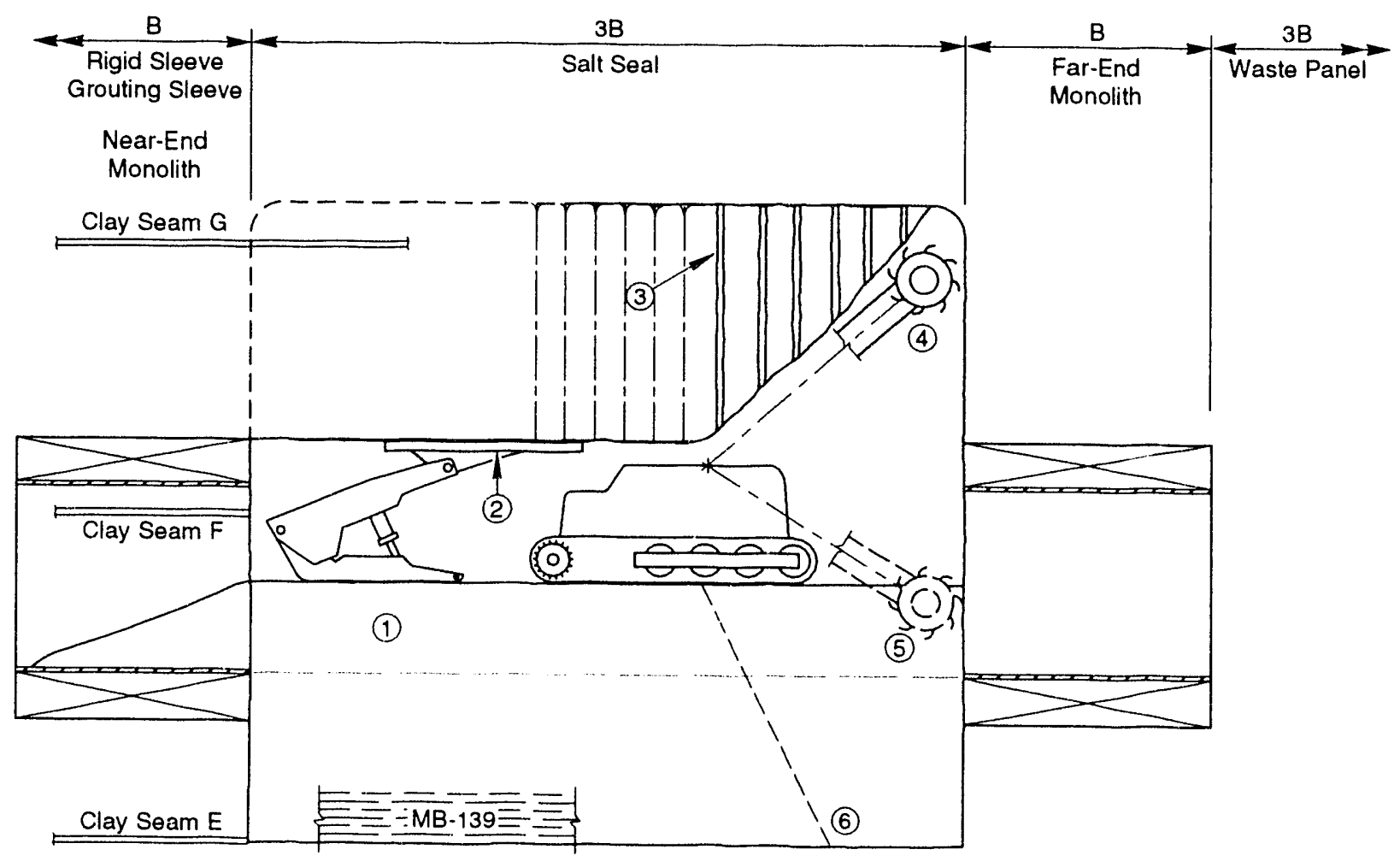

DRZ Excavation Sequence

1. Construction berm to suit the roof support shield and the shearer.

2. Install the roof support shield, under the area the rockbolts are to be removed.

3. Remove all rockbolts in the area to be excavated.

4. Excavate the roof $D R Z$ with a custommade shearer in slices. Repeat steps 2 and 3 as required.

5. Remove the construction berms, as required, for invert excavation.

6. Excavate the invert.

Notes

1. For type 2 seal systems, the grouting sleeve and DRZ grouting shall be completed prior to the DRZ excavation.

2. The roof support shield and the shearer for DRZ excavation are to be custommade to suit the dimension of the grouting sleeve.

Figure 3-8. DRZ excavation concept for salt seal. 
initial passageway. Only one size is considered for this type.

The two rigid sleeves, each $B_{1}$ long, oval-shaped steel shell, and precast concrete, are located $3 \mathrm{~B}_{2}$ apart and are installed "NOW" (Figure 3-3; for details, see Sketch SK-6) prior to further development of the drifts and panels. The rigid sleeve installation procedure is similar to that of Type 1 . At the time for salt seal construction, the concrete monoliths can be built with the concept shown in Figure 3-6.

The central $3 \mathrm{~B}_{2}$ portion of the seal will be overexcavated at a later time. The excavation boundary is similar to that for the Type 3 seals and the excavation concept shown in Figure 3-8. The construction scheme for the salt seal shown in Figure 3-7 could also be used here.

\subsection{Evaluation and Selection of Design Types}

\subsubsection{Evaluation of Design Types}

The design types are discussed in terms of the following criteria: (1) effectiveness, (2) constructibility, and (3) cost. No attempt is made in this study to rank the design types.

The construction cost evaluation is made in fourth quarter 1992 U.S. dollars. When material cost data are not available, the unit cost is based by analogy to the cost of other material available in the market. Some unit costs from the AGB final design report (Lin and Van Sambeek, 1992b) are also used in the cost estimate.

The engineering quantities and an order-of-magnitude cost estimate for each design type are presented in Appendix A. Table 3-1 tabulates the estimated unit cost of all seal designs. For comparison purposes, all unit costs are normalized with respect to the cost of the NR14 type. In general, the "NOW" rigid sleeve seals, NRxx, cost about twice that of the "LATER" seals, LGxx or LExx. It is also noted that the unit cost of the seal increases disproportionately to the size of the seal. For instance, the increase in size from $12 \times 12$ $\mathrm{ft}$ to $20 \times 12 \mathrm{ft}$ is about 1.67 times; however, the increase in unit cost is about three times from NR12 to NR20, and two times from LG12 or LE12 to LG20 or LE20. The considerations for "NOW" vs. "LATER" seals are summarized in Table 3-2. The features and viability of the types of seals are discussed in Sections 3.6.1.1 through 3.6.1.4. However, some of the assumptions made need to be verified for implementation in the design phase. 
Due to the lack of practical data for cost and schedule for large-scale emplacement of crushed salt to the required 80 to 90 percent (or greater) fractional density, the comparisons of "NOW" versus "LATER" salt seal construction are order-of-magnitude only in terms of either cost or schedule. All seal types require salt emplacement, but the volume required varies by the seal type.

Table 3-1. Order-of-Magnitude Unit Cost Estimates for Base Case and Alternative Case Seal Types

\begin{tabular}{|c|c|c|c|c|c|}
\hline $\begin{array}{l}\text { Seal } \\
\text { Type }\end{array}$ & Seal I.D. & $\begin{array}{c}\text { Base Case } \\
\text { Cost }\end{array}$ & $\begin{array}{c}\text { Normalized }^{(a)} \\
\text { Cost }\end{array}$ & $\begin{array}{l}\text { Alternative } \\
\text { Case Cost }\end{array}$ & $\begin{array}{c}\text { Normalized }^{(\mathrm{a})} \\
\text { Cost }\end{array}$ \\
\hline \multirow[t]{3}{*}{1} & NR 12 & $\$ 4,053,000$ & $73 \%$ & $\$ 3,425,000$ & $61 \%$ \\
\hline & NR 14 & $\$ 5,587,000$ & $100 \%$ & $\$ 4,693,000$ & $84 \%$ \\
\hline & NR 20 & $\$ 12,472,000$ & $223 \%$ & $\$ 10,468,000$ & $187 \%$ \\
\hline \multirow[t]{5}{*}{2} & LG 12 & $\$ 1,886,000$ & $34 \%$ & $\$ 1,704,000$ & $30 \%$ \\
\hline & LG 14 & $\$ 2,379,000$ & $42 \%$ & $\$ 2,122,000$ & $38 \%$ \\
\hline & LG 18 & $\$ 3,044,000$ & $54 \%$ & $\$ 2,660,000$ & $48 \%$ \\
\hline & LG 20 & $\$ 4,041,000$ & $72 \%$ & $\$ 3,579,000$ & $64 \%$ \\
\hline & LG 25 & $\$ 5,841,000$ & $105 \%$ & $\$ 5,163,000$ & $92 \%$ \\
\hline \multirow[t]{5}{*}{3} & LE 12 & $\$ 2,535,000$ & $45 \%$ & $\$ 2,028,000$ & $36 \%$ \\
\hline & LE 14 & $\$ 3,236,000$ & $58 \%$ & $\$ 2,632,000$ & $47 \%$ \\
\hline & LE 18 & $\$ 4,156,000$ & $74 \%$ & $\$ 3,298,000$ & $59 \%$ \\
\hline & LE 20 & $\$ 5,401,000$ & $97 \%$ & $\$ 4,277,000$ & $77 \%$ \\
\hline & LE 25 & $\$ 7,760,000$ & $139 \%$ & $\$ 6,263,000$ & $112 \%$ \\
\hline 4 & NR/LE 14 & $\$ 3,706,000$ & $66 \%$ & $\$ 2,812,000$ & $50 \%$ \\
\hline
\end{tabular}

(a) Normalized with respect to base case cost of NR14 type.

3.6.1.1 TYPE 1 - NR×x SEAL

The Type 1 - NR Seal uses a rigid sleeve installed as soon as possible after excavation to check and control the development of the DRZ around the opening and deformation of MB139. In the operational phase, it can be expected that the monolith will be effective immediately after installation since substantial healing of the salt DRZ will already have 


\section{Table 3-2. Drift and Panel Seals "NOW" Versus "LATER" Considerations}

\begin{tabular}{|c|c|c|c|c|}
\hline \multirow[b]{3}{*}{$\begin{array}{l}\text { Operational } \\
\text { Seal }\end{array}$} & \multirow{3}{*}{$\begin{array}{c}\text { NOW } \\
\text { Type 1 - NRxx }\end{array}$} & \multicolumn{2}{|c|}{ LATER } & \multirow{3}{*}{$\begin{array}{c}\text { NOW/LATER } \\
\text { Type 4 - NR/LExx }\end{array}$} \\
\hline & & Type 2 - LGxx & Type 3 - LExx & \\
\hline & & & & \\
\hline $\begin{array}{l}\text { 1. Type of } \\
\text { Barrier }\end{array}$ & $\begin{array}{l}\text { By checking develop- } \\
\text { ment and healing of } \\
\text { DRZ and using gas- } \\
\text { tight steel bulkhead } \\
\text { and concrete monolith. }\end{array}$ & $\begin{array}{l}\text { By effective grouting of } \\
\text { DRZ and MB139 and } \\
\text { using concrete mono- } \\
\text { lith with gas-tight steel } \\
\text { bulkheads. }\end{array}$ & $\begin{array}{l}\text { By removal of DRZ to } \\
\text { the bottom of MB139 } \\
\text { and either an interface } \\
\text { grouting system or lon- } \\
\text { gitudinal membrane } \\
\text { system around the con- } \\
\text { crete monolith with } \\
\text { gas-tight steel bulk- } \\
\text { heads. }\end{array}$ & Same as NR seals. \\
\hline 2. Salt DRZ & $\begin{array}{l}\text { Rigid sleeve will check } \\
\text { the DRZ development } \\
\text { and promote healing. }\end{array}$ & $\begin{array}{l}\text { DRZ. almost fully } \\
\text { developed I year after } \\
\text { excavation. Grouting } \\
\text { sleeve will promote } \\
\text { healing. Grouting in } \\
\text { salt is unproven. }\end{array}$ & $\begin{array}{l}\text { Salt DRZ will be re- } \\
\text { moved, but removal } \\
\text { may promote new } \\
\text { DRZ. }\end{array}$ & Same as NR seals \\
\hline 3. $\mathrm{MB} 139$ & $\begin{array}{l}\text { Rigid slecve checks } \\
\text { MB139 deformation } \\
\text { after installation and } \\
\text { prevents ongoing yield. } \\
\text { ing. }\end{array}$ & $\begin{array}{l}\text { Deformation grows } \\
\text { with time and yiclding } \\
\text { will occur. Grouting } \\
\text { will be used in MB139. }\end{array}$ & $\begin{array}{l}\text { MB139 will be } \\
\text { removed during seal } \\
\text { installation. }\end{array}$ & Same as NR seals \\
\hline $\begin{array}{l}\text { 4. Reduced } \\
\text { Access }\end{array}$ & $\begin{array}{l}\text { Clear passageway re- } \\
\text { duced to } 14 \times 12 \mathrm{ft} \\
\text { during panel work and } \\
\text { seal construction. Floor } \\
\text { requires ramp from } \\
\text { drift floor. }\end{array}$ & $\begin{array}{l}\text { No restriction for panel } \\
\text { work or seal construc- } \\
\text { tion. The near-end gro- } \\
\text { uting sleeve may be } \\
\text { constructed after com- } \\
\text { pletion of the salt seal. }\end{array}$ & Same as LG seals & Same as NR seals \\
\hline \multicolumn{5}{|l|}{ Salt Seal } \\
\hline 1. Salt DRZ & $\begin{array}{l}\text { Although DRZ } \\
\text { checked initially, DRZ } \\
\text { could develop during } \\
\text { salt consolidation. } \\
\text { Sequential sleeve re- } \\
\text { moval and salt em- } \\
\text { placement could mini- } \\
\text { mize DRZ develop- } \\
\text { ment. Will reheal in } \\
\text { long term. }\end{array}$ & $\begin{array}{l}\text { Salt DRZ fully devel- } \\
\text { oped and may require } \\
\text { remediation during } \\
\text { construction. Salt DRZ } \\
\text { will reheal during long } \\
\text { term. }\end{array}$ & Same as LG seals & Same as LG seals \\
\hline 2. MB139 & $\begin{array}{l}\text { MB139 will deform } \\
\text { during salt consolida- } \\
\text { tion (perhaps signifi- } \\
\text { cantly). High salt em- } \\
\text { placement density is } \\
\text { required. }\end{array}$ & MB139 removed. & Same as LG seals & Same as LG seals \\
\hline 3. Excavation & $\begin{array}{l}\text { No additional excava- } \\
\text { tion after removal of } \\
\text { rigid sleeve. }\end{array}$ & $\begin{array}{l}\text { Need to remove roof } \\
\text { bolts and poor roof } \\
\text { salt, salt DRZ in ribs } \\
\text { and floor, and MB139 } \\
\text { in salt seal region. }\end{array}$ & $\begin{array}{l}\text { Same as LG seals } \\
\text { except excavate entire } \\
\text { seal area. }\end{array}$ & Same as LG seals \\
\hline
\end{tabular}


Table 3-2. Drift and Panel Seals "NOW" Versus "LATER" Considerations (continued)

\begin{tabular}{|c|c|c|c|c|}
\hline \multirow[b]{3}{*}{$\frac{\text { Constructi- }}{\text { bility }}$} & Now & \multicolumn{2}{|c|}{ Later } & \multirow{3}{*}{$\begin{array}{c}\text { Now/Later } \\
\text { Type 4 - NR/LExx }\end{array}$} \\
\hline & Type 1 - NRxx & Type 2 - LGxx & Type 3 - LExx & \\
\hline & & & & \\
\hline $\begin{array}{l}\text { 1. Personnel } \\
\text { Safety }\end{array}$ & $\begin{array}{l}\text { No need of rock bolts } \\
\text { or roof shield for per- } \\
\text { sonnel safety. }\end{array}$ & $\begin{array}{l}\text { Roof above the drift } \\
\text { may need additional } \\
\text { rock bolts or heavy } \\
\text { roof shield for person- } \\
\text { nel safety. }\end{array}$ & Same as LG seals & Same as LG seals \\
\hline $\begin{array}{l}\text { 2. Equipment } \\
\text { Develop- } \\
\text { ment }\end{array}$ & $\begin{array}{l}\text { No special mining } \\
\text { equipment. Special } \\
\text { forklift for rigid sleeve } \\
\text { erection and demoli- } \\
\text { tion. }\end{array}$ & $\begin{array}{l}\text { Requires custom-made } \\
\text { roof shield and mining } \\
\text { shearer for removal of } \\
\text { the rock bolts and } \\
\text { DRZ. }\end{array}$ & Same as LG seals & Same as LG seals \\
\hline $\begin{array}{l}\text { 3. New } \\
\text { Technology }\end{array}$ & $\begin{array}{l}\text { As with other types, } \\
\text { salt seal emplacement } \\
\text { method to be devel- } \\
\text { oped. }\end{array}$ & $\begin{array}{l}\text { Effective DRZ } \\
\text { grouting, concrete, and } \\
\text { salt seal emplacement } \\
\text { methods to be devel- } \\
\text { oped. }\end{array}$ & $\begin{array}{l}\text { Concrete and salt seal } \\
\text { emplacement methods } \\
\text { to be developed. }\end{array}$ & Same as NR seals \\
\hline $\begin{array}{l}\text { Unit Cost } \\
14^{\prime} W \times 12^{\prime} H \\
\text { Base Case }\end{array}$ & $\$ 5,587,000$ & $\$ 2,379,000$ & $\$ 3,236,000$ & $\$ 3,706,000$ \\
\hline $\begin{array}{l}\text { Alternative } \\
\text { Case }\end{array}$ & $\$ 4,693,000$ & $\$ 2,122,000$ & $\$ 2,632,000$ & $\$ 2,812,000$ \\
\hline
\end{tabular}

been achieved during the assumed 5-year period of panel development and emplacement. Damage in MB139, which occurs during the time between excavation and sleeve installation, will not be healed naturally. Remedial grouting is not planned for this alternative, but could be used if required.

After waste emplacement, the middle section (3B) is removed and replaced by crushed salt which will be compacted to overall 80 percent fractional density. In order to develop the 95 percent fractional density required for the permanent seal, 15 percent volumetric strain is required from consolidation by creep closure. Based on the discussion in Section 2.1.2 and Equation 2-2, it can be concluded that the portion of the salt seal inside the opening will be effective in less than 100 years for the postclosure phase. The closure which provides the consolidation may, however, allow detrimental deflection of MB139 below the opening and the marker bed may not be as tight as the consolidated salt portion. Additional discussion on this consideration is provided in Section 2.2.2. 
No custom-made equipment or new technology is required for construction of this type. Three sizes of NR type are considered in this study. The NR12 seal has the minimum access of $12 \times 12 \mathrm{ft}$ considered here and would require a modification of the reference design. The reduced access has an inherent disadvantage during development, operation, and construction of the monoliths and salt seal after waste emplacement. The NR14 seal accommodates a 14- $\times 12$-ft opening for standard one-way access, while the NR20 seal provides a $20-\times 12$-ft opening for two-way access. All three rigid sleeve seals require ramping the access floor up and down (about $4 \mathrm{ft}, 4.4 \mathrm{ft}$, and $6.6 \mathrm{ft}$ for the NR12, NR14, and NR20 seals, respectively; see Sketches SK-1, SK-2, and SK-3 in Appendix D). For the NR20 seal, the ramps and seal require a minimum length of $287 \mathrm{ft}$, which does not fit in the space for the panel arrangement as required in the Design Requirement Document (Bailey et al., 1992a). Additionally, the NR20 seal would require a $31 / 4$-in thick steel shell which presents significant constructibility problems such as welding and handling.

The unit costs of the NR12, NR14, and NR20 seals are $\$ 4,053,000, \$ 5,587,000$, and $\$ 12,472,000$, respectively (see Table $3-1$ ). The use of a smaller rigid sleeve, NR12, trades off some operational handicaps for about 25 percent capital cost savings compared to the cost for a NR14 seal. The use of a larger rigid sleeve, NR20, would cost more than twice the NR14 seal. The Alternative Case, which has one operational seal at the far-end (waste side), costs about 16 percent less in comparison with the Base Case, which has redundant operational seals, one located at each end of the salt seal.

\subsubsection{TYPE 2 - LGXX SEAL}

For the Type 2- LG seal, nothing is done to the excavated opening until time for seal construction after waste emplacement. At the time of seal construction, a DRZ will have developed around the opening, including significant deformation of MB139. Remedial grouting is planned for this type of seal. Based on the assumptions made (Section 3.3), grouting will be effective for plugging the DRZ and for the potentially fractured MB139. However, these assumptions need to be verified by field demonstration.

After waste emplacement, operational seals are placed at each end of the $3 \mathrm{~B}_{2}$-long salt seal by first constructing the grouting sleeve followed by remedial grouting and placement of a monolith barrier inside the rigid sleeve at the far-end of the salt seal. Then, the opening for the salt seal is excavated to remove the salt DRZ and damaged MB139. The opening will be filled with crushed salt compacted to an overall 80 percent fractional 
density. Then, the near-end concrete monolith will be placed to confine the emplaced salt for creep consolidation. The results of rock mechanics analysis in Section 2 suggests that the salt will achieve the required density of 95 percent within 100 years. Therefore, it can be concluded that the salt seal will be effective in the postclosure phase.

The Type 2 seal will require custom-made roof shields and an excavation shearer for overexcavating the salt seal area. Also, the large volume of crushed salt in the salt seal emplacement, whether by compacted salt or by quarried-salt blocks, will require new technology. The excavation for installation of the salt seal in this type of seal is handicapped by the reduced access through the near-end sleeve and by the need for possible repairs or replacement of the heavy excavation equipment.

Table 3-1 shows that the cost of the Base Case LG seals with redundant operational seals is about 42 percent of that of the NR seals. About 10 percent additional cost savings are provided by the Alternative Case of the LG seal which has only one operational seal.

\subsubsection{TYPE 3 - LEXX SEAL}

Like Type 2, the Type 3 - LE Seal is a "LATER" seal. Seal construction starts with DRZ removal (both salt and MB139) for the total length of $5 B$, where $B$ is the width of excavation. This is followed by constructing a large cast-in-place concrete monolith operational seal at the far-end. The operational seal does not require effective grouting as in a Type 2 seal; however, an elastomeric membrane is required at the concrete/salt interface to assure that there is no leak-passage at the interface which is the most critical item of the operational seal. Next, the salt seal is constructed similar to that of Type 2. This type also requires a custom-made roof support shield and excavation shearer for the construction. The large volume of salt emplacement to 80 percent overall fractional density may require new technology to be developed. However, there is no access limitation to hinder the operation of the heavy excavation equipment because the near-end concrete monolith may be placed after completion of the salt seal emplacement.

Table 3-1 shows that the unit cost of the Type 3 seal is about 58 percent of the cost of a Type 1 seal, and is about one-third more than Type 2 for the Base Case with the redundant operational seal. For the Alternative Case with only one operational seal, the unit cost is about 80 percent of that of the Base Case. 


\subsubsection{TYPE 4 - NR/LE14 SEAL}

This design type combines features from Types 1 and 3 and subsequently inherits some of the advantages and disadvantages from these two types. As in the case of Type 1, the monolith operational seal will be effective immediately after installation since DRZ development is under control. Construction of the salt seal is similar to that of Type 3. The emplaced salt will be consolidated to the required 95 percent fractional density in 100 years or less, which provides an effective long-term seal.

This type may also require custom-made equipment to excavate the large volume of salt. Reduced access through the near-end sleeve may hinder the operation of the heavy excavation equipment.

Table 3-1 shows that the unit cost of the Type 4 seal is about 66 percent of the cost of Type 1 seal for the Base Case with redundant operational seals. For the Alternative Case with only one operational seal, the unit cost is about one-quarter less than the Base Case.

\subsubsection{Seal Type Selection and Combination}

\subsubsection{SELECTION BASIS FOR SEALS LOCATED IN EXISTING EXCAVATIONS}

There are 13 seal sites that have already been excavated (see Figure 3-1 for seal locations). The excavation sizes vary from $14 \times 12 \mathrm{ft}$ to $25 \times 12 \mathrm{ft}$. The existing sizes and the site conditions will limit the choice of design options. The "NOW" seals, NRxx type, are not applicable to existing excavations.

From the rock mechanics study (Section 2.2), it can be seen that within 1 year after creating a rectangular-shaped excavation, the damaged zone around the excavation is almost completely developed. However, the severity of damage of the DRZ in MB139 continues to increase with time. For larger excavations $(25 \times 12 \mathrm{ft})$, yielding in the marker bed is possible within the first year after excavation and can actually be observed at the WIPP. In this study, an average age of excavations for all existing drifts is assumed to be 10 years. By then, the DRZ around the excavation is expected to be fully developed, and MB139 will likely have been fractured. In order to provide an effective seal design, only "LATER" seals (Type 2 - LGxx and Type 3 - LExx) can be selected for the existing excavations, which include Seal No. 2 and Seal Nos. 5 through 16. 
The lengths of the "LATER" seals, LGxx and LExx types, are not restricted by the layout of the waste panel. The unit cost for "LATER"-type seals is about one-half or less the cost of "NOW"-type seals of similar size. However, the LGxx seals are viable only if the grouting for DRZ and damaged MB139 is effective for an operational seal.

\subsubsection{SELECTION BASIS FOR SEALS LOCATED IN NEW EXCAVATIONS}

From the results of the rock mechanics study (see Section 2), it can be shown that when a rigid structure, such as a rigid sleeve, is emplaced in salt, it will arrest development of the

DRZ around the opening and induce back pressure on the salt to promote healing of the DRZ. The rigid structure will also stop further deformation of MB139 so long as the liner remains in place. ince MB139 does not have the self-healing characteristic of the salt, it is essential to minimize damage to MB139. The effectiveness of the salt seal is assured by initial compaction of the salt to 80 percent, or more, overall fractional density.

The choice of sizes for NR type seals, however, is limited to NR14 and NR12 by the existing layout dimensions. The rigid sleeves for the NRxx type of seal need to be installed immediately after excavation for assurance of the effectiveness of the operational seal. The Base Casc eals of NRxx type are handicapped by restricted access through the near-end (drift side) sleeves for construction of the far-end (waste side) monolith and emplacement of the salt seal.

If nothing is done to the newly excavated opening until time for seal construction after waste emplacement, then Type 2-LGxx and Type 3-LExx seals are the only seal types that can be used for Seal Nos. 1, 3, 4, and Seal Nos. 17 through 30.

A Type 4 - NR/LE14 seal, which combines the features of Types 1 and 3, can also be considered for all new excavations.

\subsubsection{SEAL COMBINATION OF DESIGN ALTERNATIVES}

From the selection basis elucidated in the previous sections, LG or LE type seals are needed in the existing excavations, while seals in the new excavations could be either a NR, LG, LE or NR/LE type. Theoretically, there are a very large number of design combinations when all options are considered. In order to get a rough order-of-magnitude 
cost estimate of the whole drift and panel seals for the WIPP sealing program, four seal combinations are postulated (see Table 3-3). For each seal combination, a cost estimate is made for the Base Case and Alternative Case designs.

The Base Case design uses the IRSSD (Nowak et al., 1990) concept providing redundant operational seals. The Alternative Case design has only one operational seal placed at the far-end (waste side) and provides a plain concrete monolith inside the existing drift for the purpose of confining the near-end (drift side) of the emplaced salt. At a waste panel, there is no need of two-way traffic in the panel drift and reduction in the cross-sectional area has little impact on the ventilation requirement. Therefore, a pair of $14-\mathrm{ft}$ and $12-\mathrm{ft}$ panel accesses seem to be adequate for the construction and operation of the panel. Combinations will be developed to determine the potential cost saving by downsizing the panel accesses from $20 \mathrm{ft}$ and $14 \mathrm{ft}$ to $14 \mathrm{ft}$ and $12 \mathrm{ft}$.

Seal Combination 1 maximizes the use of "NOW RIGID," Type 1 Seals by selecting NR14 seals for all new excavations. In the existing drifts, the "LATER EXCAVATE," Type 3 - LExx seals are used. This combination does not depend on grouting for an operational seal. Seal Combination 2 uses "LATER GROUT," Type 2 - LGxx seals at all 30 seal locations. Seal Combination 3 uses "LATER EXCAVATE," Type 3 - LExx seals at all 30 seal locations. Seal Combination 4 uses the "NR/LE" concept for new excavations. In the existing drifts, the "LATER EXCAVATE," Type 3 - LExx seals are used.

\subsubsection{ROUGH ORDER-OF-MAGNITUDE COST ESTIMATE}

Herein, rough-order-of-magnitude costs imply standard construction industry estimates of \pm 50 percent.

\subsection{Unit Cost of Seals}

The engineering quantities and order-of-magnitude cost estiniate for the unit cost of Type 1, 2, 3, and 4 seals are shown in Tables A-1 through A-4 in Appendix A, and summarized in Table 3-1. 


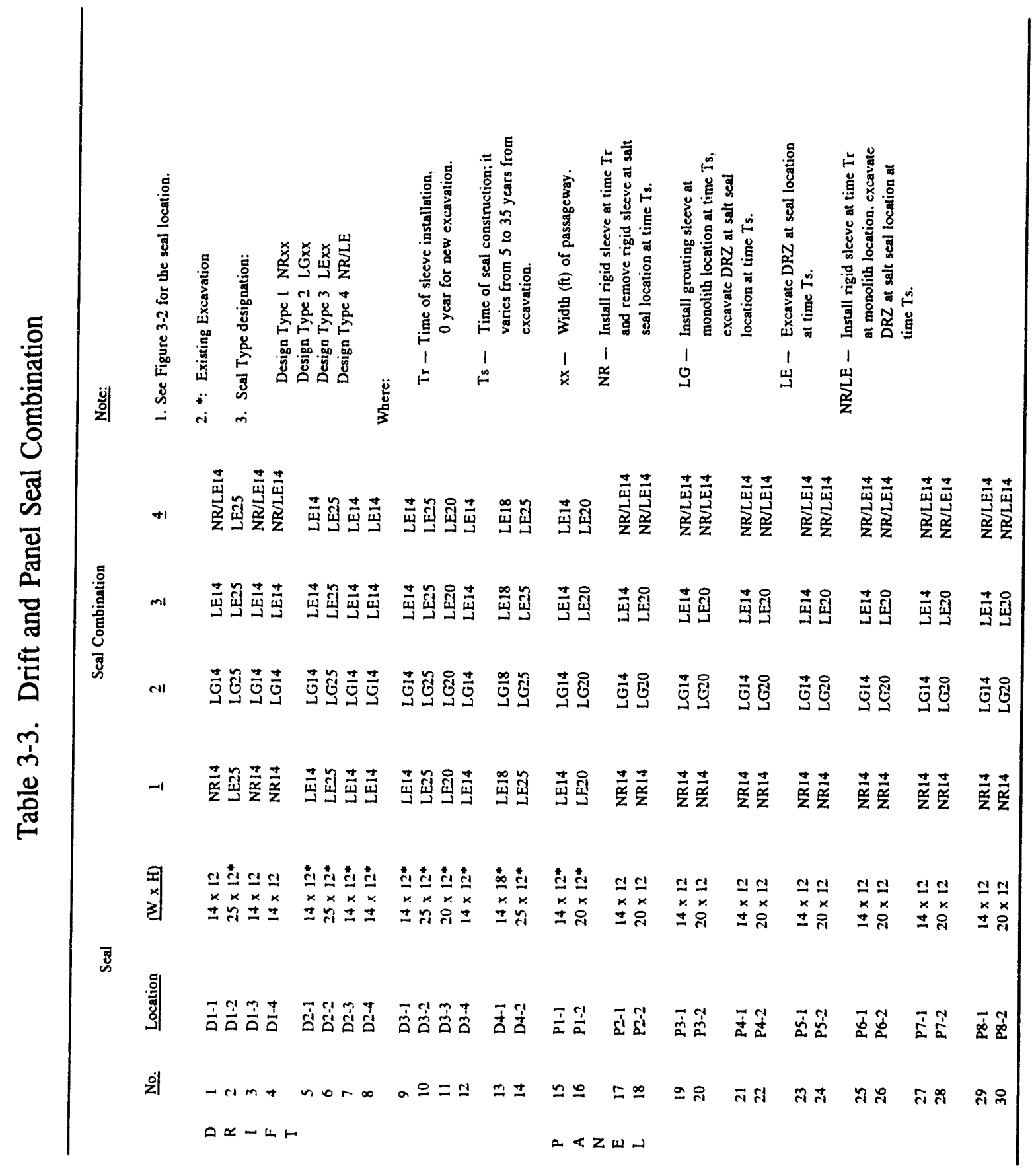




\subsection{Total Estimated Capital Cost}

The total order-of-magnitude capital cost for the WIPP drift and panel seals associated with the seal Combinations 1 through 4 are obtained by summation of the product of the number of seal type and the corresponding unit cost. Cost estimates for each individual combination are tabulated in Tables A-5 through A-11 in Appendix A. Table 3-4 shows the summary of the order-of-magnitude cost evaluation for all seal combinations.

The total cost ranges from a maximum of $\$ 160,400,000$ for the Base Case of seal Combination 1 to a minimum of $\$ 76,400,000$ for the Alternative Case of seal Combination 2A (see Table 3-4). If there is no need for the redundant operational seal, the Alternative Case has a cost about 20 to 25 percent less than the Base Case. Therefore, eliminating one of the two operational seals warrants further investigation in the preliminary design of the WIPP drift and panel seals. For the Alternative Case, the order-of-magnitude total cost is about $\$ 100$ million \pm 30 percent. Downsizing the access widths reduces the total cost about 15 percent compared to the Base Case. No specific combination of seals seems to have significant cost advantages over other combinations of seals.

Table 3-4. Summary of Rough Order-of-Magnitude Cost Evaluation

\begin{tabular}{ccc}
$\begin{array}{c}\text { Seal } \\
\begin{array}{c}\text { Combination } \\
\text { No. }\end{array}\end{array}$ & $\begin{array}{c}\text { Base Case } \\
\text { Total Amount }\end{array}$ & $\begin{array}{c}\text { Alternative Case } \\
\text { Total Amount }\end{array}$ \\
1 & $\$ 160,387,000$ & $\$ 132,487,000$ \\
$1 \mathrm{~A}^{(\mathrm{a})}$ & $\$ 149,648,000$ & $\$ 123,608,000$ \\
2 & $\$ 100,833,000$ & $\$ 89,647,000$ \\
$2 \mathrm{~A}^{(\mathrm{a})}$ & $\$ 85,753,000$ & $\$ 76,390,000$ \\
3 & $\$ 135,579,000$ & $\$ 108,960,000$ \\
$3 \mathrm{~A}^{(\mathrm{a})}$ & $\$ 115,516,000$ & $\$ 93,215,000$ \\
4 & $\$ 123,415,000$ & $\$ 100,508,000$ \\
& & \\
\hline & & \\
\hline
\end{tabular}




\subsection{Conclusion}

Since about one-half of the seal sites are in existing drifts, both "NOW" and "LATER" types of seals may be used. The "NOW" seal uses rigid sleeves in yet to be excavated drifts to check the growth of DRZ and provide backpressure for healing the DRZ in salt. It may provide the most effective operational seal among those types studied, particularly if an effective grouting procedure cannot be developed. NR seals have a constructibility problem if the clear opening through the seal must be larger than $14 \times 12 \mathrm{ft}$ or $12 \times 12 \mathrm{ft}$. The unit cost of the "NOW" sleeve is about twice that of the "LATER" sleeves.

Two types of seals, LGxx and LExx, have been studied for the "LATER" seal to be installed in the drift opening after waste emplacement. The LGxx seals use grouting of the DRZ, especially the damage in MB139, for an operational seal, but such an effective grouting procedure is yet to be developed and demonstrated. Both LG and LE types of the "LATER" seals use excavation to remove the salt DRZ and the damaged MB139 for the emplacement of the permanent salt seal component. The rock mechanics study showed that the effectiveness of these salt seals can be achieved if the emplaced salt is compacted to an overall fractional density of 80 percent or more. Both types of the "LATER" seal will require custom-made equipment for excavation.

MB139 is not protected after removal of the rigid liner from the salt seal portion of NRtype seals during salt consolidation. A combination of NR-type operational seals and LEtype salt seals (with renoval of the MB139) may solve this problem. Other variations or methods of salt emplacement could also provide acceptable control of the marker bed during the salt consolidation period.

Two cases (Base Case and Alternative Case) of seals have been studied. The Base Case uses the monolith at each end of the salt seal as redundant operational seals. The Alternative Case provides a single operational seal at the far-end (waste side) monolith and uses a plain concrete block at the near-end (drift side) monolith for confinement of the salt seal. The unit cost of the Alternative Case is about one-fifth less than that of the Base Case. The need of a redundant operational seal has not been resolved. Therefore, the Alternative Case warrants further refinement in the preliminary design of the WIPP drift and panel seals.

The cost estimate for this study is a rough order-of-magnitude in that there is no precedent for this type of underground work under the rigid control of NQA-1 requirements. 
The unit cost for the salt seal emplacement is based on an estimate for a comparable nonshrink, cement-based structure.

For the Alternative Case, the total cost for the WIPP drift and panel seals may range from about $\$ 130$ million for seal Combination 1 to about $\$ 90$ million for seal Combination 2. About 15 percent cost savings may be realized if the panel seals at the new excavations (Panel Nos. 2 through 8) uses the minimum size of $12 \times 12 \mathrm{ft}$ for passageway. This refinement would require study of the construction and operation methods for the waste panel, which are not in the scope of this study. From this study, it can be concluded that the rough order-of-magnitude cost for the WIPP drift and panel seals is about $\$ 100$ million. 


\subsection{SHAFT SEALS}

Four seal subsystems are included in the shaft sealing system. Because different materials are needed to meet the sealing requirements in each subsystem, a study of alternative materials comprised a large part of the shaft seals alternative study. The alternatives study proceeded in the following manner.

First, the purpose and requirements for the four seal subsystems were identified and are described in Sections 4.1 and 4.2. The DRD and IRSSD formed the basis for the reference design and materials, which includes concrete, bentonite, crushed salt, and compressed-salt blocks as the seal components.

Second, alternative materials were identified: asphalt or bitumen, a chemical seal material, and quarried-salt blocks. Performance of the alternative and reference materials was based on the rock mechanics analyses results (see Section 2.), literature citations, and manufacturers' information.

Third, eight material configurations in the shaft seal subsystems were evaluated in terms of sealing effectiveness, constructibility, and cost. Effectiveness became a dominant concern in the lower shaft seals because not all materials could be shown to be capable of meeting the design requirements presented in the DRD.

Finally, conclusions and recommendations on the shaft seal system alternatives were formulated and requirements for future work identified.

\subsection{Purpose}

Sealing functions for the WIPP shaft seals are to be carried out by a combination of short-term and long-term seals (Nowak et al., 1990). Short-term seals provide the initial sealing functions necessary until the long-term, crushed-salt seal component becomes adequately consolidated by creep closure of the shafts.

The design lifetime of short-term seal barriers is 100 years. The main functions of short-term seal barriers are: (1) prevent water-brine seepage into the area of long-term seals, (2) prevent gas migration from waste repository, and (3) confine the long-term seal 
during its reconsolidation period. In the reference design, the short-term seals consist of swelling clay and concrete. The swelling clay components are intended to limit water inflow from above to protect the crushed salt from saturation with brine. The concrete components provide some flow resistance to help control the release of possible gas generation in the waste disposal area. They also provide physical containment for the swelling clay and consolidating crushed-salt materials.

The design of long-term seal components is based on the DRD and the DBD (Bailey et al., 1992a; 1992b) and the IRSSD by Nowak et al. (1990). The fundamental strategy in the design of the long-term seal barriers is two-fold.

1. Use the same material for the seal as found in the repository (i.e., WIPP salt).

2. Maximize the length of the shaft section (seal barrier) with WIPP salt in the Salado Formation.

In the reference design, it is assumed that within 100 years, the creep closure of the shaft will reconsolidate the emplaced salt to nearly the same sealing capacity as the host rock. Two forms of salt material were considered for use in the long-term barriers in the reference design, WIPP crushed salt and compressed-salt blocks made of WIPP crushed salt. Little compositional difference is expected between the emplaced seal and the surrounding host rock salt from which it was mined. The salt seals are therefore expected to be mechanically and chemically stable in the WIPP environment fo: the required lifetime of the seal system. Design alternatives, including different types of sealing materials, are evaluated in this study to provide a comparison of various design options for effectiveness and relative cost. Alternatives for short-term components are considered and different ways of emplacing WIPP salt in the shaft are evaluated.

\subsection{Requirements for the Shaft Seals}

The shaft sealing subsystems provide the long-term sealing capability to meet EPA regulatory requirements for the postclosure period in terms of preventing excessive release of waste materials to the accessible environment. The shaft seals also control the down flow of brine from the water-bearing zones, separate aquifers, and provide near-surface seals to meet State of New Mexico regulations. Shaft seals are not designed to prevent brine inflow from the salt in the Salado Formation. Calculations show that brine inflow from the surrounding salt will not interfere enough to prohibit consolidation of the emplaced salt seal 
components (Nowak et al., 1990). The four WIPP shafts are the Salt Handling Shaft, the Waste Shaft, the Air Intake Shaft, and the Exhaust Shaft. All are partially lined and contain existing concrete structures (keys).

Seals are to be installed in each of the four shafts at selected locations in the lower shaft, the upper shaft, the water-bearing zone, and near-surface. Shaft seals will be emplaced starting at the bottom of the shaft and proceeding upward toward the top (see Figure 4-1).

\subsubsection{Lower Shaft Seals}

The lower shaft sealing subsystem is located within the Salado Formation in each of the four shafts (see Figure 4-1). The lower shaft sealing subsystem consists of seals within the Salado Formation, including seals below the Rustler/Salado Formations contact zone. The seals consist of short- and long-term components. A column of emplaced salt in the lower shaft seal system is the primary long-term barrier to the escape of waste materials from the repository horizon. The long-term seals control fluid flow and waste release for the purpose of meeting EPA requirements during the postclosure phase. In the reference design, it was estimated that the emplaced salt components of these seals would be sufficiently consolidated by creep closure within 100 years after emplacement to meet the long-term sealing functional requirements (Nowak et al., 1990). The DRZ at these seal locations is expected to be sufficiently healed as a result of the back pressure from the consolidating emplaced salt to meet the long-term sealing functional requirements within the same time interval of 100 years. Short-term seals in the lower shaft are intended to provide short-term waste isolation, gas flow control, and redundant water inflow control for approximately 100 years after emplacement.

Preliminary short-term criteria from the DRD for the lower-shaft seals (Bailey et al., 1992a) are:

1. Waste release rate to be determined from calculations,

2. Withstand calculated loads from gas pressure, lithostatic loading, and swelling clay,

3. Contain swelling clay and crushed-salt materials,

4. Provide seal structure permeability of $1 \times 10^{-7}$ darcy $\left(1 \times 10^{-19} \mathrm{~m}^{2}\right)$ or less, and 


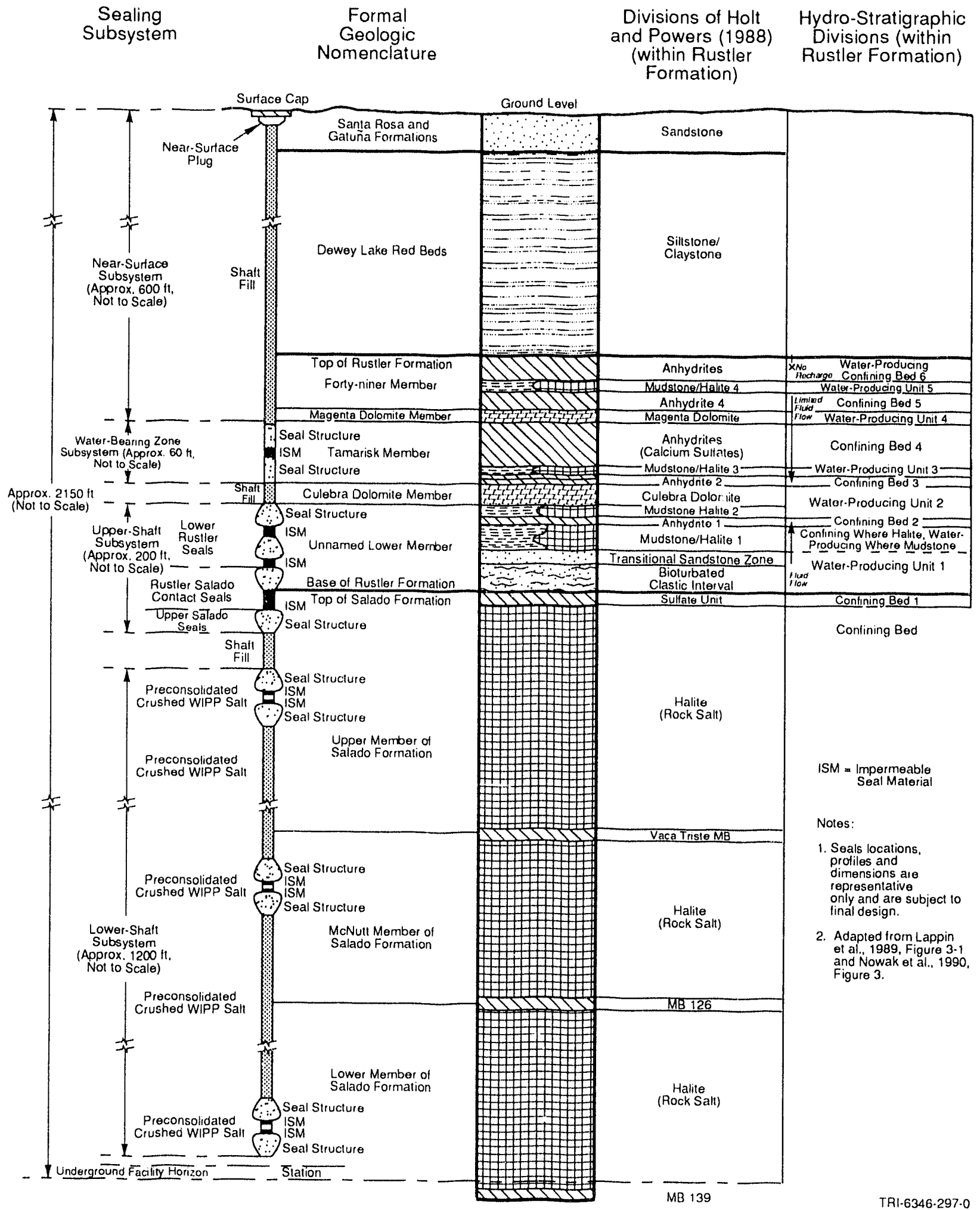

Figure 4-1. Schematic location of shaft sealing subsystems. 
5. Provide permeability of less than $2 \times 10^{-7}$ darcy $\left(2 \times 10^{-19} \mathrm{~m}^{2}\right)$ in the DRZ and the interface between the seal structure and the host rock.

Preliminary long-term criteria from the DRD for the lower-shaft seals (Bailey et al., 1992a) are:

1. Waste release rates to be provided from calculations,

2. Crushed salt to be reconsolidated by creep closure to provide permeability of $1 \times$ $10^{-8}$ darcy $\left(1 \times 10^{-20} \mathrm{~m}^{2}\right)$, and

3. Reloading from creep closure will restore DRZ permeability to $1 \times 10^{-8}$ darcy, ( 1 $\left.\times 10^{-20} \mathrm{~m}^{2}\right)$.

\subsubsection{Upper-Shaft Seals}

The upper-shaft seals consist of components in the Lower Rustler, the Rustler/Salado contact, and the Upper Salado (see Figure 4-1). Multiple seals are located in the upper shaft for redundancy. Because saturation by brine may inhibit the consolidation of emplaced salt in the lower-shaft seal, control of brine inflow from the Rustler Formation is the principal determinant of performance requirements for the upper-shaft seal system. The upper-shaft seals are designed to limit groundwater flow at least until reconsolidation of the emplaced salt in the lower shaft is sufficient for sealing effectiveness.

Preliminary criteria from the DRD for the upper-shaft seals (Bailey et al., 1992a) are:

1. Maximum allowable water flow rate from Rustler Formation to be $35 \mathrm{ft}^{3}\left(1 \mathrm{~m}^{3}\right)$ per year,

2. Withstand calculated loads from gas pressure, lithostatic, shaft fill loading, and water pressure,

3. Contain swelling clay material loads,

4. The seal structure to provide a barrier to fluid flow equivalent to permeability of 2 $\times 10^{-7}$ darcy $\left(2 \times 10^{-19} \mathrm{~m}^{2}\right)$,

5. An impermeable seal material to provide a permeability of $1 \times 10^{-7}$ darcy $\left(1 \times 10^{-19}\right.$ $\mathrm{m}^{2}$ ) or less after saturation with water, and 
6. Provide permeability of less than $2 \times 10^{-7}$ darcy $\left(2 \times 10^{-19} \mathrm{~m}^{2}\right)$ in the DRZ and the interface between the seal structure and the host rock.

\subsubsection{Water-Bearing Zone Seals}

The water-bearing zone sealing subsystem separates the Culebra and Magenta aquifers. Components consist of seal structures, swelling clay, and grout placed in the DRZ at seal locations. The components separate the aquifers by containing the swelling clay, which provides resistance to flow.

The water-bearing zone components are located in the Tamarisk Member between the Magenta Dolomite Member and the Culebra Dolomite Member (see Figure 4-1).

Preliminary criteria from the DRD for the water-bearing zone seals (Bailey et al., 1992a) are:

1. Groundwater flow between aquifers to be permanently separated.

2. Withstand calculated loads from lithostatic and shaft fill. Contain swelling clay material loads.

3. Barrier to fluid flow equivalent to permeability $2 \times 10^{-7}$ darcy $\left(2 \times 10^{-19} \mathrm{~m}^{2}\right.$.)

4. Exhibit swelling clay permeability of $1 \times 10^{-7}$ darcy $\left(1 \times 10^{-19} \mathrm{~m}^{2}\right)$ after saturation with water.

5. Grouting will achieve a permeability in the DRZ and interface between the seal structure and host rock equivalent to $2 \times 10^{-7}$ darcy $\left(2 \times 10^{-19} \mathrm{~m}^{2}\right)$.

\subsubsection{Near-Surface Shaft Seals}

Near-surface seals are placed as final cover to the shaft after all other components of the shaft sealing systems and shaft-filling material have been emplaced. They are protective covers on the top of the shaft and for that part of the shaft immediately below ground surface level. The near-surface shaft seals present markers and keep surface water out of the shaft. The nearsurface portion of the shaft is filled with earthen material. The near-surface sealing components are located at the top of each of the four shafts (see Figure 4-1). 
Preliminary criteria from the DRD for the near-surface shaft seals (Bailey et al., 1992a) are:

1. Cap, fill, and marker will meet State of New Mexico regulations,

2. Cap and marker per applicable rules and regulations, and

3. Fili shaft per applicable rules and regulations for abandonment.

\subsection{Reference Design/Materials}

The short-term sealing materials identified in the reference design are bentonite and concrete (Nowak et al., 1990). The long-term sealing materials are reconsolidated crushed salt and compressed-salt blocks placed at various elevations in the shaft from the repository level up to the top of the Salado Formation. The short-term seal consists of a bentonite layer sandwiched between two confining concrete plugs. The short-term seal provides structural support to the long-term salt seal and limits groundwater flow into the crushed salt during the short-term period. The primary requirement of the upper shaft subsystem is to limit water/brine inflow into the lower-seal subsystem during the short-term period. The reference design consists of three short-term seals in the lower subsystem, three in the upper subsystem, and one short-term seal between the main aquifers.

\subsubsection{Bentonite}

Bentonite is the main sealing material for the short-term reference shaft seals. The use of bentonite as a seal material in radioactive waste disposal has been studied in Sweden, Canada, Great Britain, Germany, and the United States (e.g., Pusch, 1979, 1982; Pusch et al., 1987; Boisson, 1989; and Gray et al., 1984).

Bentonite is the term for montmorillonite-rich clay formed by devitrification of the natural glass component of volcanic ash deposited in prehistoric lakes (Pusch, 1979; 1982). In the United States, high-quality bentonite can be obtained from deposits in Wyoming and South Dakota. Studies have been performed in Sweden using commercial bentonite powder (Volclay MX-80) to produce samples and blocks of highly compacted clay powder. Pressures in the range of 50 to $100 \mathrm{MPa}$ have been used for compaction of blocks with densities from 2 to 2.3 $\mathrm{g} / \mathrm{cm}^{3}$ (10 percent water content). 
When water contacts an unrestrained, partially water-saturated, compacted bentonite body, the bentonite will begin to swell to several times its original volume. If the bentonite is restrained, however, the bentonite will develop considerable swelling pressure. The water uptake proceeds until equilibrium is reached at which time the swelling pressure reaches a maximum value. The swelling pressure for bentonite depends on the dry bulk density and the salinity of the water and varies from $0.5 \mathrm{MPa}$ to $50 \mathrm{MPa}$. Empirical formulae which define the relationship between bulk density and swelling pressure are given by Pusch (1980) and Gray et al. (1984). The proposed emplaced density of bentonite for the reference design seals is 1.8 to $2.05 \mathrm{~g} / \mathrm{cm}^{3}$.

The very low permeability of bentonite results in an essential barrier to the flow of water. The permeability of water-saturated bentonite varies inversely with its bulk density; permeability coefficients decrease from $1 \times 10^{-12}$ to $1 \times 10^{-14} \mathrm{~m} / \mathrm{sec}$ as the density increases from 1.1 to 2.2 $\mathrm{g} / \mathrm{cm}^{3}$ (Pusch, 1980). Permeability of bentonite to brine is about an order of magnitude higher than for fresh water.

Field tests of bentonite plugs up to 1-m-diameter were carried out in Sweden (Pusch et al., 1987). Results obtained from the Swedish tests confirmed the sealing properties of bentonite. Review of the Swedish results, however, prompted some points of concern regarding the use of bentonite in the WIPP shafts.

1. Construction of a bentonite seal in a 20 -ft-diameter shaft $(6 \mathrm{~m})$ at WIPP to a density of about $2 \mathrm{~g} / \mathrm{cm}^{3}$ may not be as achievable as in the 1 -m-diameter Swedish tests. Yet, the swelling pressure depends on the emplaced density of the seal mass.

2. The Swedish tests showed significant nonuniformity in the distribution of water content. Even more nonuniformity can be expected in larger WIPP shafts. A nonuniform distribution of water will prevent a uniform build-up of swelling pressure.

3. The development of swelling pressure in the Swedish test was relatively slow. The recorded swelling pressures during the 12-month test ranged from 0 to a maximum of $2.8 \mathrm{MPa}$. Until the bentonite swelling pressure becomes greater than the hydrostatic brine pressure at the seal level, the brine could bypass the seal.

4. The bentonite swelling pressures were monitored for only 12 months so information is not available to show that swelling pressures will develop to magnitudes in excess of the brine pressure which is required to prevent the vertical migration of 
water/brine under hydrostatic pressure in the WIPP shafts.

Despite these concerns, the properties and behavior of bentonite have been studied and tested by many researchers who have concluded that bentonite should be considered as a sealing element for nuclear waste repositories. Bentonite is a durable material and is not expected to deteriorate in the WIPP environment. As already mentioned, the maximum recorded swelling pressure was $50 \mathrm{MPa}$ in laboratory tests. The recorded swelling pressures during the Swedish test were surprisingly low and may be because the water distribution was nonuniform. In order to prevent water-brine migration along the interface with the host rock, the bentonite swelling pressure must exceed the water-brine pressure. The DRD specifies that seals must be designed to include a safety factor of at least 1.1. The brine pressures shown in Table 4-1 indicate that in the iswer-sealing subsystem, a bentonite swelling pressure of $2.8 \mathrm{MPa}$ would not meet the DRD requirement.

Construction of a full cross-section shaft seal from bentonite will require the manufacturing of high-density bentonite blocks and positioning them in the shaft opening in order to obtain the high, overall emplacement density of about $2 \mathrm{gm} / \mathrm{cm}^{3}$. While these operations will probably be performed with some difficulties, the manufacturing costs for the bentonite blocks will be a significant expense. Two concrete confining components are also required: one above and one below the bentonite layer.

Bentonite can also be used in a circumferential ring rather than a full cross section. A bentonite ring is a confined annular strip of bentonite placed between a concrete component and the shaft wall. The bentonite seal ring has the following advantages because of its reduced size and geometry in comparison with a bentonite layer:

- Uniformity in the emplaced bentonite density,

- Better uniformity in the distribution of absorbed water,

- Better uniformity and higher magnitude of the swelling pressures,

- Less bentonite material (lower cost), and

- Only one concrete seal structure is required $\mathrm{p}$ s bentonite seal (lower cost).

The disadvantages of the bentonite seal ring are as follows: 
Table 4-1. Brine Pressures at Various Depths in Shafts.

\begin{tabular}{|c|c|c|c|c|c|}
\hline & $\begin{array}{c}\text { Brine } \\
\text { Density } \\
\left(\mathrm{g} / \mathrm{cm}^{3}\right)\end{array}$ & $\begin{array}{l}\text { Hydrostatic } \\
\text { Head } \\
\text { (ft) }\end{array}$ & $\begin{array}{l}\text { Brine } \\
\text { Pressure } \\
\text { (psi) }\end{array}$ & $\begin{array}{l}\text { Required } \\
\text { Seal } \\
\text { Pressure }^{(a)} \\
\text { (psi) }\end{array}$ & $\begin{array}{c}\text { Lithostatic } \\
\text { Stress } \\
\text { (psi) }\end{array}$ \\
\hline $\begin{array}{l}\text { Top of Salado } \\
\text { Formation } 851 \mathrm{ft}\end{array}$ & 1.16 & 492 & 247 & 272 & 922 \\
\hline $\begin{array}{l}\text { Top Seal Barrier } \\
\text { Salado Formation } \\
950 \mathrm{ft}\end{array}$ & 1.18 & 591 & 302 & 332 & 1,029 \\
\hline Seal at $1,500 \mathrm{ft}$ & 1.19 & 1,141 & 588 & 647 & 1,625 \\
\hline Seal at $1,700 \mathrm{ft}$ & 1.20 & 1,341 & 697 & 767 & 1,842 \\
\hline Seal at $1,800 \mathrm{ft}$ & 1.20 & 1,441 & 749 & 824 & 1,950 \\
\hline Seal at $1,900 \mathrm{ft}$ & 1.20 & 1,541 & 801 & 881 & 2,059 \\
\hline $\begin{array}{l}\text { (a) The required } \\
1992 \mathrm{a}) \text {. }\end{array}$ & I press & is 1.1 time & brine & sure (Ba & \\
\hline
\end{tabular}

- Bentonite seal rings have not been built and subjected to full-scale industrial tests,

- The adequacy of bentonite performance as a seal material for WIPP shafts has not been established,

- An interaction with water $\mathrm{c}$. brine is necessary to develop swelling pressure,

- The seal ring configuration at the interface surfaces is larger than with the bentonite layer system, ind

- Only the concrete component of the bentonite seal ring provides the cross-sectional seal.

A bentonite ring is expected to perform equal to or better at the circumference of the seal than a layer of bentonite, and the cost of the bentonite ring will be considerably lower. 


\subsubsection{Crushed Salt}

Crushed salt is a primary shaft seal material because it is compatible with the host rock and expected to consolidate into a low-permeability mass comparable to the intact salt as a result of the creep closure of the surrounding rock mass. Crushed salt has been shown to consolidate relatively quickly when subjected to a hydrostatic stress (e.g., Holcomb and Hannum, 1982; Pfeifle and Senseny, 1985; Stroup and Senseny, 1987; and Holcomb and Zeuch, 1988). It is also readily available from the mining operations. Adding bentonite may be a way to improve the properties of pure crushed salt, as bentonite further reduces the permeability (e.g., Brodsky and Pfeifle, 1992a; 1992b) and increases its radionuclide absorbing ability.

A barrier from crushed salt can be created by placing and compacting the salt in the shaft opening and confining it with concrete plugs (short-term seals). Numerous studies and laboratory tests have been performed on crushed salt and its application as a long-term seal for the WIPP Project. As a result of these studies, it has been concluded that crushed salt will achieve the required permeability of $1 \times 10^{-8}$ darcy $\left(1 \times 10^{-20} \mathrm{~m}^{2}\right)$ when it is reconsolidated to 95 percent of intact salt density. In order to satisfy the sealing criteria within 100 years, the crushed salt must reconsolidate to at least 95 percent of intact salt density. The critical items for the consolidation process are:

- Initial compacted density of the crushed salt (start at 80 to 85 percent density), and

- Sufficient closure to achieve 95 percent density at 100 years.

The specified compacted density of crushed salt in the DRD is 80 percent of the intact WIPP host rock density. Such density is obtainable for laboratory samples and salt blocks fabricated from crushed salt; however, it may not be possible to achieve it throughout a shaft opening several hundred feet long. The density of emplaced backfills in mine openings is generally 55 percent to 70 percent (Van Sambeek, 1992).

The creep-closure rate for shaft openings in the Salado Formation is discussed in Section 2. In particular, Figure 2-1 shows volumetric strains for various depths in the shafts assuming a 50-year-old shaft at the time of sealing. Figure 2-1 does not include the effect of back stresses on slowing the consolidation. With an 80 percent installed fractional density, the required consolidation to 95 percent (15 percent volumetric strain) within 100 years would only occur up to the 2,000-ft-level depth. Further, based on Figure 2-1, it can be expected that reconsolidation from an initial 85 percent to 95 percent fractional density (10 percent voiumetric strain) will be 
reached within 100 years only to depths of about $1,800 \mathrm{ft}$ and below. In order to achieve an 85 percent fractional density during the placing of crushed salt in the shaft openings, a special method of compaction or preconsolidation will need to be developed. It must also be kept in mind that the negative effect of even small back stresses has not been considered in the estimates of consolidation. The final length of the long-term seal within 100 years may be significantly reduced if back stresses develop (e.g., Sjaardema and Krieg, 1987).

The cost of the crushed-salt material will be insignificant compared to the costs of precompacting the crushed salt in the shaft opening to achieve the required density. Direct use of crushed salt without precompaction for the long-term seal is not considered to be feasible if a substantial length of the emplaced-salt seal must be reconsolidated in the 100-year time frame (see Section 2 1.1; Figure 2-1).

\subsubsection{Compressed-Salt Blocks}

Compressed-salt blocks represent a precompacted form of "crushed" salt. Compressing crushed salt into blocks yields a material with density and properties somewhere between crushed salt and the quarried-salt blocks, which will be described later. Experience in the Small-Scale Seal Performance Tests (SSSPT) at WIPP shows that compressed-salt blocks can be manufactured and installed to overall fractional densities of 83 to 84 percent (Torres et al., 1992). In order to obtain a desired fractional block density over 90 percent, a special manufacturing method must be developed. A crushed-salt mortar will be needed to reduce the voids between adjacent compressed-salt blocks.

The main advantage of using compressed-salt blocks is the possibility to achieve a higher initial overall seal density compared to compacted crushed salt. As was described for crushed salt, obtaining an overall fractional density of 85 percent is critical to obtaining a seal density of 95 percent within 100 years. At present, only limited data and information are available on the mar dfacturing method and physical properties of such salt blocks. The required fractional density of individual compressed-salt blsiks is greater than 90 percent considering a 10 percent mortar volume. Compressed-salt blocks provide the following advantages over quarried-salt blocks (which will be described later):

- Fabrication and storage of blocks can be on the surface and in one place, 
- Costs for manufacturing and handling compressed blocks will be lower than for quarrying blocks,

- Number of rejected blocks may be smaller, and

- Manufacturing tolerances can be tighter and imperfections will be smaller than those obtained by quarrying.

The density of compressed-salt blocks will not match that of the quarried block. However, if the fractional density of individual blocks can be kept above 90 percent, compressed-salt blocks should be seriously considered. Based on a 90 percent overall density of compressed-salt blocks and creep closure (see Figure 2-1), the reconsolidation process could reach 1,700-ft depth in 100 years, creating a $400-\mathrm{ft}-$ long seal barrier.

It is anticipated that the cost of manufacturing crushed-salt blocks will be lower than quarrying salt blocks, but will probably be higher than for compacting crushed salt in the shafts.

\subsubsection{Concrete}

Concrete has an important role in the WIPP shaft seals because of its characteristic rapid development of structural properties. Concrete can be designed to suit specific performance requirements of the WIPP environments. Properties can be changed by adjusting the mix proportions and ingredients - chemical, phase composition, and particle characteristics of the cementitious binder; "inert" components; coarse and fine aggregate; chemical and other admixtures; soluble salts; and water - and the way the concrete is batched, mixed, emplaced, and cured. A large data base and extensive experience are available in the form of American Concrete Institute codes, standards, and special publications. The technology for use of concrete is well established for underground uses in the oil, gas, and mining industries. Additionally, a number of methods have been developed for nondestructive, in situ evaluation of concrete properties. Some shortcomings or uncertainties for concrete are its geochemical compatibility in terms of alterations and phase stability in the presence of high-ionic, high-magnesium brines, interface problems at the contact between the concrete and host rock, and large-volume emplacement concerns. Some of these concerns have been addressed in the concrete formulations contained in the DBD (Bailey et al., 1992b).

The ingredients for concrete are generally abundant and inexpensive. The concrete elements of the shaft seals can be constructed with the industrial codes and standards in the U.S. Some 
types of concrete have been known to last for thousands of years; the Portland cement concretes have been used throughout the world for about 200 years with good results. A large number of contractors are also available for construction/emplacement.

Discussions of the WIPP shaft sealing system require that a distinction be made between static abutments and the sealing elements. The principal functions of a concrete seal structure are to confine other sealing materials (bentonite, chemical seal ring, bitumen, preconsolidated crushed salt, or salt blocks) and to provide resistance to gas flow. As a redundant function, the concrete seal structure provides resistance to groundwater flow. Assuming that these functions are adequately satisfied, the dimensions of a concrete seal structure are dictated by structural considerations. The concrete seal structure must have sufficient structural integrity, be sufficiently impermeable to liquids and gases, and have a corrosion resistance over the duration of the short-term period. During construction of massive concrete seal structures, the heat generated from the exothermic hydration reaction can raise the temperature of the concrete to high levels (Van Sambeek, 1987). This will cause thermal cracking during cooling of the mass and lead to permanent damage. The high temperature may negatively affect other sealing materials and increase the creep closure of the contiguous salt rock. The subject of detrimental temperature effects on the concrete seal structure and sealing materials should be addressed in a separate study (e.g., inspecting the results of large monolith constructions at Weeks Island, Louisiana).

Concrete structures will be exposed to the following loads:

- Vertical pressure exerted by swelling bentonite,

- Weight of the plug itself,

- Vertical pressure exerted by the weight of overlying fill,

- Lateral rock pressures,

- Brine pressure, and

- Pressure from gases generated in the repository.

For the reference design, it was assumed that the length of a concrete plug should be greater than the shaft diameter and not smaller than $33 \mathrm{ft}(10 \mathrm{~m})$. The assumed shape is a truncated cone to resist vertical pressures. 


\subsubsection{Alternative Seal Materials}

Materials other than those proposed for the reference shaft seals have widespread sealing applications in construction and industry. In the mining industry, asphalt sealing systems and the Dow Chemical Seal Ring have gained wide acceptance. Asphalt has been used for about 50 years and has successfully sealed out water inflows at high hydrostatic pressures. The Dow Chemical Seal Ring has been used for 25 years to seal off potential water inflows at hydrostatic pressures up to 1,370 psi (see Table 4-2). Other sealing materials are finding increasing usage in building maintenance and underground construction. Transportation tunnels and their ventilation shafts are waterproofed by materials such as epoxy adhesives, elastomeric sealants, and high-density polyethylent (HDPE) membranes, the latter particularly as a gas-tight tunnel lining membrane. These other materials appear to have restricted potential as WIPP shaft sealing system materials. The materials under consideration in this study are asphalt, chemicaland bentonite-seal rings, and quarried-salt blocks.

Table 4-2. Dow Chemical Seal Ring Installation Locations and Hydraulic Pressure Resisted

\begin{tabular}{|c|c|c|c|}
\hline Shaft & $\begin{array}{c}\text { Date } \\
\text { Installed }\end{array}$ & $\begin{array}{l}\text { Resisted } \\
\text { Pressure }\end{array}$ & $\underline{\text { Reference }}$ \\
\hline $\begin{array}{l}\text { Alwinsal No. 1, } \\
\text { Saskatchewan }\end{array}$ & 1967 & $1,040 \mathrm{psi}$ & Storck, 1968 \\
\hline $\begin{array}{l}\text { Alwinsal No. 2, } \\
\text { Saskatchewan }\end{array}$ & 1974 & $1,080 \mathrm{psi}$ & $\begin{array}{l}\text { Potash Corporation } \\
\text { of Saskatchewan }\end{array}$ \\
\hline $\begin{array}{l}\text { Rockenville No. } 1 \text {, } \\
\text { Saskatchewan }\end{array}$ & 1968 & $1,200 \mathrm{psi}$ & Pence et al., 1971 \\
\hline $\begin{array}{l}\text { Rockeinville No. } 2 \text {, } \\
\text { Saskatchewan }\end{array}$ & 1969 & $1,200 \mathrm{psi}$ & Pence et al., 1971 \\
\hline $\begin{array}{l}\text { Cominco No. 2, } \\
\text { Saskatchewan }\end{array}$ & 1982 & $1,100 \mathrm{psi}$ & \\
\hline $\begin{array}{l}\text { Dennison Mines No. } 1 \\
\text { New Brunswich }\end{array}$ & 1983 & $1,000 \mathrm{psi}$ & \\
\hline Boulby, England & 1971 & $1,370 \mathrm{psi}$ & Cleasby et al., 1975 \\
\hline
\end{tabular}




\subsubsection{ASPHALT}

In Europe, asphalt is favored for waterproofing mining shafts that are subject to subsequent movement (subsidence). In these applications, the annular gap between the shaft liner and the shaft wall is filled with asphalt to provide (1) water tightness of the shaft liner, (2) an interface seal between the liner and the aquiclude rock to prevent downward leakage, and (3) to absorb the effects of vertical and horizontal rock movement caused by subsidence. The experience gained in sealing mine shaft linings is applicable to sealing nuclear waste repositories. For the WIPP Project, asphalt can be applied as a short-term sealing component in all four shafts. In order to prevent a seal failure due to loss of sealant by seepage into the rock mass, the asphalt must be contained by a leak-tight liner and aquiclude rock (such as the Salado formation). Furthermore, the asphalt seal must be able to maintain a pressure greater than the water pressure; otherwise, the asphalt will be forced out by the water pressure resulting in leakage.

At temperatures expected in the shafts, asphalt (bitumen) is a viscoelastic material that is both water-insoluble and chemically stable in solutions of chlorides, sulfates, and nitrates, as well as halite and potash brine. The asphalt used as a seal in shafts is produced by mixing bitumen at high temperatures with rock dust filler or aggregates which are neither soluble nor expandable in water. The filler material is used to obtain the desired specific gravity to meet the sealing requirement. Voids in the asphalt mixture between rock particles are completely filled with bitumen due to the high bitumen content in the mixture. The specific gravity of asphalt is greater than that of water or brine, hence for any given vertical interval, the pressure of the asphalt column will be greater than the respective hydrostatic pressure of the formation water. Consequently, the asphalt column forms an impervious barrier which will not allow water or brine to penetrate or infiltrate through the asphalt itself nor through the interface between the contiguous rock and the asphalt mass, provided the asphalt column is approximately equal in height to the water or brine column.

A key characteristic of asphalt is its low viscosity, enabling it to penetrate into the fissures and crevices of the DRZ in the contiguous rock and to displace the water. The depth of penetration dependents on:

- the width of fissures,

- viscosity of bitumen/asphalt,

- pressure height of the asphalt column, and 
- time for penetration.

Oellers (1983) presents a study on the penetration depth of bitumen in relation to the type (viscosity) of bitumen and penetration time. The analysis indicates that after 75 years and at a column height of $170 \mathrm{~m}(560 \mathrm{ft})$, bitumen B200 will penetrate up to $50 \mathrm{~m}(165 \mathrm{ft})$ and bitumen $\mathrm{B} 80$ up to $15 \mathrm{~m}(50 \mathrm{ft})$ into a $1-\mathrm{mm}$-wide fissure. The depth of asphalt penetration is expected to be less than that for bitumen because of the filler material in asphalt.

Because asphalt is a mixture of bitumen and filler particles, the filler particles will tend to settle in the bitumen mass as time passes. "ettling results in a lower specific gravity in the upper portion of the asphalt column and a higher specific gravity in the lower portion. Studies were made to determine the sinking rate of filler particles (Kerkhoven, 1959; Oellers, 1983) in a bitumen mass. The rate of settling of particles (about $4 \mathrm{~m}$ in 100 years) is considered acceptable for the WIPP sealing system requirements. An example (Kerkhoven, 1959; Oellers, 1983) of sedimentation behavior of an asphalt mixture $\left(\rho_{A}=1.3 \mathrm{~g} / \mathrm{cm}^{3}\right)$ with bitumen B300 (low viscosity) is that after 75 years of settling, an asphalt density greater than $1.27 \mathrm{~g} / \mathrm{cm}^{3}$ was sustained to within $6 \mathrm{~m}$ from the top of the asphalt column.

The asphalt column must be confined at the bottom by a concrete structure. The height of the asphalt column will diminish with time because of asphalt losses by penetration into the contiguous rock. To avoid topping the asphalt column from the surface and to compensate for the penetration losses, an additional length of asphalt column can be provided. The length of the additional column can be evaluated from the rock condition and type of bitumen used. A 5-ft layer of fine sand and 15- $\mathrm{ft}$ layer of sand-asphalt barrier can be placed ai the bottom of the asphalt column to prevent escape of asphalt through the interface between the concrete plugs and the shaft wall (Oellers and Sitz, 1985).

\subsubsection{DOW CHEMICAL SEAL RING}

The Dow Chemical Seal Ring was developed in the U.S. and Canada to provide a fluid-tight barrier in boreholes and shafts. The seal ring may have application as short-term seals in the lower- and upper-shaft sealing subsystems at the WIPP. The Dow Chemical seal is normally applied as a narrow annular band, approximately $2 \mathrm{~m}$ in height at the interface between an aquiclude rock and the outside surface of the shaft liner. The sealing properties result from the swelling pressure of the chemical seal material. Chemical seal rings are widely used together with watertight liners in shafts; example potash and salt mines are listed in Table 4-2. Chemical seal rings were installed in the WIPP shafts in 1981. Thus, at the end of the waste emplacement 
phase (35 years), chemical seal rings will have been in place at least 45 years and can be examined in situ to evaluate its durability under WIPP conditions. Currently, chemical seals are being installed in the two Markel Isolation Bulkheads for the Strategic Petroleum Reserve at Weeks Island, Louisiana. The seal rings have been used successfully for about 25 years. In two instances, some repressurization was performed to obtain a satisfactory seal (Storck, 1968, and Cleasby et al., 1975). The main purpose of the repressurization was to initiate the swelling process.

The chemical seal ring is an elastic, polymeric material. It can be mixed and placed as a slurry that sets and cures into a nonpermeable, rubber-like material. The engineering properties of the cured polymer are given in Table 4-3. This polymeric compound increases its volume

(swells) when contacted by water and maintains its integrity as a sealing material in its swollen state. In confined conditions, the swelling properties pressurize the state of the seal. This compound is sufficiently pliable to accommodate any expansion or contraction of a confining concrete plug.

As stated, the chemical seal ring is placed as a slurry of mixed powdered polymer. The initial viscosity of the slurry is very low (approximately 4 poises). The setting of a chemical ring is controlled by the addition of a catalyst to the slurry during mixing. The seal ring material is considered to be set when the viscosity reaches 10,000 poises.

Penetration of the chemical seal ring into the fissures of the contiguous rock has not been investigated. A low initial viscosity allows some penetration into the rock fissure before the slurry sets. Once set, no further penetration by the rubbery ring material is possible. The seal can be pressurized by cementitious grout after the slurry has set (Cleasby et al., 1975).

According to manufacturer's literature (Dowell Division of the Dow Company), laboratory tests were made of the development of swelling pressure in a confined chemical seal without water. The swelling pressure recorded 80 lays after setting was 220 psi. Field measurements of Dow Chemical seal show that the pressure exerted against a shaft liner after setup is in the range of 90 to $150 \mathrm{psi}$. The swelling pressure in rigidly restrained tests in the laboratory with optimum water exposure reaches 4,000 to $5,000 \mathrm{psi}$. The swelling pressure depends on the tightness of the confinement, amount of the entrapped air in the seal mass, and the amount of water available. 
Table 4-3. Properties of Dowell Chemical Seal Ring Formulations (Pence et al., 1971).

\begin{tabular}{|c|c|c|c|c|}
\hline Property & $\begin{array}{l}\text { Thickness, } \\
\text { Inches }\end{array}$ & $\begin{array}{l}\text { ASTM } \\
\text { Method }\end{array}$ & 201 System & 300 System \\
\hline Tensile Strength, Ultimate, psi & $1 / 8$ & D412 & 61 & 60 \\
\hline Tensile Strength, Ultimate, psi & $1 / 4$ & D412 & 80 & 56 \\
\hline Elongation, Ultimate, percent & $1 / 8$ & D412 & 118 & 330 \\
\hline Elongation, Ultimate, percent & $1 / 4$ & D412 & 137 & 335 \\
\hline Secant Modulus at $2 \%$ Elongation, psi & $1 / 4$ & D638 & 151 & 33 \\
\hline Shear Strength, psi of Shear Area & $1 / 2$ & D732 & 192 & 58 \\
\hline Tear Resistance, lbs/in of Thickness & $1 / 8$ & D1004 & 13.1 & 7.8 \\
\hline Tear Resistance, lbs/in of Thickness & $1 / 2$ & D1004 & 14.7 & 7.1 \\
\hline Hardness, Durometer A & $1 / 2$ & D2240 & 30 & 10 \\
\hline Thermal Conductivity, BTU in $/ \mathrm{hr}^{\circ} \mathrm{F} \mathrm{ft}^{2}$ & 1 & $\begin{array}{l}\text { Dow Heat } \\
\text { Flow Meter } \\
\text { Method } \\
\text { (Modified) }\end{array}$ & 3.3 & 2.0 \\
\hline $\begin{array}{c}\text { Compressive Strength, psi at: } \\
5 \% \text { Deformation } \\
10 \% \text { Deformation } \\
25 \% \text { Deformation }\end{array}$ & $\begin{array}{l}1 \\
1 \\
1\end{array}$ & $\begin{array}{l}\text { D695 } \\
\text { D695 } \\
\text { D695 }\end{array}$ & $\begin{array}{r}7.3 \\
15.0 \\
44.0\end{array}$ & $\begin{array}{l}1.3 \\
2.7 \\
8.0\end{array}$ \\
\hline Compressive Modulus, psi & 1 & D695 & 146 & 27 \\
\hline Resistivity, ohm-cm & $1 / 4$ & $\mathrm{D} 257$ & $2.7 \times 10^{7}$ & $5.2 \times 10^{7}$ \\
\hline Compressibility, in/in/psi & - & - & - & $7.02 \times 10^{-6}$ \\
\hline $\begin{aligned} & \text { Density, } \mathrm{gra} / \mathrm{cm}^{3} \\
& \mathrm{lbs} / \mathrm{gal} \\
& \mathrm{lbs} / \mathrm{cu} \mathrm{ft}\end{aligned}$ & $\begin{array}{l}- \\
- \\
-\end{array}$ & $\begin{array}{l}- \\
-\end{array}$ & $\begin{array}{l}1.367 \\
11.40 \\
85.27\end{array}$ & $\begin{array}{c}1.194 \\
9.96 \\
74.50\end{array}$ \\
\hline
\end{tabular}

The life expectancy of a chemical seal ring is not known; the material is relatively new and there is no method for determining exactly how long it will last. Manufacturers' literature indicates that accelerated tests have been conducted for periods of 90 days to 4 years in concentrated environments of acid, caustic brine, ozone, ammonia, hydrocarbons, and fresh water. In all cases, the chemical seal compound has maintained its integrity and sealing properties without any apparent deterioration.

The disadvantages of the chemical seal ring are that:

1. An interaction with water or brine is necessary to develop a high swelling pressure, 
2. The 100-year longevity of the chemical seal material has not been established, and

3. The chemical seal material is proprietary to Dow Chemical and they may be the only source of data and information.

The advantages of the chemical seal ring are that:

1. The sealing performance of chemical seal rings have been proven up to $1,370 \mathrm{psi}$ (Table 4-2),

2. No failure of a chemical seal ring has been recorded, and

3. Installation of a chemical seal ring is simple and can be accomplished in a relatively short time.

\subsubsection{QUARRIED-SALT BLOCKS}

The principal advantage of using quarried-salt blocks as a form of emplaced salt is that their density is essentially equal to the density of the host rock. The overall densiiy of an assemblage of salt blocks will be less than that of the blocks because of the joints between the blocks and the gap at the shaft wall. A stacked salt block seal will also contain voids because of dimension tolerances and surface and shape imperfections. These voids and joints will be eliminated by brittle and viscoplastic deformation caused by creep closure of the shaft excavation wall, but such deformation will result in partial destruction of the monolithic structure of the salt blocks. Van Sambeek (1988) proposes using salt mortar between quarried blocks and in the gap at the shaft wall. The reconsolidation of the seal barrier will then be reduced to consolidation of the salt mortar. The salt mortar area constitutes 10 to 12 percent of the total cross-sectional seal area in comparison to 100 percent for the crushed-salt seal area. A description of the salt mortar properties is given by Van Sambeek (1988).

Construction of a long-term seal barrier from quarried-salt blocks probably provides the longest and earliest long-term seal. This is because the fractional density of the blocks is equal to that of the host rock and consolidation of the barrier is reduced to consolidation of any crushed-salt mortar only. As a result, the consolidation time for the barrier is significantly reduced.

To calculate whether or not reconsolidation can occur in a 100-year time frame, the following assumptions were made concerning a quarried-salt-block seal: 
- Joints between blocks are $3 / 8$ in wide and are filled with a salt mortar,

- Gap between the salt blocks and the shaft wall is 3 in wide and is mortar-filled,

- Salt mortar has an initial fractional density of 50 percent,

- Horizontal joints are not considered,

- Back pressure slowing the creep closure is not considered,

- Seal installation is in a 50-year-old shaft, and

- Salt blocks are $12 \times 12 \times 12$ in $(0.03$ cubic $\mathrm{m})$.

Based on these assumptions, the emplaced fractional density is nearly 90 percent, but the mortar (with a fractional density of only 50 percent) must still be consolidated to achieve a true, overall 95 percent fractional density. According to the volumetric strains for various depths in a shaft shown in Figure 2-1, reconsolidation of the mortar to 95 percent fractional density will reach approximately the 1,500 -ft depth below the surface within 100 years. This would create a 600 $\mathrm{ft}$-long seal in the lower-shaft seal subsystem.

The advantage of using the quariied-salt blocks is that within 100 years the length of the reconsolidated salt seal barrier will be about twice that of crushed salt. The disadvantages of quarried-salt blocks are:

- Cutting and removing blocks from an in situ location at the WIPP repository horizon and storing them on the surface will be both troublesome and time-consuming,

- Cost of retrieving, shipping, handling, and placing blocks in the shaft can be very significant, and

- The number of rejected blocks could be relatively high.

\subsection{Description of Seal Design Alternatives}

Each of the four shafts will be sealed using four sealing subsystems: a lower-shaft, an upper-shaft, a watci-uearing zone, and a near-surface sealing subsystem. The lower sealing subsystem will consist of: 
- A long-term, emplaced-salt seal,

- A short-term seal above the long-term, emplaced-salt seal,

- Emplaced salt above the short-term seal,

- A short-term seal above the emplaced salt, and

- Plain (unreinforced) concrete above the short-term seal.

Unless an asphalt column is used, the upper sealing subsystem will consist of a short-term seal barrier and a plain concrete fill above the short-term seal and the water-bearing sealing subsystem will consist of a short-term seal barrier. If asphalt is used, the upper and the waterbearing zone subsystems will consist of an asphalt column.

For all arrangements, the near-surface sealing subsystem will consist of earthen fill, a concrete cap at the silaft collar, and a grout curtain around the collar.

\subsubsection{Lower-Shaft Sealing Subsystem}

The lower-shaft seals will be located between the top of the Salado Formation and stations at the repository level (see Sketch SK-7 in Appendix D). At the top of the Salado Formation, a reinforced concrete foundation key has been constructed in each shaft. In the conceptual design, it is assumed that these foundation keys will remain in place but the keys are not considered to be part of the lower-shaft sealing subsystem. The shaft station and the shaft brow will be filled with concrete to approximately 30 to $40 \mathrm{ft}$ above the station level. This concrete plug will serve as a base for the long-term seal barrier. The following levels below the surface are specified for the four WIPP shafts.

$\begin{array}{lccc} & \begin{array}{c}\text { Top of } \\ \text { Salado } \\ \text { Formation }\end{array} & \begin{array}{c}\text { Bottom } \\ \text { Foundation } \\ \text { Key }\end{array} & \begin{array}{c}\text { Shaft } \\ \text { Station } \\ \text { Level }\end{array} \\ \text { Waste Shaft } & 844 \mathrm{ft} . & 900 \mathrm{ft} . & 2,158 \mathrm{ft} . \\ \text { Air Intake Shaft } & 822 \mathrm{ft} . & 903 \mathrm{ft} . & 2,162 \mathrm{ft} . \\ \text { Exhaust Shaft } & 851 \mathrm{ft} . & 907 \mathrm{ft} . & 2,157 \mathrm{ft} . \\ \text { Salt Handling Shaft } & 851 \mathrm{ft} . & 880 \mathrm{ft} . & 2,162 \mathrm{ft} .\end{array}$




\subsubsection{SHORT-TERM SEAL BARRIERS}

Within the Salado formation, all four shafts are unlined. The shaft walls are probably damaged by creep, weathering, and excavation methods, and a disturbed rock zone has already formed (see Section 2.2.1). In order to obtain a tight interface between the seal material and the rock wall, the damaged part of the excavation wall should be removed. At present, it is estimated that the she it radius will have to be incr aased approximately $2 \mathrm{ft}$ at the short-term seal locations.

$\begin{array}{lccc} & \begin{array}{c}\text { Excavated } \\ \text { Radius }\end{array} & \underline{\text { Increase }} & \begin{array}{c}\text { Overexcavated } \\ \text { Radius }\end{array} \\ \text { Waste Shaft } & 10 \mathrm{ft} & 2 \mathrm{ft} . & 12 \mathrm{ft} \\ \text { Air Intake } & 10 \mathrm{ft} & 2 \mathrm{ft} . & 12 \mathrm{ft} \\ \text { Exhaust Shaft } & 7.5 \mathrm{ft} & 2 \mathrm{ft} . & 9.5 \mathrm{ft} \\ \text { Salt Handling Shaft } & 5.9 \mathrm{ft} & 2 \mathrm{ft} . & 7.9 \mathrm{ft}\end{array}$

Two locations for the short-term seal are proposed in the lower shaft seal subsystem. One is placed just above the long-term seal and a second one is in the upper part of the Salado Formation below the existing foundation key. The shaft section between these two short-term barriers will be filled with some form of WIPP salt. The shaft section between the top of the second short-term seal barrier and bottom of the upper shaft sealing subsystem (except the asphalt seal alternative) will be backfilled with plain concrete to provide structural competence to the shaft lining. Locations for the short-term seal barriers will be linked together with the top of the long-term seal barriers. That is, they should be placed at the top of the expected reconsolidation depth of the salt barriers in the 100-year time frame.

\subsection{Bentonite Layer Seal}

The concept for a bentonite layer seal is shown on Sketch SK 8 in Appendix D (concept of this type of seal was taken from Stormont (1988) and Nowak et al. (1990). The seal barrier is comprised of:

- A lower, 33-ft-thick, concrete plug,

- A $13-\mathrm{ft}-$ thick bentonite layer emplaced to about $2.0 \mathrm{~g} / \mathrm{cm}^{3}$ density, and 
- An upper 33-ft-thick concrete plug.

The lower and upper concrete plugs are designed to confine the bentonite disk and to form redundant water-brine seals. Both plugs will be located in salt. The closure generated by creep of the excavation wall will create a tight interface with the concrete, resulting in a positive seal. However, structural competence should be the principal function of a concrete plug. The bentonite layer is emplaced in the shaft after removal of any weathered salt rock within the seal area.

The bentonite plug will be constructed from blocks compacted from air-dried bentonite powder. The assumed size of bentonite block is $12 \times 12 \times 12 \mathrm{in}$. The assumed thickness of the bentonite plug is $13 \mathrm{ft}$. The upper concrete plug will be equipped with water-injecting pipes and a silica sand layer, 3-4 in thick, will be placed between the bentonite layer and upper concrete plug. The silica sand will be composed of screened $0.5-2 \mathrm{~mm}$ particl '; to facilitate effective saturation. The water-injecting pipes can be made of almost any material or they can be just holes in concrete. After completion of the water injection operation, the pipes or holes will be grouted and capped. As the pipes or holes are located above the bentonite layer, they will not constitute a leakage path through the seal barrier. A detail design of the water-injecting arrangement would be part of the design phase. The purpose of the sand layer is to evenly distribute water from injecting pipes into the bentonite mass and to initiate the swelling process. The suggested bulk density of the bentonite blocks is 2.0 to $2.2 \mathrm{~g} / \mathrm{cm}^{3}$ with a 10 percent water content. The average density of the bentonite in the seal is expected to be in the range of 1.95 to $2.0 \mathrm{~g} / \mathrm{cm}^{3}$.

\subsection{Bentonite Seal Ring}

The bentonite seal ring barrier (see Sketch SK-9 in Appendix D) is composed of a concrete plug with a bentonite ring on the outside of the plug. On the top of the seal ring, a thin layer of sand will be placed. The primary function of the plug is structural support; the actual sealing function lies with the bentonite ring. Two locations for bentonite seal rings are proposed: a bottom seal with one bentonite ring and a top seal with two bentonite rings. The concrete plug is assumed to be cylindrically shaped with a bottom key and be either 36 or $57 \mathrm{ft}$ long, depending on the number of bentonite seal rings.

The bentonite seal ring will be constructed from compacted bentonite powder or blocks and will be located between the concrete and the host rock. The assumed size of the bentonite seal ring is $10 \mathrm{ft}$ long (vertically) and 16 in thick. The bentonite seal ring is expected to have an 
average installed density that is slightly higher $\left(2.05 \mathrm{~g} / \mathrm{cm}^{3}\right)$ than that of the bentonite layer seal because it can be easily compacted in a 16-in narrow slot. Similar to the bentonite disk, swelling of bentonite can be initiated with a 2- to 3 -in sand layer and water injection pipes in the upper part of the concrete plug. Again, the weathered salt rock within the seal area would need to be removed.

\subsection{Chemical Seal}

The concept for a chemical seal is adopted from the sealing practice in the salt and potash mining industry. Based on experience in shafts, the recommended size for the chemical seal ring is $7 \mathrm{ft}$ high and 6 in wide. The Dow Chemical seal ring assumed is a No. 300 system for slurry placement mixed with silica flour particles or $3 / 4$ in aggregate. The arrangement for the Dow Chemical seal ring is shown in Sketch SK-10. The concept of this seal, including waterinjecting pipes, is similar to that of the bentonite seal rings.

\subsubsection{LONG-TERM SEAL BARRIERS}

The long-term seal barrier in the lower shaft system will be some form of emplaced WIPP salt: precompacted crushed salt, compressed-salt blocks, or quarried-salt blocks. The use of each of these materials in the long-term seal was discussed in Section 4.3.

\subsubsection{Upper-Shaft Sealing Subsystem}

The upper-shaft sealing subsystem will be located in the Rustler formation and above. The top of the existing reinforced concrete key structure is below the Culebra aquifer. Important depths for the upper-shaft sealing subsystem are: 
Bottom of

Culebra

Aquifer

(ft)

Waste Shaft

Air Intake Shaft

Exhaust Shaft

Salt Handling

Shaft
729

709

736

734
Top of

Top of

Shaft Key

(ft)

834

843.5

841

842.4
Salado

Formation

(ft)

844

822

851

851

\subsubsection{SHORT-TERM SEAL BARRIER}

The principal function of the upper-shaft, short-term barrier is to prevent any water migration from the Rustler Formation into the lower shaft during the short-term period. Performance of this barrier is critical to the whole lower-shaft sealing subsystem. Four types of seal barriers are considered:

- Bentonite layer seal,

- Bentonite seal ring,

- Chemical seal ring, and

- Asphalt column.

In the Rustler formation, the shafts are lined with concrete. Installation of a concrete liner does not need to be made in dry conditions (concrete liners in shafts are sometimes installed with water inflows over $100 \mathrm{~g}$.pm). However, seals must be installed in a dry environment because their effectiveness depends on interaction with water in a fully confined space. Before removing any liner, the region between the bottom of the Culebra and top of the Magenta aquifers must be completely grouted. At the planned seal locations, the shaft liner must be removed and the walls scaled and cleaned in order to obtain a firm interface for the seal barrier. The exact location of the seal barrier will be selected after removal of the concrete liner and a visual inspection of the host rock condition. It is assumed that the shaft excavation radius must be increased along the seal location approximately $2 \mathrm{ft}$. 


$\begin{array}{lrc} & \begin{array}{c}\text { Excavated } \\ \text { Radius }\end{array} & \begin{array}{c}\text { Overexcavated } \\ \text { Radius }\end{array} \\ \text { Waste Shaft } & 11.5 \mathrm{ft} & 13.5 \mathrm{ft} \\ \text { Air Intake Shaft } & 10.2 \mathrm{ft} & 12.2 \mathrm{ft} \\ \text { Exhaust Shaft } & 8.3 \mathrm{ft} & 10.3 \mathrm{ft} \\ \text { Salt Handling Shaft } & 5.9 \mathrm{ft} & 7.9 \mathrm{ft}\end{array}$

\subsection{Bentonite Layer Seal}

The description and data for the bentonite layer barrier for the upper shaft sealing subsystem are the same as those for the lower-shaft sealing subsystem (see Sketch SK-8 in Appendix D). The required bentonite swelling pressure (see Table 4-4) for an upper-shaft seal in the Rustler Formation may be adequate because of the lower brine pressures encountered.

The bentonite layer seal barrier will be located between the following approximate depths:

$\begin{array}{ll}\text { Waste Shaft } & 834-755 \mathrm{ft} \\ \text { Air Intake Shaft } & 844-765 \mathrm{ft} \\ \text { Exhaust Shaft } & 841-762 \mathrm{ft} \\ \text { Salt Handling Shaft } & 842-762 \mathrm{ft}\end{array}$

4.4.2.1.2 Bentonite Seal Ring

A bentonite seal ring in the Rustler Formation would be similar to the top seal barrier in the lower-shaft seal subsystem (see Sketch SK-9 in Appendix D). It would be constructed with two bentonite rings. The seal is located below the Culebra aquifer. The upper bentonite seal ring should face the anhydrite-confining bed. The barriers will be located between the following approximate depths:

$\begin{array}{ll}\text { Waste Shaft } & 729-786 \mathrm{ft} \\ \text { Air Intake Shaft } & 709-766 \mathrm{ft} \\ \text { Exhaust Shaft } & 736-793 \mathrm{ft} \\ \text { Salt Handling Shaft } & 734-791 \mathrm{ft}\end{array}$


Table 4-4. Brine and Rock Pressures Against Seals in the Upper-Shaft Seal System.

\begin{tabular}{lccccc}
\hline & $\begin{array}{c}\text { Depth } \\
(\mathrm{ft})\end{array}$ & $\begin{array}{c}\text { Head } \\
(\mathrm{ft})\end{array}$ & $\begin{array}{c}\text { Brine } \\
\text { Pressure } \\
(\mathrm{psi})\end{array}$ & $\begin{array}{c}\text { Required } \\
\text { Pressure } \\
(\mathrm{psi})\end{array}$ & $\begin{array}{c}\text { Lithostatic } \\
\text { Pressure } \\
(\mathrm{psi})\end{array}$ \\
$\begin{array}{l}\text { Top of Salado } \\
851\end{array}$ & 492 & 247 & 272 & 922 \\
$\begin{array}{l}\text { Rustler Seal } \\
\text { Water-Bearing }\end{array}$ & 770 & 411 & 207 & 227 & 834 \\
$\begin{array}{l}\text { Zone Seal } \\
\text { The }\end{array}$ & 670 & 311 & 156 & 172 & 726
\end{tabular}

(a) Includes 1.1 safety factor specified in DRD (Bailey et al., 1992a).

\subsection{Chemical Seal}

This seal is similar to the top chemical seal ring in the lower shaft seal subsystem (see Sketch SK-10 in Appendix D) and is located at the same depth as the bentonite seal ring. The seal is constructed with two chemical rings.

\subsection{Asphalt Column}

The asphalt seal is placed as a continuous column in the shaft opening. The concrete liner must be removed in the aquiclude section (Salado Formation) and any aquifer formations. The exact locations where the liner should be removed will be decided during construction. Because asphalt's specific gravity is greater than that of water or brine, it creates an overpressure system which prevents downward water/brine migration along the host rock and asphalt interface. The asphalt, which has a low viscosity, will penetrate into fissures and crevices in the contiguous rock and seal the DRZ.

The asphalt seal consists of:

- an asphalt column,

- a sand asphalt seal at the bottom, and

- a lower concrete plug, $50 \mathrm{ft}$ long, with a chemical seal ring. 
The pressure required at the bottom of the asphalt column to prevent water flow is about $315 \mathrm{psi}(2.2 \mathrm{MPa})$. Such a seal requires a $560-\mathrm{ft}$-long asphalt column of $1.3 \mathrm{~g} / \mathrm{cm}^{3}$ density asphalt. An aoditional 100-ft-length is provided to compensate for potential loss of asphalt into the salt DRZ. In order to prevent leakage of asphalt at the bottom of the column, two layers of sand and sand asphalt are installed as an additional seal. The chemical seal ring around the concrete plug is also installed to prevent leakage of asphalt into the lower shaft. The lower concrete plug must be designed to carry the weight of the asphalt column and to withstand the swelling pressure of the chemical seal ring.

Asphalt is insoluble in water and chemicals and does not pose a pollution threat for the aquifer waters. The use of asphalt in European shafts has not created any environmental problems. If asphalt creates a problem for the New Mexico Water Authorities, a lining scheme could be used in which the asphalt would not come into contact with the aquifers.

The asphalt seals will be located between the following depths:

$\begin{array}{lc}\begin{array}{l}\text { Asphalt } \\ \text { Column } \\ (\mathrm{ft})\end{array} & \begin{array}{c}\text { Lower } \\ \text { Concrete } \\ (\mathrm{ft})\end{array} \\ 292-952 & 952-1,002 \\ 297-957 & 957-1,007 \\ 297-957 & 957-1,007 \\ 270-930 & 930-980\end{array}$

\subsubsection{Water-Bearing Zone Sealing Subsystem}

The water-bearing zone sealing subsystem has the function of separating the Culebra and Magenta aquifers. The seal barrier will be located in the Tamarisk Member of the Rustler Formation in the Anhydrite No. 3 bed. The seal barrier will be located between the following depths:

$\begin{array}{ll}\text { Waste Shaft } & 621-705 \mathrm{ft} \\ \text { Air Intake Shaft } & 598-685 \mathrm{ft} \\ \text { Exhaust Shaft } & 627-714 \mathrm{ft} \\ \text { Salt Handling Shaft } & 626-710 \mathrm{ft}\end{array}$


The exact location of the seal will be established after visual inspection of the host rock during construction.

As the seal has to be installed in a dry environment, both aquifers (Magenta and Culebra) should be sealed by grouting before removing the existing shaft liner. To obtain an undisturbed interface between the seal material and rock wall, part of the excavation wall must be removed. It is assumed that the shaft excavation radius will be increased $1.5 \mathrm{ft}$ at the seal barrier location. Four alternatives for the seals are considered: a bentonite layer seal, a bentonite seal ring, a chemical seal ring, and asphalt seal column. The installation of any of these alternatives would be similar to that described in the lower-shaft sealing subsystem.

\subsubsection{Near-Surface Shaft Sealing Subsystem}

The near-surface shaft seal prevents migration of surface water through the interface between the shaft liner and the Santa Rosa and Gatuna Sandstone Formations. Moreover, it should form a protective cover for the shaft. This protective cover should be built in the existing collar structure.

The depths of the existing collars and the Santa Rosa and Gatuna Sandstone Formations are:

$\begin{array}{lcc} & \text { Collar } & \begin{array}{c}\text { Santa Rosa and } \\ \text { Gatuna Sandstone }\end{array} \\ \text { Waste Shaft } & 21 \mathrm{ft} & - \\ \text { Air Intake Shaft } & 16 \mathrm{ft} & - \\ \text { Exhaust Shaft } & 10 \mathrm{ft} & 54 \mathrm{ft} \\ \text { Salt Handling Shaft } & - & 45 \mathrm{ft}\end{array}$

Preventing water migration on the interface can be achieved through cementitious grouting of the interface along the Santa Rosa and Gatuna Sandstone Formations. The protective cover of the shaft will be in the form of a concrete cap located at the surface and built into the existing collar structure. Below the concrete cap, the inside of the shaft will be filled with earthen fill. 


\subsection{Evaluation of Alternatives}

Eight alternative sealing arrangements were considered for the WIPP shafts:

1. Bentonite layer seal and crushed salt (Sketch SK-8 in Appendix D),

2. Bentonite layer seal and quarried-salt blocks (Sketch SK-8 in Appendix D),

3. Bentonite ring seals and crushed salt (Sketch SK-9 in Appendix D),

4. Bentonite ring seals and quarried-salt blocks (Sketch SK-9 in Appendix D),

5. Chemical seal rings and crushed salt (Sketch SK-10 in Appendix D),

6. Chemical seal rings and quarried-salt blocks (Sketch SK-10 in Appendix D),

7. Asphalt seal column and crushed salt (Sketch SK-11 in Appendix D), and

8. Asphalt seal column and quarried-salt blocks (Sketch SK-11 in Áppendix D).

The costs for the alternative sealing arrangements and the expected performance of the sealing materials is described below.

\subsubsection{Cost Evaluation}

Order-of-magnitude capital costs for the four shafts using the eight shaft sealing alternatives are shown below. Further breakdowns of the costs are given in Appendix B.

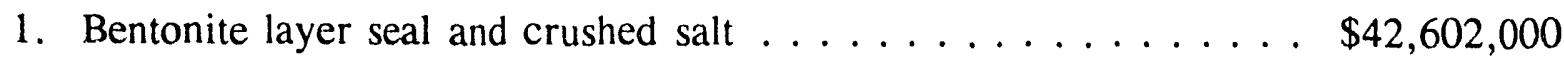

2. Bentonite layer seal and quarried-salt blocks $\ldots \ldots \ldots \ldots \ldots . \$ \$ 69,811,000$

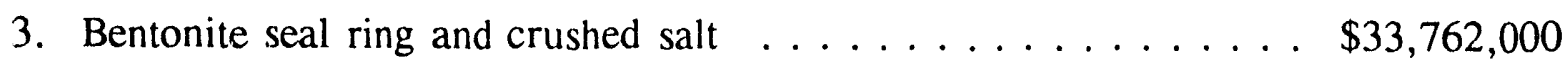

4. Bentonite seal ring and quarried-salt blocks . . . . . . . . . \$60,950,000

5. Chemical seal ring and crushed salt $\ldots \ldots \ldots \ldots \ldots \ldots \ldots 39,132,000$

6. Chemical seal ring and quarried-salt blocks . . . . . . . . \$ \$66,320,000

7. Asphalt column and crushed salt $\ldots \ldots \ldots \ldots \ldots \ldots \ldots$. . . $\$ 46,221,000$

8. Asphalt column and quarried-salt blocks . . . . . . . . . . \$73,394,000 
NOTE: The costs shown are for labor and materials only.

\subsubsection{Material Performance Evaluation}

Each of the eight arrangements of seal components for lower- and upper-shaft sealing subsystems for the WIPP shafts is expected to comply with the preliminary DRD requirements. Specific concerns about selecting the appropriate seal materials are addressed for the short-term and long-term seals in the following subsections.

\subsubsection{LONG-TERM SEALS}

Selection of the long-term seal material ultimately depends on the required length of reconsolidated salt above the shaft station. Three materials are considered, each with a higher emplaced fractional density. Emplacement at a higher density results in shorter reconsolidation times and a longer length of reconsolidated salt. The effective length of the reconsolidated crushed-salt barrier density after 100 years is expected to be about $310 \mathrm{ft}$ for an emplaced fractional density of 85 percent. Quarried-salt blocks can be installed at nearly the same density as intact salt, such that only the salt mortar between blocks requires reconsolidation. The length of the reconsolidated quarried-salt barrier after 100 years is about $610 \mathrm{ft}$ for an emplaced mortar volume of 10 percent. Compressed-salt blocks are similar to quarried blocks, but with a lower block density. The reconsolidated length after 100 years is about $410 \mathrm{ft}$ for blocks with a starting fractional density of 90 percent and a 10 percent salt-mortar volume.

If a 300-ft-length for the long-term salt seal is adequate, then crushed salt emplaced at 85 percent fractional density is the most economical long-term seal material. If the long-term seal barrier must be more than $300 \mathrm{ft}$, then either quarried-salt blocks (600 ft reconsolidated length) or compressed-salt blocks (400 ft reconsoliclated length) must be considered, and a higher cost incurred.

\subsubsection{SHORT-TERM SEALS}

Performance of the short-term barriers is crucial during the first 100 years as the barriers cannot be monitored, modified, tested, or maintained after installation. Three materials (other than concrete) were considered for the short-term seals: bentonite, the Dow Chemical seal, and 
asphalt. The sealing performance of the last two materials has been confirmed through successful applications in mine shafts. Bentonite performance has not been confirmed in mining or similar projects.

The somplexity of the confined bentonite layer seal component results in high material and construction costs. Bentonite- and chemical-seal rings, which use a simpler and more economical structure, provide an attractive sealing arrangement because the reduced volume of sealing material and simpler construction. Both types of ring seals, however, block the flow only at the interface with the shaft wall. Flow at locations other than the interface is blocked by the concrete structures only. An advantage of the Dow Chemical seal ring over the bentonite seal ring is that it has been successfully applied in mine shafts and has withstood water/brine pressures up to $1,300 \mathrm{psi}$. The performance of asphalt as a sealing component has also been proven in mine shafts. There are no known cases of failure of asphalt as a seal component in shafts. Based on this experience, it is unlikely that the asphalt seal, if properly installed, will fail or deteriorate. Asphalt will penetrate into the fissures and openings of the contiguous rock and decrease the permeability of the DRZ during the short-term sealing period. Installation of an asphalt seal column, however, is costly and time-consuming.

\subsection{Conclusion and Recommendations}

The proposed shaft seal alternatives are based on reference design/materials, new material

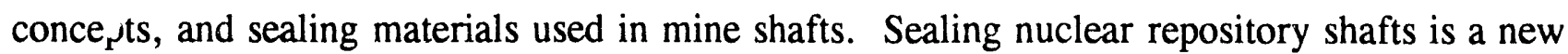
and without-precedent operation. Available information on seal materials developed in laboratories and scientific institutions is not adequate for engineering design. No engineering description of a shaft sealing operation of the required performance is available in the literature. In this alternatives study, additional sealing alternatives are introduced using different, promising sealing materials. Alternatives were considered for long- and short-term seal barriers. At this time, a fully defensible recommendation of any of the presented alternatives cannot be made.

The long-term seal alternatives are crushed salt, compressed-salt blocks, and quarried-salt

blocks. Sealing performance for all three alternatives is based on the same premises. The sealing materials must achieve 95 percent density of the intact salt within 100 years after emplacement. The length of the seal barrier attaining this density depends on the emplaced density of each of the three materials. 
The design criteria (DRD) do not define the required length of the long-term seal barriers. The crushed salt with an emplaced density of 85 percent could form a 300 -ft-long seal barrier in 100 years. During small-scale compaction tests on crushed salt, greater than 85 percent densities have not been achieved. Four considerations related to the length requirement of the long-term seal barrier are:

- Decrease length requirement (less than $300 \mathrm{ft}$ ) for crushed salt,

- Develop a compacting method for emplacing crushed salt in shaft at greater than 85 percent density,

- Develop a method to fabricate compressed-salt blocks to greater than 90 percent density, and

- Use quarried blocks.

For the short-term seal barrier, the following alternatives were considered:

- Bentonite layer with two confining plugs,

- Bentonite seal ring or rings around a concrete plug,

- Chemical seal ring or rings around a concrete plug, and

- Asphalt column in the shaft opening.

The first three alternatives are for the lower and upper sealing subsystem, the fourth one is only for the upper sealing subsystem.

Use of bentonite as a sealing material is promising in the upper sealing subsystem. In order to use bentonite in the lower sealing subsystem, compaction and swelling pressure tests on an industrial scale need to be performed. The difference between a bentonite liyer seal and a bentonite ring seal will be mainly in cost. The bentonite layer seal is a full, cross-section seal, while the bentonite ring seal is an interface (circumferential) seal only.

Chemical seal rings have been used in mine shafts with good results. Since chemical seal rings can develop high swelling pressure, they can be used in both the lower and upper sealing subsystems. Studies on the longevity of the chemical seal material and its interaction with brine water are recommended. 
Asphalt has been used successfully for sealing shaft linings. There are no known cases of failure of asphalt as a seal component. It can be expected that asphalt will be a reliable seal in the upper sealing subsystem including the water-bearing zone. In addition, the penetration of asphalt into the contiguous rock will help seal the fractures in the DRZ. 


\subsection{BOREHOLE SEALS}

The borehole seals portion of the alternatives study was performed by first identifying and ciescribing the purpose and requirements for the borehole seals. The purpose and requirements described in Sections 5.1 and 5.2 were taken from the DRD (Bailey e: al., 1992a).

Secondly, the boreholes requiring sealing (Section 5.3) and sealing strategies (Section 5.4) were identified. Two schemes were evaluated: (1) the DRD borehole sealing scheme, which involves only boreholes located within the facility boundary, and (2) a proposed alternative scheme, which is based on Christensen et al. (1983) borehole classification.

Thirdly, four sealing alternatives, comprising cementitious grout, asphalt and combinations of cementitious grout, crushed salt, and crushed salt/bentonite mix were evaluated. Materials, emplacement methods, and constructibility considerations are discussed in Section 5.6.

Finally, the alternatives are evaluated in terms of their effectiveness and costs in Section 5.7, and discussions and conclusions are give ! in Section 5.8.

\subsection{Purpose}

Boreholes drilled in the vicinity of the repository are potential preferential pathways for groundwater flow and hazardous mixed waste release to the accessible environment. To mitigate this potential, borehole seals will be designed to limit the volume of water that could be introduced via the boreholes to the repository from the overlying water-bearing zones and the amount of contaminated brine that could move up the boreholes to either the surface or the water-bearing zones.

This portion of the seal design alternative study examines and compares four borehole sealing alternatives with respect to seal effectiveness, emplacement techniques, and order-ofmagnitude capital cost for three cases as follows:

Case 1 - Nine boreholes located within the facility boundary as indicated in the Design Requirements Document (DRD); 
Table 5-1. Borehole Sealing Subsystem (from Bailey et al., 1992a)

\section{Functional Requirements \\ SALADO PENETRATING \\ 1. Limit release of waste materials in gaseous medium during the short- term period.}

2. Limit water flow through the boreholes down to the underground area of the repository; limit saturation of consolidating salt in the repository during the short-term period.

3. Prevent excessive release of waste materials from the repository to the accessible environment during the long-term period.

4. Separate the water-bearing aquifers.

5. Provide borehole cap and markers.

WATER-BEARING PENETRATING

1. Separate the water-bearing aquifers.

2. Provide borehole cap and marker.

$$
\text { Performance Criteria }
$$

Constraints/Assumptions

1. Waste release rate from performance assessment. Permeability 2 $\times 10^{-7}$ darcy $\left(2 \times 10^{-19}\right.$ meters squared $)^{(a)}$.

2. Maximum allowable water flow rates 35.3 cubic ft ( 1 cubic meter) per year. Provide flow barrier with an equivalent permeability of $1 \times 10^{-7}$ darcy $\left(1 \times 7^{-19}\right.$ meters squared) or less ${ }^{(a)}$.

3. Waste release rates as a function of time from performance assessment. Permeability $1 \times 10^{-8}$ darcy $\left(10^{-20} \text { meters squared }\right)^{(a)}$.

4. Borehole seals will separate the aquifers in the boreholes between the Culebra and Magenta waterbearing members. These seals' performance will exceed the standards of approved practice permeability $2 \times 10^{-7}$ darcy $^{(a)}$.

5. Borehole seals will meet or exceed applicable regulations ${ }^{(\text {b) }}$.

1. Borehole seals will separate the aquifers in the boreholes between the Culebra and Magenta waterbearing members. These seals' performance will exceed the standards of approved practice $2 \times$ $10^{-7}$ darcy $^{(a)}$.

2. Borehole seals will meet or exceed applicable regulations ${ }^{(\mathrm{h})}$.

NOTE: It is assumed that borehole seals have the same functional requirements as shaft seals.

(a) Nowak et al., 1990

(b) State of New Mexico Minerals and Natural Resource Department 
Case 2 - Twelve boreholes meeting Condition 1 (see Section 5.3); and

Case 3 - Fifteen boreholes meeting Conditions 1 and 2 (see Section 5.3).

\subsection{Requirements for the Borehole Seals}

Prelinninary functional requirements and performance criteria for Salado penetrating and water-bearing penetrating borehole seals are provided in the DRD (Bailey et al., 1992a) and reproduced here in Table 5-1. According to the DRD, the water-bearing penetrating borehole seals (WBBS) separate the water-bearing aquifers and a borehole cap and marker are to be provided. The DRD gives the Salado-penetrating borehole seals (SBS) the following short-term and long-term functional requirements.

For the short term, the Salado-penetrating borehole seals shall:

- limit release of waste material in gaseous form,

- limit water flow through the boreholes down to the underground area of the repository, and

- limit saturation of consolidating salt in the repository.

During the long-term period, the Salado-penetrating borehole seals shall prevent excessive release of waste material from the repository to the accessible environment.

An assumption explicitly made in the DRD is that borehole seals have the same functional requirements as shaft seals. Further definition of borehole criteria is planned by Sandia National Laboratories and it is anticipated that modifications will be made because of different functions and locations of boreholes. Note-worthy differences between shafts and boreholes that have implications on sealing include:

- Location - Unlike the boreholes, the shafts are a direct link between the repository and the upper aquifers,

- Size - According to Daemen et al. (1983), there would be a much greater generation of heat of hydration for cement-based plugs in shafts than in boreholes, 


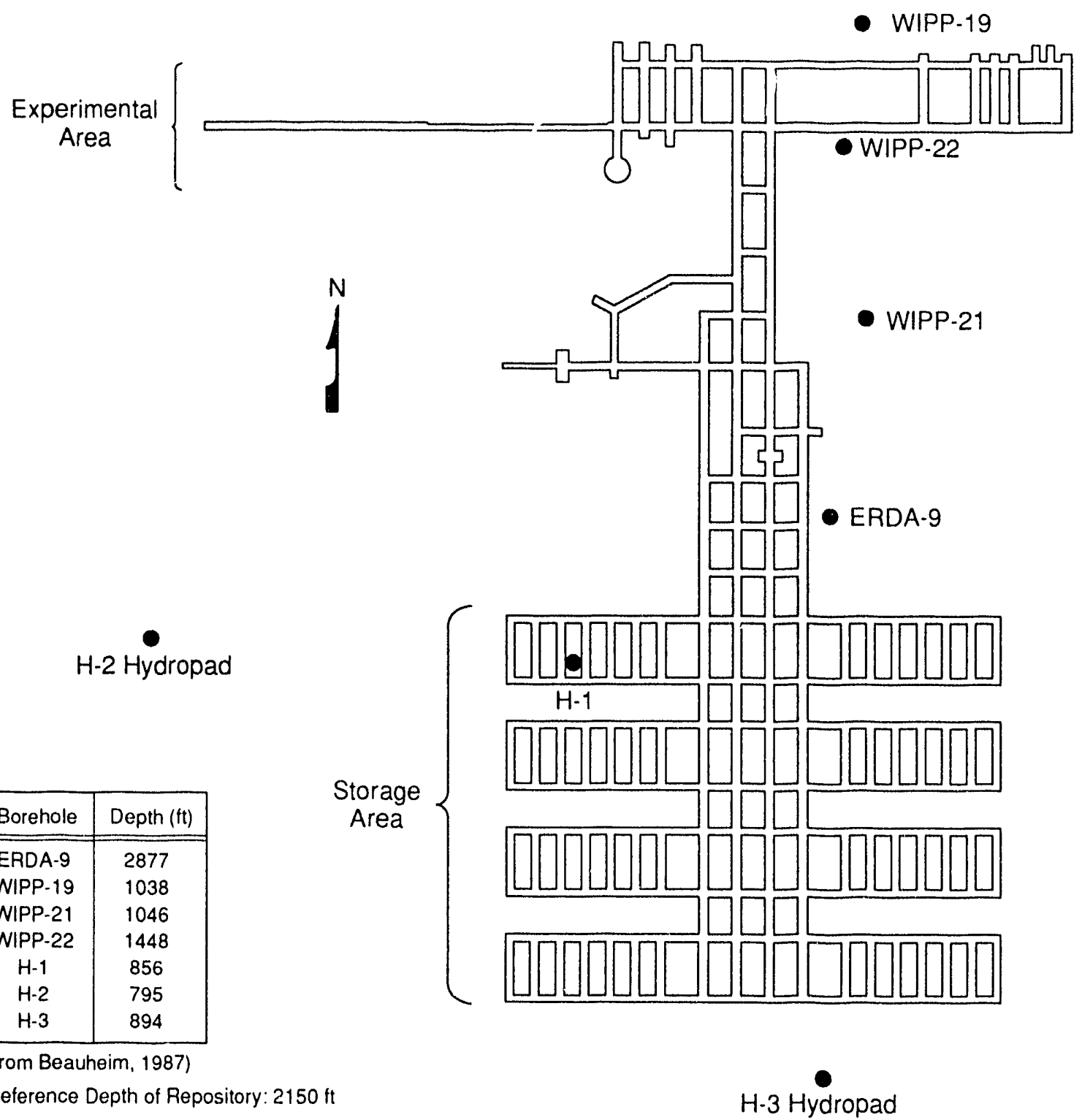

TR1-6330-34-3

Figure 5-1. Approximate locations of boreholes in relation to the WIPP underground (from Lappin et al., 1989, p. 1-3). 
- Emplacement method - As opposed to shaft sealing, borehole sealing entails remote emplacement,

- Excavation method - Blasting during excavation for some of the shafts would cause fracturing of surrounding rock and increase the DRZ. Field and laboratory tests indicate only a small effect of the disturbed zone is associated with boreholes (less than 3 percent of the borehole radius vs. 30 to $100+$ percent of the radius for shafts; Christensen and Peterson, 1981; Kelsall et al., [1982]), and

- Seal Construction Schedule - Whereas shafts must be left open during the operational phase, boreholes can be sealed now or later.

\subsection{Boreholes Requiring Sealing}

Existing borehole and casing locations and depths are presented in Appendix B of Brinster (1991) as a compilation of geohydrologic data from various sources. Coordinates given for each borehole in Table B-1 of Brinster are Universal Transverse Coordinates converted to the study area coordinates.

Figure 4-11 of the Data Base Document shows boreholes within the facility boundary as those to be sealed. This figure is reproduced tere as Figure 5-1.

- Sketch SK-12 in Appendix D of this report presents three location figures - the WIPP Site Boring Locations (Stormont, 1984), a General Location Map (adapted from Lappin et al., 1989), and a figure showing Borehole Classification as to Location (Christensen et al., 1983). The Borehole Classification as to Location is an alternative scheme which could be used to determine boreholes requiring sealing.

Christensen et al. (1983) proposes plugging only those boreholes meeting either Condition 1 or Condition 2, defined as follows.

Condition 1: Boreholes terminating in the Salado formation and within $300 \mathrm{~m}(1,000$ $\mathrm{ft}$ ) horizontally of the maximum potential lateral extent of repository development. (This involves 12 boreholes.) 
Condition 2: Boreholes terminating below the Salado/Castile interface within 3,168 $\mathrm{m}$ ( 2 miles) of the site center. These boreholes might link the upper and lower aquifers and could conceivably exhibit a two-aquifer communication scenario with faster diffusion rates than those in Condition 1. (This involves 3 additional boreholes.)

Boreholes meeting either of these conditions are identified in Christensen et al. (1983) and in Sketch SK-12 in Appendix D, and may be sealed in accordance with the functional requirements and performance criteria defined in the DRD. Technically, however, the seals for these boreholes do not need to meet the stringent requirements of the DRD.

\subsection{Borehole Sealing Strategy}

The conclusions reached from consideration of a worst-case, two-aquifer communication scenario in open existing boreholes, as part of the Final Environmental Impact Statement (FEIS, US DOE, 1980) and from a study by Intera Environmental Consultants, Inc. (1981) are incorporated into the sealing strategy. In this scenario, an uncased, open borehole is assumed to penetrate the Rustler, the center of the repository, and the Bell Canyon aquifer. Such a borehole, which connects the upper and lower aquifers, might dissolve salt faster than one penetrating only the upper aquifer because circulation could be established between the two aquifers in the former case. Based on flow rates calculated from the FEIS assessments for the two-aquifer communication scenario, it would take more than $1.3 \mathrm{My}$ (for the unplugged case) an: $30 \mathrm{My}$ (for the plugged case) to dissolve the repository contents. The plugged case assumes that the cement grout used ultimately degrades to a condition equivalent to that of sand. The whole-body dose received by the maximally exposed individual is about 0.012 percent of the natural background radiation. Subsequent hydrologic investigations and calculations by Intera (1981) indicate that the FEIS calculations are very conservative.

Nons of the existing boreholes penetrate the WIPP facility. Therefore, salt has to be dissolved between a borehole and the repository for breach of the repository to occur. In boreholes penetrating only the upper aquifer, the dissolution is controlled by diffusion and proceeds so slowly that it poses no threat to the WIPP even if the borehole were left open (Stormont, 1988). 
Since concerns regarding long-term performance are alleviated for borehole seals, cementitious mixtures can be used as the principal seal material (Stormont, 1988).

Borehole sealing entails remote emplacement and requires the sealing material completely fill the borehole and makes good contact with the borehole wall, especially in boreholes penetrating rock susceptible to substantial washouts (Christensen et al., 1980). Cement grouts have known flow properties and established emplacement techniques that produce good rock/seal contact. Even if the grout degrades into its constituents (principally sand), adequate resistance to flow should exist (Stormont, 1984).

\subsection{Evaluation Considerations}

To fulfill their primary functions as detailed in Section 5.2, borehole plugs should provide a variety of secondary functions, including mechanical support for the surrounding rock, maintenance of their own physical integrity, and minimization of water movement.

\subsubsection{Seal Effectiveness}

The effectiveness of the seal material is examined from the following perspectives.

- Permeability of the seal - the performance criterion for borehole seals with regards to permeability is given in the DRD as $1 \times 10^{-7}$ darcy $\left(1 \times 10^{-19} \mathrm{~m}^{2}\right)$ or less, as compared to the expected permeability of the host rock salt $10^{-10}$ to $10^{-8}$ darcy $\left(10^{-22}\right.$ to $10^{-20} \mathrm{~m}^{2}$ ).

- Stability/Longevity - prediction of long-term behavior of seal materials using models is difficult to verify because of the diversity between the seal and rock material and the long time of interest. Similarity between the seal material and its host formation implies compatibility, which increases long-term stability of the sealing system, reduces the burden on predictive modeling, and adds confidence in long-term isolation.

- Swell Potential - the potential of the seal material to swell, fill voids, heal fractures within the seal and the host rock. 
- Remediation of Disturbed Rock Zone (DRZ) - the potential for increased permeability within a DRZ is of concern to any sealing program. Around a borehole, the DRZ results primarily from energy imparted during drilling. Field tests indicate only a small disturbed zone is associated with boreholes (Christensen and Peterson, 1981).

\subsubsection{Emplacement Techniques}

It is not obvious that all candidate seal materials can be adequately emplaced and retain the low permeabilities (exhibited in laboratory tests) over an extended period of time. In particular, remote emplacement poses special problems for some seal material types including assurance of complete filling of the void and avoiding bridging. The technology for cementing of boreholes (whether cased or not) is well established and considerable experience exists within contractor organizations.

\subsection{Description of Alternatives}

Four candidate borehole sealing alternatives (see Sketch SK-13 in Appendix D), are considered.

- Alternative A - A cementitious grout alternative, using the reference saltwater (BCT-1F) and freshwater (BCT-1FF) formulations described by Gulick and Wakeley (1987).

- Alternative B - An alternative using BCT-1FF grout in combination with crushed salt.

- Alternative $\mathrm{C}$ - An alternative using BCT-1FF grout in combination with a bentonite-crushed-salt mixture.

- Alternative D - An alternative using asphalt. 


\subsubsection{Definition}

5.6.1.1 ALTERNATIVE A: CEMENTITIOUS GROUT

Gulick and Wakeley (1987) provide the reference formulations and properties for candidate grouts to be used in the WIPP sealing program. Both a freshwater grout (BCT1FF) and a saltwater grout (BCT-1F) are specified. As shown in Sketch SK-13 in Appendix $\mathrm{D}$, Alternative A would place saltwater grout in the borehole to the top of the Culebra dolomite member (approximately at $200 \mathrm{~m}(700 \mathrm{ft})$ ). The use of saltwater grout in the Salado would preclude dissolution of the hast rock. The freshwater grout mix would then be used to fill up the borehole to the ground surface (approximately the remaining nonsalt strata). A concrete plug would be placed at the top of the borehole, as shown in Sketch SK13 in Appendix D.

\subsubsection{ALTERNATIVE B: FRESHWATER GROUT AND CRUSHED SALT}

In Alternative B, crushed salt would replace the saltwater BCT-1F grout in Alternative A. Crushed salt would be placed generally from the bottom of the borehole to a depth of approximately $200 \mathrm{~m}(700 \mathrm{ft})$. To protect the underlying crushed salt from saturation by inflow of water from the upper aquifer, a single, 4-m-long (13-ft) bentonite seal would be placed above it. Calculations by Stormont and Arguello (1988) show that this length of bentonite seal would sufficiently reduce water flow to the crushed-salt layer to allow reconsolidation of the crushed salt. Freshwater grout mix would then be used to fill up the borehole to the ground surface. A concrete plug would be placed at the top of the borehole, as shown in Sketch SK-13 in Appendix D.

\subsubsection{ALTERNATIVE C: FRESHWATER GROUT AND BENTONITE-CRUSHED SALT}

Alternatives B and C are identical except that the crushed salt in Alternative B would be replaced with a bentonite/crushed-salt mixture in Alternative C. Use of bentonite as a sealing material is discussed in Section 4.3.1. 
Alternative D would use asphalt exclusively to seal the boreholes. Previous WIPP seal concepts have not included asphalt, and the experimental program has not evaluated asphalt as a candidate seal material. As previously noted by Stormont (1988), asphalt warrants consideration as a possible seal material based on its successful applications, especially in Germany.

Asphalt's low viscosity enables it to penetrate fissures of the DRZ in the contiguous rock and to displace water. The degree of penetration depends on the width of fissures, viscosity of the asphalt, pressure of the asphalt column, and the time for penetration. Use of asphalt as a sealing material is discussed in Section 4.3.5.1.

The asphalt in Alternative $\mathrm{D}$ is produced by mixing bitumen with limestone filler at high temperatures. To reduce the possibility of asphalt running out into the formation continuously leading to an incessant fall in the level of asphalt, type 80 or type 65 asphalt should be considered. The penetration rate of the candidate asphalt decreases with increasing penetration depth. The time at which asphalt flow into the borehole walls ceases depends basically on the width of the fissures (Kerkhoven, 1959). The depth of asphalt penetration will diminish when dust filler particles are included. The asphalt and limestone filler mixture should be homogeneous, free from water, and should not foam when heated to $370^{\circ} \mathrm{F}$. Furthermore, it should conform to requirements of the American Association of State Highway and Transportation Officials (AASHTO) and the American Society for Testing and Materials (ASTM) publications for Asphalt and Filler Materials. A concrete plug would be placed at the surface, as shown in Sketch SK-13 in Appendix D.

\subsubsection{Emplacement Considerations and Constructibility}

\subsubsection{BOREHOLE CLEANING AND CONDITIONING}

Boreholes would be surveyed by downhole TV camera methods, and/or geophysical and caliper logs taken to determine the extent of borehole deterioration, including borehole enlargement or closure, or any other conditions which could adversely affect the emplacement/performance of seals. Boreholes would be cleaned and conditioned, as required, prior to sealing. This may involve washing, reaming and, if necessary, redrilling the boreholes to provide fresh and stable borehole walls. These measures would ensure the integrity of the boreholes as it affects seal placement and performance. 
Figure 5-2 shows a partially cased borehole being cleaned and conditioned with the aid of cleaning tools at the end of a drill string and circulating slurry. The drill string is lowered from a drill rig at the surface.

\subsubsection{3OREHOLE CASING}

Boreholes that penetrate the Salado (with the exception of borehole ERDA-9), are unlined below the Salado/Rustler contact. Therefore, for the purpose of this study, two representative casing lengths are assumed $-260 \mathrm{~m}(850 \mathrm{ft})$ from the ground surface to the Salado/Rustler contact and $850 \mathrm{~m}(2,800 \mathrm{ft})$ from ground surface to the bottom of the Salado for ERDA-9. Given that metal casing will corrode over long time periods leaving a permeable flowpath through the seal (American Society for Testing and Materials, [1966]), it seems judicious to either perforate or remove the casing.

The concepts behind several methods for casing perforation and removal are shown in Figure 5-3. As indicated in the figure, perforation of the casing can be effected either by using an expandable knife tool at the end of a drill rod or using a fired projectile.

Casing removal can be done by wash-over, underreaming or milling methods. As indicated in Figure 5-4, wash-over methods involve a wash pipe having an inside diameter slightly larger than the casing which slips over the casing and cuts through the cement that bonds the casing to the host rock.

In the underreaming method, expandable cutter heads at the end of a drill string are used to remove the casing. The underreamer is inserted to a desired elevation, the cutters are expanded by applying hydraulic pressure to the drill string, and grinding downward to remove the casing.

In milling operations, the mill has a fixed diameter and is run on the end of a drill string until it encounters the casing from the top. Rotation of the drill string and application of a downward force then grinds the casing up, allowing it to be removed by the circulation of a fluid down the drill string.

Complete casing removal is not recommended for two reasons.

1. Casing removal methods are difficult at best, and in the shallow, unconsolidated zones, their removal could cause enough damage to the borehole to more than offset the benefits of removal. Damage related to the stability of the borehole 


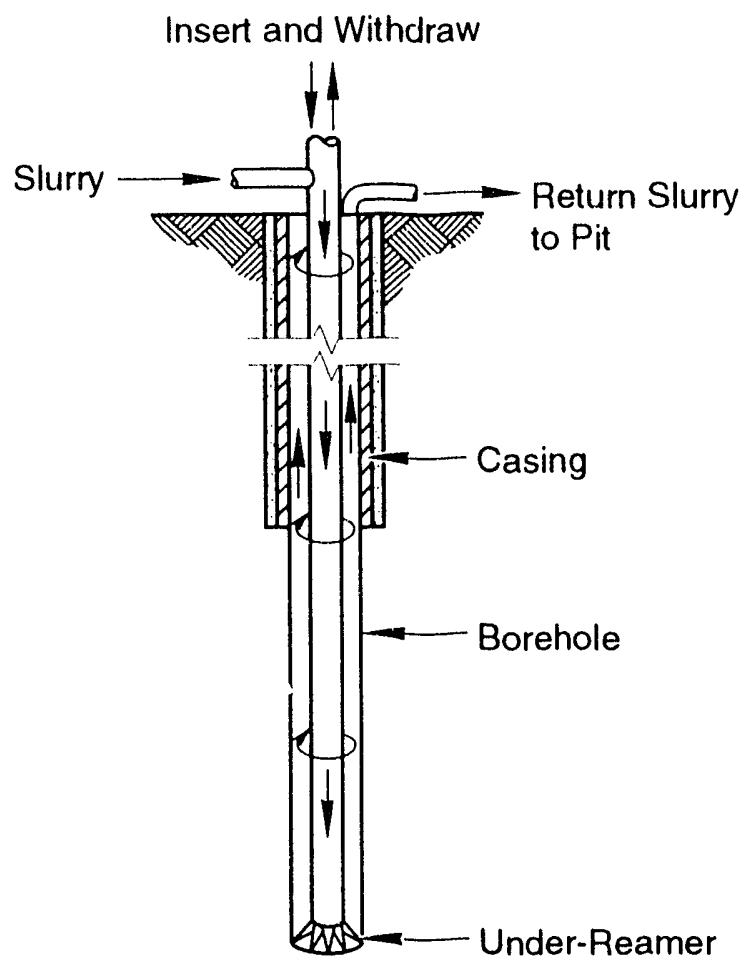

Figure 5-2. Borehole cleaning and conditioning.

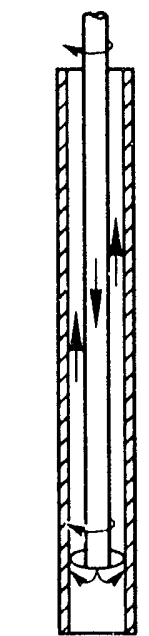

Expandable Knife Tool

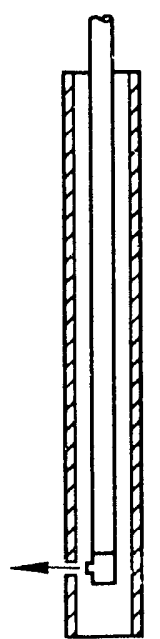

Fired Projectile

TRI.6121.67-0

Figure 5-3. Perforation of borehole casing. 


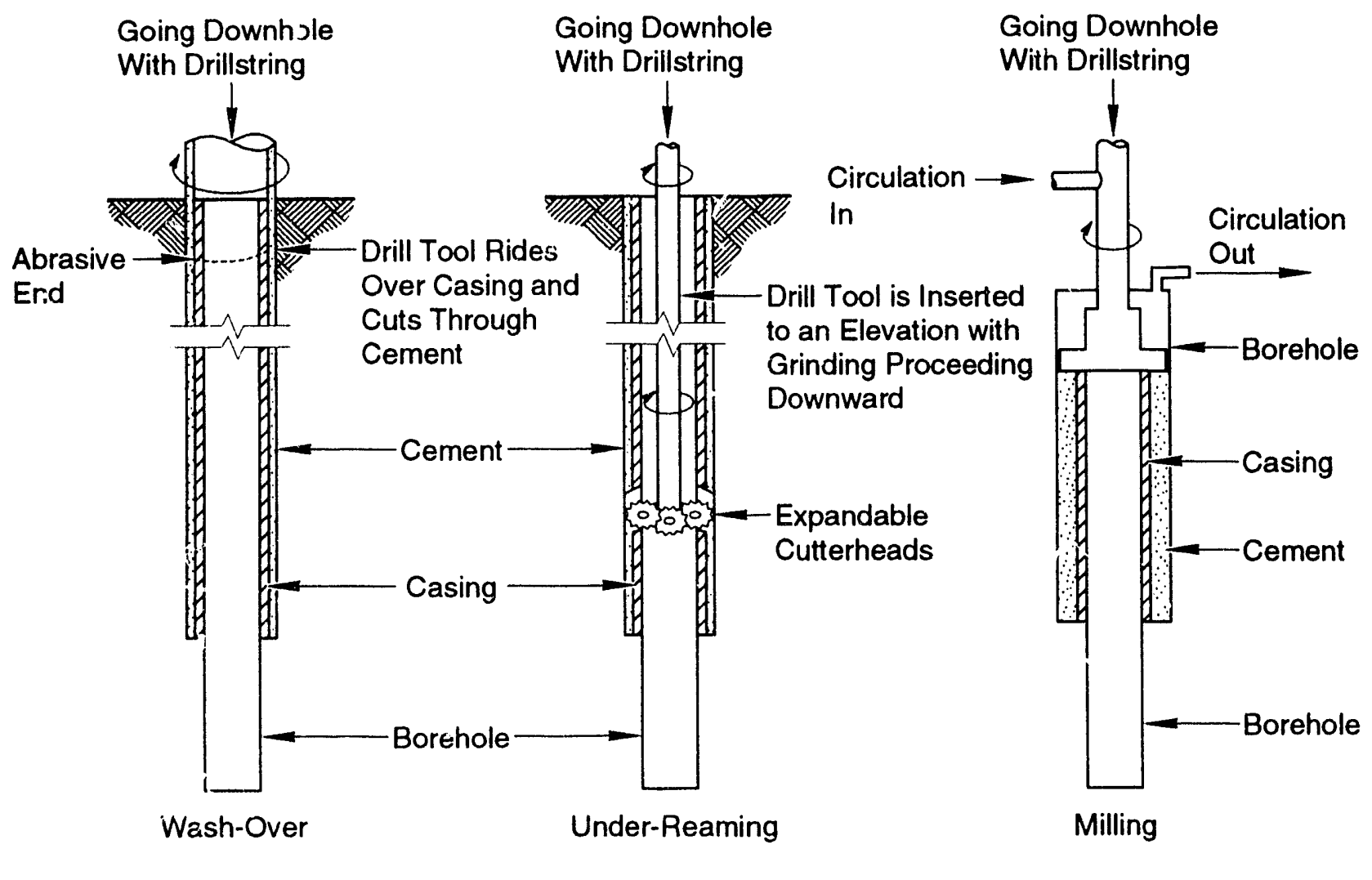

Figure 5-4. Removal of casing. 
walls and subsequent borehole enlargement would be likely in the shallower zones; therefore, it is not recommended that milling operations be attempted as this would require all the casing be removed. However, at greater depths where the formations are more consolidated and certainly in the salt sections, the underreaming method of casing removal would be possible. As a precautionary note, it should be understood that as the depth increases, the difficulty of the mechanical work increases, but the maximum depth of $2,800 \mathrm{ft}$ is certainly within the current technology level for the underreaming of casing.

2. Removal of the casing in any of the boreholes where fresh water is cemented behind the casing could facilitate fresh water inflow from the upper aquifer, making sealing of the lower portions of the boreholes difficult for Alternatives $B$ and $C$, which use crushed salt.

Well casings can be perforated as an alternative to casing removal. Each well should be carefully evaluated to determine if perforating or selective casing removal would be the best solution. If perforating is chosen, a fired projectile is the recommended method of

perforating. The perforation interval and the thickness of the injection zone would depend on the sealing alternative.

It is proposed that casings be perforated with a fired projectile in all cases, except for alternatives using the crushed salt or bentonite/crushed-salt mix, where casing removal below the Salado/Rustler contact would be warranted. The perforation interval and thickness of the injection zone would depend on the sealing alternative.

\subsubsection{CEMENTITIOUS GROUT INJECTION}

Figure 5-5 illustrates an emplacement concept for placing cementitious grout mix in the borehole. The grout pipe is filled with the grout mix and lowered to the bottom of the cleaned borehole. The mix is then deposited by opening the foot valve located at the bottom of the grout pipe. The pipe is withdrawn as the mix is being deposited. The tip of the pipe is maintained at a minimum of three borehole diameters below the surface of the grout mix to ensure absence of entrapped air in the deposited mix. 


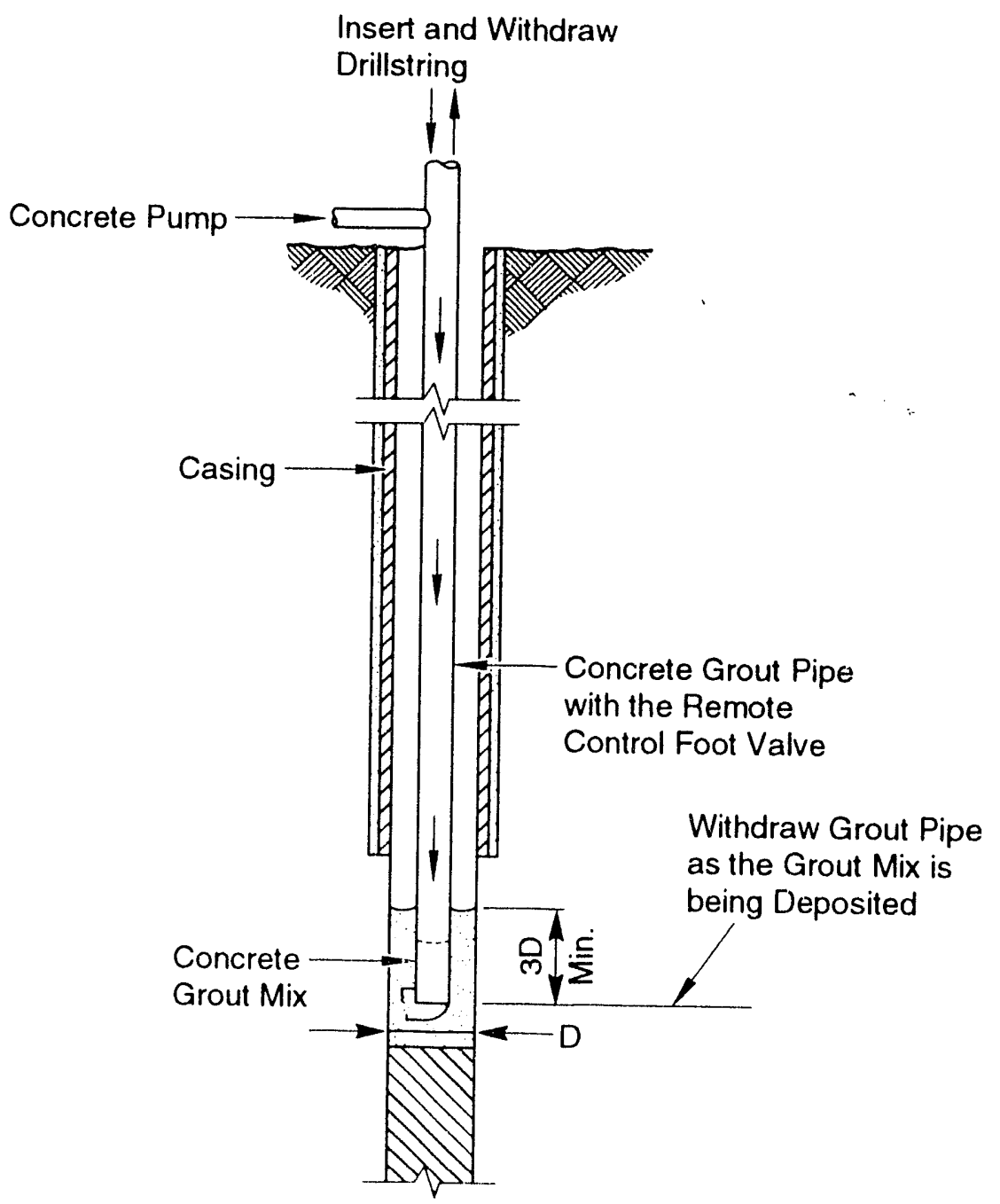

TRI.6121.69.0

Figure 5-5. Emplacement of cementitious grout mix. 


\subsubsection{ASPHALT INJECTION}

A conceptual method of emplacing asphalt borehole seals is illustrated in Figure 5-6. Asphalt injection involves use of a packer above an injection zone. For the cased hole, the injection zone is defined by the zone of perforated casing. The asphalt is injected through a pipe to fill the borehole and the annulus between the casing and the borehole wall.

Asphalt is prepared into mastic in the refinery, or alternatively, filled into convective tube heaters on-site at a temperature of $350^{\circ} \mathrm{F}$ from insulated trucks. The injection pipe will be sumped about $15 \mathrm{~m}(50 \mathrm{ft})$ into the asphalt in the borehole during placement to achieve a tremmie effect. The tremmie pipe is withdrawn as the asphalt is being deposited. To avoid premature cooling of the asphalt during placement, heating strips may be placed as required for maintaining the optimum temperature of asphalt in the borehole. The heating device will be removed before placing the surface concrete cap.

Details of asphalt preparation, mixing, and placement will need to be developed and called out in appropriate specifications that would be prepared in later stages of design.

\subsubsection{EMPLACEMENT AND COMPACTION OF SALT/BENTONITE-SALT MIX}

A conceptual method of emplacing crushed salt or a bentonite/crushed-salt mixture is illustrated in Figure 5-7. A custom-made material transporter/compactor is required for emplacement and compaction of the seal material. The material will be deposited and compacted in lifts of about one borehole diameter. For cost evaluations in this study, the density for the emplaced salt is assumed to be 80 percent fractional density at all depths. The required density of the emplaced salt or salt-bentonite mix would need to be refined in the preliminary design phase. Furthermore, the emplacement tools and methodology need to be verified in the detailed design phase.

It is anticipated that boreholes with relatively shallow casing (uncased below the Salado/Rustler contact) or in effect, all boreholes except ERDA-9, can be dewatered, and crushed salt or bentonite/crushed-salt mixture can be emplaced as outlined here. Wellbore conditions at each of the well sites will need to be considered when actual plugging operations commence. 


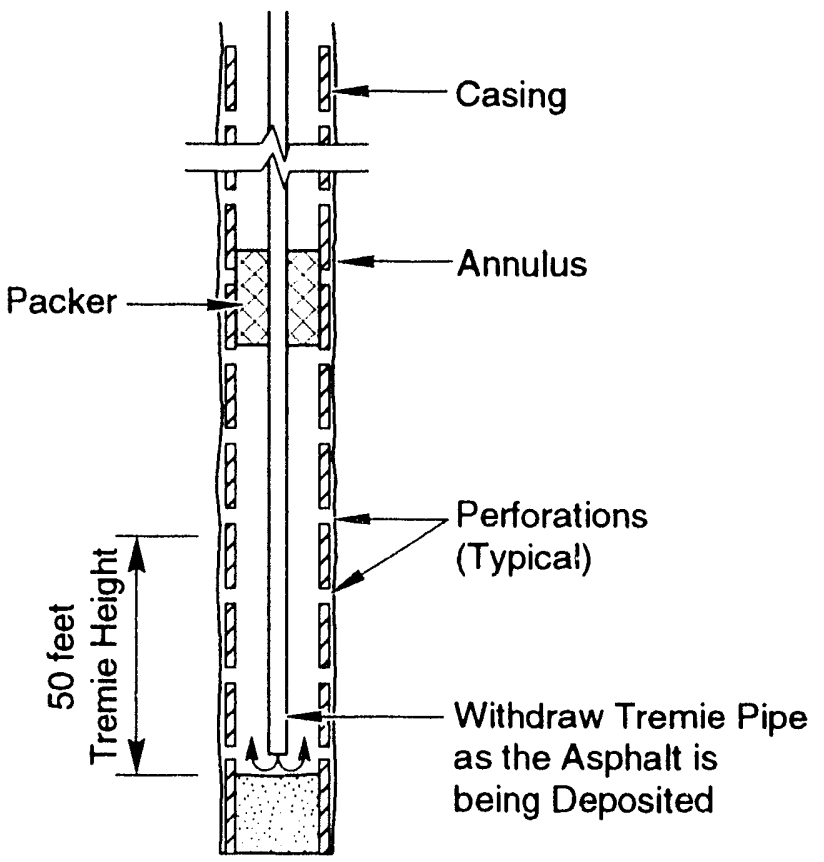

TRI.6121.70-0

Figure 5-6. Emplacement of asphalt injection. 

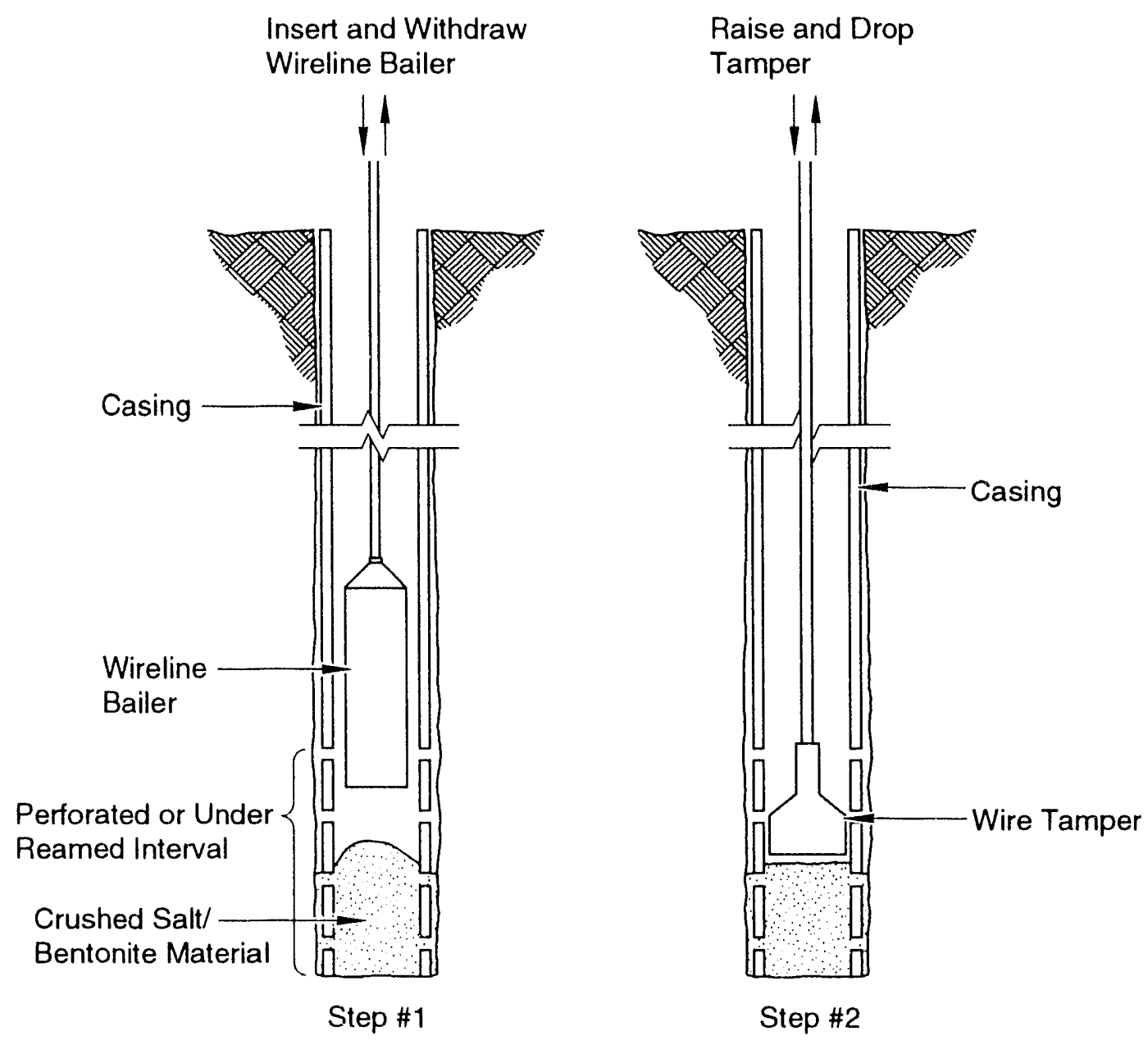

TRI.6121-71.0

Figure 5-7. Emplacement and compaction of crushed-salt/bentonite salt mix. 


\subsection{Evaluation of Alternatives}

This section will compare and evaluate the relative strengths and weaknesses of the candidate borehole seal alternatives using the evaluation criteria identified in Section 5.5. No attempt to either rank them or pick the best seal alternative will be made in this seal design alternative study.

\subsubsection{Seal Effectiveness}

Permeability - According to the DRD, the short-term performance criterion for limiting waterflow for boreholes is given as $1 \times 10^{-7}$ darcy $\left(1 \times 10^{-19} \mathrm{~m}^{2}\right)$.

Both BCT 1-FF (fresh water grout) and bentonite seals have permeabilities of $1 \times 10^{-7}$ darcy $\left(1 \times 10^{-19} \mathrm{~m}^{2}\right)$, which meet the short-term performance requirements. By using the coarser available grinds of cement and using water reducers and retarders, the water-tocement ratio in the grouts was reduced, thus reducing permeability and porosity and increasing density and strength.

In summary, with regards to permeability, Alternative A (the cementitious grout alternative) would readily satisfy the short-term performance criteria in the DRD, required to:

- limit release of waste materials in gaseous form during the short-term period, and

- limit water flow through the boreholes, down to the underground area of the repository, etc.

However, the sealing alternative barely satisfies performance criterion during the long-term period. It is recognized that the physical separation of the boreholes from the repository will likely preclude any waste material from ever entering the boreholes.

On the other hand, Alternatives $\mathrm{B}$ and $\mathrm{C}$ which would use crushed salt or bentonitecrushed salt mixture might meet both short and long-term criteria for the corresponding functions outlined. Creep of host rock from the bottom of hole to about a 1,800-ft-depth is expected to adequately reconsolidate the crushed-salt fill (as was discussed in Section 4). 
Asphalt (proposed in Alternative D) is a bituminous material produced by the distillation of crude oil. Many of its properties can be tailored by the distillation process and by the addition of weighting materials and blending and dissolving agents. The functional requirements can therefore be called out in the specifications.

Stability/Longevity - Real-time observance of the long-term chemical and mechanical stability of sealing materials in their host geologic environment is not possible. Therefore, similarity between the seal material and the host formation enhances compatibility, which increases long-term stability of the sealing system.

Asphalt should perform well as a long-term seal because bacterial degradation requires micro-organisms and moisture and proceeds very slowly even when these conditions are met (ZoBell and Molecke, 1978). To reduce the possibility of asphalt running out into the formation and leading to an incessant fall in the level of asphalt, type 80 or type 65 asphalt should be considered.

With regard to bentonite, clays exist naturally in geologic formations, including bedded salt, and clay sealants have been used by man for as long as 2,100 years (Lee, 1985). Furthermore, at nonelevated temperatures, bentonite transformations to other clays are expected to be very slow, on the order of millions of years (Meyer and Howard, 1983).

The long-term stability of the cementitious grout formulations BCT 1-F and BCT 1-FF is unknown. Even though sulfate attack is resisted by developing cements low in tricalcium aluminate, cementitious grouts will usually not be in chemical equilibrium with their environmer.t (Lambert, 1980). Potential mineralogic phase changes in the plug, rock, and groundwater system could occur.

In summary, Alternatives $B$ and $C$ which utilize crushed salt and bentonite, albeit in conjunction with the freshwater grout formulation, have merit. Similarly, Alternative D, which uses asphalt, has merit as well. However, long-term stability of Alternative A (with its cementitious grouts) is uncertain.

Swell Potential - Mixtures containing bentonite develop swelling pressures if confined and saturated with water. Therefore, the bentonite/crushed-salt mixture in Sealing Alternative $\mathrm{C}$ should swell and fill voids, heal fractures within the bentonite seal and also, to a limited degree, in the adjacent host rock. Consequently, the crushed-salt filler material 
merely acts as an inert filler, and the swelling pressures of the mixture should depend primarily on the effective clay density (Gray et al., 1984).

Alternative $\mathrm{C}$ (bentonite/crushed-salt mixture in combination with BCT 1-FF grout) is the superior alternative in this regard. The BCT-1FF grout is an expansive grout, developed to improve the interface bonding with the host rock. The expansion is based on the formation of calcium aluminate phases such as ettringite (Gulick et al., 1982). The expansion will improve the mechanical bond and should reduce plug movement and permeability especially at the interface.

Remediation of the DRZ - The DRZ surrounds the borehole in rock and has physical characteristics differing from those of the virgin formation. The potential for increased permeability in this zone is of concern to the WIPP sealing program.

Effective cementitious grouts to be used in grouting fractures in the host rock need to be developed in the preliminary design phase to supplement the data in the DBD. Crushed salt/bentonite seals will provide backpressure which will eventually heal the DRZ.

Asphalt in Alternative D has a specific gravity that is 30 to 40 percent greater than water. It therefore tends to move out into the formation rather than formation water moving into the borehole. Its low viscosity facilitates its penetration into fissures and fractures of the host rock. It will also provide some backpressure to heal the DRZ.

\subsubsection{Emplacement Techniques}

The desirability of a crushed-salt seal option is offset by concerns regarding inadequate remote emplacement techniques and poor consolidation when saturated with brine from the host rock salt. Concerns over bridging during remote emplacement in a relatively small diameter can be reduced by initially screening the salt to eliminate large grains. However, the conceptual emplacement method discussed in Section 5.6.2.5 using a material transporter/compactor should be considered.

It should be noted that for Alternatives B and C, the casing in boring ERDA-9 would have to be removed below about $213 \mathrm{~m}$ ( $700 \mathrm{ft}$ ), despite the difficulty anticipated with casing removal. This would be necessary to ensure a continuous interface between the crushed-salt seal and the halite host rock in the zone occupied by the crushed-salt seal. 


\subsubsection{Cost}

An order-of-magnitude cost evaluation is made for the capital cost of WIPP borehole sealing. The cost of design, finance, and management are not included. The costs are in fourth quarter 1992 U.S. dollars. A brief cost estimate and the assumptions made for the cost estimate are presented in Appendix C. A summary of the total capital cost for sealing using the three cases of WIPP boreholes for the four alternatives is shown in Table 5-2.

\section{Table 5-2. Order-of-Magnitude Cost Estimate $(\times \$ 1.0 \mathrm{M})$ Summary of Total Capital Cost for Borehole Seal Alternatives ${ }^{(a)}$.}

\begin{tabular}{|c|c|c|c|c|c|}
\hline Case & $\begin{array}{l}\text { Total } \\
\text { Hole } \\
\text { Length } \\
\text { (ft) }\end{array}$ & $\begin{array}{c}\text { Alternative A } \\
\text { Concrete Seal }\end{array}$ & $\begin{array}{l}\text { Alternative B } \\
\text { Upper Concrete Seal } \\
\text { Lower Salt Scal }\end{array}$ & $\begin{array}{l}\text { Alternative C } \\
\text { Upper Concrete Seal } \\
\text { Lower Bentonite/ } \\
\text { Salt Mix }\end{array}$ & $\begin{array}{c}\text { Alternative } \\
\text { D } \\
\text { Asphalt Seal }\end{array}$ \\
\hline $\begin{array}{l}\text { Case } 1 \\
9 \text { Boreholes }^{(b)}\end{array}$ & 11,677 & $\$ 2.102$ & $\$ 2.699$ & $\$ 2.736$ & $\$ 1.402$ \\
\hline $\begin{array}{l}\text { Case } 2 \\
\text { (Condition 1) } \\
12 \text { Boreholes }^{(\mathrm{c})}\end{array}$ & 17,993 & $\$ 2.860$ & $\$ 3.576$ & $\$ 3.638$ & $\$ 2.052$ \\
\hline $\begin{array}{l}\text { Case } 3 \\
\text { (Conditions } 1 \& \\
2 \text { ) } \\
15 \text { Boreholes }^{(c)}\end{array}$ & 29,762 & $\$ 4.978$ & $\$ 5.188$ & $\$ 5.293$ & $\$ 3.444$ \\
\hline \multicolumn{6}{|c|}{$\begin{array}{l}\text { (a) Cost for material and labor only. } \\
\text { (b) DRD requires sealing } 7 \text { boreholes; } 2 \text { additional holes, P-2 and P-3, located within the WIPP } \\
\text { boundary have been included. } \\
\text { (c) Conditions } 1 \text { and } 2 \text { as per Christensen et al. (1983). }\end{array}$} \\
\hline
\end{tabular}

The capital cost for Case 1 (Base Case) borehole seals is about $\$ 2.1, \$ 2.7, \$ 2.74$ and $\$ 1.4$ million for Alternatives $\mathrm{A}, \mathrm{B}, \mathrm{C}$, and $\mathrm{D}$, respectively. In general, the following trends can be observed from Table 5-2.

1. The order-of-magnitude cost for Cases 2 and 3 are about 150 percent and 250 percent of the Base Case cost. 
2. There is no significant cost difference among Alternatives $A, B$, and $C$ and the cost of Alternative $\mathrm{D}$ is about one-third less than those of Alternatives $\mathrm{A}, \mathrm{B}$, and C.

3. The worst case cost for WIPP borehole seals considering Conditions 1 and 2 borehole seals ( 15 totai) is about 5 million dollars in fourth quarter 1992 costs.

\subsection{Discussions and Conclusions}

\subsubsection{Discussions}

Except for Alternative D which uses asphalt exclusively, the alternatives examined in this study use cementitious grouts, crushed salt, bentonite, and concrete in various combinations.

Alternative A - This alternative uses cementitious grout for the whole length of the borehole. The simplicity of handling and emplacement of the grout makes it an attractive alternative. It meets the short-time performance criteria called out in the DRD; however, the geochemical and geophysical stability of the concrete for the long-term $(10,000$ years) performance at WIPP underground environment cannot be assured. In this study, conservative assumptions were made for the as-built borehole conditions and the unit cost for factory-packaged, nonshrink cementitious grout. The capital cost for Alternative A is about $\$ 2.1, \$ 2.9$ and $\$ 5$ million for Cases 1,2 , and 3, respectively.

Alternatives B and C - These alternatives use emplaced salt or a salt/bentonite mix for the borehole seal and a grout seal above the salt formation. They can be designed to meet both short-term and long-term criteria for functions called out in the DRD. However, there is no precedence for emplacing salt in a borehole to an 80 to 90 percent fractional density. The emplacement tools and methodology for the salt seal would need to be developed and verified for implementation in the final design. Again conservative assumptions are made for the cost evaluation. The capital costs for these alternatives are about the same as those for Alternative A.

Alternative D - This alternative uses an asphalt column for the whole length of the borehole seal. Asphalt columns have been widely used in European mines for effective sealing of groundwater for about 50 years. The ingredients of asphalt are known to be stable. However, the asphalt placed with a unit density of about $1.3 \mathrm{~g} / \mathrm{cm}^{3}$ produces a 
hydraulic head which is greater than the hydrostatic pressure of the groundwater, and therefore, it may leak out through seepage into the fissures of the host rocks. Nevertheless, the filler material and cooling of bitumen will increase the viscosity and slow down and eventually halt the seepage. The creep closure of salt around the asphalt column will also reduce the size of the fissures with time and reduce the leakage. The uppermost portion of the borehole at the collar contains a significant portion of the total volume of the asphalt column. The asphalt inside the collar may serve as reserve for nominal leakage during early years after placement of the asphalt column.

The capital cost for this alternative is about $\$ 1.4, \$ 2$, and $\$ 3.4$ million for Cases 1,2 , and 3 , respectively. It is the low-cost alternative being about one-third less than the cost of the other three alternatives.

Cases 1, 2, and 3-Case 1 includes nine Base Case borehole seals required by the DRD. Cases 2 and 3 are studied only for the purpose of obtaining cost data for decision making. From Table 5-2, it can be seen that for all four alternatives, Case 1 has the least cost and Cases 2 and 3 cost about 50 percent and 150 percent, respectively, more than the Base Case.

\subsubsection{Conclusion}

This borehole seal study indicates that Alternative D, asphalt column, is one of the viable types of borehole seal, which could be further developed. Asphalt has been used for a fairly long time for water-tight shaft linings but has not been widely used as a borehole seal. The capital cost of an asphalt column seal is about one-third less than the cost of the other three alternatives studied. Asphalt column seals can be constructed with known technology. Seepage of asphalt into the host rnck, if there is any, will take place early after emplacement and is beneficial in terms of sealing the fractures around the borehole.

The order-of-magnitude cost for the conservative Case 3 borehole seals is about $\$ 5$ million in fourth quarter 1992. U.S. dollars. However, improvements in the cost estimate can be made by detailed examination of the as-built data and/or field verification of the boreholes to eliminate the need for the conservative assumptions made in this study. A summary of comparisons of all alternatives is shown in Table 5-3. 
Table 5-3. Summary of Comparisons of Alternatives.

\begin{tabular}{|c|c|c|c|c|}
\hline \multicolumn{5}{|c|}{ Alternatives } \\
\hline & $\begin{array}{c}\text { A } \\
\text { Cementitious } \\
\text { Grout }\end{array}$ & $\begin{array}{c}\text { B } \\
\text { BCT-1FF/Crushed } \\
\text { Salt }\end{array}$ & $\begin{array}{c}\text { C } \\
\text { BCT-1FF/ } \\
\text { Bentonite- } \\
\text { Crushed Salt } \\
\text { Mix }\end{array}$ & $\begin{array}{c}\text { D } \\
\text { Asphalt }\end{array}$ \\
\hline Seal Effectiveness & $\begin{array}{l}\text { Cementitious grout } \\
\text { needs to be devel- } \\
\text { oped. Satisfies } \\
\text { short-term criteria. } \\
\text { Barely satisfies } \\
\text { long-term criteria. }\end{array}$ & $\begin{array}{l}\text { Can meet both } \\
\text { short- and long- } \\
\text { term criteria. }\end{array}$ & Same as B. & Same as B. \\
\hline Salt DRZ & $\begin{array}{l}\text { Backpressure will } \\
\text { heal DRZ. }\end{array}$ & Same as $\mathrm{A}$. & Same as $\mathrm{A}$. & $\begin{array}{l}\text { Superior sealant } \\
\text { and provides } \\
\text { backpressure } \\
\text { unless a breach } \\
\text { drains it away. }\end{array}$ \\
\hline Material Stability & Uncertain. & Good. & Good. & Good. \\
\hline \multicolumn{5}{|l|}{ Constructibility: } \\
\hline $\begin{array}{l}\text { 1. Removal of } \\
\text { Casing }\end{array}$ & $\begin{array}{l}\text { Removal not } \\
\text { recommended, } \\
\text { perforation } \\
\text { preferred. }\end{array}$ & Required. & Required. & Same as $\mathrm{A}$. \\
\hline 2. Equipment & $\begin{array}{l}\text { No special } \\
\text { equipment } \\
\text { required. }\end{array}$ & $\begin{array}{l}\text { May require } \\
\text { custom-made } \\
\text { material transport- } \\
\text { er/ } \\
\text { compactor }\end{array}$ & Same as $B$. & $\begin{array}{l}\text { No special } \\
\text { equipment } \\
\text { required. }\end{array}$ \\
\hline 3. New Technology & None required. & $\begin{array}{l}\text { Emplacement tool, } \\
\text { methodology to be } \\
\text { developed and } \\
\text { verified. }\end{array}$ & Same as $B$. & None required. \\
\hline \multicolumn{5}{|l|}{ Cost: } \\
\hline Case 1 & $\$ 2,100,000$ & $\$ 2,700,000$ & $\$ 2,740,000$ & $\$ 1,400,000$ \\
\hline Case 2 & $\$ 2,860,000$ & $\$ 3,580,000$ & $\$ 3,640,000$ & $\$ 2,050,000$ \\
\hline Case 3 & $\$ 4,980,000$ & $\$ 5,190,000$ & $\$ 5,290,000$ & $\$ 3,440,000$ \\
\hline
\end{tabular}




\subsection{FUTURE WOFK}

The design :nd construction of all seals can be made with the prevailing industrial codes and standards in the United States. However, some assumptions made for this study, specifically Assumptions Nos. 6 anc' 7 of Section 3.3, need to be verified for implementation in the detailed design of the seals.

Assumption 6 of Section 3.3 relates to the effective grouting for the operational/temporary drift seal. Assumption 7 of Section 3.3 provides an estimate of the upper bound unit cost for placement of the long-term salt seal. These assumptions and other design issues need to be refined as follows.

1. Eevelopment of grouting for effective control of the leakage path in DRZ and MB139. For the "LATER. GROUT" type of seals (LGxx) described in Section 3 to be viable, it is necessary to identify the grout material that is compatible with the geochemical and geophysical environment of the WIPP salt and grouting technology. Otherwise, the design options are limited to either rigid sleeves in new drift and panel excavations or "LATER EXCAVATE" type of seals (LExx), which requires the removal of the DRZ in salt as well as the damaged MB139. It should be noted that the development of grout is occurring as part of the Sandia National Laboratories' seal program for WIPP.

2. Strength testing of concrete under confining pressure to facilitate reduction of the steel plate thickness of the rigid sleeves for improved constructibility. The stateof-the-art concrete technology uses the unconfined strength, $f_{c}^{\prime}$, of the concrete for the design of the rigid sleeve. The thicknesses of the steel sleeves for Type 1 seal (Section 3) ranged from $13 / 4$ in to $31 / 4$ in, which could pose some constructibility problems. The loading on the rigid sleeve is applied gradually by creep-closure of the salt and the concrete stress is subjected to the confinement pressure exerted by the steel liner. The objective of the testing is to establish a data base to increase the allowable stress of the concrete in the rigid sleeve and reduce the thickness of the steel liner.

3. Salt Seal Emplacement Study. The objective of the study will be to evaluate alternative methods of salt seal emplacement and establish a database for estimating emplacement densities and the costs associated with achieving those 
densities.

- Salt Block Manufacturing Study - Rock mechanics studies predict that crushed salt will consolidate under a low pressure of about $1 \mathrm{MPa}(150 \mathrm{psi})$ or less until the density of the salt reaches 95 percent fractional density, if given enough time. The shape of the block may be a cube, a cylinder, or a hexagon prism. The density of the salt block may be increased by increasing the time of pressure application.

- In-Situ Compaction of Crushed Salt - Crushed salt may be placed and consolidated in layers of about equal thickness or by use of mechanical expansion devices (by balloon or expanded wedges) to create the required volumetric strain for the consolidation. Full-scale tests in a drift and/or a shaft are required to establish the methodology for in situ compaction of crushed salt.

- Salt Block Quarrying Feasibility Study - Salt block quarrying may use a trackmounted core drill to harvest cylindrical core from the ribs of drifts in the WIPP test area. A custom-made shearer or wire saw may be used to cut salt blocks between two drifts. These concepts need further study, particularly in terms of cost for cutting, handling, and storing (warehousing) of blocks for later use.

4. Development of a Non-Rigid Liner System for DRZ Control. The NRxx seals (Section 3) use a rigid sleeve system erected soon after excavation to check development of the DRZ and to provide the back pressure for healing of the DRZ in salt. Based on rock mechanics analysis (Section 2.3), the average back pressure (liner loading) on the rigid sleeve is between 2,500 psi and 3,500 psi. In mining and tunneling industries, it is commonly known that a nominal 2-in thick shotcrete can stabilize mined opening from raveling. Similarly, a nominal back pressure of approximately 150-300 psi may stop formation of DRZ in salt. If the liner loading is limited to $150-300 \mathrm{psi}$, the thickness of the steel sleeve can be reduced from about $21 / 2$ in to about $1 / 2$ in, which would have a significant impact on the capital cost and constructibility. Therefore, a nonrigid liner system should be studied, which would produce a nominal back pressure to check development of the DRZ. The nonrigid liner system could be made of a thin steel shell liner with an elasto-perfectly plastic material, such as Hexcell Tubecore honeycomb or foam-concrete, between the steel shell and the host rock. The structure-salt interaction of the nonrigid liner system needs to be evaluated by rock mechanic analysis and verified by a large-scale test program. 
5. Development of a Large-Scale (About 150-Cubic-Yard/8-Hour Shift) Concrete Casting Plan. The plan should be developed to include a demonstration of placement of approximately 50 cubic yards (or more) of concrete at the WIPP horizon with instrumentations for monitoring the heat of hydration, expansion or contraction, and permeability through the concrete mass. Concrete formulations developed by Waterways Experiment Station (WES) should be used as a basis for commercial ready-mixes of fresh-water and salt-water concrete using local (Carlsbad, New Mexico) aggregates and commercial facilities.

The concrete should be batched, mixed, and delivered in 6-cubic-yard units to the WIPP site and placed underground at a constant rate without interruption from start to finish. The concrete could be transported through the Waste shaft; however, it is preferable to use the Salt Handling shaft or the Air Intake shaft without interfering with the normal functions of these shafts. 


\subsection{REFERENCES}

American Society for Testing and Materials. [1966]. Significance of Tests and Properties of Concrete and Concrete-Making Materials. ASTM Special Technical Publication No. 169A. Philadelphia, PA: American Society for Testing and Materials.

Argüello, J.G. 1988. WIPP Panel Entry Seal - Numerical Simulation of Seal Composite Interaction for Preliminary Design Evaluation. SAND87-2804. Albuquerque, NM: Sandia National Laboratories.

Bailey, D.A., M. Grieves, and D. Mann. 1992a. "Preliminary Design Criteria for the Waste Isolation Pilot Plant Sealing System Design Requirements Document." Albuquerque, NM: Sandia National Laboratories.

Bailey, D.A., M. Grieves, and D. Mann. 1992b. "Preliminary Design Criteria for the Waste Isolation Pilot Plant Sealing System Data Base Document." Albuquerque, NM: Sandia National Laboratories.

Boisson, J.Y. 1989. "Study on the Erosion Possibilities by Flowing Ground Waters on Bentonite Plugs Expanded From Borehole Into Fractures," NEA/CEC Workshop on Sealing of Radioactive Waste Repositories, Brunswick, DE, May 22-25, 1989. Paris, France: Organisation for Economic Co-Operation and Development. 229-244.

Brinster, K.F. 1991. Preliminary Geohydrologic Conceptual Model of the Los Medaños Region Near the Waste Isolation Pilot Plant for the Purpose of Performance Assessment. SAND89-7147. Albuquerque, NM: Sandia National Laboratories.

Brodsky, N.S., and T.W. Pfeifle. 1991a. Consolidation of the Waste Isolation Pilot Plant Crushed Salt/Bentonite Mixtures as a Function of Confining Pressure and Moisture Content as Compared With Constitutive Model Predictions. SAND91-7071. Albuquerque, NM: Sandia National Laboratories.

Brodsky, N.S., and T.W. Pfeifle. 1991b. Brine Permeability of Consolidated Crushed Salt from the Waste Isolation Pilot Plant. Topical Report RSI-0408. Rapid City, SD: $\mathrm{RE} / \mathrm{SPEC}$, Inc. 
Callahan, G.D., A.F. Fossum, and D.K. Svalstad. 1989. Documentation of SPECTROM-32: A Finite Element Thermomechanical Stress Analysis Program. DOE/CH/10378-2. Argonne, IL: US Department of Energy, Chicago Operations Office. Vols. 1-2.

Christensen, C.L., and E.W. Peterson. 1981. The Bell Canyon Test Summary Report. SAND80-1375. Albuquerque, NM: Sandia National Laboratories.

Christensen, C.L., R.D. Statler, and E.W. Peterson. 1980. "Down-Hole Television (DHTV) Applications in Borehole Plugging," Proceedings of the Workshop on Borehole and Shaft Plugging, Columbus, OH, May 7-9, 1980. SAND80-(0459C. Paris, France: Organisation for Economic Co-Operation and Development. 385-387.

Christensen, C.L., C.W. Gulick, and S.J. Lambert. 1983. Sealing Concepts for the Waste Isolation Pilot Plan (WIPP) Site. SAND81-2195. Albuquerque, NM: Sandia National Laboratories.

Cleasby, J.V., G.E. Pearse, M. Grieves, and G. Thorburn. 1975. "Shaft-Sinking at Boulby Mine, Cleveland Potash, Ltd.," Transactions of the Institute of Mining and Metallurgy, Section A. Vol. 84, no. 818, A7-A28.

Daemen, J.J.K, J.C. Stormont, N.I. Colburn, D.L. South, S.A. Dischler, K. Fuenkajorn, W.B. Greer, G.S. Adisoma, D.E. Miles, B. Kousari, and J. Bertucca. 1983. Rock Mass Sealing - Experimental Assessment of Borehole Plug Performance, Annual Report June 1982 - May 1983. NUREG/CR-3473. Washington, DC: Division of Health, Siting and Waste Management, Office of Nuclear Regulatory Research, US Nuclear Regulatory Commission.

Fossum, A.F., N.S. Brodsky, K.S. Chan, and D.E. Munson. [1992.] "Experimental Evaluation of a Constitutive Model for Inelastic Flow and Damage Evolution in Solids Subjected to Triaxial Compression," Proceedings of the 34th U.S. Symposium on Rock Mechanics, University of Wisconsin, Madison, WI, June 27-30, 1993. (Copy on file at the Waste Management and Transportation Library, Sandia National Laboratories, Albuquerque, NM). 
Gray, M.N., S.C.H. Cheung, and D.A. Dixon. 1984. The Influence of Sand Content on Swelling Pressures and Structure Developed in Statically Compacted Na-Bentonite. AECL7825. Pinawa, Manitoba: Whiteshell Nuclear Research Establishment, Atomic Energy of Canada Limited.

Gulick, C.W., and L.D. Wakeley. 1987. Reference Properties of Cement-Based Plugging and Sealing Materials for the Waste Isolation Pilot Plant (WIPP). Technical Report SL-89-17; SAND87-2817. Vicksburg, MS: Department of the Army, Waterways Experiment Station, Corps of Engineers.

Gulick, C.W., Jr., J.A. Boa, and A.D. Buck. 1982. Borehole Plugging Materials Development Program Report 3. SAND81-0065. Albuquerque, NM: Sandia National Laboratories.

Holcomb, D.J., and D.W. Hannum. 1982. Consolidation of Crushed Salt Backfill Under Conditions Appropriate to the WIPP Facility. SAND82-(1630). Albuquerque, NM: Sandia National Laboratories.

Holcomb, D.J., and M. Shields. 1987. Hydrostatic Creep Consolidation of Crushed Salt With Added Water. SAND87-1990. Albuquerque, NM: Sandia National Laboratories.

Holcomb, D.J., and D.H. Zeuch. 1988. Consolidation of Crushed Rock Salt, Part I: Experimental Results for Dry Salt Analyzed Using a Hot-Pressing Model. SAND88-1469. Albuquerque, NM: Sandia National Laboratories.

Intera Environmental Consultants, Inc. 1981. Consequence Assessment of Hydrological Communications Through Borchole Plugs. SAND81-7164. Albuquerque, NM: Sandia National Laboratories.

Kelsall, P.C., J.B. Case, and C.R. Chabannes. [1982.] A Preliminary Evaluation of the Rock Mass Disturbance Resulting From Shaft, Tunnel, or Borchole Excavation. ONWI-411. [Columbus, $\mathrm{OH}$ : Office of Nuclear Waste Isolation,] Battelle Memorial Institute.

Kerkhoven, R.E. 1959. "Bitumen in Mine Shaft Construction," De Ingenieru. Vol. 71, no. 8. (Translation of Article published in De Ingenicur). 
Lambert, S.J. 1980. "A Strategy for Evaluating the Long-Term Stability of Hole-Plugging Materials in Their Geological Environments," Proceedings of the Workshop on Borehole and Shaft Plugging, Columbus, $\mathrm{OH}$, May 7-9, 1980. SAND8()-0359C. Paris, France: Organisation for Economic Co-Operation and Development. 343-352.

Lappin, A.R., R.L. Hunter, D.P. Garber, and P.B. Davies, eds. 1989. Systems Analysis, Long-Term Radionuclide Transport, and Dose Assessments, Waste Isolation Pilot Plant (WIPP), Southeastern New Mexico; March 1989. SAND89-0462. Albuquerque, NM: Sandia National Laboratories.

Lee, C.F. 1985. A Case History on Long-Term Effectiveness of Clay Sealant. Technical Record TR-338. Pinawa, Manitoba: Atomic Energy of Canada Limited, Whiteshell Nuclear Research Establishment.

Lin, M.S., and L.L. Van Sambeek. 1992a. Waste Isolation Pilot Plant: Alcove Gas Barrier Trade-Off Study. SAND91-7099. Albuquerque, NM: Sandia National Laboratories.

Lin, M.S., and L.L. Van Sambeek. 1992b. Waste Isolation Pilot Plant: Alcove Gas Barrier Final Design Report. SAND92-7307. Albuquerque, NM: Sandia National Laboratories.

Meyer, D., and J.J. Howard, eds. 1983. Evaluation of Clays and Clay Minerals for Application to Repository Sealing. ONWI-486. Columbus, OH: Office of Nuclear Waste Isolation, Battelle Memorial Institute.

Munson, D.E., and K.L. DeVries. 1990. "Progress in Validation of Structural Codes for Radioactive Waste Repository Applications in Bedded Salt," GEOVAL 90, Safety Assessment of Radioactive Waste Repositories, Stockholm, Sweden, May 14-17, 1990. SAND89-2176. Paris, France: Organisation for Economic Co-Operation and Development. 522-529.

Munson, D.E., and K.L. DeVries. 1991. "Development and Validation of a Predictive Technology for Creep Closure of Underground Rooms in Salt," Proceedings: 7th International Congress on Rock Mechanics, Aachen, Germany, September 12-16, 1991. Ed. W. Wittke. SAND90-1147C. Vol. 7, 127-134. 
Munson, D.E., T.M. Torres, and R.L. Jones. 1988. "Results of a Large, In Situ, Heated Axisymmetric Pillar Test at the Waste Isolation Pilot Plant (WIPP)," Key Questions in Rock Mechanics, Proceedings of the 29th U.S. Symposium, University of Minnesota, Minneapolis, MN, June 13-15, 1988. Eds. P.A. Cundall, R.L. Sterling, and A.M. Starfield. SAND87-2257C. Brookfield, VT: A.A. Balkema. 641-651.

Munson, D.E., K.L. DeVries, and G.D. Callahan. 1990. "Comparison of Calculations and In Situ Results for a Large, Heated Test Room at the Waste Isolation Pilot Plant (WIPP)," Rock Mechanics, Contributions and Challenges: Proceedings of the 31st U.S. Symposium, Golden, CO, June 18-20, 1990. Eds. W.A. Hustrulid and G.A. Johnson. SAND89-2268C. Brookfield, VT: A.A. Balkema. 389-396.

Munson, D.E., R.L. Jones, and K.L. DeVries. 1991. "Analysis of Early Creep Closures in Geomechanically Connected Underground Rooms in Salt," Rock Mechanics as a Multidisciplinary Science, Proceedings of the 32nd U.S. Symposium, University of Oklahoma, Norman, OK, July 10-12, 1991. Ed. J-C. Roegiers. SAND90-2081C. Brookfield, VT: A.A. Balkema. 881-888.

Munson, D.E., K.L. DeVries, D.M. Schiermeister, W.F. DeYonge, and R.L. Jones. 1992. "Measured and Calculated Closures of Open and Brine Filled Shafts and Deep Vertical Boreholes in Salt," Rock Mechanics, Proceedings of the 33rd U.S. Symposium, Santa Fe, NM, June 3-5, 1992. Eds. J.R. Tillerson and W.R. Wawersik. SAND91-1869. Brookfield, VT: A.A. Balkema. 439-448.

Nowak, E.J., J.R. Tillerson, and T.M. Torres. 1990. Initial Reference Seal System Design: Waste Isolation Pilot Plant. SAND90-0355. Albuquerque, NM: Sandia National Laboratories.

Oellers, T. 1983. "Asphalt - An Active Sealing Medium for Shaft Construction," Glückauf: Zeitschrift für Technik und Wirtschaft des Bergbaus. Vol. 119, no. 12, 567-570.

Oellers, T., and P. Sitz. 1985. "Design and Calculation of Gas Tight and Liquid Tight Shaft Seals," Shaft-Sinking and Tunneling Colloquium, Berlin, F.R. Germany, February 21, 1985. CONF-8502123. Essen, F.R. Germany: Verlag Glückauf. 48-56. 
Pence, S.A., A.I. McCallum, and V. DeKorompay. 1971. "Water-Swellable Polymeric Sealant Protects Salt In Potash Shafts," Canadian Institute of Mining and Metallurgy Bulletin. Vol. 64, no. 714, 72-76.

Pfeifle, T.W., and P.E. Senseny. 1985. Permeability and Consolidation Of Crushed Salt From The WIPP Site. Topical Report RSI-0278. Rapid City, SD: RE/SPEC, Inc.

Pusch, R. 1979. "Highly Compacted Sodium Bentonite For Isolating Rock-Deposited Radioactive Waste Products," Nuclear Technology. Vol. 45, 153-157.

Pusch, R. 1980. Permeability of Highly Compacted Bentonite. SKBF/KBS 80-16. Stockholm: Svensk Kärnbränsleförsörjning A.B.

Pusch, R. 1982. "Mineral-Water Interactions and Their Influence on the Physical Behavior of Highly Compacted Sodium Bentonite," Canadian Geotechnical Journal. Vol. 19, no. 3, 381-387.

Pusch, R., L. Börgesson, and G. Ramqvist. 1987. Final Report of the Borehole, Shaft, and Tunnel Sealing Test. Volume II: Shaft Plugging. SKB-SP-TR-87-02. Stockholm: Svensk Kärnbränsleförsörjning A.B.

Ratigan, J.L., L.L. Van Sambeek, K.L. DeVries, and J.D. Nieland. 1991. The Influence of Seal Design on the Development of the Disturbed Rock Zone in the WIPP Alcove Seal Tests. Topical Report RSI-(0400 Rapid City, SD: RE/SPEC, Inc.

Sjaardema, G.D., and R.D. Krieg. 1987. A Constitutive Model for the Consolidation of WIPP Crushed Salt and Its Use in Analyses of Backfilled Shaft and Drift Configurations. SAND87-1977. Albuquerque, NM: Sandia National Laboratories.

Storck, U. 1968. First Use of Double Steel and Concrete Sandwich Lining for Keeping High Pressure Water Out of Potash Shaft. [Canadian Institute of Mining and Metallurgy.] (Copy on file at the Waste Management and Transportation Library, Sandia National Laboratories, Albuquerque, NM).

Stormont, J.C. 1984. Plugging and Sealing Program for the Waste Isolation Pilot Plant (WIPP). SAND84-1057. Albuquerque, NM: Sandia National Laboratories. 
Stormont, J.C. 1988. Preliminary Seal Design Evaluation for the Waste Isolation Pilot Plant. SAND87-3083. Albuquerque, NM: Sandia National Laboratories.

Stormont, J.C. 1990. "Discontinuous Behaviour Near Excavations in a Bedded Salt Formation," International Journal of Mining and Geologic Engineering. SAND89-2403. Vol. 8, no. 1, 35-56.

Stormont, J.C., and J.G. Arguello. 1988. Model Calculations of Flow Through Shaft Seals in the Rustler Formation. SAND87-2859. Albuquerque, NM: Sandia National Laboratories.

Stormont, J.C., E.W. Peterson, and P.L. Lagus. 1987. Summary of and Observations About WIPP Facility Horizon Flow Measurements Through 1986. SAND87-(176. Albuquerque, NM: Sandia National Laboratories.

Stormont, J.C., C.L. Howard, and J.J.K. Daemen. 1991. In Situ Measurements of Rock Salt Permeability Changes Due to Nearby Excavation. SAND90-3134. Albuquerque, NM: Sandia National Laboratories.

Stroup, D.E., and P.E. Senseny. 1987. Influence of Bentonite Content on Consolidation and Permeability of Crushed Salt from the WIPP. Topical Report RSI-0309. Rapid City, SD: RE/SPEC, Inc.

Torres, T.M., C.L. Howard, and R.E. Finley. 1992. Development, Implementation, and Early Results: Test Series D, Phase 1 of the Small-Scale Seal Performance Tests. SAND91-2001. Albuquerque, NM: Sandia National Laboratories.

US Department of Energy (US DOE). 1980. Final Environmental Impact Statement, Waste Isolation Pilot Plant. DOE/EIS-(0)26. Washington, DC: US Department of Energy, Assistant Secretary for Defense Programs. Vols. 1-2.

Van Sambeek, L.L. 1986. "Creep of Rock Salt Under Inhomogeneous Stress Conditions." $\mathrm{PhD}$ dissertation. Golden, CO: Department of Mining Engineering, Colorado School of Mines.

Van Sambeek, L.L. 1987. Thermal and Thermomechanical Analyses of WIPP Shaft Seals. SAND87-7(139. Albuquerque, NM: Sandia National Laboratories. 
Van Sambeek, L.L. 1988. Considerations for the Use of Quarried Salt Blocks in Seal Components at the WIPP. Topical Report RSI-(340. Rapid City, SD: RE/SPEC, Inc.

Van Sambeek, L.L. 1992. "Testing and Modeling of Backfill Used in Salt and Potash Mines," Rock Support in Mining and Underground Construction, Proceedings of the International Symposium on Rock Support, Sudbury, Ontario, Canada, June 16-19, 1992. Eds. P.K. Kaiser and D.R. McCreath. Brookfield, VT: A.A. Balkema. 583-589.

ZoBell, C.E., and M.A. Molecke. 1978. Survey of Microbial Degradation of Asphalts With Notes on Relationship to Nuclear Waste Management. SAND78-1371. Albuquerque, NM: Sandia National Laboratories. 
APPENDIX A

A-1 


$$
\text { A-2 }
$$




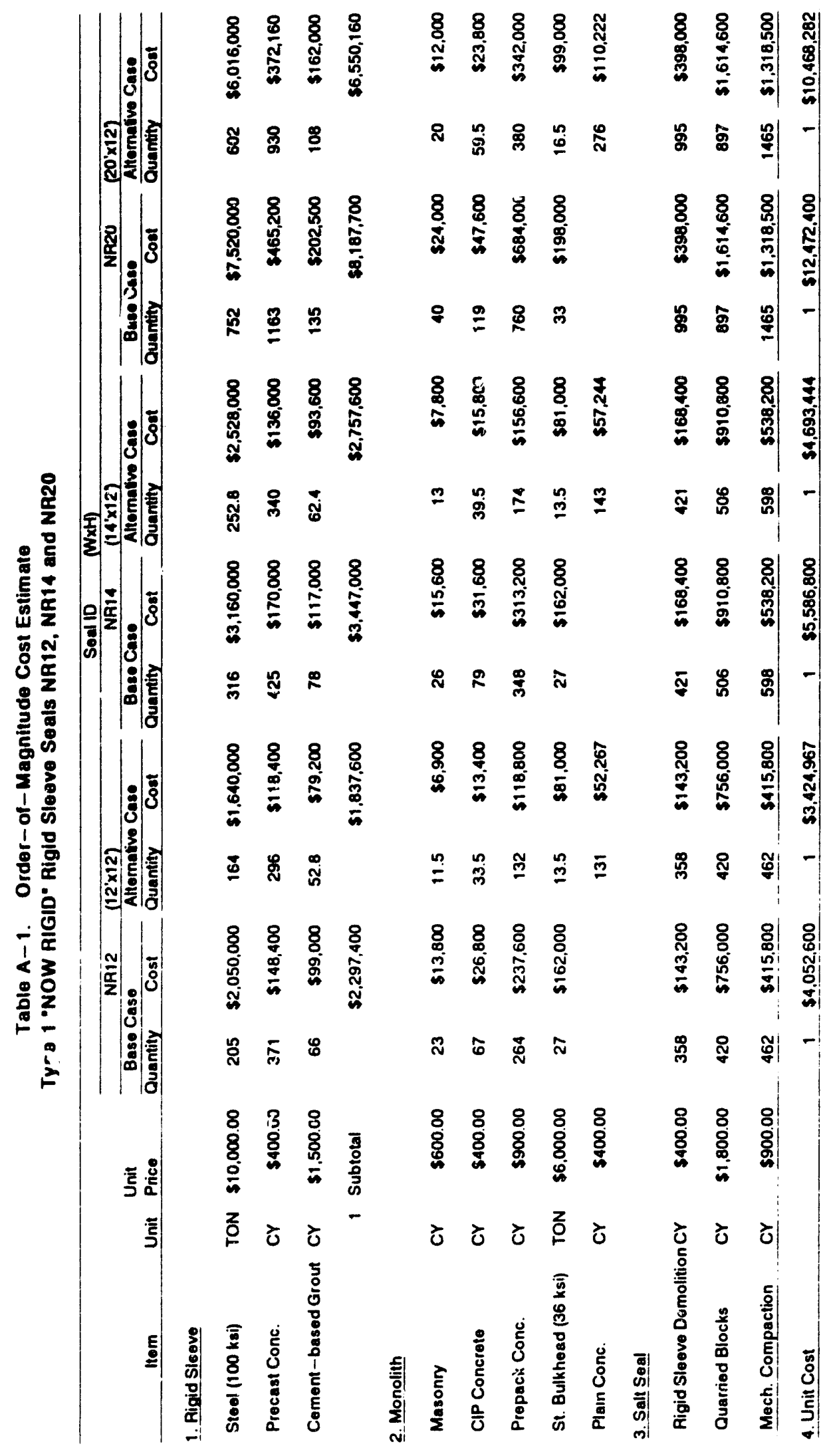




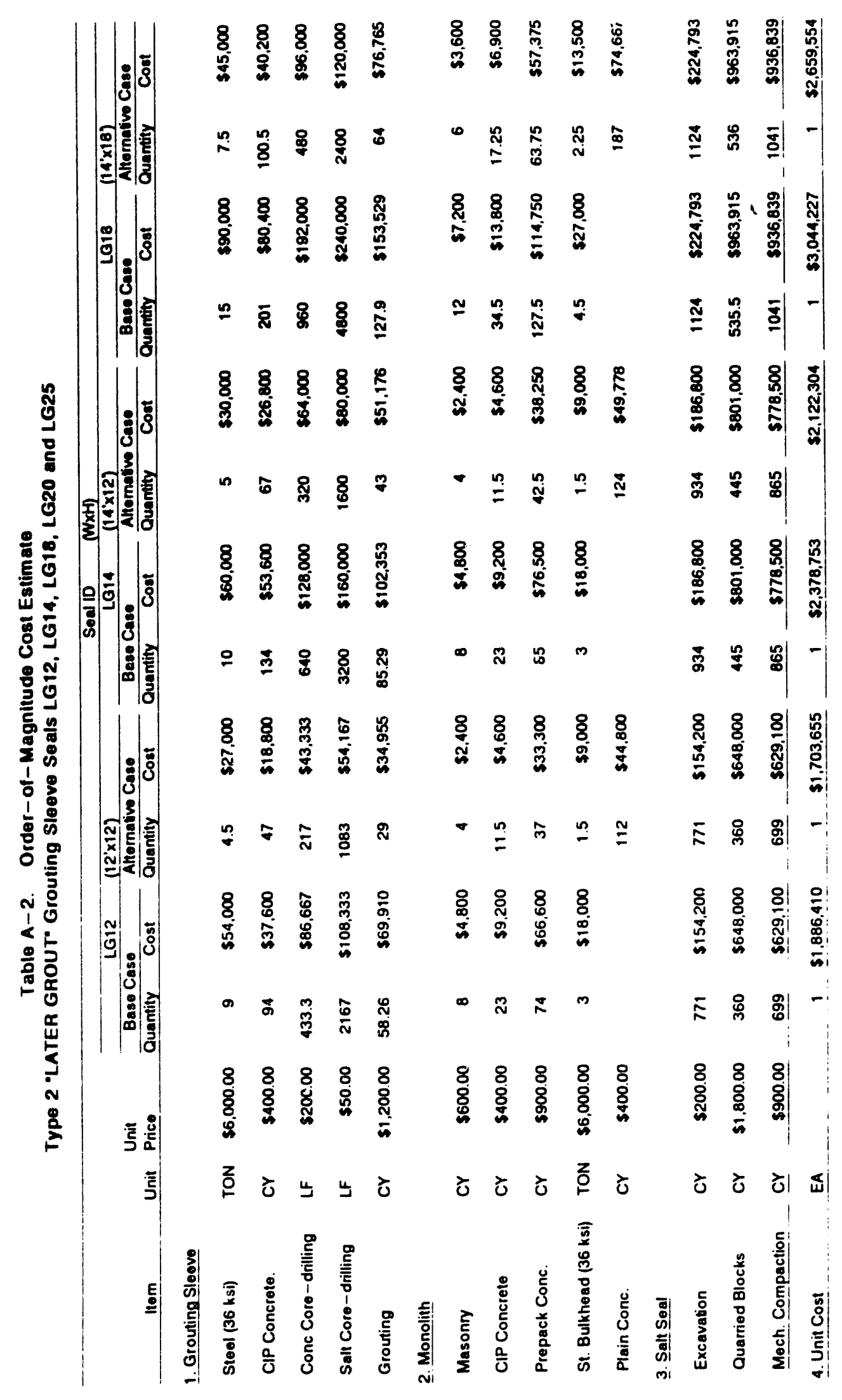




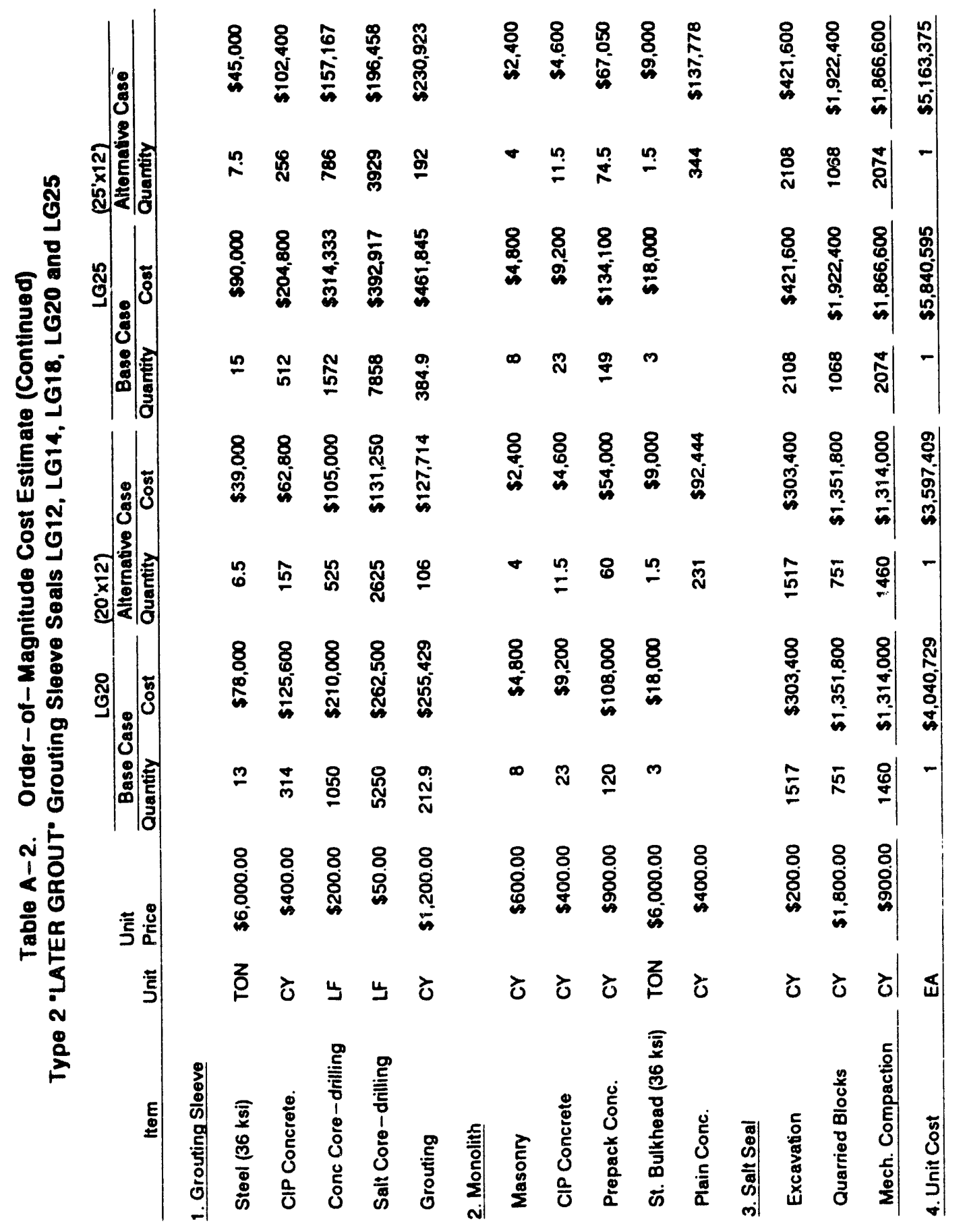




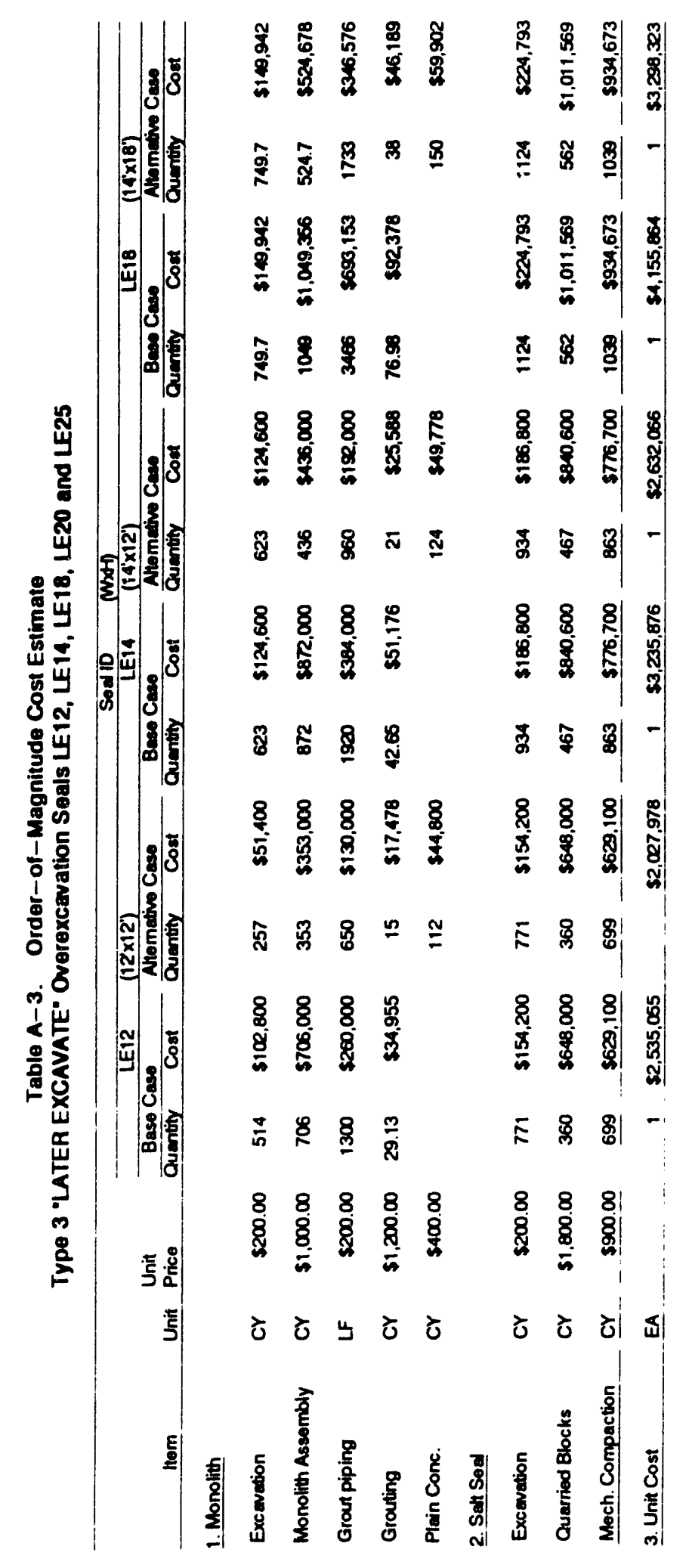




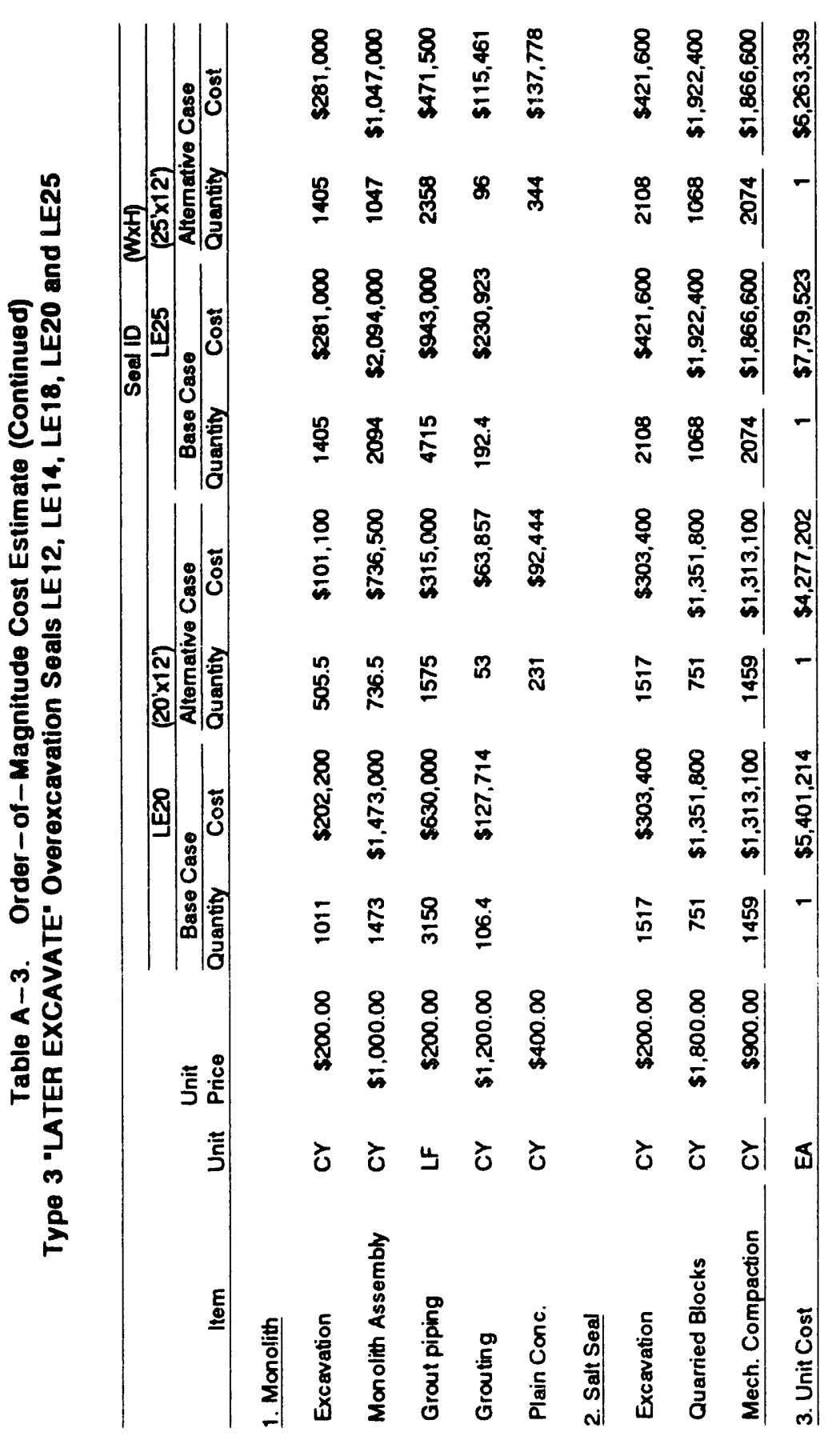


Table A-4. Order-of-Magnitude Cost Estimate,

Type 4 Rigid Sleeve/ Overexcavation Seals NRIL14

\begin{tabular}{|c|c|c|c|c|c|c|}
\hline \multirow[b]{2}{*}{ Hom } & \multirow[b]{2}{*}{ Unit } & \multirow{2}{*}{$\begin{array}{l}\text { Unit } \\
\text { Price }\end{array}$} & \multicolumn{2}{|c|}{$\begin{array}{c}\text { Sod ID } \\
\text { NRVLE14 } \\
\text { Bns Cos }\end{array}$} & \multicolumn{2}{|c|}{$\frac{W x-1)}{\left(14 \times 12820 \times 12^{\prime}\right)}$} \\
\hline & & & Ouentity & Cost & Quentity & Cost \\
\hline \multicolumn{7}{|l|}{ 1. Figid Sleovo } \\
\hline Steel (100 ksi) & TON & $\$ 10,000.00$ & 127 & $\$ 1,270,000$ & 64 & $\$ 635,000$ \\
\hline Precast Conc. & CY & $\$ 400.00$ & 170 & $\$ 68,000$ & 85 & $\$ 34,000$ \\
\hline Coment-based Grout & CY & $\$ 1,500.00$ & 31 & $\$ 46,800$ & 16 & $\$ 23,400$ \\
\hline \multicolumn{7}{|l|}{ 2. Monolith } \\
\hline Masonny & $\mathrm{Cr}$ & $\$ 400.00$ & 26 & $\$ 10,400$ & 13 & $\$ 5,200$ \\
\hline CIP Concrete & CY & $\$ 400.00$ & 79 & $\$ 31,600$ & 39.5 & $\$ 15,800$ \\
\hline Prepack Conc. & $\mathrm{Cr}$ & $\$ 900.00$ & 348 & $\$ 313,200$ & 174 & $\$ 156,600$ \\
\hline St. Bulkhead (36 ksi) & TON & $\$ 6,000.00$ & 27 & $\$ 162,000$ & 13.5 & $\$ 81,000$ \\
\hline Plain Conc. & CY & $\$ 400.00$ & & & 143 & $\$ 57,244$ \\
\hline \multicolumn{7}{|l|}{ 3. Salt Seal } \\
\hline Excenation & $\mathrm{CY}$ & $\$ 200.00$ & 934 & $\$ 186,800$ & 934 & $\$ 186,800$ \\
\hline Quarried Blocks & CY & $\$ 1,800.00$ & 467 & $\$ 840,600$ & 467 & $\$ 840,600$ \\
\hline Mech. Compaction & $\mathrm{CY}$ & $\$ 900.00$ & 863 & $\$ 776,700$ & 863 & $\$ 776,700$ \\
\hline 4. Unit Cost & $E A$ & & 1 & $\$ 3,706,100$ & & $\$ 2,812,344$ \\
\hline
\end{tabular}


Table A-5. Rough Order-of-Magnitude Cost Evaluation of Combination 1

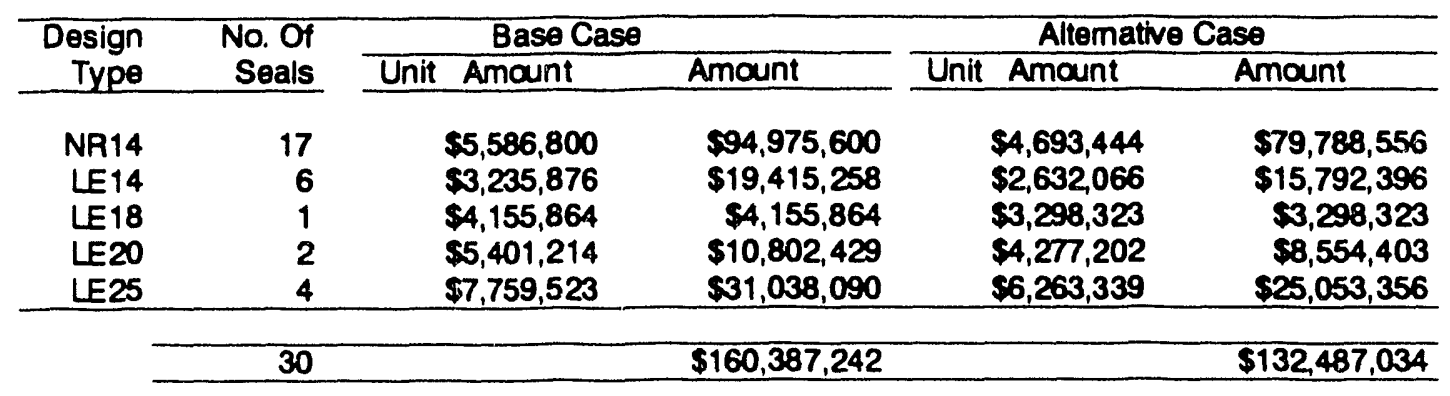

Table A-6. Rough Order-of-Magnitude Cost Evaluation of Combination 1A

\begin{tabular}{|c|c|c|c|c|c|}
\hline \multirow{2}{*}{$\begin{array}{c}\text { Design } \\
\text { Type }\end{array}$} & \multirow{2}{*}{$\begin{array}{l}\text { No. Of } \\
\text { Seals }\end{array}$} & \multicolumn{2}{|c|}{ Base Case } & \multicolumn{2}{|c|}{ Altemative Case } \\
\hline & & Unit Amount & Amount & Unit Amount & Amount \\
\hline NA12 & 7 & $\$ 4,052,600$ & $\$ 28,368,200$ & $\$ 3,424,967$ & $\$ 23,974,767$ \\
\hline NR14 & 10 & $\$ 5,586,800$ & $\$ 55,868,000$ & $\$ 4,693,444$ & $\$ 46,934,444$ \\
\hline LE 14 & 6 & $\$ 3,235,876$ & $\$ 19,415,258$ & $\$ 2,632,066$ & $\$ 15,792,396$ \\
\hline LE18 & 1 & $\$ 4,155,864$ & $\$ 4,155,864$ & $\$ 3,298,323$ & $\$ 3,298,323$ \\
\hline LE20 & 2 & $\$ 5,401,214$ & $\$ 10,802,429$ & $\$ 4,277,202$ & $\$ 8,554,403$ \\
\hline LE25 & 4 & $\$ 7,759,523$ & $\$ 31,038,090$ & $\$ 6,263,339$ & $\$ 25,053,356$ \\
\hline & 30 & & $\$ 149,647,842$ & & $\$ 123,607,690$ \\
\hline
\end{tabular}

Table A-7. Rough Order-of-Magnitude Cost Evaluation of Combination 2

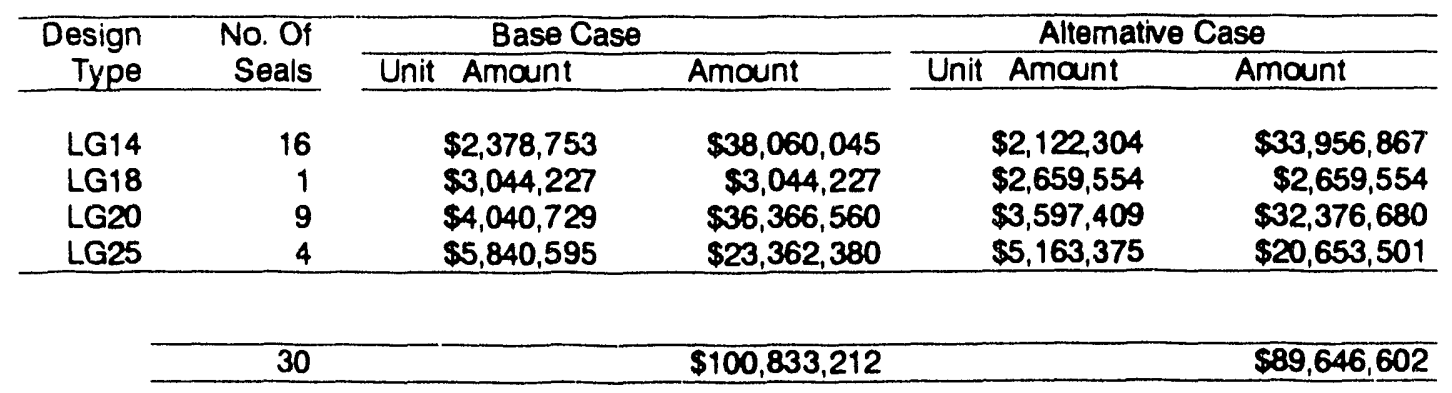


Table A-8. Rough Order-of-Magnitude Cost Evaluation of Combination 2A

\begin{tabular}{|c|c|c|c|c|c|}
\hline Design & No. Of & Base Ca & & Altemat & \\
\hline Type & Seals & Unit Amount & Amount & Unit Amount & Amount \\
\hline LG12 & 7 & $\$ 1,886,410$ & $\$ 13,204,871$ & $\$ 1,703,655$ & $\$ 11,925,585$ \\
\hline LG14 & 16 & $\$ 2,378,753$ & $\$ 38,060,045$ & $\$ 2,122,304$ & $\$ 33,956,867$ \\
\hline LG18 & 1 & $\$ 3,044,227$ & $\$ 3,044,227$ & $\$ 2,659,554$ & $\$ 2,659,554$ \\
\hline LG2 & 2 & $\$ 4,040,729$ & $\$ 8,081,458$ & $\$ 3,597,409$ & $\$ 7,194,818$ \\
\hline LG25 & 4 & $\$ 5,840,595$ & $\$ 23,362,380$ & $\$ 5,163,375$ & $\$ 20,653,501$ \\
\hline
\end{tabular}

$30-\$ 85,752,980$

$\$ 76,390,325$

Table A-9. Rough Order-of-Magnitude Cost Evaluation of Combination 3

\begin{tabular}{|c|c|c|c|c|c|}
\hline \multirow{2}{*}{$\begin{array}{r}\text { Design } \\
\text { Type }\end{array}$} & \multirow{2}{*}{$\begin{array}{r}\text { No. Of } \\
\text { Seals } \\
\end{array}$} & \multicolumn{2}{|c|}{ Base Case } & \multicolumn{2}{|c|}{ Altemative Case } \\
\hline & & Unit Amount & Amount & Unit Amount & Amount \\
\hline $\begin{array}{l}\text { LE14 } \\
\text { LE18 } \\
\text { LE20 } \\
\text { LE25 }\end{array}$ & $\begin{array}{r}16 \\
1 \\
9 \\
4\end{array}$ & $\begin{array}{l}\$ 3,235,876 \\
\$ 4,155,864 \\
\$ 5,401,214 \\
\$ 7,759,523\end{array}$ & $\begin{array}{r}\$ 51,774,022 \\
\$ 4,155,864 \\
\$ 48,610,930 \\
\$ 31,038,090 \\
\end{array}$ & $\begin{array}{l}\$ 2,632,066 \\
\$ 3,298,323 \\
\$ 4,277,202 \\
\$ 6,263,339 \\
\end{array}$ & $\begin{array}{r}\$ 42,113,056 \\
\$ 3,298,323 \\
\$ 38,494,815 \\
\$ 25,053,356 \\
\end{array}$ \\
\hline & 30 & & $\$ 135,578,907$ & & $\$ 108,959,550$ \\
\hline
\end{tabular}

Table A-10. Rough Order-of-Magnitude Cost Evaluation of Combination 3A

\begin{tabular}{|c|c|c|c|c|c|c|}
\hline \multirow{2}{*}{$\begin{array}{r}\text { Design } \\
\text { Type }\end{array}$} & \multirow{2}{*}{$\begin{array}{r}\text { No. Of } \\
\text { Seals }\end{array}$} & \multicolumn{3}{|c|}{ Base Case } & \multicolumn{2}{|c|}{ Altemative Case } \\
\hline & & Unit & Amount & Amount & Unit Amount & Amount \\
\hline LE12 & 7 & & $\$ 2,535,055$ & $\$ 17,745,385$ & $\$ 2,027,978$ & $\$ 14,195,843$ \\
\hline LE14 & 16 & & $\$ 3,235,876$ & $\$ 51,774,022$ & $\$ 2,632,066$ & $\$ 42,113,056$ \\
\hline LE18 & 1 & & $\$ 4,155,864$ & $\$ 4,155,864$ & $\$ 3,298,323$ & $\$ 3,298,323$ \\
\hline LE20 & 2 & & $\$ 5,401,214$ & $\$ 10,802,429$ & $\$ 4,277,202$ & $\$ 8,554,403$ \\
\hline LE25 & 4 & & $\$ 7,759,523$ & $\$ 31,038,090$ & $\$ 6,263,339$ & $\$ 25,053,356$ \\
\hline
\end{tabular}


Table A-11. Rough Order-of-Magnitude Cost Evaluation of Combination 4

\begin{tabular}{|c|c|c|c|c|c|}
\hline \multirow{2}{*}{$\begin{array}{c}\text { Design } \\
\text { Type } \\
\end{array}$} & \multirow{2}{*}{$\begin{array}{r}\text { No. Of } \\
\text { Seals } \\
\end{array}$} & \multicolumn{2}{|c|}{ Base Case } & \multicolumn{2}{|c|}{ Alternative Case } \\
\hline & & Unit Amount & Amount & Unit Amount & Amount \\
\hline $\begin{array}{r}\text { NR/LE14 } \\
\text { LE25 } \\
\text { LE14 } \\
\text { LE18 } \\
\text { LE20 } \\
\end{array}$ & $\begin{array}{r}17 \\
4 \\
6 \\
1 \\
2 \\
\end{array}$ & $\begin{array}{l}\$ 3,706,100 \\
\$ 7,759,523 \\
\$ 3,235,876 \\
\$ 4,155,864 \\
\$ 5,401,214\end{array}$ & $\begin{array}{r}\$ 63,003,700 \\
\$ 31,038,090 \\
\$ 19,415,258 \\
\$ 4,155,864 \\
\$ 10,802,429 \\
\end{array}$ & $\begin{array}{l}\$ 2,812,344 \\
\$ 6,263,339 \\
\$ 2,632,066 \\
\$ 3,298,323 \\
\$ 4,277,202 \\
\end{array}$ & $\begin{array}{r}\$ 47,809,856 \\
\$ 25,053,356 \\
\$ 15,792,396 \\
\$ 3,298,323 \\
\$ 8,554,403\end{array}$ \\
\hline
\end{tabular}




\section{A-12}




\section{APPENDIX B}

B-1 


$$
\text { B-2 }
$$




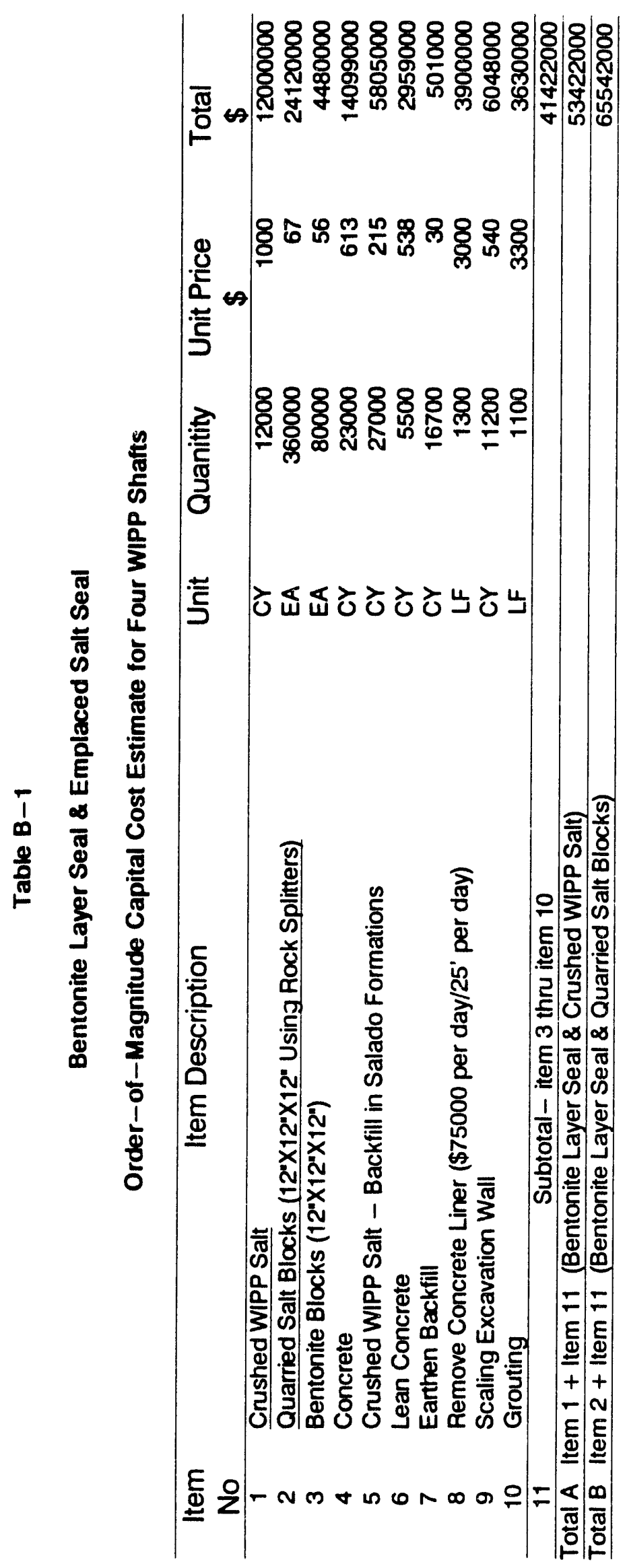

B-3 


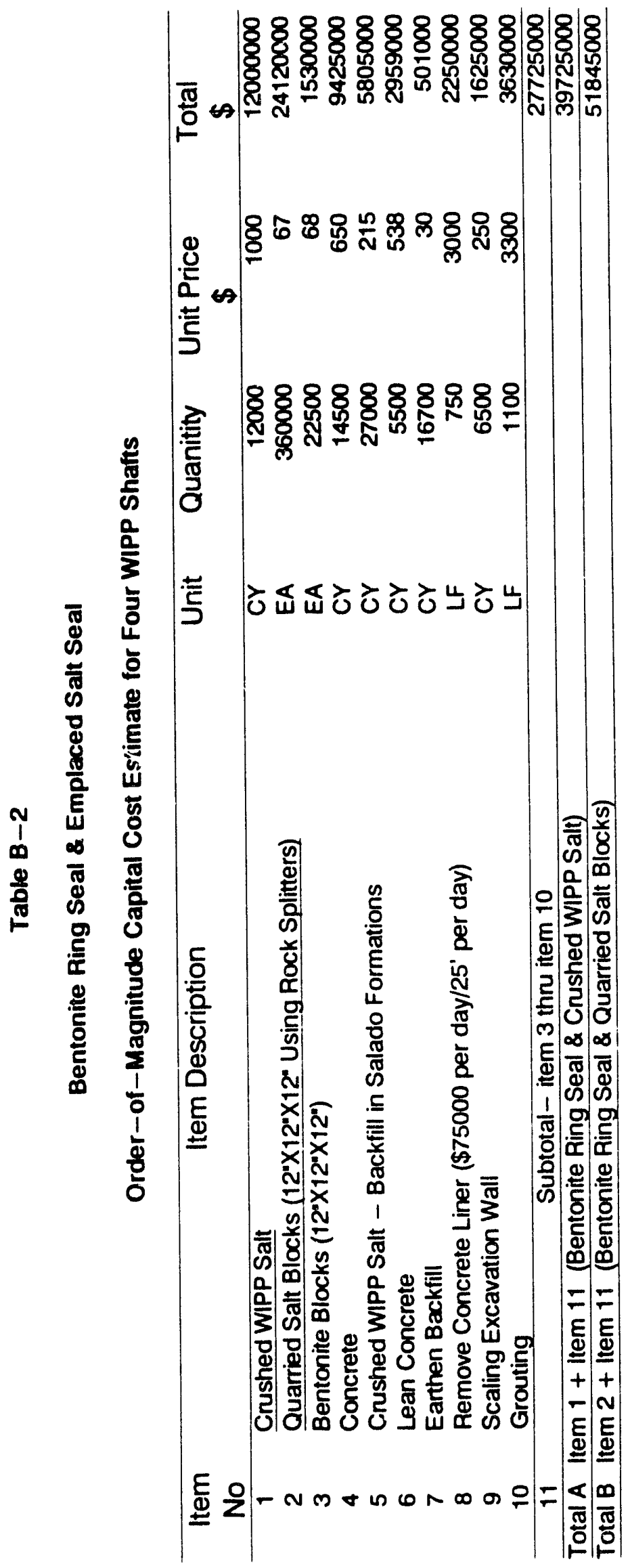




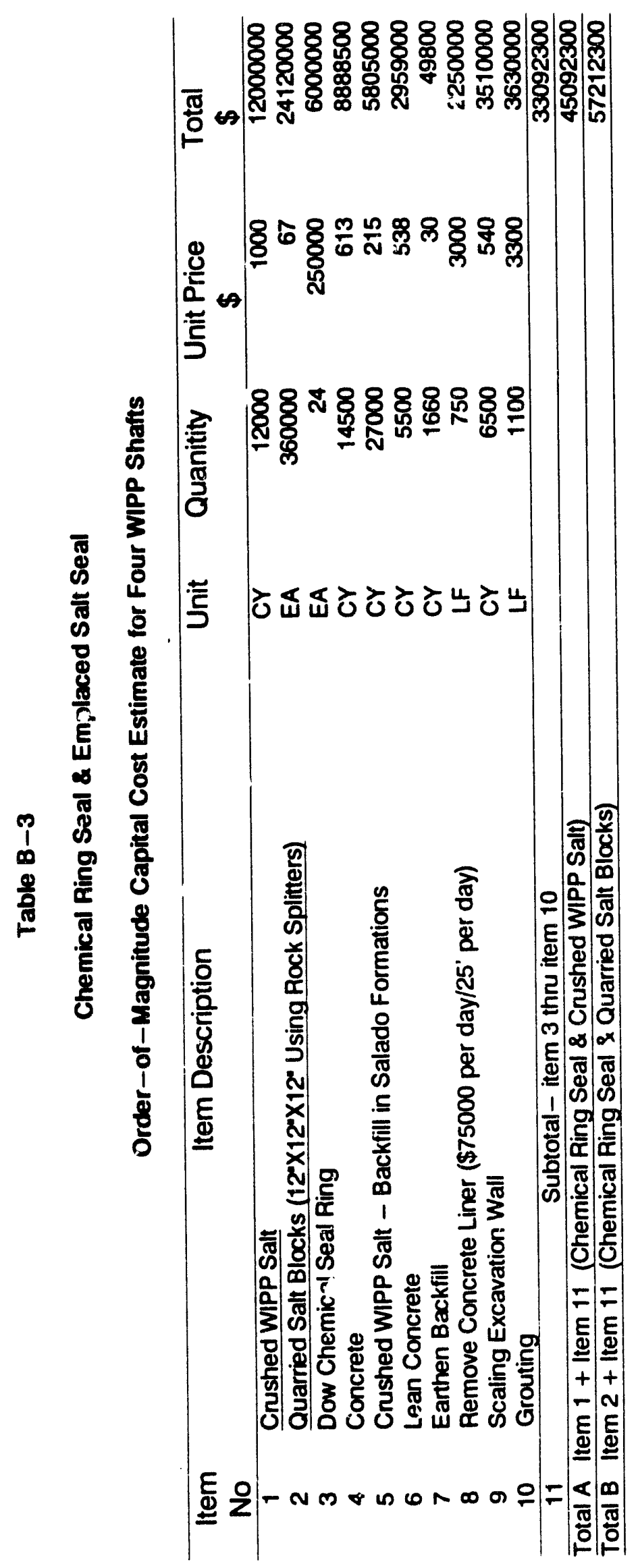




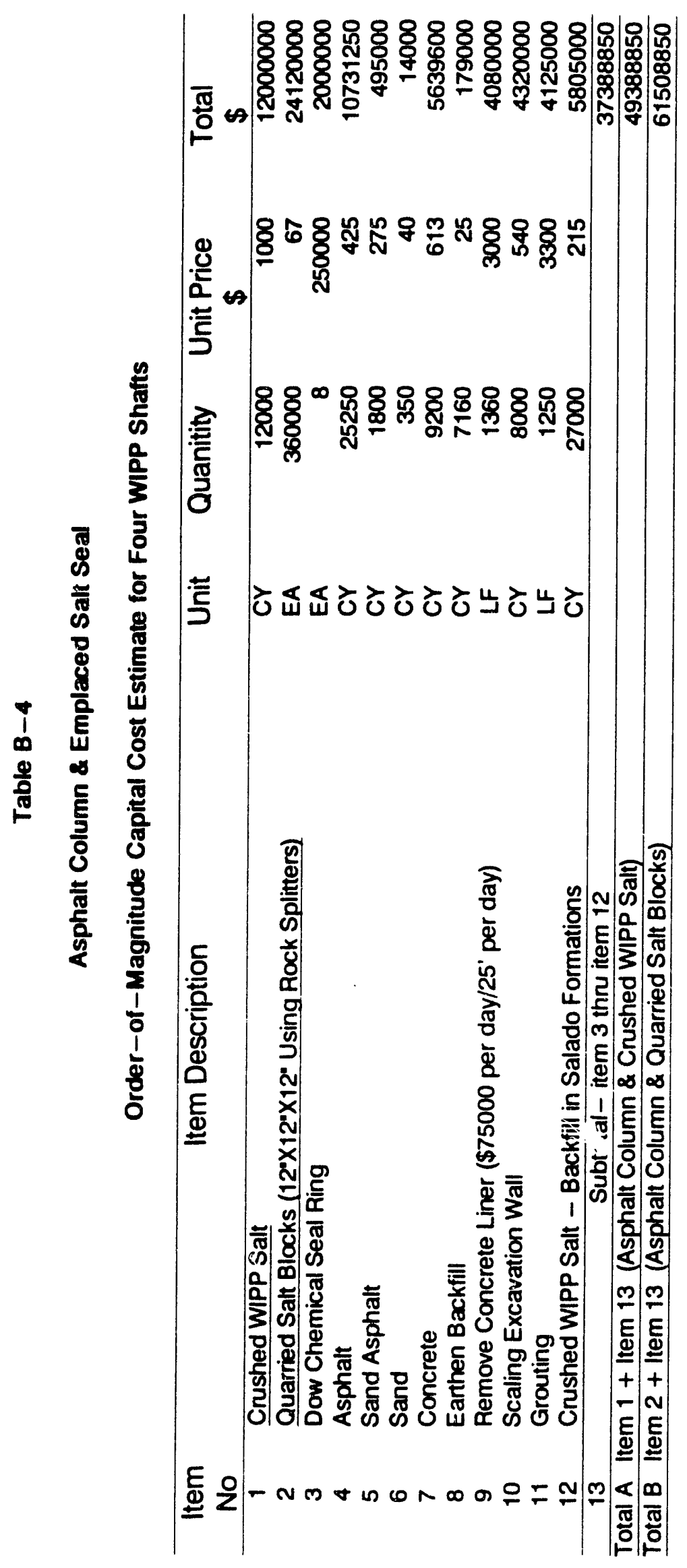

B-6 
APPENDIX C

C-1 
C-2 
Table C-1 - WIPP Conceptual Seal Design

Alternative Study

Borehole Sealing Unit Costs

\begin{tabular}{|c|c|c|}
\hline SEALMATERIAL & UNIT CosT $^{(5)}$ & MATERIAL \& LABOR \\
\hline $\begin{array}{l}\text { Cementitious } \\
\text { Grout }^{(1)}\end{array}$ & $\$ 1,800 / C Y(\$ 120 / L F)$ & \$80/LF \& \$40/LF \\
\hline Crushed Salt ${ }^{(2)}$ & $\$ 1,650 / \mathrm{CY}(\$ 110 / \mathrm{LF})$ & \$9/LF \& \$65/LF \\
\hline $\begin{array}{l}\text { Bentonite/ } \\
\text { Crushed Salt }{ }^{(3)}\end{array}$ & $\$ 1,750 / C Y(\$ 117 / L F)$ & \$47/LF \& \$70/LF \\
\hline Asphalt $^{(4)}$ & $\$ 900 / C Y(\$ 60 / L F)$. & \$16/LF \& \$34/LF \\
\hline ACTIVITY & & UNIT COST \\
\hline $\begin{array}{l}\text { Drilling with } \\
\text { Casing Removal }\end{array}$ & & $\$ 300 / L F$ \\
\hline $\begin{array}{l}\text { Drilling with } \\
\text { Casing Perforated }\end{array}$ & & $\$ 60 / L F$ \\
\hline $\begin{array}{l}\text { Drilling with } \\
\text { No Casing }\end{array}$ & & $\$ 45 / \mathrm{LF}$ \\
\hline
\end{tabular}

\section{NOTES:}

(1) Material cost based on prepackaged non-shrink grout.

(2) Crushed salt emplaced anci compacted in-situ to $80 \%+/$ - fractional density.

(3) Salt-Bentonite mixture emplaced and compacted in-situ to $80 \%+/$ - fractional density

(4) Asphalt density is taken as $1.3 \mathrm{~g} / \mathrm{cm}^{3}+1-$

(5) Cost per linear foot based on an assumed average borehole diameter of 18 inches after casing removal. 
Table C-2 - WIPP Conceptual Seal Design Alternative Study

Borehole Sealing Alternative Cost Estimate

\begin{tabular}{|c|c|c|c|c|c|c|c|}
\hline Item & Borehole & Depth & Casing Depth & \multicolumn{4}{|c|}{$\frac{\text { Cost of Altematives }}{\mathrm{A}} \mathrm{B} \quad \mathrm{C}=\mathrm{D}$} \\
\hline 1 & ERDA-9 & 2,877 & 2,877 & 0.518 & 1.019 & 1.034 & 0.345 \\
\hline 2 & WIPP-19 & 1,038 & 850 & 0.187 & 0.208 & 0.211 & 0.125 \\
\hline 3 & WIPP-21 & 1,046 & 850 & 0.188 & 0.209 & 0.211 & 0.126 \\
\hline 4 & WIPP-22 & 1,448 & 850 & 0.261 & 0.253 & 0.259 & 0.174 \\
\hline 5 & $H-1$ & 856 & 856 & 0.154 & 0.190 & 0.191 & 0.103 \\
\hline 6 & H-2 & 795 & 795 & 0.143 & 0.165 & 0.166 & 0.095 \\
\hline 7 & $\mathbf{H}-\mathbf{3}$ & 894 & 894 & 0.161 & 0.206 & 0.207 & 0.107 \\
\hline 8 & P-3 & 785 & 785 & 0.141 & 0.161 & 0.161 & 0.094 \\
\hline 9 & B-25 & 901 & 901 & $\begin{array}{l}\text { Rework } \\
\text { backfill }\end{array}$ & $\begin{array}{l}\text {; portion } \\
\text { ed with s }\end{array}$ & $\begin{array}{l}\text { of hole (to } \\
\text { nd. }\end{array}$ & $450 \mathrm{ft})$. \\
\hline 10 & P-2 & 1,938 & 850 & 0.349 & 0.288 & 0.296 & 0.233 \\
\hline TOTAL & ase 1 (DRD based) & 11,677 & 9,607 & 2.102 & 2.699 & 2.736 & 1.402 \\
\hline 11 & WIPP-18 & 1,730 & 850 & 0.311 & 0.284 & 0.292 & 0.208 \\
\hline 12 & P-5 & 1,800 & 850 & 0.108 & 0.292 & 0.300 & 0.216 \\
\hline 13 & $P-4$ & 1,885 & 850 & 0.339 & 0.301 & 0.310 & 0.226 \\
\hline TOTAL & ase 2 (Condition 1) & 17,993 & 13,058 & 2.860 & 3.576 & 3.638 & 2.052 \\
\hline 14 & WIPP-12 & 3,884 & 850 & 0.699 & 0.533 & 0.547 & 0.446 \\
\hline 15 & WIPP-13 & 3,808 & 850 & 0.685 & 0.525 & 0.538 & 0.457 \\
\hline 16 & DOE-1 & 4,077 & 850 & 0.734 & 0.554 & 0.570 & 0.489 \\
\hline $\begin{array}{l}\text { TOTAL: } \\
\text { (Co }\end{array}$ & $\begin{array}{l}\text { se } 3 \\
\text { ions } 1 \& 2 \text { ) }\end{array}$ & 29,762 & 15,608 & 4.978 & 5.188 & 5.293 & 3.444 \\
\hline
\end{tabular}


APPENDIX D

D-1 
D-2 


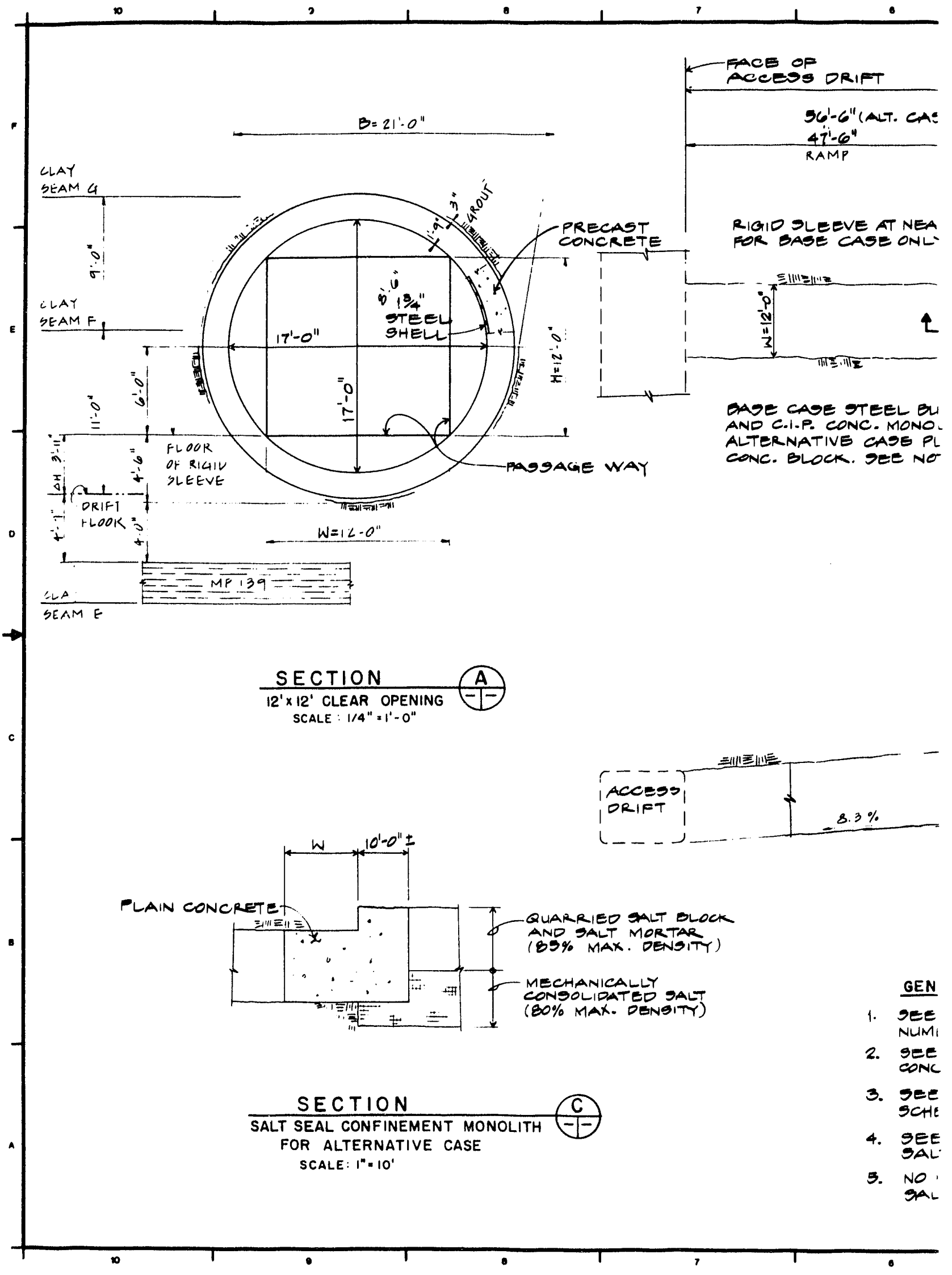




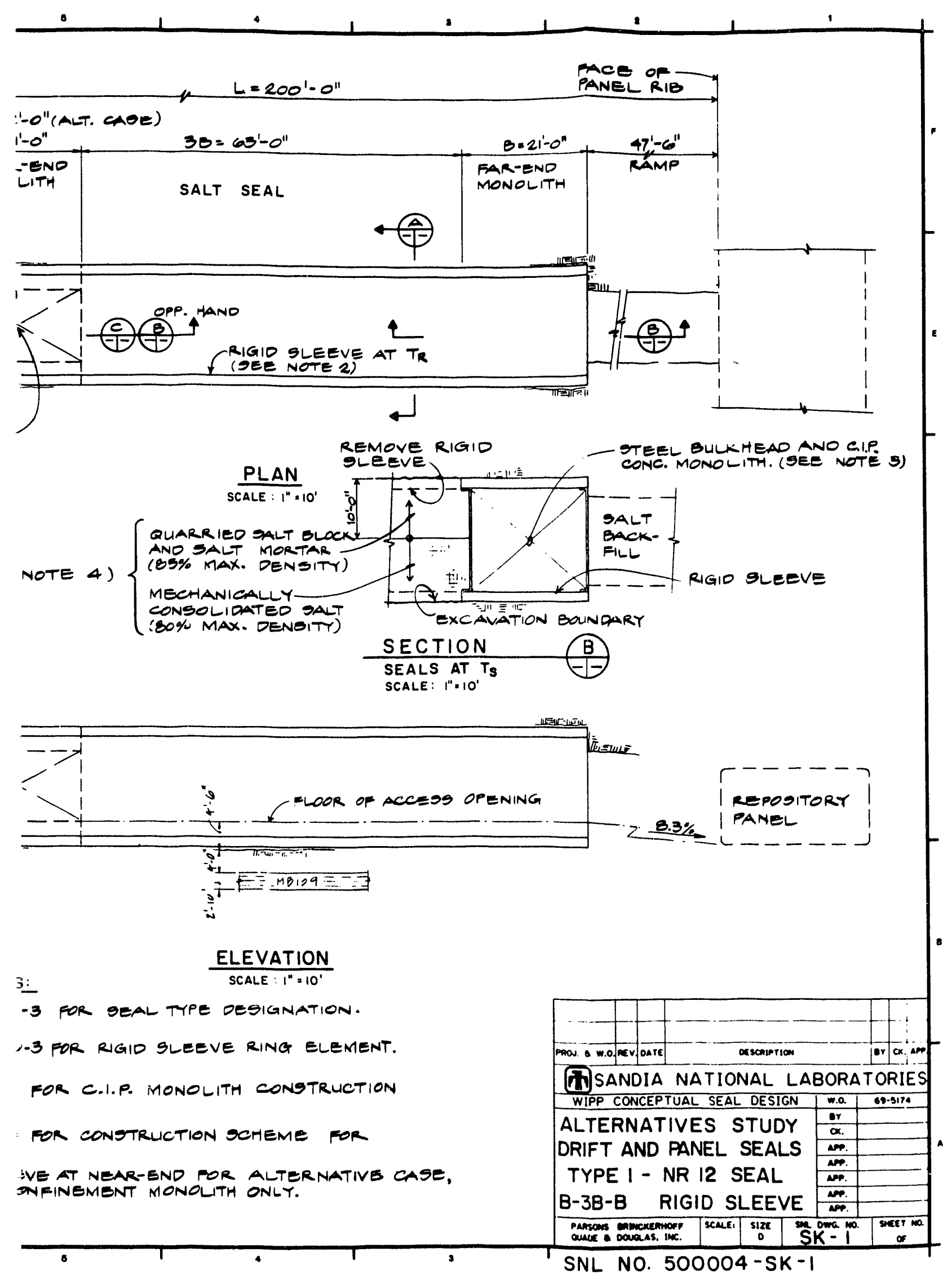

D-3 


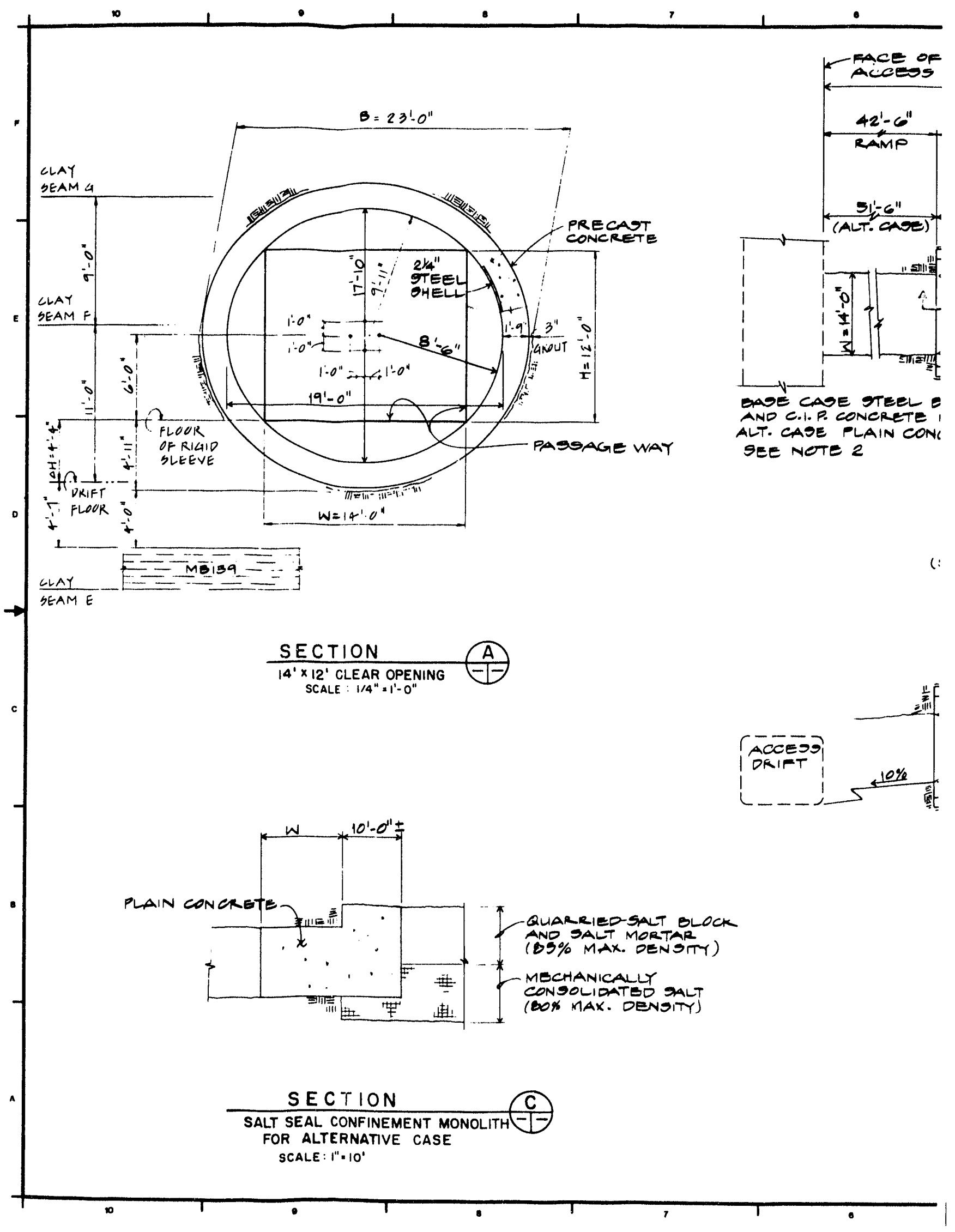




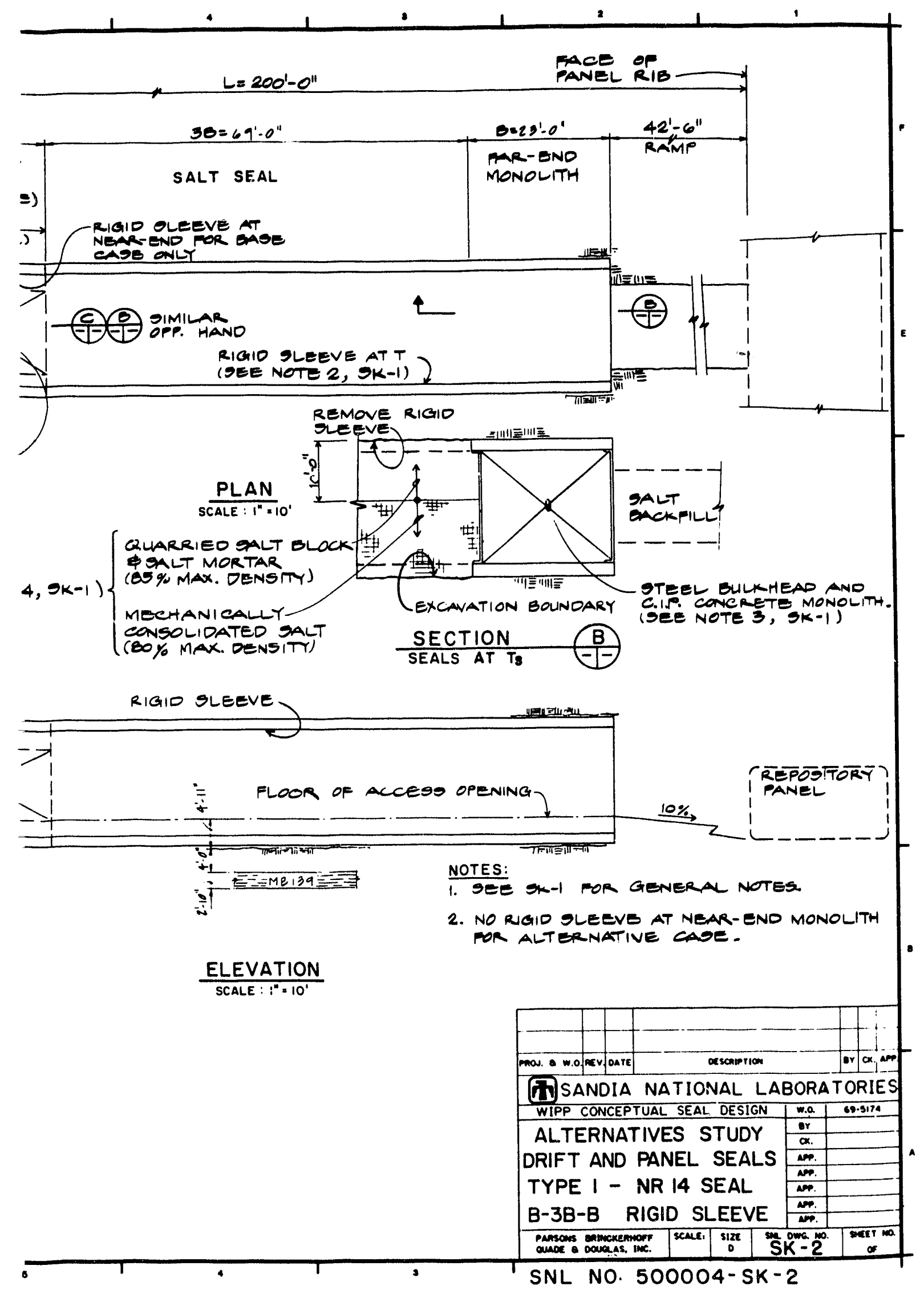




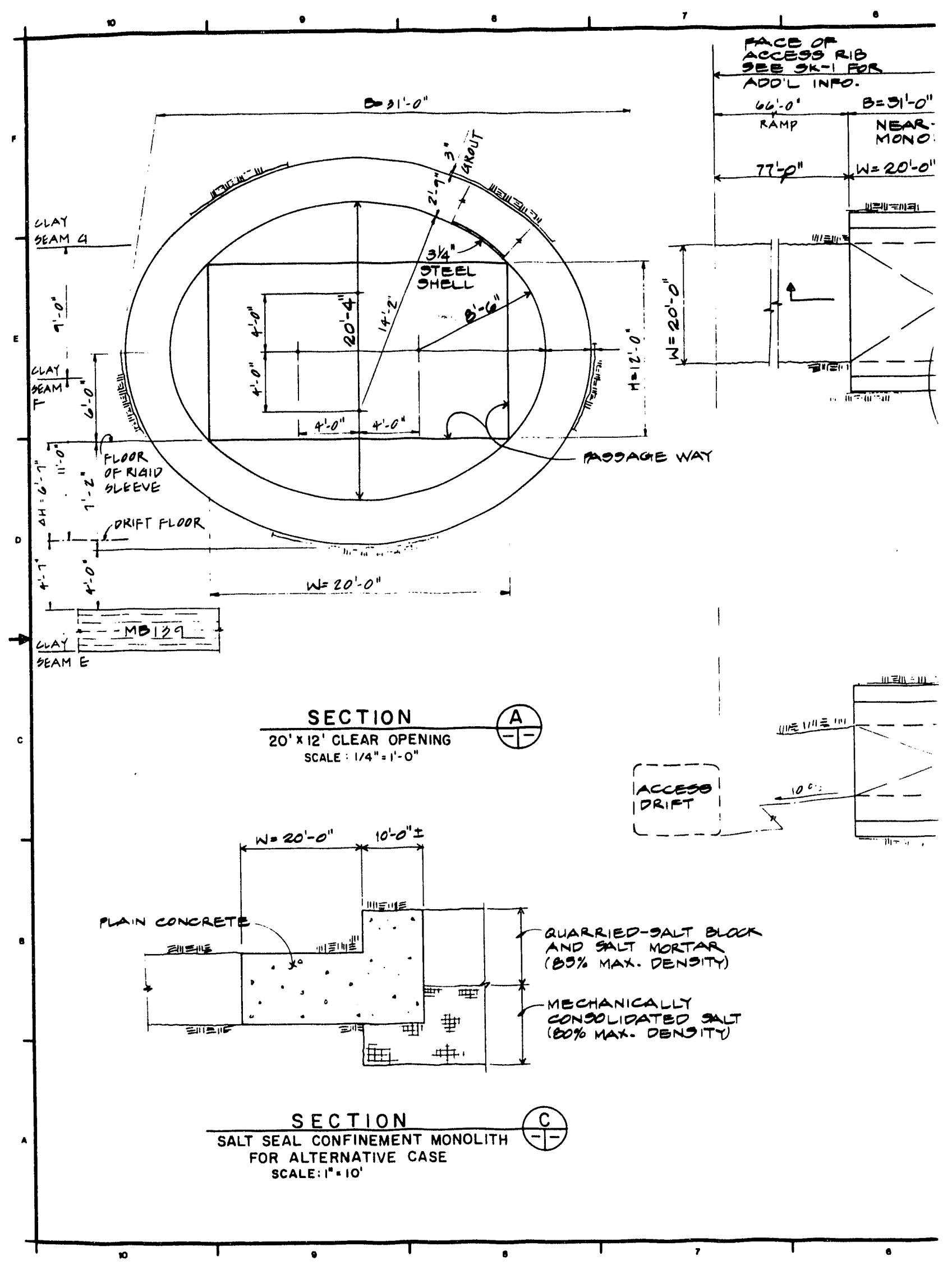




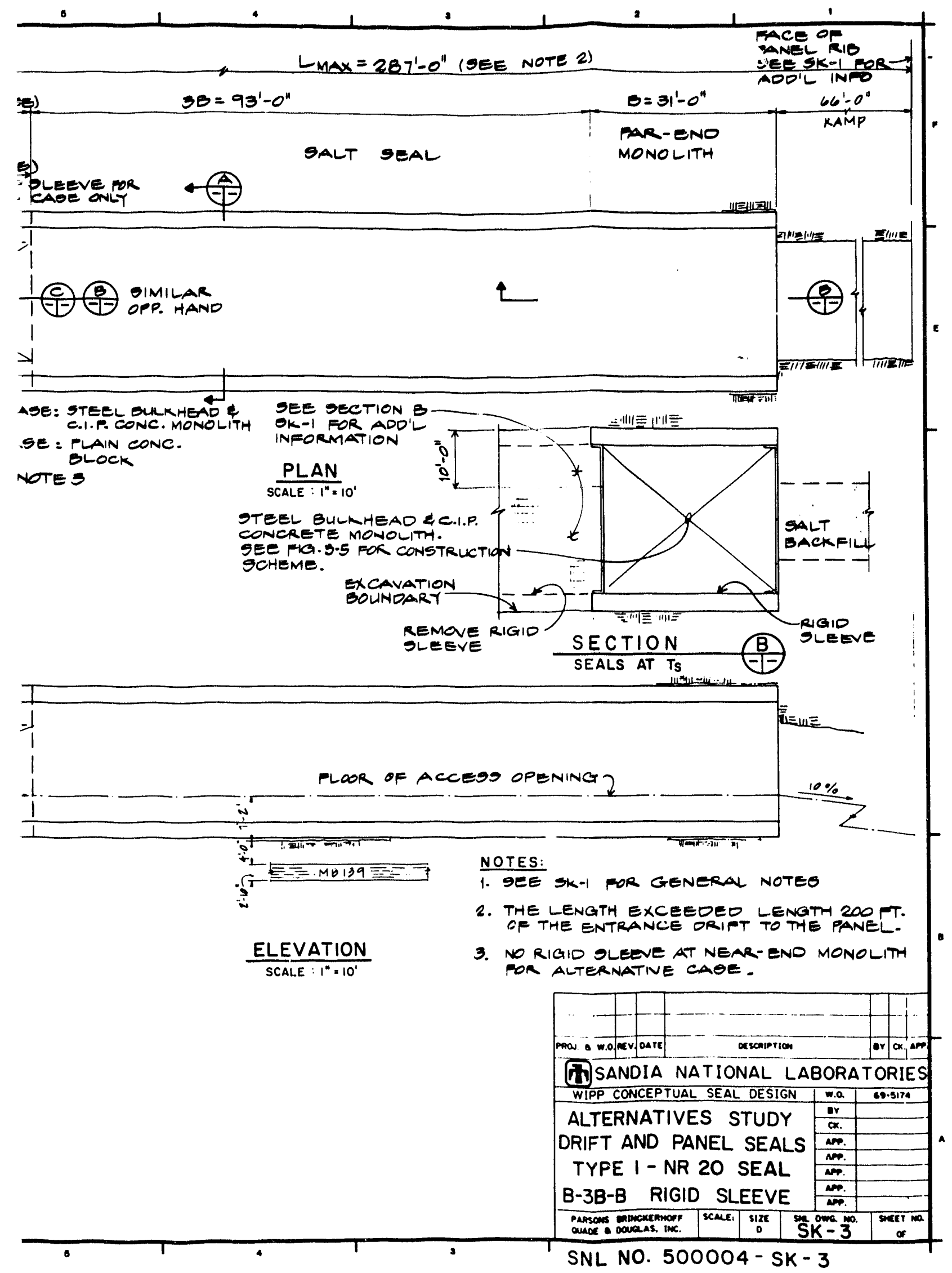

D-5 


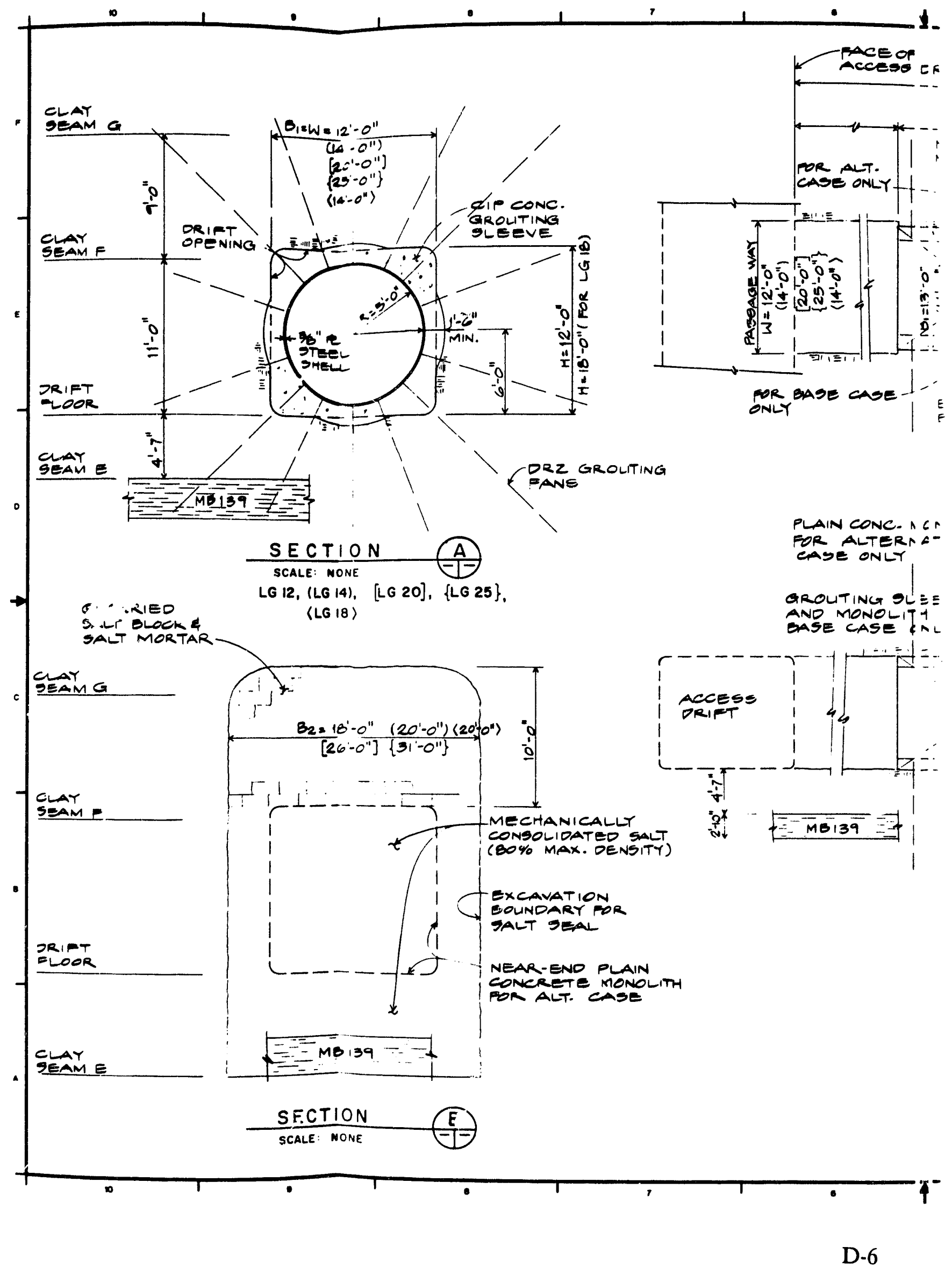




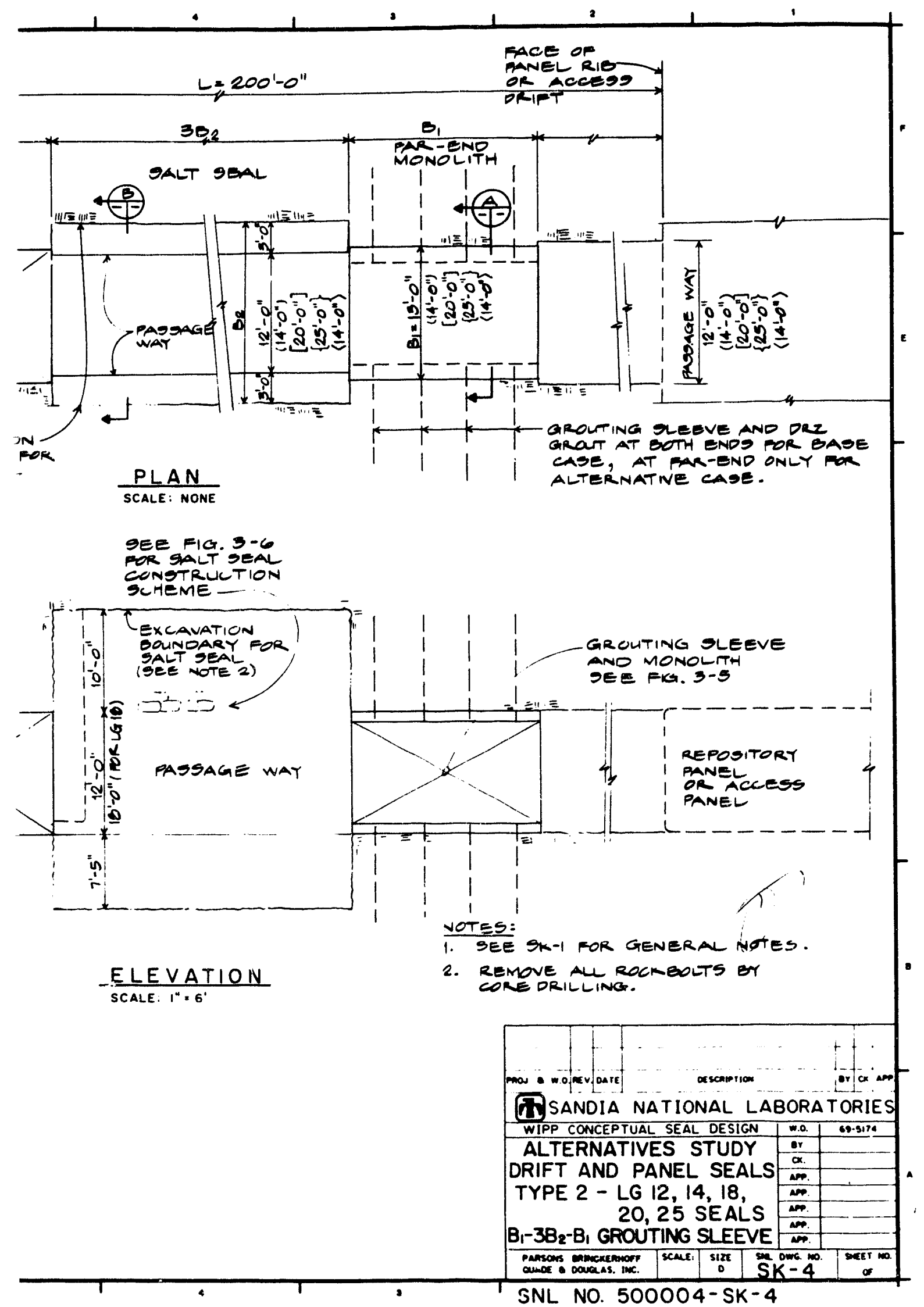




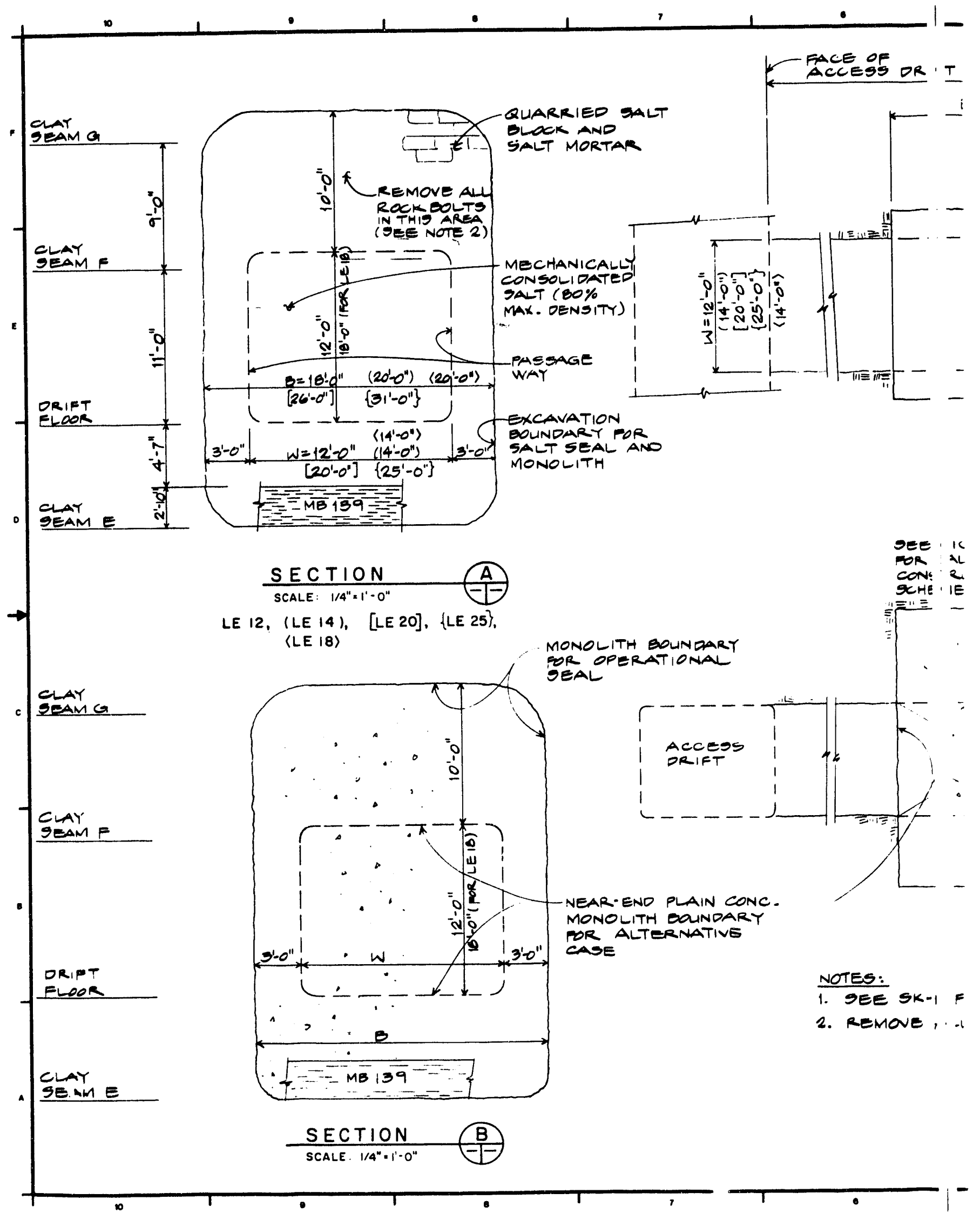



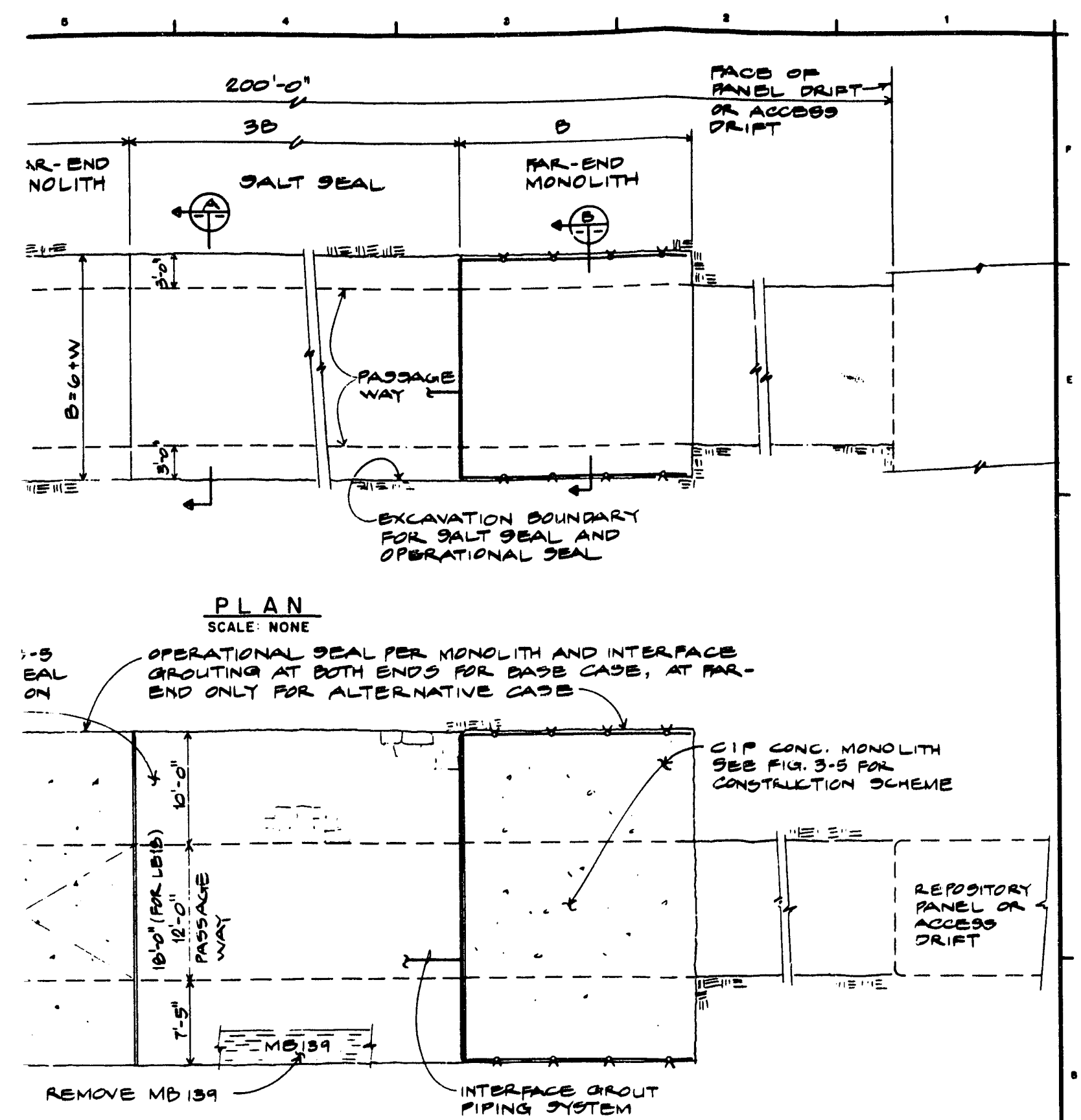

\section{ELEVATION \\ SCALE: NONE}

GENERAL NOTES.

ICKEOLTS OI CORE ORILLING

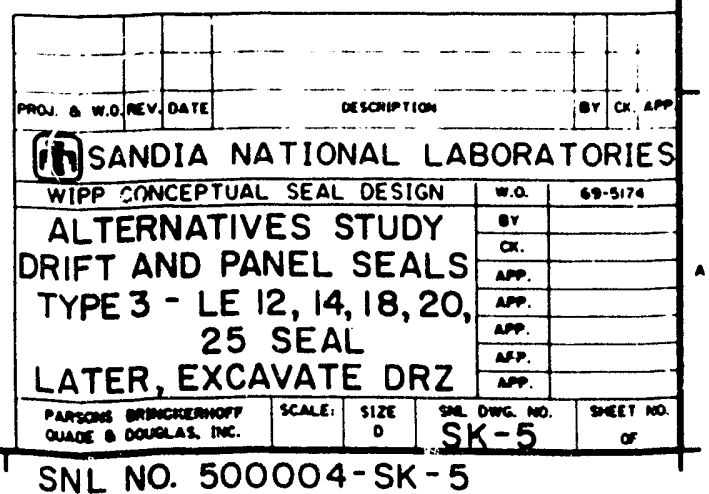

D-7 


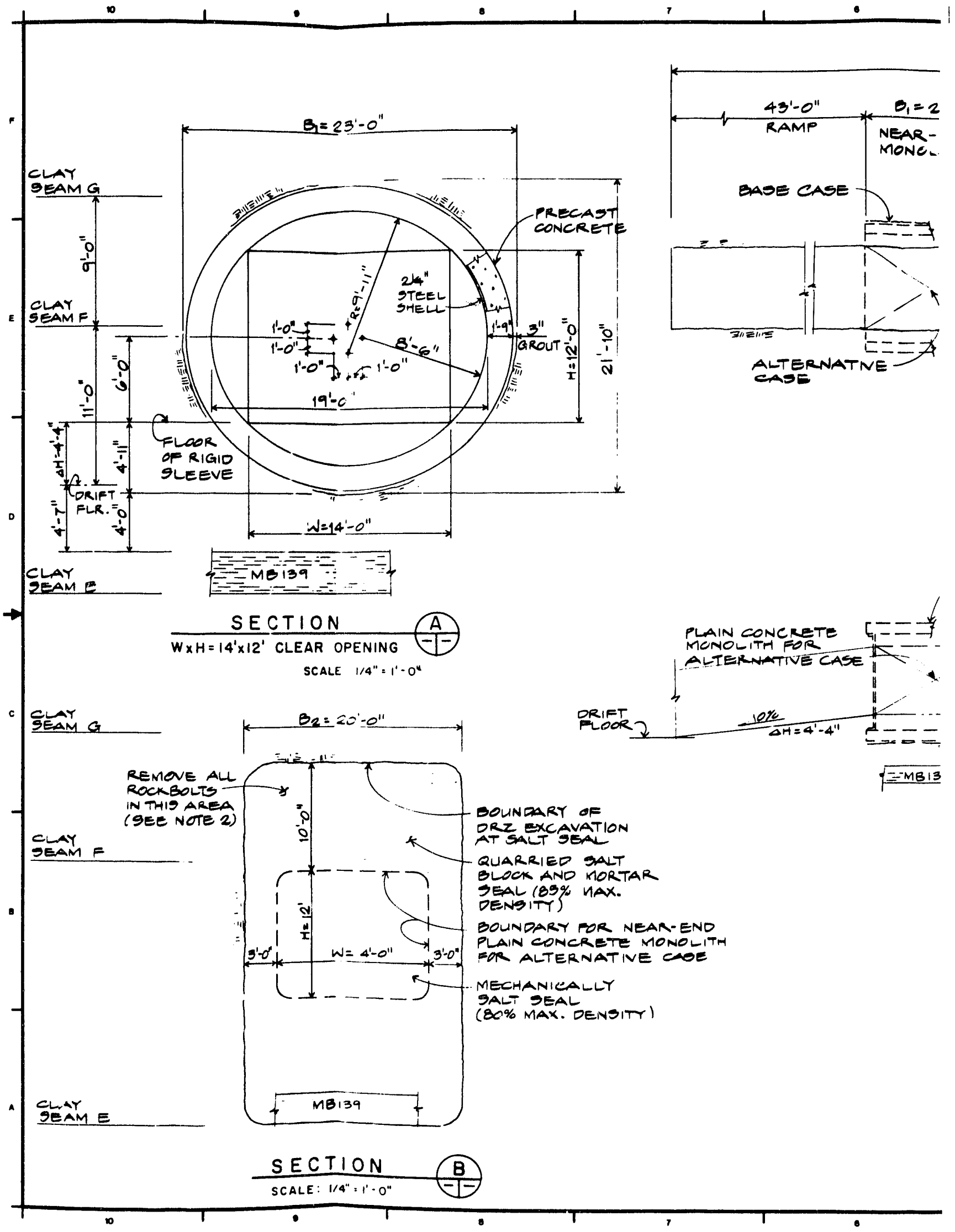

D-8 


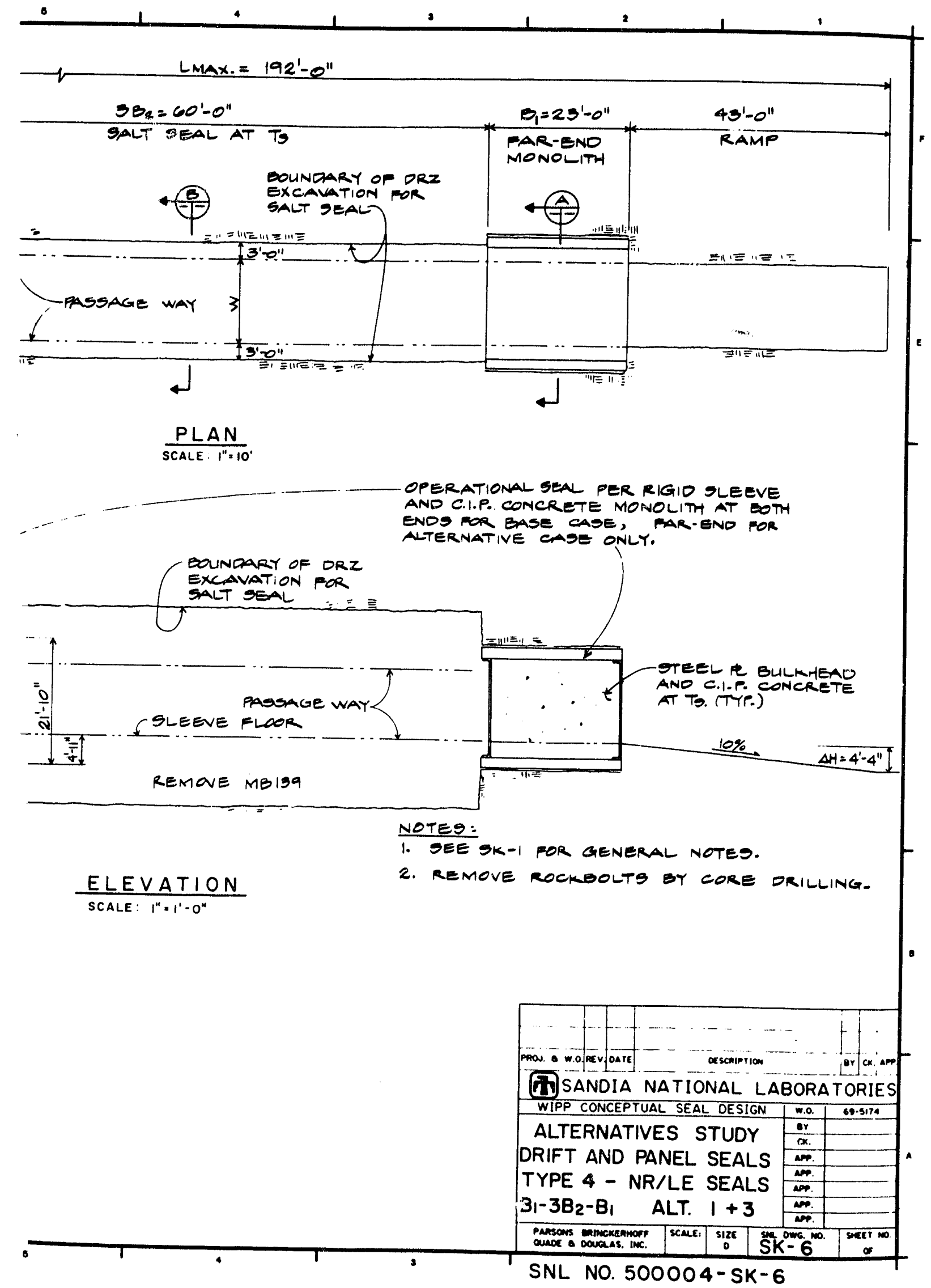




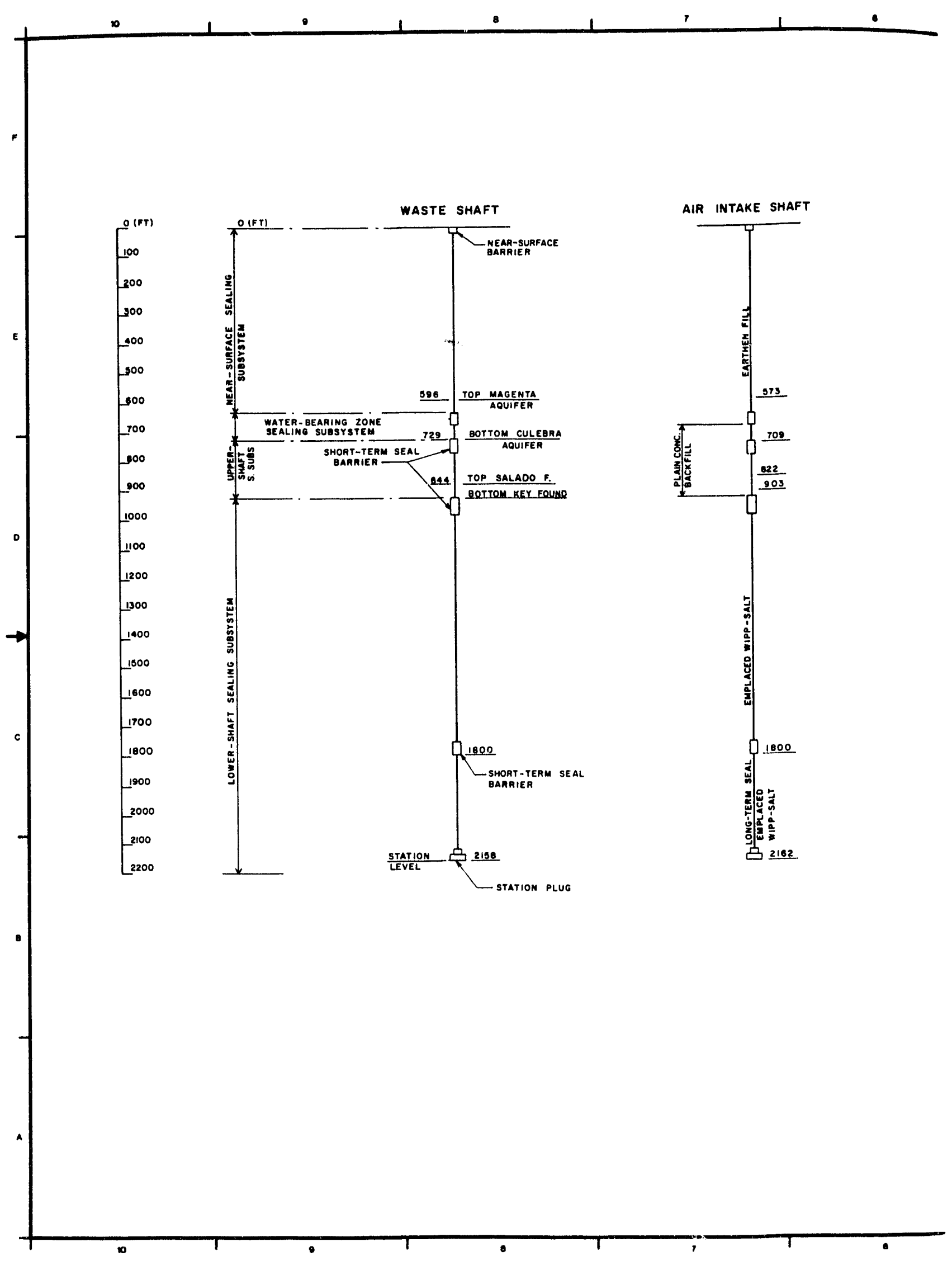




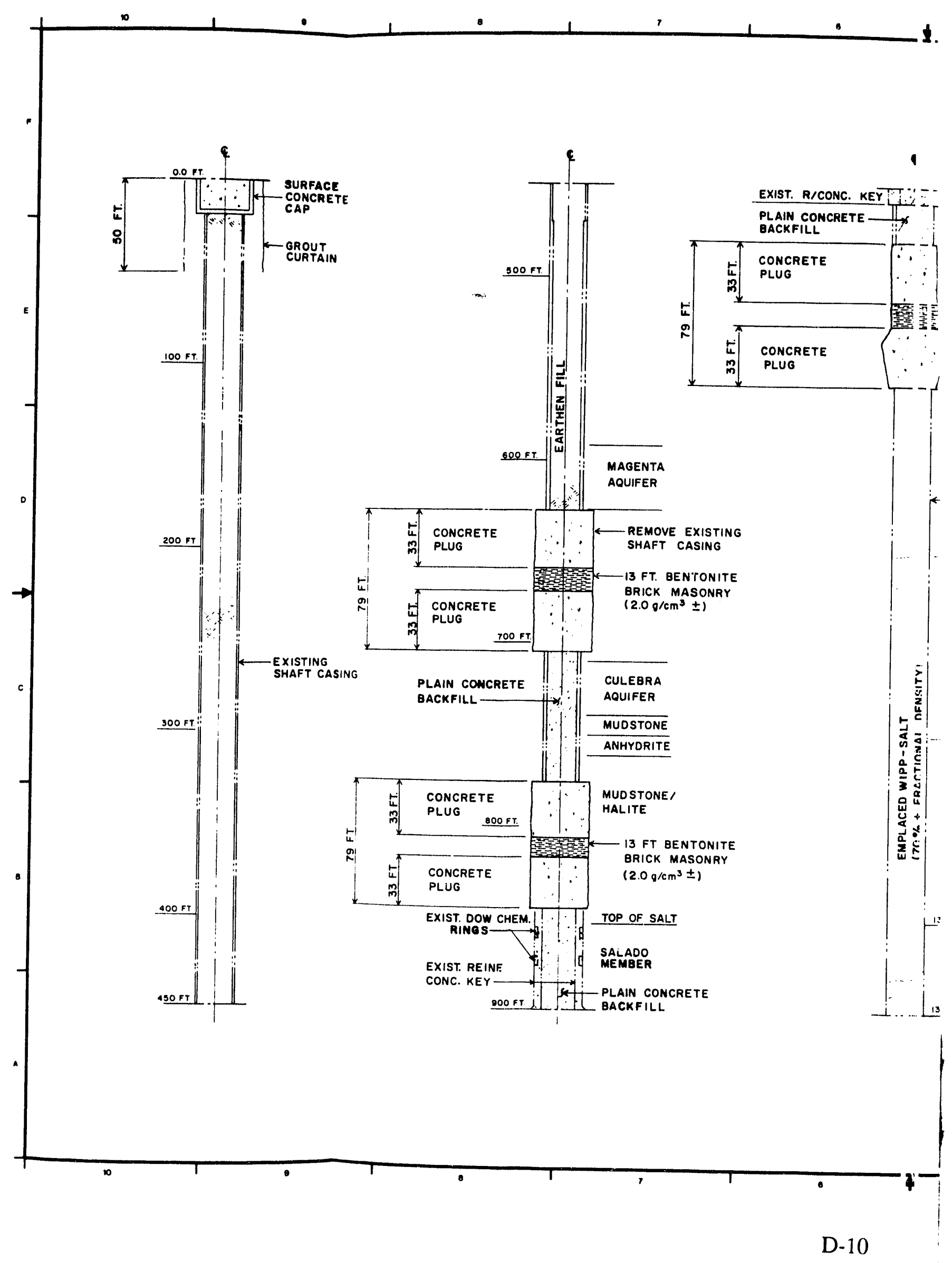




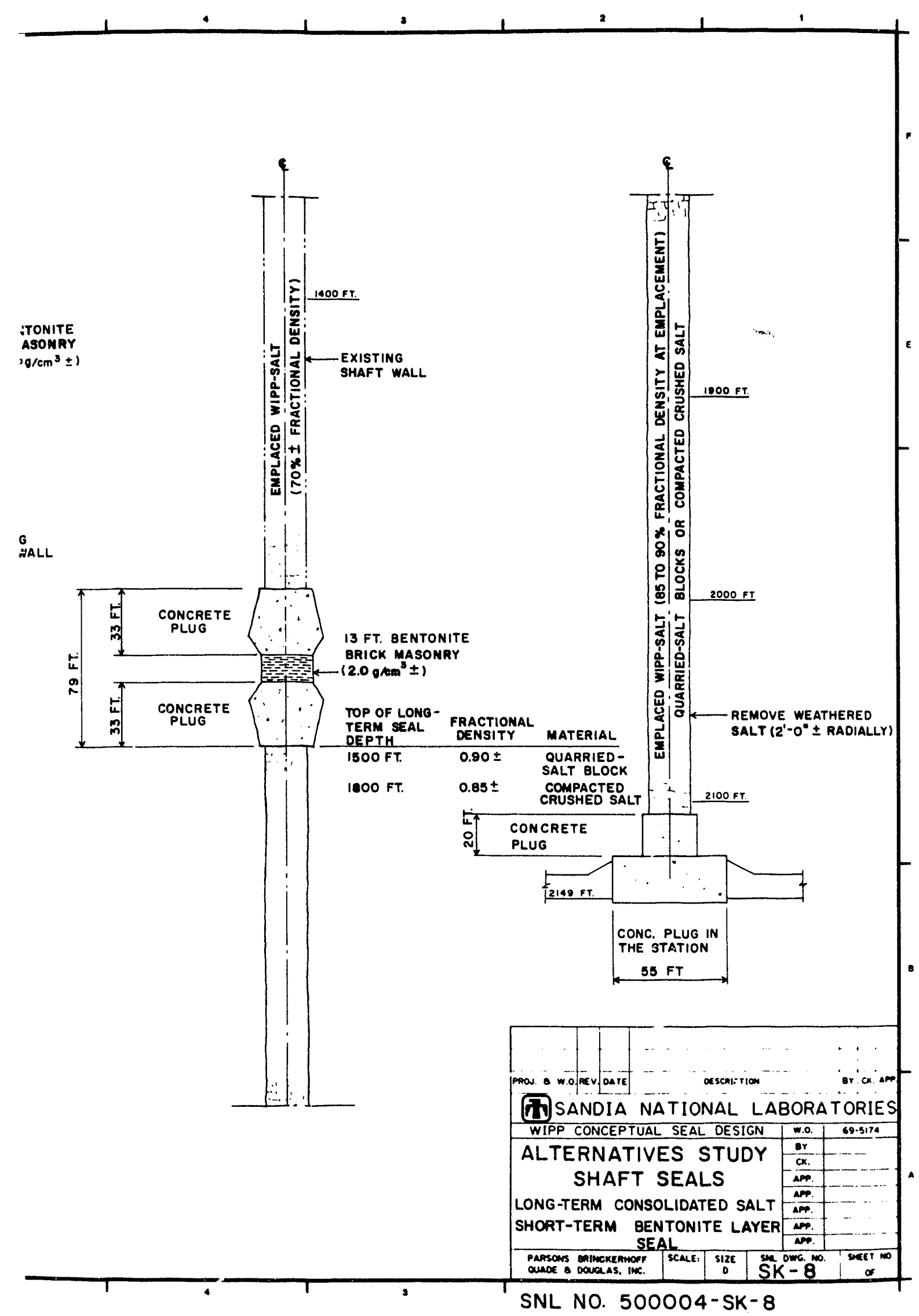




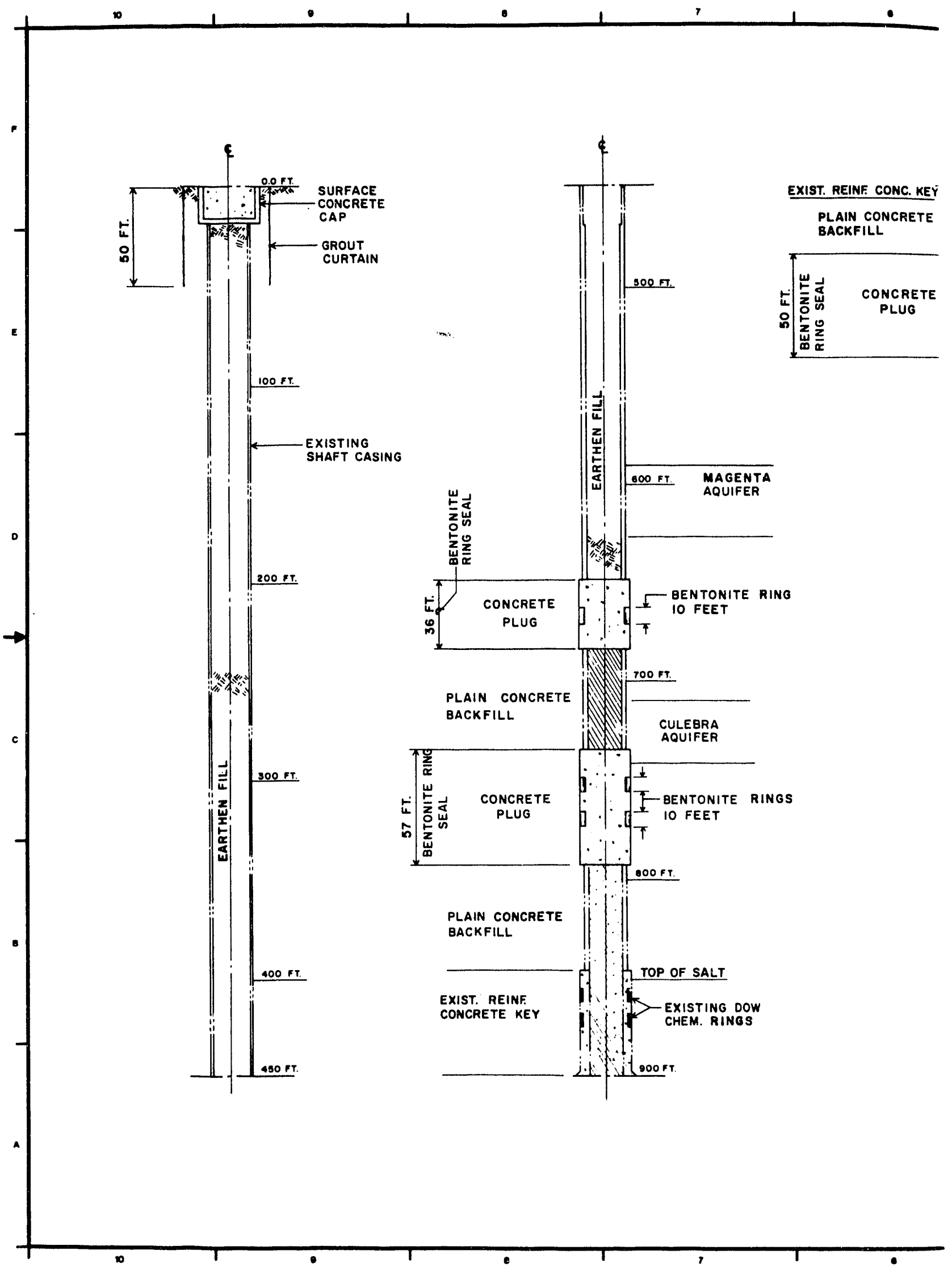




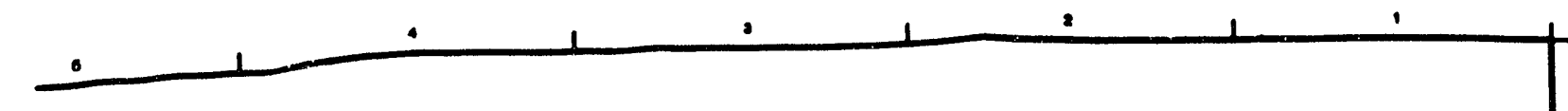

:NTONITE FEET

IFT.

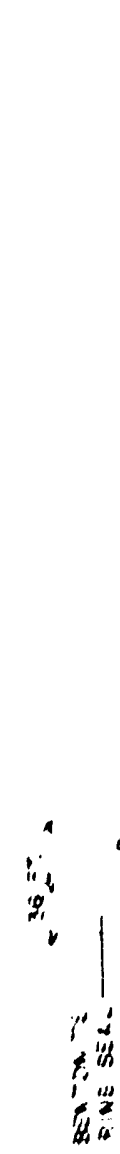

ri

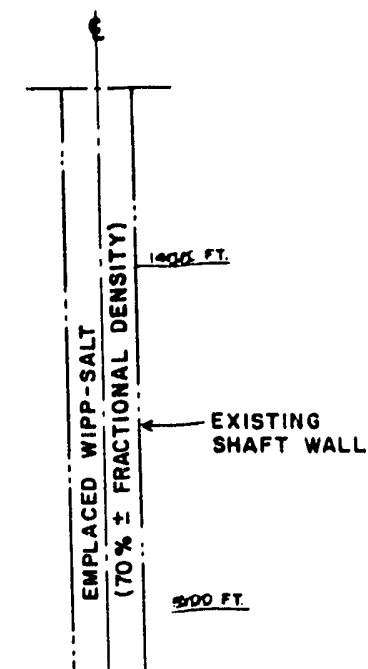

EXISTINO SHAFT WALL
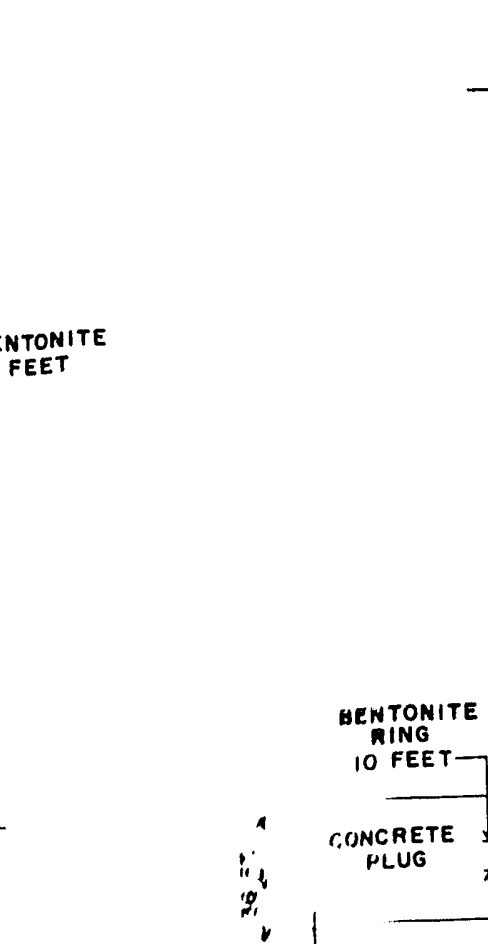

保

T.

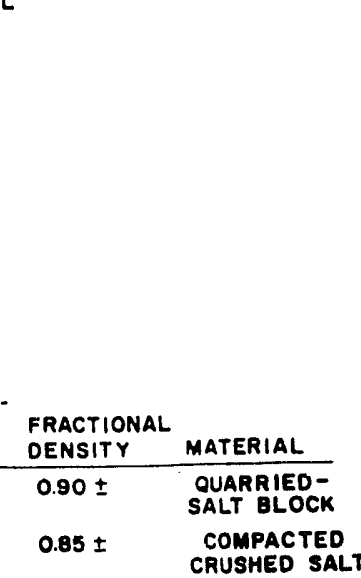

TOP OF LONG TERM SEAL FRACTIONAL

$1500 \mathrm{FT}$.

$1800 \mathrm{FT}$.

$0.85 \pm$

CRUSHED SAL

$1000 \mathrm{rT}$.

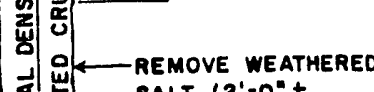

SALT $\left(2^{\prime}-O^{\prime \prime} \pm\right.$

RADIALLY)

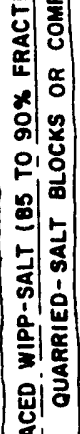

$2000 \mathrm{FI}$
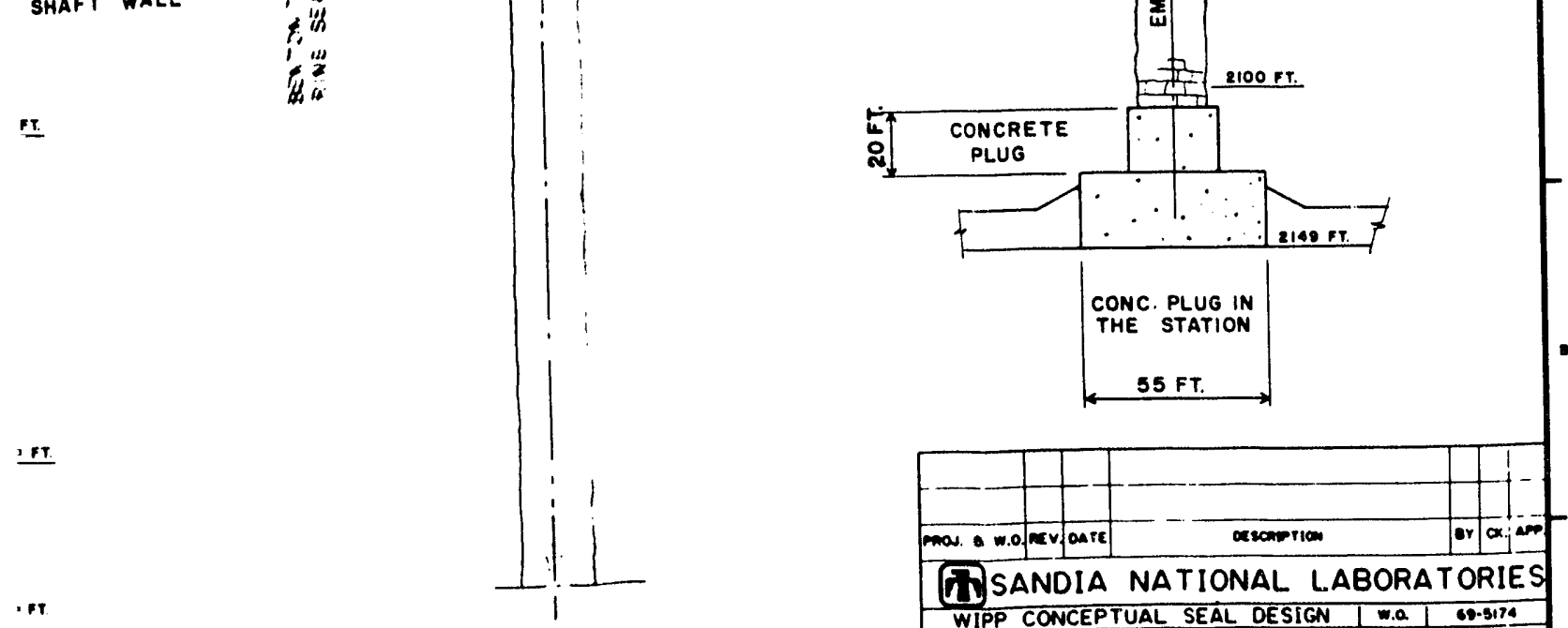

SANDIA NATIONAL LABORATORIES \begin{tabular}{ll|l|l} 
WIPP CONCEPTUAL SEAL DESIGN & w.a & 60.3174
\end{tabular} ALTERNATIVES STUDY

SHAFT SEALS

LONG-TERM CONSOLIDATED SALT SHORT-TERM BENTONITE RING

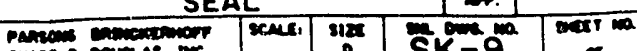

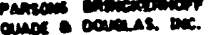

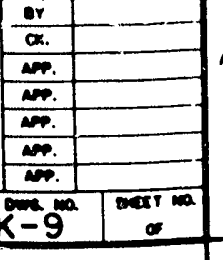

SNL NO. $500004-$ SK-9

D-11 


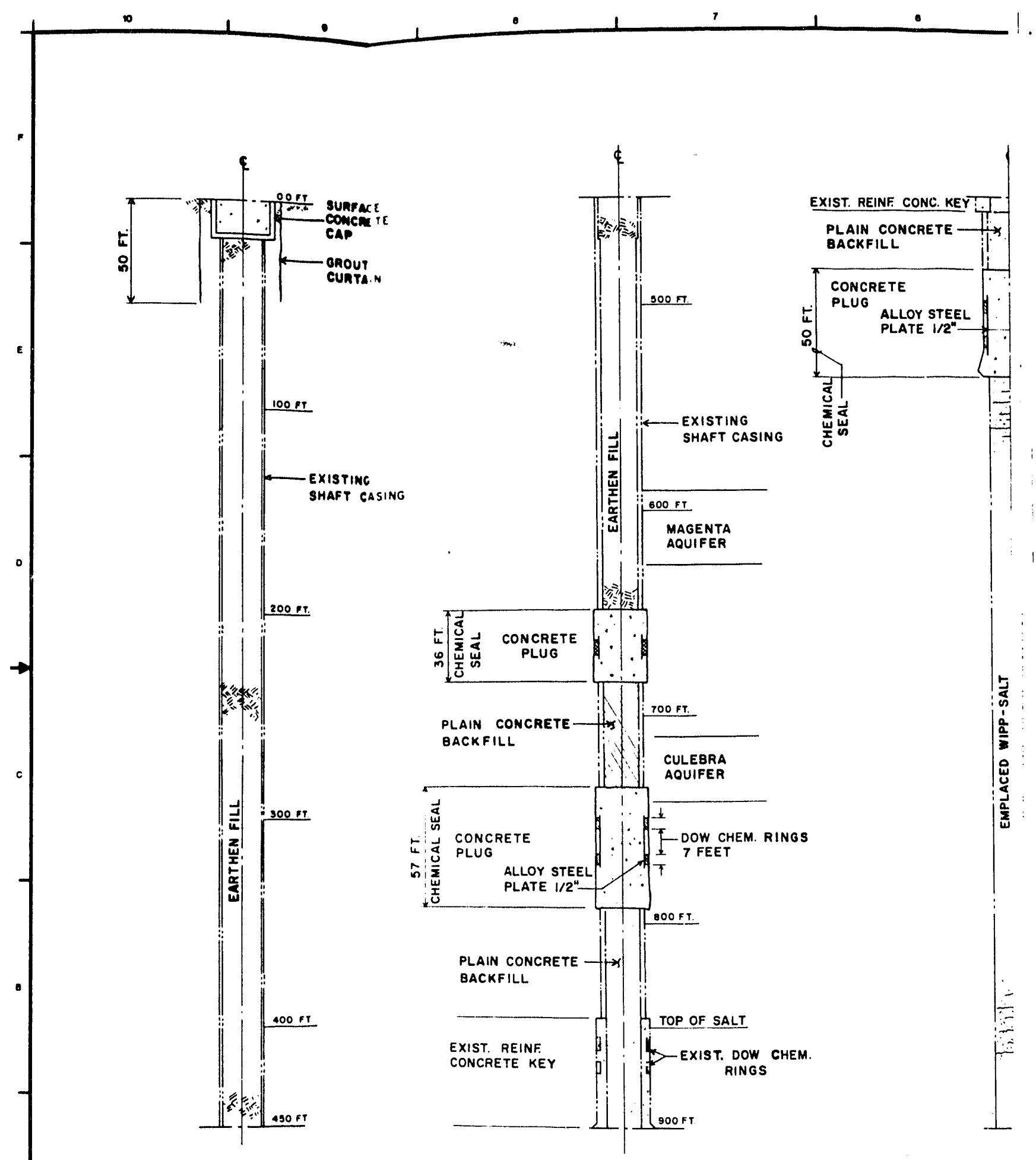

D-12 


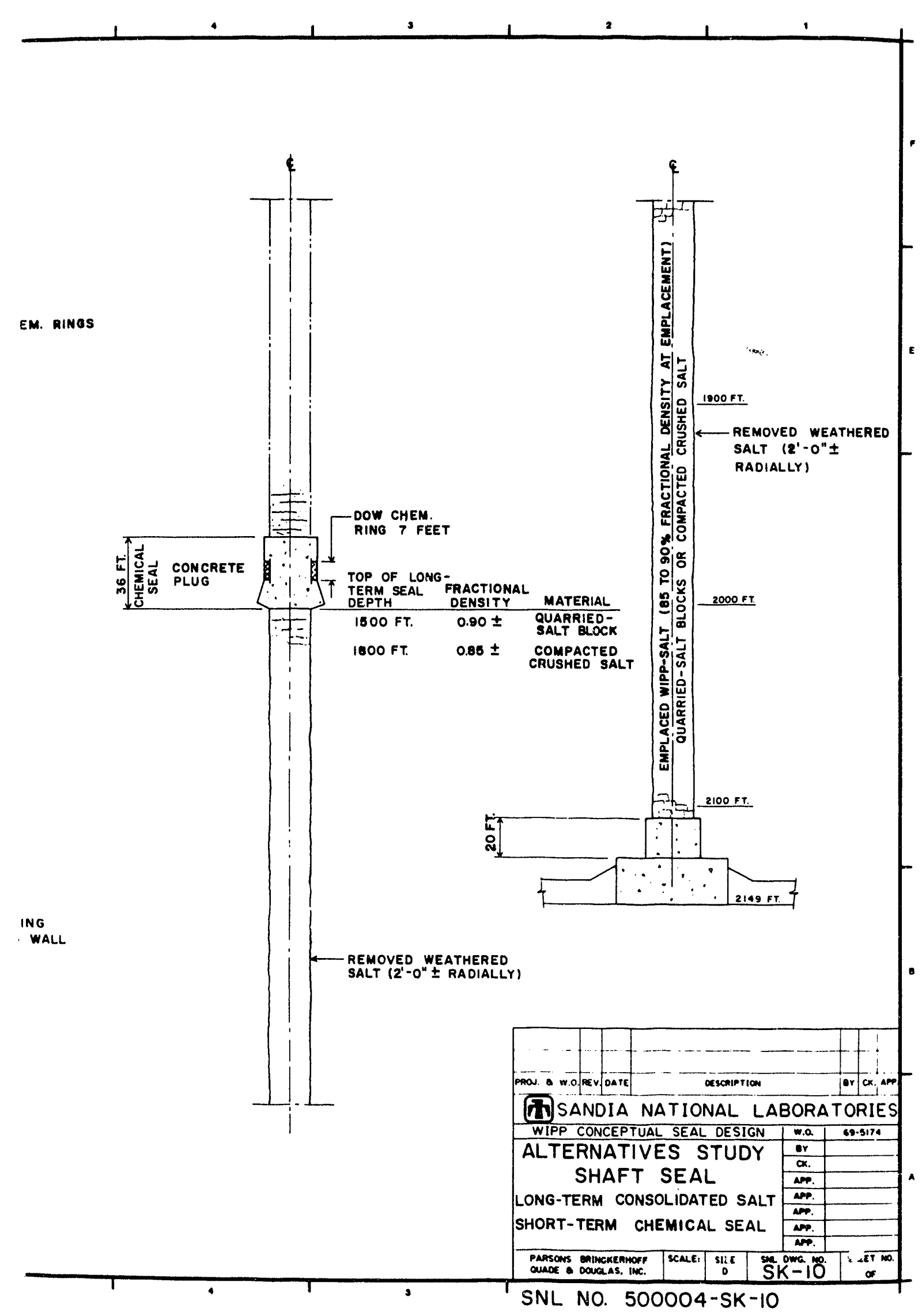




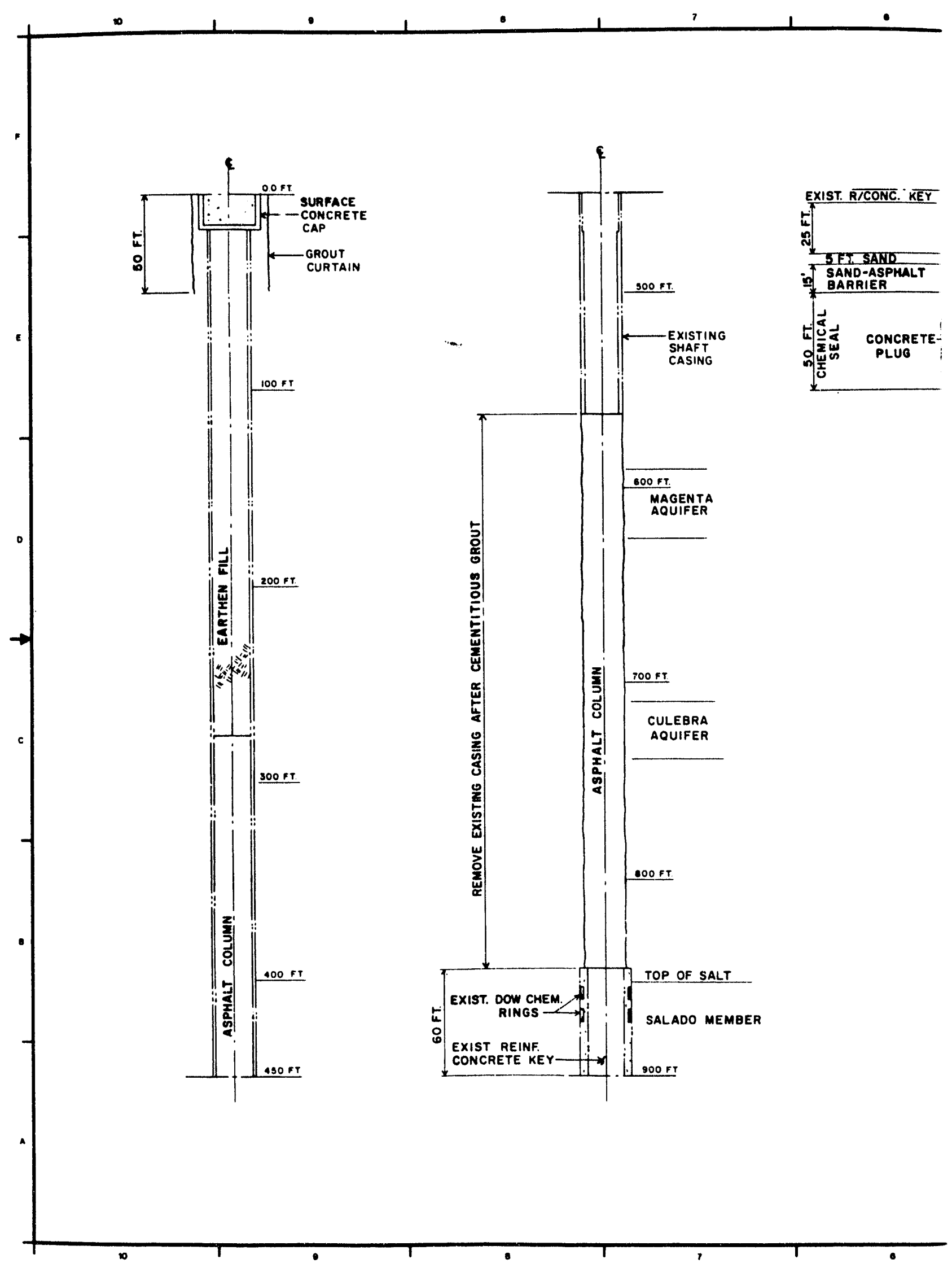




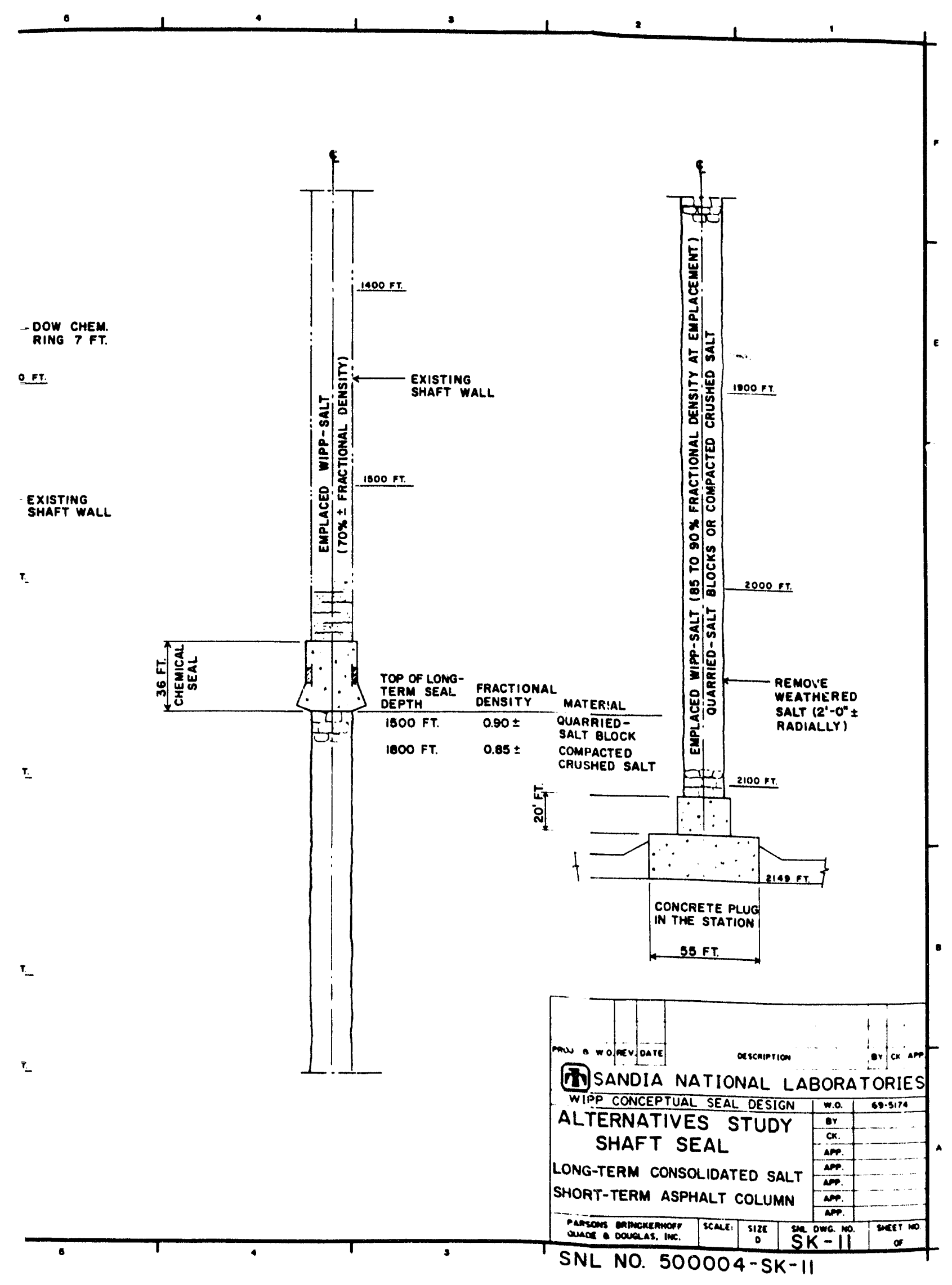

D-13 


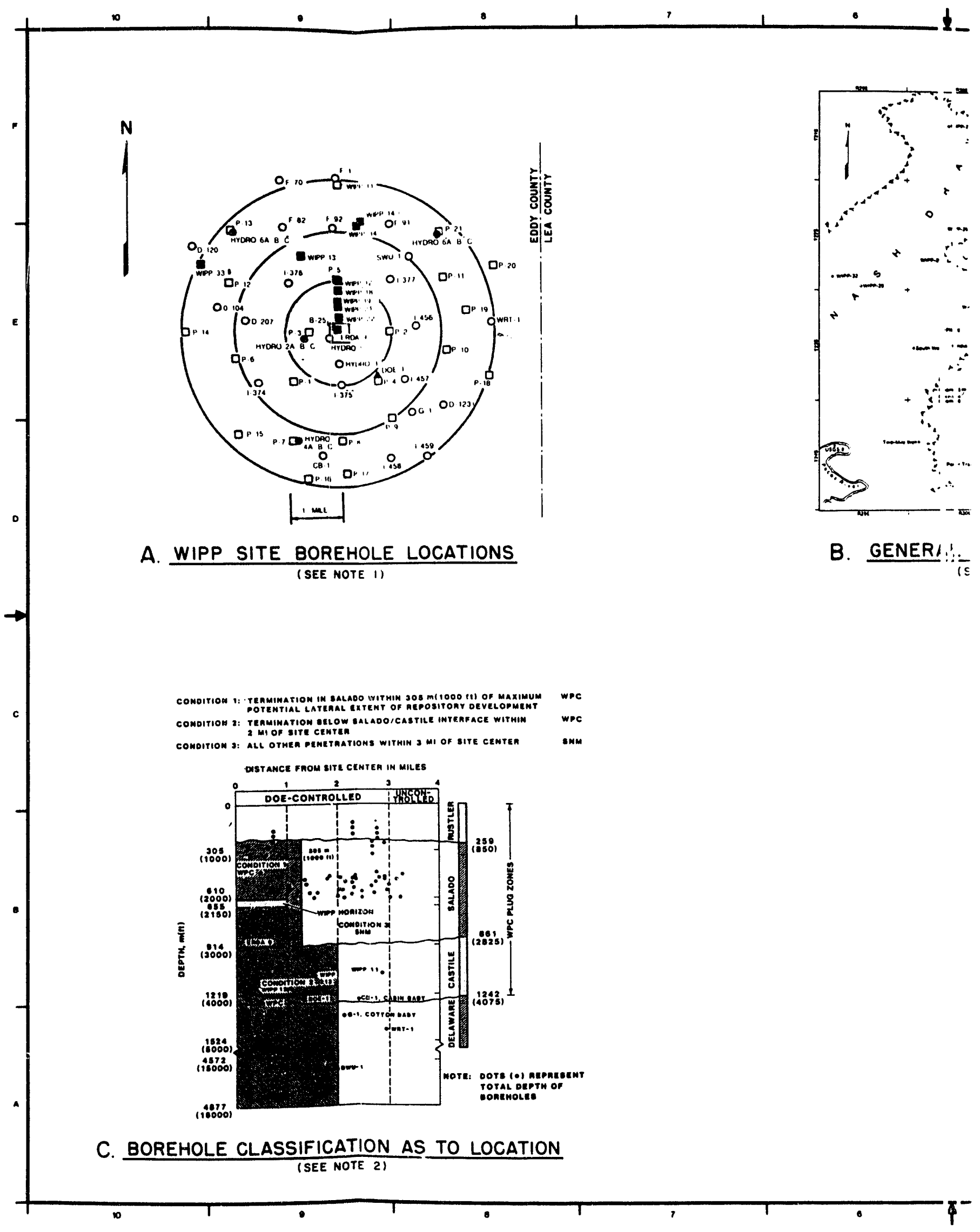

D-14 


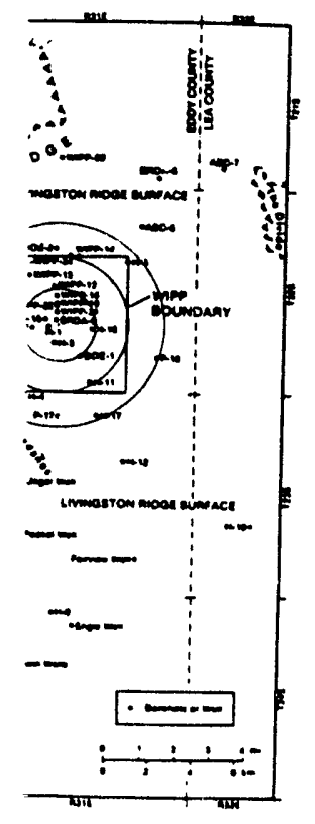

mers

1. Mrpp site sorenole location Plan edopted erou surpia Ror the Weate Inolition pliot plant (mipp)". Progras John (ant, 1904

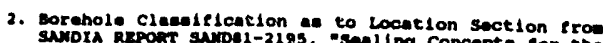
mate reolotion pilot pient (WIPP) Site", by c. L.

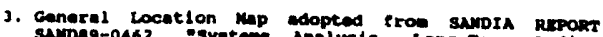
ong-ters hedio Isolitition Pilot plane (WIPP: southeostern Mew Mexilo, Marah 19ag", by A. R. Leppin, et el.

4. Boranole coordinates are provlded in Appenull o of il of the vol Madance

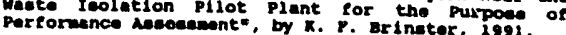

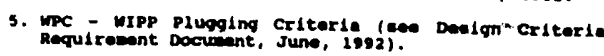

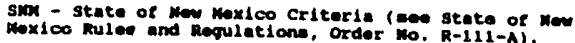

ON MAP

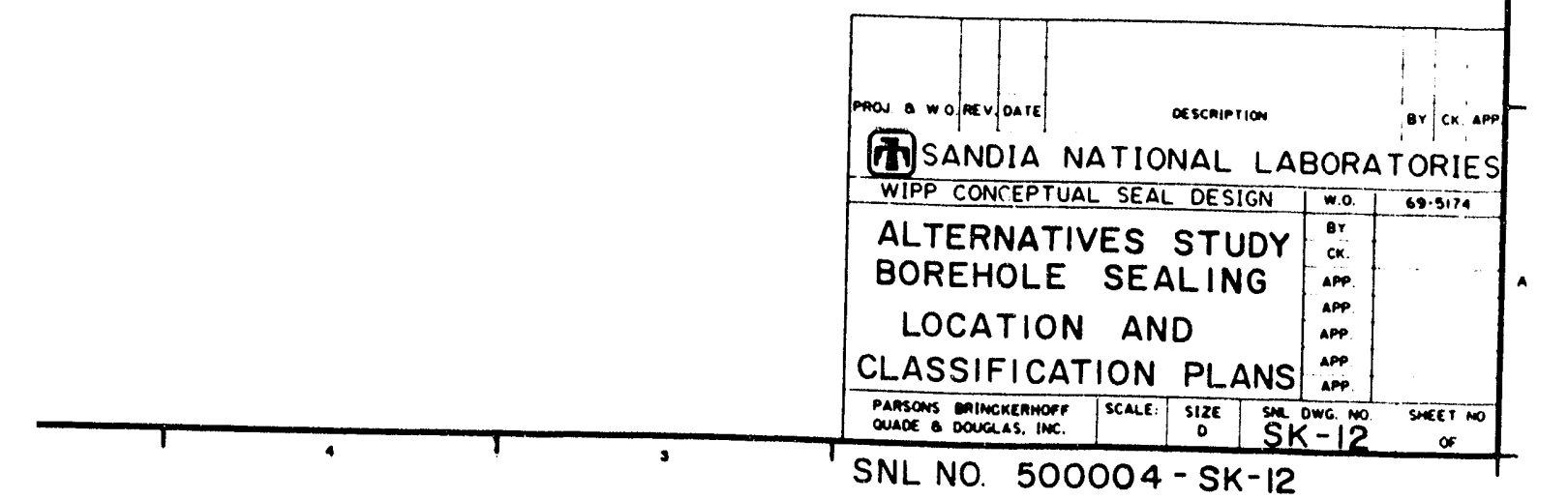




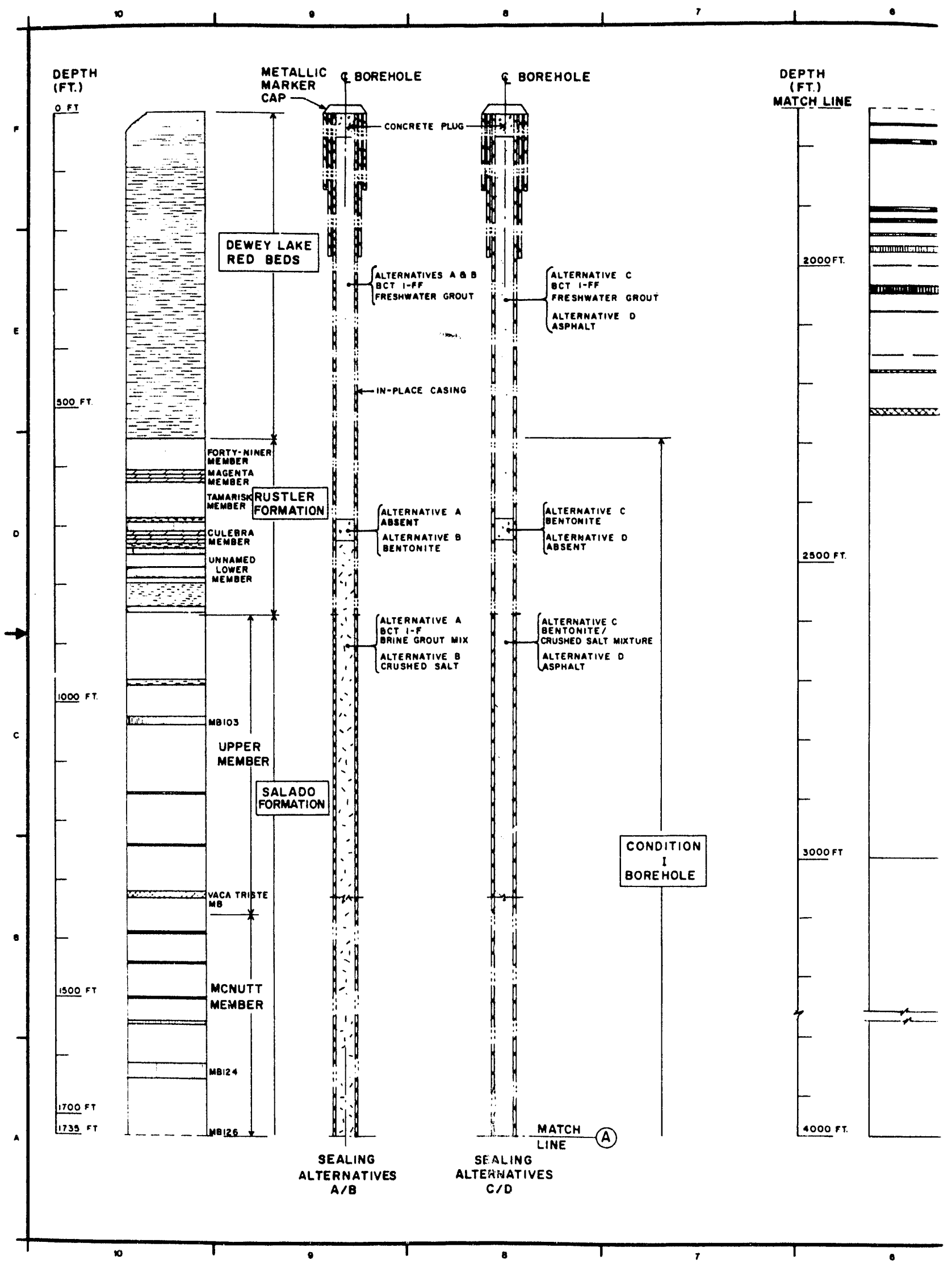


$4 \quad 1 \quad 3$

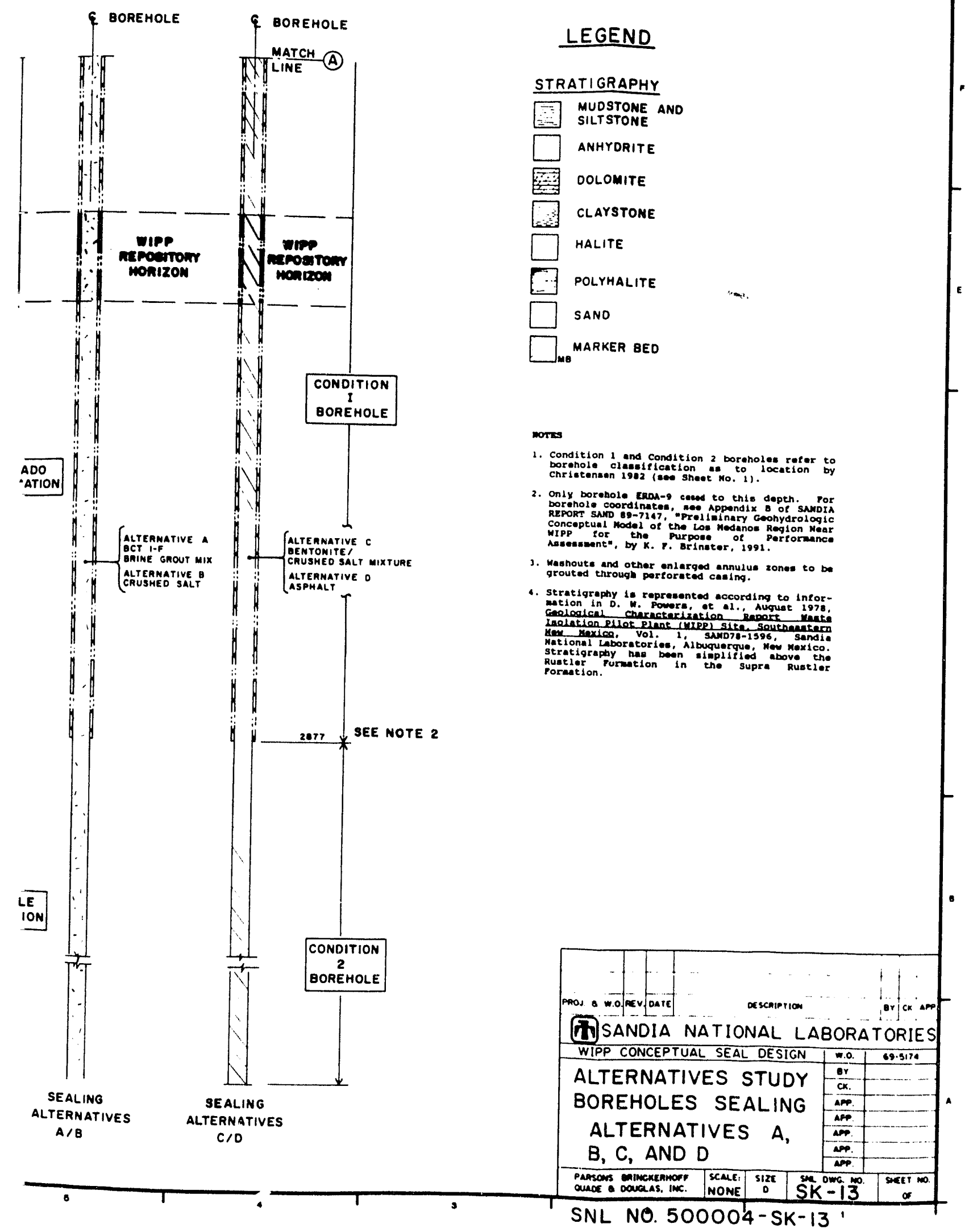

D. 15 


\section{PERFORMANCE ASSESSMENT DISTRIBUTION LIST}

(Send Distribution list changes to M.M. Gruebel, Dept. 6342, Sandia

National Laboratories, PO Box 5800, Albuquerque, NM 87185-5800)

\section{Federal Agencies}

US Department of Energy (2)

Office of Environmental Restoration and Waste Management

Attn: $E M-1$

C. Frank, EM-50

Washington, DC 20585

US Department of Energy (3)

Office of Environmental Restoration and Waste Management

Attn: M. Frei, EM-34 (Trevion II)

Director, Waste Management Projects

Washington, DC 20585-0002

US Department of Energy

Office of Environmental Restoration and Waste Management

Attn: J. Lytle, EM-30 (Trevion II)

Washington, DC 20585-0002

US Department of Energy

Office of Environmental Restoration and Waste Management

Attn: S. Schneider, EM-342

(Trevion II)

Washington, DC 20585-0002

US Department of Energy (3)

WIPP Task Force

Attn: G.H. Daly

S. Fucigna

B. Bower

12800 Middlebrook Rd.

Suite 400

Germantown, MD 20874

US Department of Energy (4)

Office of Environment, Safety and Health

Attn: R.P. Berube, EH-20

C. Borgstrum, EH-25

R. Pelletier, EH-231

K. Taimi, EH-232

Washington, DC 20585
US Department of Energy (5)

WIPP Project Integration Office

Attn: W.J. Arthur III

R. Becker

P. Dickman

L.W. Gage

P.J. Higgins

D.A. Olona

PO Box 5400

Albuquerque, NM 87115-5400

US Department of Energy (10)

WIPP Project Site Office (Carlsbad)

Attn: A. Hunt (4)

V. Daub (4)

J. Lippis

$\mathrm{K}$. Hunter

PO Box 3090

Carlsbad, NM 88221-3090

US Department of Energy, (5)

Office of Civilian Radioactive Waste Management

Attn: Deputy Director, RW-2

Associate Director, RW-10

Office of Program

Administration and

Resources Management

Associate Director, RW-20

Office of Facilities

Siting and Development

Associate Director, $\mathrm{RW}-30$

Office of Systems

Integration and

Regulations

Associate Director, RW-40

Office of Ex.ernal

Relations ari Policy

Office of Geologic Repositories

Forrestal Building

Washington, DC 20585

US Department of Energy

Attn: National Atomic Museum Library

Albuquerque Operations office

PO Box 5400

Albuquerque, NM 87185 
US Department of Energy

Research \& Waste Management Division

Attn: Director

PO Box E

Oak Ridge, TN 37831

US Department of Energy (2)

Idaho Operations office

Fuel Processing and Waste

Management Division

785 DOE Place

Idaho Falls, ID 83402

US Department of Energy

Savannah River Operations office

?efense Waste Processing

Facility Project office

Attn: W.D. Pearson

PO Box A

Aiken, SC 29802

US Department of Energy (2)

Richland Operations office

Nuclear Fuel Cycle \& Production

Division

Attn: R.E. Gerton

825 Jadwin Ave.

PO Box 500

Richland, WA 99352

US Department of Energy (3)

Nevada Operations office

Attn: J.R. Boland

D. Livingston

P.K. Fitzsimmons

2753 S. Highland Drive

Las Vegas, NV 89183-8518

US Department of Energy (2)

Technical Information Center

PO Box 62

Oak Ridge, TN 37831

US Department of Energy (2)

Chicago Operations office

Attn: J.C. Haugen

9800 South Cass Avenue

Argonne, IL 60439

US Department of Energy

Los Alamos Area Office

52835 th Street

Los Alamos, NM 87544
US Department of Energy (3)

Rocky Flats Area Office

Attn: W.C. Rask

G. Huffman

T. Lukow

PO Box 928

Golden, CO 80402-0928

US Department of Energy

Dayton Area Office

Attn: R. Grandfield

PO Box 66

Miamisburg, OH 45343-0066

US Department of Energy

Attn: E. Young

Room E- 178

GAO/RCED/GTN

Washington, DC 20545

US Bureau of Land Management

101 E. Mermod

Carlsbad, NM 88220

US Bureau of Land Management

New Mexico State Office

PO Box 1449

Santa Fe, NM 87507

US Environmental Protection Agency (2)

Office of Radiation Protection Programs

ANR -460

Washington, DC 20460

US Nuclear Regulatory Commission

Division of Waste Management

Attn: H. Marson

Mail Stop 4-H-3

Washington, DC 20555

US Nuclear Regulatory Commission (4) Advisory Committee on Nuclear Waste

Attn: D. Moeller

M.J. Steindler

P.W. Pomeroy

W.J. Hinze

7920 Norfolk Ave.

Bethesda, MD 20814 
Defense Nuclear Facilities Safety Board

Attn: D. Winters

625 Indiana Ave. NW

Suite 700

Washington, DC 20004

Nuclear Waste Technical Review Board (2)

Attn: Library

1100 Wilson Blvd., Suite 910

Arlington, VA 22209-2297

Energy and Science Division

Office of Management and Budget

Attn: K. Yuracko

72517 th Street NW

Washington, DC 20503

US Geological Survey (2)

Water Resources Division

Attn: C. Peters

4501 Indian School NE

Suite 200

Albuquerque, NM 87110

\section{State Agencies}

New Mexico Bureau of Mines and Mineral Resources

Socorro, NM 87801

New Mexicu Energy, Minerals and Natural Resources Department Attn: Librarian

2040 South Pacheco

Santa Fe, NM 87505

New Mexico Energy, Minerals and Natura1 Resources Department

New Mexico Radioactive Task Force (Governor's WIPP Task Force)

Attn: A. Lockwood, Chairman C. Wentz, Policy Analyst

2040 South Pacheco

Santa Fe, NM 87505

Bob Forrest

Mayor, City of Carlsbad

PO Box 1569

Carlsbad, NM 88221
Executive Director

Carlsbad Department of Development Attn: C. Bernard

PO Box 1090

Carlsbad, NM 88221

New Mexico Environment Department Secretary of the Environnent (3)

Attn: J. Espinosa

PO Box 968

1190 St. Francis Drive

Santa Fe, NM 87503-0968

New Mexico Environment Department

Attn: P. McCasland

WIPP Project Site Office

PO Box 3090

Carlsbad, NM 88221-3090

New Mexico State Engineer's Office

Attn: M. Chudnoff

PO Box 25102

Santa Fe, NM 87504-5102

Environmental Evaluation Group (5)

Attn: R. Neill

7007 Wyoming Blvd. NE

Suite F-2

Albuquerque, NM 87109

\section{Advisory Committee on Nuclear Facility Safety}

John F. Ahearne

Executive Director, Sigma Xi

99 Alexander Drive

Research Triangle Park, NC 27709

James E. Martin

109 Observatory Road

Ann Arbor, MI 48109

WIPP Panel of National Research Council's

Board on Radioactive Waste Management

Charles Fairhurst, Chairman

Department of Civil and

Mineral Engineering

University of Minnesota

500 Pillsbury Dr. SE

Minneapolis, MN 55455-0220 
John O. Blomeke

3833 Sandy Shore Drive

Lenoir City, TN 37771-9803

John D. Bredehoeft

Western Region Hydrologist

Water Resources Division

US Geological Survey (M/S 439)

345 Middlefield Road

Menlo Park, CA 94025

Fred M. Ernsberger

$1325 \mathrm{NW}$ 10th Avenue

Gainsville, FL 32601

Rodney C. Ewing

Department of Geology

University of New Mexico

200 Yale NE

Albuquerque, NM 87131

B. John Garrick

PLG, Inc.

Suite 400

4590 MacArthur Blvd.

Newport Beach, CA 92660-2027

Leonard F. Konikow

US Geological Survey

431 National Center

Reston, VA 22092

Jeremiah O'Driscoll

505 Valley Hill Drive

Atlanta, GA 30350

Christopher Whipple

Clement International Corp.

160 Spear St.

Suite 1380

San Francisco, CA 94105-1535

National Research Council (3)

Board on Radioactive

Waste Management

RM HA456

Attn: P.B. Myers (2)

G.J. Grube

2101 Constitution Ave.

Washington, DC 20418

\section{Performance Assessment Peer Review Panel}

G. Ross Heath

College of Ocean and

Fishery Sciences, HN-15

583 Henderson Hall

University of Washington

Seattle, WA 98195

Thomas H. Pigford

Department of Nuclear Engineering

4159 Etcheverry Hall

University of California

Berkeley, CA 94720

Thomas A. Cotton

JK Research Associates, Inc.

4429 Butterworth Place NW

Washington, DC 20016

Robert J. Budnitz

President, Future Resources

Associates, Inc.

2000 Center Street

Suite 418

Berkeley, CA 94704

C. John Mann

Department of Geology

245 Natural History Bldg.

1301 West Green Street

University of Illinois

Urbana, IL 61801

Frank W. Schwartz

Department of Geology and Mineralogy

The Ohio State University

Scott Hall

1090 Carmack Rd.

Columbus, $\mathrm{OH} \quad 43210$

\section{National Laboratories}

Argonne National Laboratory (2)

Attn: A. Smith

D. Tomasko

9700 South Cass

Bldg. 201

Argonne, IL 60439 
Battelle Pacific Northwest Laboratory

(3)

Attn: R.E. Westerman, MSIN P8-44

S. Bates

Sattelle Boulevard

Richland, WA 99352

Idahı National Engineering Laboratory (i)

Attn:

H. Loo

$\mathrm{R}$. Klinger

Mail Stop 5108

Idaho Falls, ID 83403-4000

Los Alamos National Laboratory

Attn: B. Erdal, $\mathrm{CNC}-11$

PO Box 1663

Los Alamos, NM 87545

Los Alamos National Laboratory

Attn: A. Meijer

PO Box 1663

Mail Stop J514

Los Alamos, NM 87545

Los Alamos National Laboratory (3) HSE - 8

Attn: M. Enoris

L. Soholt

$\mathrm{J}$. Wenzel

PO Box 1663

Los Alamos, NM 87545

Los Alamos National Laboratory EM-7

Attn: S. Kosiewicz

PO Box 1663

Mail Stop J595

Los Alamos, NM 87545

Oak Ridge National Laboratory

Transuranic Waste Manager

Attn: D.W. Turner

PO Box 2008

Bldg. 3047

Oak Ridge, TN 37831-6060

Pacific Northwest Laboratory

Attn: B. Kennedy

PO Box 999

Richland, WA 99352
Savannah River Plant (2)

Attn: R.G. Baxter

Bldg. 704-S

K.W. Wierzbicki

BIdg. $703-\mathrm{H}$

Aiken, SC 29808-0001

Westinghouse-Savannah River Technology Center (4)

Attn: N. Bibler

J.R. Harbour

M.J. Plodinec

G.G. Wicks

Aiken, SC 29802

\section{Corporations/Members of the Public}

Benchmark Environmental Corp.

Attn: C. Frederickson

4501 Indian School NE

Suite 105

Albuquerque, NM 87110

City of Albuquerque

Public Works Department

Utility Planning Division

Attn: W.K. Summers

PO Box 1293

Albuquerque, NM 87103

Deue1 and Associates, Inc.

Attn: R.W. Prindle

7208 Jefferson NE

Albuquerque, NM 87109

Disposal Safety, Inc.

Attn: B. Ross

1660 L Street NW

Suite 314

Washington, DC 20036

Ecodynamics (2)

Attn: P. Roache

R. Blaine

PO Box 9229

Albuquerque, NM 87119-9229

EG \& G Idaho (3)

1955 Fremont Street

Attn: C. Atwood

C. Hertzler

T.I. Clements

Idaho Falls, ID 83415 


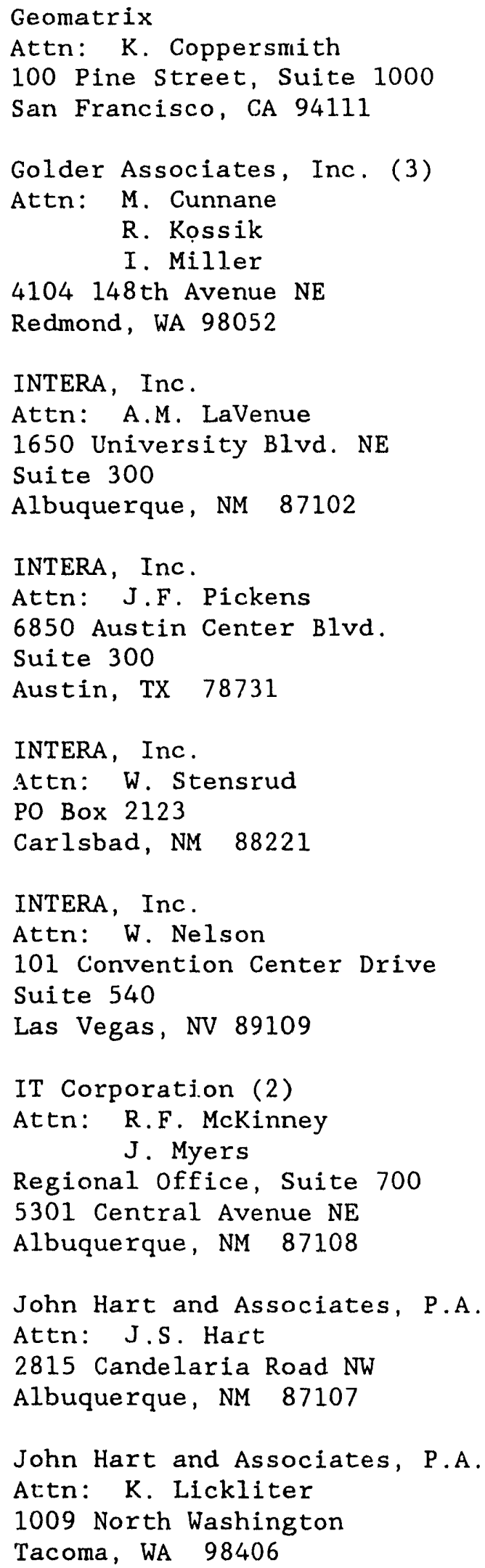

MACTEC (1)

Aten: D.K. Duncan

8418 Zuni Road SE

Suite 200

Albuquerque, NM 87108

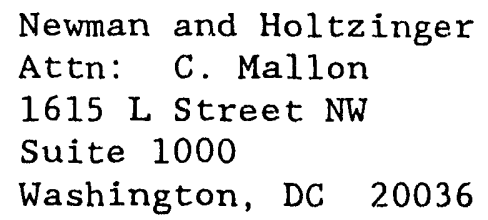


Science Applications International Corporation (2)

Attn: D.C.Royer C.G. Pflum

101 Convention Center Dr.

Las Vegas, NV 89109

Science Applications International Corporation (2)

Attn: M. Davis

J. Tollison

2109 Air Park Road SE

Albuquerque, NM 87106

Science Applications International Corporation (2)

Attn: J. Young

D. Lester

18706 North Creek Parkway, Suite 110

Bothell, Wh 98011

Southwest Research Institute

Center for Nuclear Waste Regulatory Analysis (2)

Attn: P.K. Nair

6220 Culebra Road

San Antonio, TX 78228-0510

Systems, Science, and Software (2)

Attn: E. Peterson

Box 1620

P. Lagus

La Jolla, CA 92038

TASC

Attn: S.G. Oston

55 Walkers Brook Drive

Reading, MA 01867

Tech Reps, Inc. (7)

Attn: J. Chapman

C. Crawford

V. Cilliland

D. Marchand

J. Stikar

P. Oliver

D. Scott

5000 Marble NE, Suite 222

Albuquerque, NM 87110
Tolan, Beeson \& Associates

Attn: T.L. Tolan

2320 W. 15 th Avenue

Kennewick, WA 99337

TRW Environmental Safety Systems (2)

Attn: I. Sacks, Suite 800

L. Wildman, Suite 1300

2650 Park Tower Drive

Vienna, VA 22180-7306

Westinghouse Electric Corporation (4)

Attn: Library

C. Cox

L. Fitch

R.F. Kehrman

PO Box 2078

Carlsbad, NM 88221

Westinghouse Hanford Company

Attn: D.E. Wood

MSIN HO- 32

PO Box 1970

Richland, WA 99352

Western Water Consultants

Attn: D. Fritz

1949 Sugarland Drive \#134

Sheridan, WY 82801-5720

Western Water Consultants

Attn: P.A. Rechard

PO Box 4128

Laramie, WY 82071

P. Drez

8816 Cherry Hills Road NE

Albuquerque, NM 87111

D.W. Powers

Star Route Box 87

Anthony, TX 79821

Shirley Thieda

PO Box 2109, RR1

Bernalillo, NM 87004

Jack Urich

c/O CARD

144 Harvard SE

Albuquerque, NM 87106 


\section{Universities}

University of California

Mechanical, Aerospace, and

Nuclear Engineering Department (2)

Attn: W. Kastenberg

D. Browne

5532 Boelter Hall

Los Angeles, CA 90024

University of California

Mine Engineering Dept.

Attn: N. Cook

Rock Mechanics Engineering

Berkeley, CA 94720

University of Hawaii at Hilo

Attn: S. Hora

Business Administration

Hilo, H. 96720-4091

University of New Mexico

Geology Department

Attn: Library

Albuquerque, NM 87131

University of New Mexico

Research Administration

Attn: H. Schreyer

102 Scholes Hall

Albuquerque, NM 87131

University of Wyoming

Department of Civil Engineering

Attn: V.R. Hasfurther

Laramie, WY 82071

University of Wyoming

Department of Geology

Attn: J.I. Drever

Laramie, WY 82071

University of Wyoming

Department of Mathematics

Attn: R.E. Ewing

Laramie, WY 82071

\section{Libraries}

Thomas Brannigan Library

Attn: D. Dresp

$106 \mathrm{~W}$. Hadley St.

Las Cruces, NM 88001
Hobbs Public Library

Attn: $M$. Lewis

509 N. Ship Street

Hobbs, NM 88248

New Mexico State Library

Attn: N. McCallan

325 Don Gaspar

Santa Fe, NM 87503

New Mexico Tech

Martin Speere Memorial Library

Campus Street

Socorro, NM 87810

New Mexico Juniex College

Pannell Library

Attn: R. Hill

Lovington Highway

Hobbs, NM 88240

Carlsbad Municipal Library

WIPP Public Reading Room

Attn: L. Hubbard

$101 \mathrm{~S}$. Hąlagueno St.

Carlsbad, NM 88220

University of New Mexico

General Library

Government Publications Departmene

Albuquerque, NM $\mathbf{8 7 1 3 1}$

\section{NEA/Performance Assessment Advisory Group (PAAG)}

P. Duerden

ANSTO

Lucas Heights Research Laboratories Private Mail Bag No. 1

Menai, NSW 2234

AUSTRALIA

Gordon S. Linsley

Division of Nuclear Fuel Cycle and Was te Management

International Atomic Energy Agency

PO Box 100

A-1400 Vienna, AUSTRIA

Nicolo Cadelli

Commission of the European Comnunities 200, Rue de la Loi

B-1049 Brussels, BELGIUM 


\author{
R. Heremans \\ Organisme Nationale des Déchets \\ Radioactifs et des Matiéres \\ Fissiles \\ ONDRAF \\ Place Madou 1, Boitec 24/25 \\ $\$-1030$ Brussels, BELGIUM \\ J. Marivoet \\ Centre d'Etudes de l'Energie Nucléaj \\ $\mathrm{CEN} / \mathrm{SCK}$ \\ Boeretang 200 \\ B-2400 Mo1, BELGIUM \\ P. Conlon \\ Waste Management Division \\ Atomic Energy Control Board (AECB) \\ PO Box 1046 \\ Ottawa, Canada KIP 559, CANADA \\ A.G. Wikjord \\ Manager, Environmental and Safety \\ Assessment Branch \\ Atomic Energy of Canada Limited \\ Whiteshell Nuclear Research \\ Establishment \\ Pinewa, Manitoba ROE 1 LO \\ CANADA \\ Jukka-Pekka Salo \\ Teollisuuden Voima Oy (TVO) \\ Fredrikinkatu 51-53 B \\ SF-00100 Helsinki \\ FINLAND
}

Timo Vieno

Technical Research Centre of Finland (VTT)

Nuclear Energy Laboratory

PO Box 208

SF-02151 Espoo, FINLAND

Timo Äikăs

Teollisuuden Voima Oy (TVO)

Fredrikinkatu 51-53 B

SF-00100 Helsinki, FINLAND
M. Claude Ringeard

Division de la Sécurité et de la Protection de 1'Environment (DSPE)

Commissariat á l'Energie Atomique

Agence Nationale pour la Gestion des Déchets Radioactifs (ANDRA)

Route du Panorama Robert Schuman

B. P. No. 38

F-92266 Fontenay-aux-Roses Cedex

FRANCE

Gérald Ouzounian

Agence Nationale pour la Gestion des Déchets Radioactifs (ANDRA)

Route du Panorama Robert Schuman

B.P. No. 38

F-92266 Fontenay-aux-Roses Cedex

FRANCE

Claudio Pescatore

Division of Radiation Procection and Waste Management

OECD Nuclear Energy Agency

38, Boulevard Suchet

F-75016 Paris, FRANCE

M. Dominique Greneche

Commissariat á l'Energie Atomique

IPSN/DAS/SASICC/SAED

B.P. No. 6

F-92265 Foiıtenay-aux-Roses Cedex

FRANCE

Robert Fabriol

Bureau de Recherches Géologiques et Miniéres (BRGM)

B.P. 6009

45060 Orléans Cedex 2, FRANCE

P. Bogorinski

Gesellschaft für Reaktorsicherheit (GRS) $\mathrm{mbH}$

Schwertnergasse 1

D-5000 Köln 1, GERMANY

R. Storck

GSF - Institut für Tieflagerung

Theodor-Heuss-Strabe 4

D-3300 Braunschweig, GERMANY 
Ferrucio Gera

ISMES S.P.A

Via del Crociferi 44

I-00187 Rome, ITALY

Hiroyuki Umeki

Isolation System Research Program

Radioactive Waste Management Project

Power Reactor and Nuclear Fuel

Development Corporation (PNC)

1-9-13, Akasaka

Minato-ku

Tokyo 107, JAPAN

P. Carboneras Martinez

ENRESA

Calle Emilio Vargas, 7

R-28043 Madrid, SPAIN

Tönis Papp

Swedish Nuclear Fuel and Waste Management Co.

Box 5864

S 10248 Stockholm, SWEDEN

Conny Hägg

Swedish Radiation Protection Institute (SSI)

Box 60204

S-104 01 Stockholm, SWEDEN

J. Hadermann

Paul Scherrer Institute

Waste Management Programme

CH-5232 Villigen PSI, SWITZERLAND

$\mathrm{J}$. Vigfusson

USK- Swiss Nuclear Safety Inspectorate

Federal Office of Energy

$\mathrm{CH}-5303$ Würenlingen, SWITZERLAND

D.E. Billington

Departmental Manager-Assessment Studies

Radwaste Disposal R\&D Division AEA Decommissioning \& Radwaste

Harwell Laboratory, B60

Didcot Oxfordshire OX11 ORA

UNITED KINGDOM
P. Grimwood

Waste Management Unit BNFL

Sellafield

Seascale, Cumbria CA20 1PG

UNITED KINGDOM

Alan J. Hooper

UK Nirex Ltd

Curie Avenue

Harwe11, Didcot

Oxfordshire, OXI1 ORH

UNITED KINGDOM

Jerry M. Boak

Yirca Mountain Project office

$U$. Department of Energy

PO Box 98608

Las Vegas, NV 89193

Seth M. Coplan (Chairman)

US Nuclear Regulatory Commission

Division of High-Level Waste Management

Mail Stop 4-H-3

Washington, DC 20555

A.E. Van Luik

INTERA/M\&O

The Valley Bank Center

101 Convention Center Dr.

Las Vegas, NV 89109

\section{NEA/PSAG User's Group}

Shaheed Hossain

Division of Nuclear Fuel Cycle and Waste Management

International Atomic Energy Agency

Wagramerstrasse 5

PO Box 100

A-1400 Vienna, AUSTRIA

Alexander Nies (PSAC Chairman)

Gesellschaft für Strahlen- und

Institut für Tieflagerung

Abteilung für Endlagersicherheit

Theodor-Heuss-Strasse 4

D-3300 Braunschweig, GERMANY 
Eduard Hofer

Gesellschaft für Reaktorsicherheit (GRS) $\mathrm{MBH}$

Forschungsgelände

D-8046 Garching, GERMANY

Andrea Saltelli

Commission of the European Communities

Joint Resarch Centre of Ispra

I-21020 Ispra (Varese), ITALY

Alejandro Alonso

Cátedra de Tecnología Nuclear

E.T.S. de Ingenieros Industriales

José Gutiérrez Abascal, 2

E-28006 Madrid, SPAIN

ENRESA (2)

Attn: M. A. Cuñado

F. J. Elorza

Calle Emilio Vargas, 7

E-28043 Madrid, SPAIN

\section{Pedro Prado}

CIEMAT

Instituto de Tecnologia Nuclear

Avenida Complutense, 22

E-28040 Madri.d, SPAIN

Nils A. Kjellbert

Swedish Nuclear Fuel and Waste

Management Company (SKB)

Box 5864

S-102 48 Stockholm, SWEDEN

Björn Cronhjort

Swedish National Board for Spent

Nuclear Fuel (SKN)

Sehlsedtsgatan 9

S-115 28 Stockholm, SWEDEN

Richard A. Klos

Paul-Scherrer Institute (PSI)

$\mathrm{CH}-5232$ Villingen PSI

SWITZERLAND

NAGRA (2)

Attn: C. McCombie

F. Van Dorp

Hardstrasse 73

$\mathrm{CH}-5430$ Wettingen, SWITZERLAND
N. A. Chapman

Intera Information Technologies

Park View House, 14B Burton Street

Melton Mowbray

Leicestershire, LE13 IAE

UNITED KINGDOM

Daniel A. Galson

Galson Sciences Ltd.

35, Market Place

Oakham

Leicestershire LE15 6DT

UNITED KINGDOM

David P. Hodgkinson

Intera Information Technologies

Chiltern House

45 Station Road

Henley-on-Thames

Oxfordshire RG9 1AT, UNITED KINGDOM

Brian G.J. Thompson

Department of the Environment: Her

Majesty's Inspectorate of Pollution

Room A5.33, Romney House

43 Marsham Street

London SW1P 2PY, UNITED KINGDOM

Intera Information Technologies

Attn: M.J.Apted

3609 South Wacisworth Blvd.

Denver, CO 80235

US Nuclear Regulatory Commission (2)

Attn: R. Codell

N. Eisenberg

Mail Stop 4-H-3

Washington, DC 20555

Battelle Pacific Northwest

Laboratories

Attn: P.W. Eslinger

PO Box 999, MS K2-32

Richland, WA 99352

Center for Nuclear Waste Regulatory Analys is (CNWRA)

Southwest Research Institute

Attn: B. Sagar

Po Drawer 28510

6220 Culebra Road

San Antonio, TX 78284 


\section{Geostatistics Expert Working Group (GXG)}

Rafael L. Bras

R.L. Bras Consulting Engineers

44 Percy Road

Lexington, MA 02173

Jesus Carrera

Universidad Politécnica de Cataluña

E.T.S.I. Caminos

Jordi, Girona 31

E-08034 Barcelona, SPAIN

Gedeon Dagan

Department of Fluid Mechanics and Heat Transfer

Tel Aviv University

PO Box 39040

Ramat Aviv, Tel Aviv 69978

ISRAEL

Ghislain de Marsily (GXG Chairman)

University Pierre et Marie Curie

Laboratorie de Geologie Applique

4, Place Jussieu - T.26 - 5e etage

75252 Paris Cedex 05

FRANCE

\author{
Alain Galli \\ Centre de Geostatistique \\ Ecole des Mines de Paris \\ 35 Rue St. Honore \\ 77035 Fontainebleau, FRANCE \\ Steve Gorelick \\ Department of Applied Earth Sciences \\ Stanford University \\ Stanford, CA 94305-2225 \\ Peter Grindrod \\ INTERA Information Technologies Ltd. \\ Chiltern House \\ 45 Station Road \\ Henley-on-Thames \\ Oxfordshire, RG9 1AT \\ UNITED KINGDOM
}

\author{
Alan Gutjahr \\ Department of Mathematics \\ New Mexico Institute of Mining and \\ Technology \\ Socorro, NM 87801 \\ C. Peter Jackson \\ Harwell Laboratory \\ Theoretical Studies Department \\ Radwaste Disposal Division \\ Bldg. 424.4 \\ Oxfordshire Didcot Oxon OXl1 ORA \\ UNITED KINDGOM \\ Peter Ki Lanidis \\ 60 Peter Coutts Circle \\ Stanford, CA 94305 \\ Rae Mackay \\ Department of Civil Engineering \\ University of Newcastle Upon Tyne \\ Newcastle Upon Tyne NE1 7RU \\ UNITED KINGDOM \\ Dennis McLaughlin \\ Parsons Laboratory \\ Room 48-209 \\ Department of Civil Engineering \\ Massachusetts Institute of Technology \\ Cambridge, MA 02139 \\ Shlomo P. Neuman \\ College of Engineering and Mines \\ Department of Hydrology and Water \\ Resources \\ University of Arizona \\ Tucson, AZ 85721 \\ Christian Ravenne \\ Geology and Geochemistry Division \\ Institut Francais du Pétrole \\ $1 \& 4$, Av. de Bois-Préau BP311 \\ 92506 Rueil Malmaison Cedex \\ FRANCE \\ Yoram Rubin \\ Department of Civil Engineering \\ University of California \\ Berkeley, CA 94720
}




\section{Foreign Addresses}

Studiecentrum Voor Kernenexgie Centre D'Energie Nucleaire

Attn: A. Bonne

SCK/CEN

Boeretang 200

B-2400 Mol, BELGIUM

Atomic Energy of Canada, Ltd. (3)

Whiteshe11 Research Estab.

Attn: M.E. Stevens

B.W. Goodwin

D. Wushke

Pinewa, Manitoba

ROE 1LO, CANADA

Esko Peltonen

Industrial Power Company Ltd.

TVO

Fredrikinkatu 51-53

SF-00100 Helsinki 10, FINLAND

Jean-Pierre Olivier

OECD Nuclear Energy Agency (2)

38, Boulevard Suchet

F-75016 Paris, FRANCE

D. Alexandre, Deputy Director

ANDRA

31 Rue de la Federation

75015 Paris, FRANCE

Claude Sombret

Centre D'Etudes Nucleaires

De La Vallee Rhone

CEN/VALRHO

S.D.H.A. BP 171

30205 Bagnols-Sur-Ceze, FRANCE

Bundesministerium fur Forschung und Technologie

Postfach 200706

5300 Bonn 2, GERMANY

Bundesanstalt fur Geowissenschaften und Rohstoffe

Attn: $M$. Langer

Postfach 510153

3000 Hanover 51, GERMANY
Gesellschaft fur Reaktorsicherheit (GRS) (2)

Attn: B. Baltes

W. Muller

Schwertnergasse 1

D-5000 Cologne, GERMANY

Insitut fur Tieflagerung (2)

Attn: K. Kuhn

Theodor-Heuss-Strasse 4

D-3300 Braunschweig, GERMANY

Physikalisch-Technische Bundesanstalt

Attn: P. Brenneke

Postfach 3345

D-3300 Braunschweig, GERMANY

Shingo Tashiro

Japan Atomic Energy Research Institute

Tokai-Mura, Ibaraki-Ken

319-11, JAPAN

Netherlands Energy Research

Foundation (ECN)

Attn: L.H. Vons

3 Westerduinweg

PO Box 1

1755 ZG Petten, THE NETHERLANDS

Johan Andersson

Swedish Nuclear Power Inspectorate Statens Kärnkraftinspektion (SKI)

Box 27106

S-102 52 Stockholm, SWEDEN

Fred Karlsson

Svensk Karnbransleforsorjning

AB SKB

Box 5864

S-102 48 Stockholm, SWEDEN

Nationale Genossenschaft fur die

Lagerung Radioaktiver Abfalle

(NAGRA) (2)

Attn: S. Vomvoris

P. Zuidema

Hardstrasse 73

$\mathrm{CH}-5430$ Wettingen, SWITZERLAND 
AEA Technology

Attn: J.H. Rees

D5W/29 Culham Laboratory

Abington

Oxfordshire OX14 3DB, UNITED KINGDOM

AEA Technology

Attn: W.R. Rodwe11

044/A31 Winfrith Technical Centre

Dorchester

Dorset DT2 8DH, UNITED KINGDOM

AEA Technology

Attn: J.E. Tinson

B4244 Harwell Laboratory

Didcot, Oxfordshire OXI1 ORA

UNITED KINGDOM

D.R. Knowles

British Nuclear Fuels, plc

Risley, Warrington

Cheshire WA3 6AS, 1002607

UNITED KINGDOM
6343 Staff (3)

6345 R.C. Lincoln

6345

6347

6348

6351

6352

6352

6400

6613

6613

6613

6622

6641

7141

7151

7613-2

Staff (9)

D.R. Schafer

J.T. Hulmes

R.E. Thompson

D.P. Garber

S.E. Sharpton

N.R. Ortiz

R.M. Cranwe11

R. L. Iman

C. Leigh

M.S.Y. Chu

R.E. Luna, Acting

Technical Library (5)

Technical Publications

Document Processing for DOE/OSTI (10)

8523-? Central Technical Files

9300 J.E. Powell

9310 J.D. Plimpton

9.330

\section{Interna!}

$\begin{array}{ll}1 & \text { A. Narath } \\ 20 & \text { O.E. Jones } \\ 1502 & \text { J.C. Cummings } \\ 1511 & \text { D.K. Gartling } \\ 6000 & \text { D.L. Hartley } \\ 6100 & \text { R.W. Lynch } \\ 6115 & \text { P.B. Davies } \\ 6119 & \text { E.D. Gorham } \\ 6119 & \text { Staff (14) } \\ 6121 & \text { J.R. Tillerson } \\ 6121 & \text { F.D. Hansen } \\ 6121 & \text { Staff (7) } \\ 6233 & \text { J.C. Eichelberger } \\ 6300 & \text { D.E. E1lis } \\ 6302 & \text { L.E. Shephard } \\ 6303 & \text { S.Y. Pickering } \\ 6303 & \text { W.D. Weart } \\ 6305 & \text { S.A. Goldstein } \\ 6306 & \text { A.L. Stevens } \\ 6312 & \text { F.W. Bingham } \\ 6313 & \text { L.S. Costin } \\ 6331 & \text { P.A. Davis } \\ 6341 & \text { Sandia WIPP Central Files (100) } \\ 6342 & \text { D.R. Anderson } \\ 6342 & \text { Staff (30) } \\ 6343 & \text { S.A. Orrell, Acting } \\ & \end{array}$



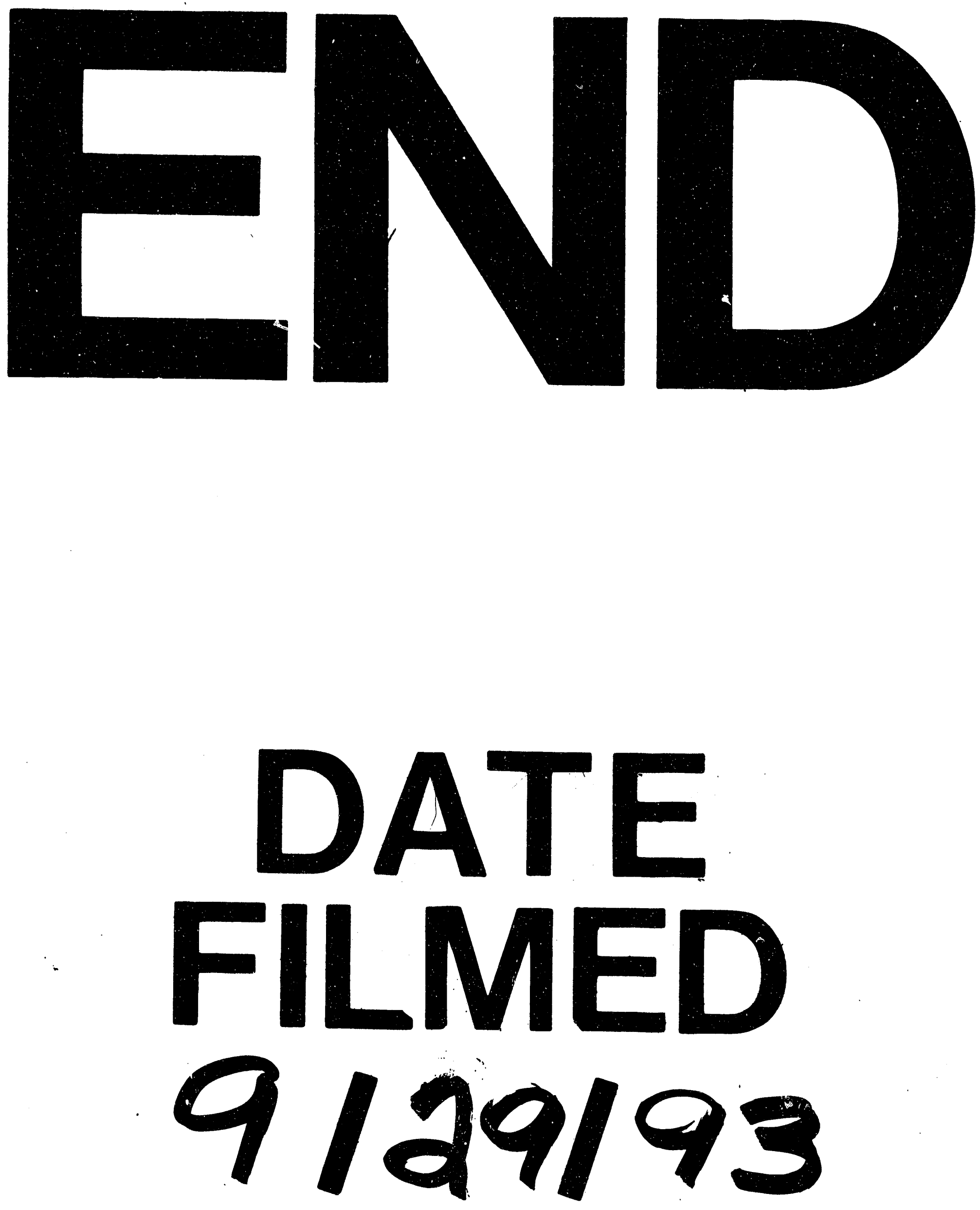
